Aus der Abteilung Anatomie und Embryologie

(Prof. Dr. med. C. Viebahn)

im Zentrum Anatomie

der Medizinischen Fakultät der Universität Göttingen

\title{
Muster und Funktionen von Apoptose und Proliferation während der Morphogenese der Somiten \\ von Tupaia belangeri (Tupaiidae, Scandentia, Mammalia)
}

\author{
INAUGURAL - DISSERTATION \\ zur Erlangung des Doktorgrades \\ der Medizinischen Fakultät \\ der Georg-August-Universität zu Göttingen
}

vorgelegt von

Benedikt Büttner

aus

Miltenberg 
Dekan: Prof. Dr. med. C. Frömmel

I. Berichterstatter: Prof. Dr. med. W. Knabe

II. Berichterstatter/in: Prof. Dr. med. J. Großhans

III. Berichterstatter/in: Prof. Dr. rer. nat. A. Mansouri

Tag der mündlichen Prüfung: 30. Januar 2012 


\section{INHALTSVERZEICHNIS}

I. EINLEITUNG

II. MATERIAL UND METHODEN

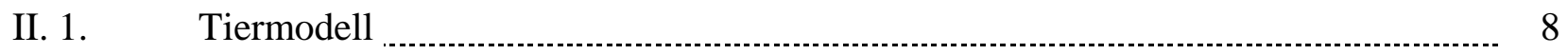

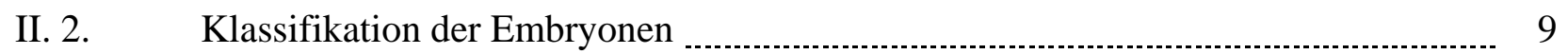

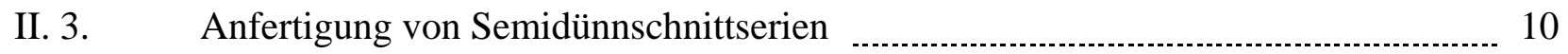

II. 4. Diagnose apoptotischer und mitotischer Zellen _............................................ 10

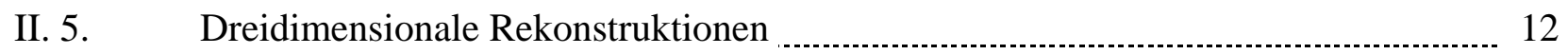

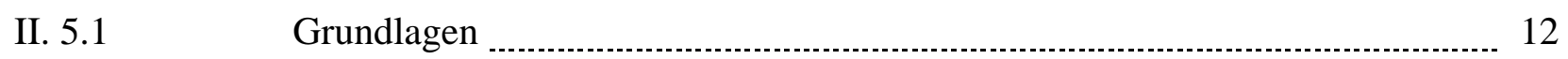

II. 5.2 Ausstattung des Scan- und Rekonstruktionssystems _................................... 13

II. 5.3 Datenakquisition

II. 5.4 Aufbau der Rekonstruktionen …........................................................ 15

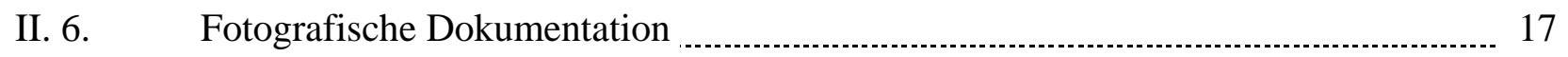

III. ERGEBNISSE

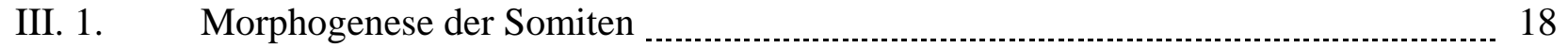

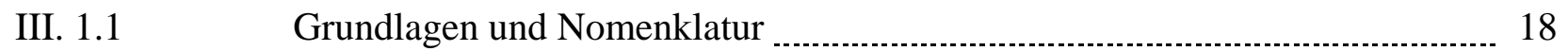

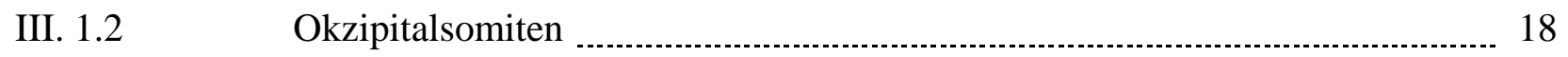

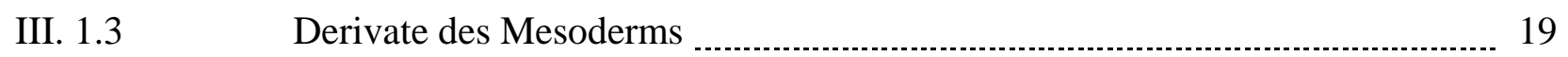

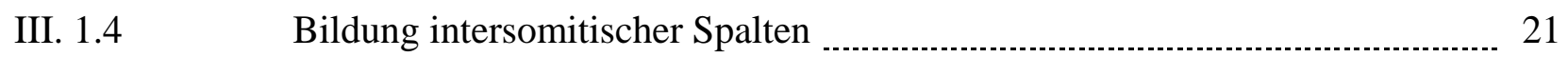

III. 1.5 Spalt-assoziierte Grenzzellen _.......................................................... 22

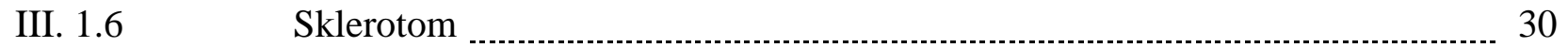

III. 1.7 Dermomyotom und Myotom ……....................................................... 32

III. 2. Apoptose- und Proliferationsereignisse ........................................................ 39

III. 2.1 Apoptose im Seitenplattenmesoderm und im ungegliederten Mesoderm ....... 39

III. 2.2 Proliferation im Seitenplattenmesoderm und im ungegliederten Mesoderm ... 41

III. 2.3 Apoptose und Proliferation in der Chorda dorsalis _................................... 54

III. 2.4 Apoptose und Proliferation in den epithelialen Somiten …….......................... 55

III. $2.5 \quad$ Apoptose im Sklerotom _........................................................................... 55 
III. 2.6

III. 2.7

III. 2.8

III. 2.9
Proliferation im Sklerotom 56

$$
\text { Apoptose im Dermomyotom }
$$
64

Proliferation im Dermomyotom . 66

Apoptose und Proliferation im Myotom

\section{DISKUSSION}

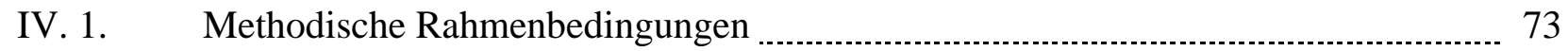

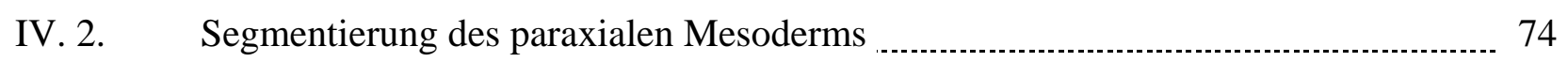

IV. $2.1 \quad$ Okzipitalsomiten

IV. $2.2 \quad$ Bildung intersomitischer Spalten _.................................................... 75

IV. 2.3 Grenzzellen und mesenchymal-epitheliale Transition (MET) _...................... 79

IV. $2.4 \quad$ Apoptosemuster $\ldots$

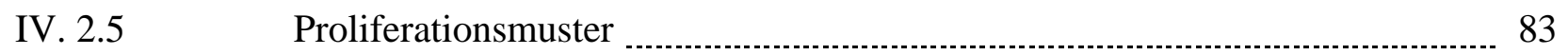

IV. 3. Apoptose- und Proliferationsmuster in den epithelialen Somiten ........................... 84

IV. 4. Apoptose- und Proliferationsmuster in der Chorda dorsalis _................................ 85

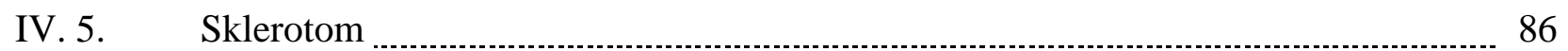

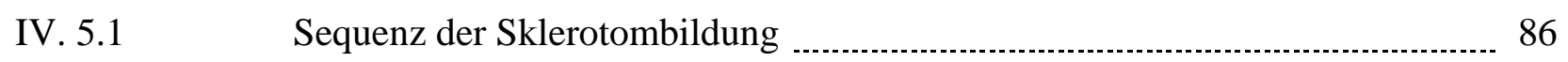

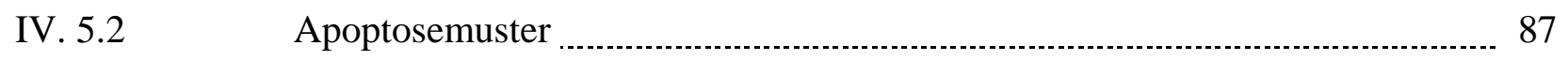

IV. $5.3 \quad$ Proliferationsmuster

IV. 6. Dermomyotom und Myotom _ _ _ 91

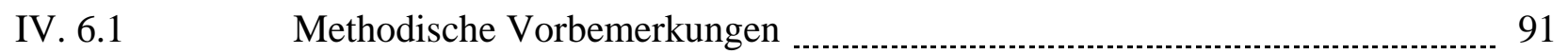

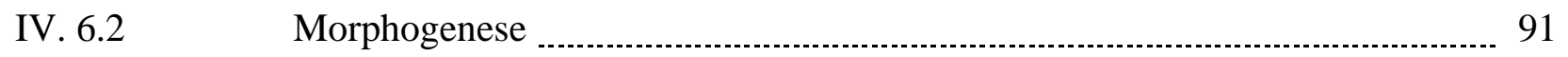

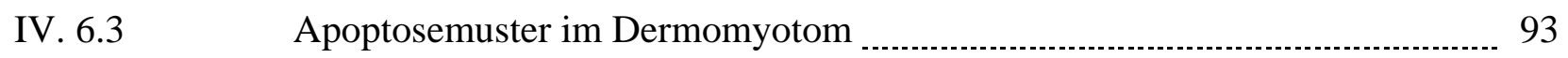

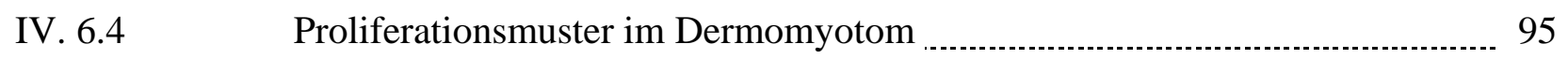

IV. $6.5 \quad$ Apoptose- und Proliferationsmuster im Myotom ……................................ 96

IV. 7. Apoptose- und Proliferationsmuster im Seitenplattenmesoderm _........................... 97

IV. 8. Apoptose- und Proliferationsmuster am kaudalen Embryonalpol _.......................... 98

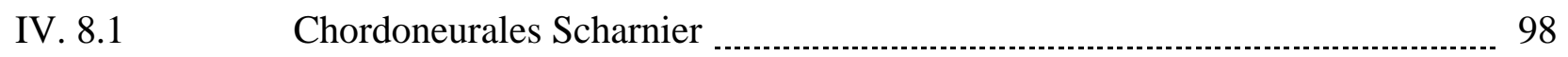

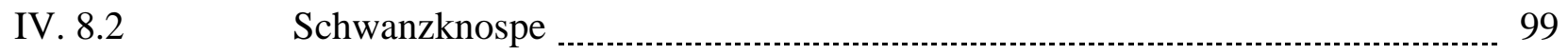

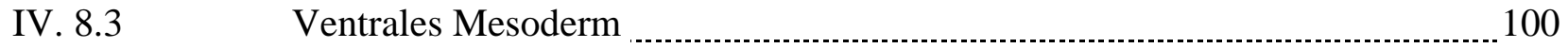


V. ZUSAMMENFASSUNG

VI. LITERATURVERZEICHNIS 


\section{EINLEITUNG}

Somiten oder „Urwirbel“ (Remak 1855) sind epitheliale Zellballen, die beidseits der Neuralanlage in engem zeitlichen Zusammenhang mit der Neurulation aus dem Mesenchym des paraxialen Mesoderms abgegliedert werden. Unmittelbar anschließend bilden diese Somiten, wiederum bilateral symmetrisch, segmental angeordnete Sklerotome, Dermomyotome und Myotome aus, die wesentliche Beiträge zur Entstehung von Wirbeln, Bandscheiben und Rippen, aber auch von Muskulatur und Haut leisten. Zeitlich parallel gehen die Nierenanlagen aus dem intermediären Mesoderm und die Körperhöhlen aus dem Seitenplattenmesoderm hervor (zur Übersicht: Christ und Ordahl 1995, Brand-Saberi et al. 1996, Christ et al. 2007). Der segmentale Charakter der Somiten sowie ihrer Derivate widerspiegelt sich auch in der strukturellen Organisation benachbarter Organanlagen, beispielsweise in der Gliederung des Nerven- und Gefäßsystems. Letztlich entwickeln sich alle metameren Strukturen der Körperwand auf der Grundlage der Somitenmetamerie (Christ et al. 1979, 1998, Brand-Saberi und Christ 2000). Der der Somitenabgliederung zugrunde liegende Prozess wird durch die „segmentation clock“ gesteuert (Palmeirim et al. 1997). Diese molekulare Uhr nimmt unter den zahlreichen faszinierenden Entdeckungen, die in den zurückliegenden zehn bis zwanzig Jahren auf dem Gebiet der Mesodermforschung gelungen sind, eine Sonderstellung ein, weil sie, exemplarisch für viele andere biologische Prozesse, die periodische Entstehung gleichartiger Segmente aus einer größeren zusammenhängenden Organanlage zu erklären vermag.

Die im Rahmen der vorliegenden Arbeit durchgeführten Untersuchungen konzentrierten sich zunächst auf die möglichen Beiträge von Apoptose- und Proliferationsprozessen zur Segmentierung des paraxialen Mesoderms. Hierbei stellte sich rasch heraus, dass solche Untersuchungen nur dann erfolgversprechend sind, wenn gleichzeitig auch grundlegende strukturelle, bisher teils kontrovers diskutierte, teils unzureichend angegangene Aspekte des Segmentierungsprozesses thematisiert werden. Solche ergänzend in die Arbeit aufgenommenen Fragestellungen betreffen beispielsweise den exakten zeitlichen und räumlichen Ablauf der Bildung intersomitischer Spalten sowie den möglichen Beitrag Spalt-organisierender Grenzzellen. Berücksichtigt wurden aber auch Apoptose- und Proliferationsprozesse in anderen, dem paraxialen Mesoderm benachbarten Mesodermabschnitten sowie innerhalb der aus den Somiten hervorgehenden Sklerotome, Dermomyotome und Myotome. Die auf Einzelzellniveau durchgeführten dreidimensionalen Rekonstruktionen sollen dazu beitragen, Abläufe von Morphogeneseprozessen, die bisher überwiegend durch Genexpressionsanalysen untersucht worden sind (zur Übersicht: Christ et al. 2007, Dequéant und Pourquié 2008), zellulär präziser zu fassen und die Entstehung von Fehlbildungen (Andrade et al. 2007, Sewell und Kusumi 2007, Shifley und Cole 2007, Pourquié 2011) besser zu verstehen. 
Die bereits erwähnte ,segmentation clock“ (Palmeirim et al. 1997) beinhaltet im Kern die Vorstellung, dass Somiten periodisch immer dann aus dem paraxialen Mesoderm abgegliedert werden, wenn eine bestimmte Konstellation aktuell exprimierter Gene vorliegt. Nach wie vor ist der „Taktgeber“" dieses Uhrwerks nicht bekannt. Dennoch werden von vielen Arbeitsgruppen zwei Hauptkomponenten des segmentation-clock-Modells übereinstimmend favorisiert (zur Übersicht: Cinquin 2007, Dequéant und Pourquié 2008, Aulehla und Pourquié 2010, Gibb et al. 2010): (1) Die „Uhr“Komponente, die durch die oszillierende Expression von Genen des notch-Signalweges in paraxialen Mesodermzellen charakterisiert ist, und (2) die „,determination front“, die im Verlauf des Abgliederungsprozesses von kranial nach kaudal fortschreitet. Molekular ist diese „Entscheidungsfront“ jeweils dort positioniert, wo ein von kranial absteigender Expressionsgradient für Retinsäure auf die von kaudal aufsteigenden Expressionsgradienten für Gene der Wnt- und der fibroblast-growthfactor-Gruppe trifft. Während eines Oszillationszyklus der molekularen Uhr (Komponente 1) wandert die „determination front“ innerhalb des zusammenhängenden paraxialen Mesoderms um eine Somitenlänge nach kaudal. Alle paraxialen Mesodermzellen, die hierbei von der „determination front“ passiert wurden, sind kompetent, auf das periodische Signal der „Uhr “ zu reagieren. Unmittelbar danach ist die segmentale Identität aller zu einem neu entstehenden Somiten zugehörigen paraxialen Mesodermzellen molekular festgelegt (Rawls et al. 2000, Tam et al. 2000, Pourquié und Tam 2001).

Umstritten ist die Frage, inwieweit unabgegliederte ,prospektive“ Somiten, die bereits über eine molekulare Identität verfügen, strukturelle Kennzeichen einer metameren Gliederung aufweisen. Solche „Somitomere“ wurden als „circular buttons of paraxial mesoblast“ erstmals beim Haushuhn (Meier 1979), später auch bei anderen Wirbeltieren beobachtet (Jacobson AG 1988). Zahlreiche Argumente sprechen aber dagegen, Somitomeren eine segmentale Identität zuzusprechen (zur Übersicht: Gossler und Hrabĕ de Angelis 1998). Erstens reichen diese kettenartig angeordneten Somitomere viel weiter nach kaudal als alle molekular definierten prospektiven Somiten (Jacobson AG 1988). Zweitens steht fest, dass migrierende Zellen innerhalb des ungegliederten paraxialen Mesoderms die mutmaßlichen Grenzen zwischen benachbarten Somitomeren nicht respektieren (Tam 1988, Stern et al. 1988, Bagnall et al. 1992). Drittens konnte gezeigt werden, dass die Somitenbildung auch dann prinzipiell ungestört abläuft, wenn zuvor experimentelle „Durchmischungen“ des Ausgangsmaterials durchgeführt worden waren (Packard et al. 1993). Angesichts dieser Fülle von Befunden, die die funktionelle Bedeutung von Somitomeren in Frage stellen, vertreten die schärfsten Kritiker dieses Konzepts mittlerweile die Auffassung, dass Somitomere, die bisher lediglich rasterelektronenmikroskopisch nachgewiesen werden konnten (zur Übersicht: Tam und Trainor 1994), als Präparationsartefakte aufzufassen sind (Wood und Thorogood 1994). 
Aktuelle Forschungsvorhaben zur ,segmentation clock“ zielen primär darauf ab, das Zusammenspiel derjenigen molekularen Komponenten zu entschlüsseln, die prospektiven Somiten einen segmentalen Charakter und (später auch) eine segmentale Identität verleihen. Hierdurch treten strukturelle Abläufe, die die molekular getroffene Entscheidung umsetzen, in den Hintergrund. Diese inhaltliche Verkürzung widerspiegelt sich beispielsweise schon terminologisch darin, dass der aktuell in Abgliederung begriffene Somit S0 definitionsgemäß vollständig von dem zuvor abgegliederten Somiten SI abgegliedert ist, aber noch vollständig mit dem kaudal folgenden paraxialen Mesoderm zusammenhängt. Störungen im Ablauf komplizierter Morphogeneseprozesse resultieren aber nicht nur aus „Fehlern“ bei der (genetisch fixierten) Entscheidungsfindung, sondern auch aus Fehlern, die bei der Umsetzung der genetischen Vorgaben auftreten.

Wie notwendig eine intensivere Auseinandersetzung mit den strukturellen Grundlagen der Somitogenese ist, geht unter anderem daraus hervor, dass der formale Ablauf der Bildung intersomitischer Spalten bis heute uneinheitlich dargestellt wird. So soll die Spaltbildung beim Zebrafisch (Danio rerio, Cyprinidae: Stickney et al. 2000, Barrios et al. 2003) sowie bei Xenopus laevis (Wilson PA et al. 1989) von lateral nach medial fortschreiten. Dagegen beginnt sie bei der Prachtbarbe (Barbus conchonius, Cyprinidae: Wood und Thorogood 1994) offenbar zentral. Für das Haushuhn wird unterschiedlich entweder ein dorsolateraler (Lipton und Jacobson 1974) oder ein medialer Beginn der intersomitischen Spaltbildung angegeben (Kulesa und Fraser 2002).

Mit der Klärung der Frage nach dem exakten Ablauf der intersomitischen Spaltbildung hängt die Anschlussfrage zusammen, inwieweit „Spalt-organisierende Grenzzellen“, deren Existenz auf der Grundlage experimentell am Haushuhn erhobener Daten postuliert worden ist (Sato et al. 2002, Sato und Takahashi 2005), tatsächlich vorkommen. Mindestens ebenso unklar sind die mögliche Herkunft sowie das Schicksal solcher mutmaßlichen Grenzzellen. Die vorliegende Arbeit versucht, auch diese Fragen durch strukturelle Analyse hochaufgelöst eingescannter Semidünnschnitte anzugehen und einer Antwort näher zu bringen.

Im Zusammenhang mit der intersomitischen Spaltbildung drängt sich eine weitere Frage auf. Es ist seit langem bekannt, dass die Abtrennung primär zusammenhängender Organanlagen oft mit dem gehäuften Auftreten von Zelltodereignissen einhergeht (Ernst 1926, Glücksmann 1951). Typische, bereits von diesen frühen Autoren dokumentierte Beispiele hierfür sind Ablösungsvorgänge des Linsenbläschens und des Ohrbläschens aus dem Oberflächenektoderm. Insofern liegt die in meiner Arbeit zu überprüfende Vermutung nahe, dass auch die Abgliederung von Somiten aus dem zusammenhängenden paraxialen Mesoderm durch Apoptoseprozesse unterstützt wird. Einschränkend muss allerdings hinzugefügt werden, dass „mechanische“ Funktionen von programmiertem Zelltod 
im Rahmen der Embryogenese zwar vielfach postuliert, aber nur in den seltensten Fällen bewiesen und aufgeklärt worden sind. Ein gutes Beispiel für derartige jahrzehntelang ausgetragene Kontroversen ist die Frage, inwieweit Apoptoseereignisse für den Verschluss der Neuralfalten zum Neuralrohr verantwortlich sind (Scheffel 2009, auch zur Übersicht). Andererseits gibt es auch weniger umstrittene Beispiele für mechanische morphogenetische Funktionen von programmiertem Zelltod, beispielsweise bei der Ausbildung von Fingern aus der Handplatte (zur Übersicht: Zuzarte-Luis und Hurle 2005).

Unsere Arbeitsgruppe hat sich wiederholt mit der Frage auseinandergesetzt, inwiefern räumlich und zeitlich gerichtet ablaufende Apoptose- und Proliferationsereignisse in die Frühentwicklung von Organanlagen eingreifen. Bisher standen für uns Morphogeneseprozesse im Vorderhirn (Knabe und Kuhn 1999, Knabe et al. 2000), in den Rhombomeren (Knabe et al. 2004), im Rückenmark (Scheffel 2009) sowie in den neurogenen Plakoden im Vordergrund (Washausen et al. 2005, Knabe et al. 2009). Die vorliegende Arbeit schlägt eine Brücke zwischen ektodermalen und mesodermalen Organanlagen, nicht zuletzt, um Folgeuntersuchungen zu ermöglichen, die sich mit den Interaktionen von Signalzentren im Rückenmark, in den Somiten sowie im Seitenplattenmesoderm befassen werden. Methodisch konnte hierbei auf das in Vorarbeiten etablierte, in Kooperation mit der Firma ZEISS entwickelte Scan- und Rekonstruktionssystem zurückgegriffen werden (Knabe et al. 2002, Süss et al. 2002, Brunnett et al. 2003, Kienel et al. 2007). Der entscheidende Vorteil dieses Systems besteht darin, dass zelluläre Ereignisse bei maximaler lichtmikroskopischer Auflösung strukturell diagnostiziert werden können, hierfür aber nicht aus ihrem Zusammenhang innerhalb großer Organanlagen herausgelöst werden. Im Vorfeld hatte sich immer wieder gezeigt, dass gerade die Möglichkeit, komplex strukturierte raumzeitliche Muster zellulärer Ereignisse in dreidimensionalen Rekonstruktionen zu analysieren, die weit über die Erfassung des eigentlichen Zielorgans hinausgingen, zu neuen Einsichten führte. Aus diesem Grunde beinhalten die für die Untersuchung der Morphogenese der Somiten von Tupaia belangeri durchgeführten dreidimensionalen Rekonstruktionen nicht nur das paraxiale Mesoderm, sondern auch das axiale und intermediäre Mesoderm sowie das Seitenplattenmesoderm. Speziell wollten wir herausfinden, ob Apoptoseprozesse eine generelle Bedeutung bei der Abgliederung mesodermaler Kompartimente aus größeren zusammenhängenden Mesodermformationen haben könnten. Publizierte Voruntersuchungen zur Abgliederung der Chorda dorsalis (Stemple 2004, 2005), zur Grenzziehung zwischen paraxialem und intermediärem Mesoderm (Wilm et al. 2004) sowie zur „Aufspaltung“ des Seitenplattenmesoderms in Somato- und Splanchnopleura (Funayama et al. 1999) enthalten praktisch keine Hinweise auf mögliche Beiträge durch Apoptoseprozesse. Dagegen dokumentieren unsere am Beispiel von Tupaia belangeri erstellten Rekonstruktionen, dass Apoptoseprozesse weit zahlreicher als bisher bekannt im Rahmen mesodermaler Abgliederungsvorgänge auftreten. 
Die im Gradienten von kranial nach kaudal fortschreitende Entwicklung von Somiten umfasst nicht nur deren Abgliederung aus dem paraxialen Mesoderm, sondern auch die Ausbildung eines mesenchymalen zentralen Somitozöls („Urwirbelkern”: Remak 1855) sowie die Differenzierung der Somiten. Hierbei geht zunächst aus ventralen Somitenabschnitten das mesenchymale Sklerotom hervor (zur Übersicht: Christ et al. 2004, 2007, Yusuf und Brand-Saberi 2006). Die Bezeichnung „Sklerotom“ wurde von Hatschek (1880, zitiert nach Williams 1910) eingeführt und bezieht sich darauf, dass Sklerotomzellen wesentlich zur Bildung des Achsenskeletts beitragen (Christ et al. 2007). Die nach Abschluss der Sklerotombildung epithelial verbliebenen dorsalen Somitenabschnitte bilden das Dermomyotom. Ein solches Dermomyotom stellt eine nahezu rechteckige, durch vier „Lippen“ begrenzte „Platte“ dar (Remak 1855, Kölliker 1879, Scaal und Christ 2004), aus der sowohl die Dermis der Rückenregion als auch - bis auf wenige Muskeln des Kopfes (Noden und Francis-West 2006) - die gesamte Skelettmuskulatur hervorgeht (zur Übersicht: Scaal und Christ 2004, Yusuf und Brand-Saberi 2006, Christ et al. 2007). Jedes Dermomyotom bringt zunächst ein epaxiales Myotom hervor, das sich überwiegend von medialen Dermomyotomabschnitten ableitet (Denetclaw et al. 1997, Huang und Christ 2000, Olivera-Martinez et al. 2000). Dermomyotom und unterlagerndes epaxiales Myotom bilden eine Einheit, die in der frühen Literatur als „Rückentafel“ (Remak 1855) oder „Hautmuskelplatte“ bezeichnet worden ist (Rabl 1888). Hypaxiale Myotome, die überwiegend von lateralen Dermomyotomabschnitten abstammen (Denetclaw und Ordahl 2000, Huang und Christ 2000, Olivera-Martinez et al. 2000), werden ausschließlich in der Rumpfregion ausgebildet. Sie schließen ventral unmittelbar an die zugehörigen epaxialen Myotome an. Epaxiale Myotome bringen die ortsständige authochthone Rückenmuskulatur, hypaxiale Myotome die ortsständige autochthone Muskulatur der Brust- und Bauchwand hervor (zur Übersicht: Scaal und Christ 2004, Christ et al. 2007). Dagegen migrieren hypaxiale Muskelvorläuferzellen okzipital, zervikal sowie in Höhe der Extremitätenknospen zu deutlich weiter entfernt liegenden Zielorten und differenzieren erst dort, beispielsweise innerhalb der Extremitätenknospe, zu Muskelanlagen (zur Übersicht: Dietrich et al. 1998, Dietrich 1999, Christ et al. 2007). Bei der Identifikation von Apoptose- und Proliferationsmustern, die zur Bildung epaxialer und/oder hypaxialer Myotome beitragen könnten, muss berücksichtigt werden, dass mindestens drei Modelle existieren, die die Rekrutierung von Muskelvorläuferzellen aus Dermomyotomen unterschiedlich beschreiben (zur Übersicht: Hollway und Currie 2005). Dagegen herrscht weitgehende Übereinstimmung darüber, dass die mesenchymale Anlage der Dermis aus zentralen Abschnitten des Dermomyotoms hervorgeht (zur Übersicht: Scaal und Christ 2004, Christ et al. 2007).

Während der Abgliederung von Somiten sowie im Verlauf von Differenzierungsschritten bereits abgegliederter Somiten verändern paraxiale Mesodermzellen, die entweder mesenchymale oder epitheliale Eigenschaften haben können, zum Teil mehrfach ihren „Status“. Im Schrifttum werden sol- 
che Statuswechsel, „Transformationen“ oder „Transitionen“ allerdings nicht immer einheitlich benannt. Zur Vermeidung sprachlich bedingter Irritationen verwendet die vorliegende Arbeit - auf der Grundlage der anschließend zitierten Referenz-Publikationen - durchgehend eine einheitliche Terminologie. Demnach bezeichnen wir den bei der Abgliederung von Somiten aus dem paraxialen Mesoderm erfolgenden Übergang von mesenchymalen paraxialen Mesodermzellen zu epithelialen Somitenzellen als mesenchymal-epitheliale Transition („MET“: Nakaya et al. 2004, Takahashi et al. 2005, Chaffer et al. 2007, Takahashi und Sato 2008). Dagegen unterliegt die Bildung mesenchymaler Sklerotomzellen aus ventralen Abschnitten des epithelialen Somiten einer epithelial-mesenchymalen Transition („EMT“: Christ et al. 2004, 2007). Schließlich verwenden wir den Begriff „Deepithelialisierung“ überall dort, wo Zellen den epithelialen Verband eines Dermomyotoms verlassen, um entweder in Myotom oder Dermis integriert zu werden, oder als migrierende Myoblasten zu weit entfernten Zielgebieten zu wandern (Scaal und Christ 2004, Gros et al. 2004, Ben-Yair und Kalcheim 2005, Christ et al. 2007).

Statuswechsel paraxialer Mesodermzellen stellen „Entscheidungssituationen“ dar, in deren Folge korrekturbedürftige „Fehlspezifizierungen“ von Vorläuferzellen auftreten sollten. Deshalb haben wir untersucht, ob Apoptoseereignisse in zeitlichem und/oder räumlichem Zusammenhang mit den oben skizzierten METs, EMTs und De-epithelialisierungsprozessen nachweisbar sind. Dass Apoptosen bei vergleichbaren Statuswechseln tatsächlich Vorläuferzellen eliminieren können, wurde am Beispiel der mit einer EMT einhergehenden Delamination (ektodermaler) Neuralleistenzellen bereits umfassend dokumentiert (Homma et al. 1994, Knabe et al. 2004, 2009, Washausen et al. 2005, Scheffel 2009). Dagegen sind systematische Untersuchungen zum Vorkommen von Apoptosen im Rahmen von Statuswechseln paraxialer Mesodermzellen rar: Sanders (1997) befasste sich orientierend mit dem Auftreten von Apoptosen im Sklerotom, während Hirata und Hall (2000), wiederum beim Haushuhn, zwar eine gute Übersicht über das Apoptosevorkommen in zahlreichen Organanlagen vermitteln, aber von einer detaillierten Analyse einzelner Morphogeneseschritte absehen.

Apoptose- und Proliferationsereignisse in der Chorda dorsalis haben wir nicht zuletzt deshalb dreidimensional rekonstruiert, weil die Chorda dorsalis als Signalzentrum in die Sklerotomentwicklung eingreift (zur Übersicht: Christ et al. 2000, Dockter 2000). Dagegen wurde eine regulatorische Beteiligung der Chorda dorsalis an der Abgliederung von Somiten vielfach verneint (Haushuhn: Packard und Jacobson 1976, Hirano et al. 1995, Sato und Takahashi 2005, Linker et al. 2005; Wachtel: Packard 1980; Labormaus: Correira und Conlon 2000). Lediglich Packard et al. (Wachtel: 1993) postulierten frühzeitig, dass Signale aus dem Rückenmark und/oder aus der Chorda dorsalis die bilateral-symmetrische Abgliederung von Somiten unterstützen. Tatsächlich konnte diese Hypothese unlängst bestätigt werden. Bei Hühnerembryonen greifen Signale aus der Chorda dorsalis direkt in 
den Ablauf der oben skizzierten „segmentation clock“ ein (Resende et al. 2010). Die vorliegende Untersuchung zeigt am Beispiel von Tupaia belangeri, dass Apoptose- und Proliferationsereignisse in der Chorda dorsalis zeitlich sowohl mit der Somitenabgliederung als auch mit der Sklerotombildung eng korreliert sind. Darüber hinaus dokumentieren wir erste Anhaltspunkte dafür, dass Apoptose- und Proliferationsereignisse, die in der Chorda dorsalis ablaufen, für die Morphogenese der Bodenplatte des Rückenmarks relevant sind, deren intrinsische Apoptosemuster kürzlich rekonstruiert und diskutiert wurden (Scheffel 2009). 


\section{MATERIAL UND METHODEN}

\section{1. Tiermodell}

Tupaia belangeri (Tupaiidae, Scandentia, Euarchontoglires, Eutheria, Theria, Mammalia) wird seit mehr als hundert Jahren von zahlreichen Forschergruppen eingehend untersucht. Hierbei kristallisierte sich in den zunächst überwiegend mit klassisch morphologischen Techniken durchgeführten vergleichend anatomischen Untersuchungen zunehmend heraus, dass mit Tupaia belangeri ein besonders Primaten-nahes Tiermodell zur Verfügung stehen könnte. Aufgrund der schwierigen Einordenbarkeit wurde Tupaia belangeri allerdings vorerst einer eigenen Ordnung „Scandentia“ zugerechnet (Wible und Covert 1987, Diogo et al. 2009). Die Frage der „Primaten-Nähe“ von Tupaia belangeri wird bis zum heutigen Tage kontrovers diskutiert. Demnach bilden die Scandentia und die Primatophora (Primaten und Dermoptera) aufgrund aktueller molekulargenetischer Forschungsergebnisse Schwesterkladen, die sich in erster Ordnung von den Euarchonta abgespalten haben (Janečka et al. 2007). Aktuelle zytogenetische Untersuchungen fassen dagegen die Scandentia und die Dermoptera zu einer Schwesterklade zusammen, die sich neben den Primaten von den Supraprimaten (Euarchontoglires) abgeleitet hat (Nie et al. 2008).

Unabhängig von der endgültigen Klärung ihres systematischen Status verfügt die Tupaia belangeri, verglichen mit den weit häufiger zu Forschungszwecken eingesetzten Labormäusen und Laborratten, über zahlreiche ursprüngliche Säugetier-Merkmale, deren eingehende Untersuchung vielversprechende Ergebnisse hervorbringt (zur Übersicht: Cao et al. 2003). Aktuelle Forschungsprojekte beschäftigen sich insbesondere mit Fragestellungen aus der Neuroembryologie (Knabe und Kuhn 1998, 1999, 2000, Knabe et al. 2000, 2004, 2007, 2008, 2009, Washausen et al. 2005, Scheffel 2009), Neuroanatomie (Wong P und Kaas 2009, Day-Brown et al. 2010, Herculano-Houzel et al. 2010), Stressforschung (Fuchs und Flügge 2002, Fuchs 2005, Zambello et al. 2010), Ophthalmologie (Phillips und McBrien 2004, McBrien et al. 2006), Parasitologie (Zuo et al. 2010) und Virologie (Köck et al. 2001, Glebe et al. 2003, 2005, Xu et al. 2007, Bremer et al. 2009, Amako et al. 2010, Tong et al. 2011).

Die Altersbestimmung der Embryonen von Tupaia belangeri lässt sich exakt durchführen, weil die Ovulation durch die Kopulation induziert wird und relativ konstant ca. 15-16 Stunden nach der Kopulation erfolgt (Kriesell 1977). Die Dauer der Gestation wird im Mittel mit 43,7 Tagen angegeben (Kuhn und Schwaier 1973), wobei Embryonaltag 1 definitionsgemäß dem Tag der Befruchtung entspricht. Die Jungtiere werden nackt und blind in einem dunklen Nest geboren. Sie öffnen zwischen dem 14. und 16. postnatalen Tag ihre Augen und verlassen das Nest um den 21. postnatalen Tag. Die in dieser Arbeit verwendeten Embryonen stammen einerseits aus dem früheren Battelle-Institut 
in Frankfurt/Main, andererseits aus der Zucht des Deutschen Primatenzentrums (DPZ) in Göttingen (AZ: 32.22/Vo und 10-1.031Ri/Lo). Sie wurden in den Jahren 1982 bis 1989 für Projekte im Rahmen des ehemaligen Sonderforschungsbereichs 89 (Kardiologie) gewonnen.

\section{2. Klassifikation der Embryonen}

Die vorliegende Arbeit entstand im Rahmen von DFG-Projekten der AG Neuroembryologie (Abt. Anatomie und Embryologie, Universitätsmedizin Göttingen), die sich mit den Mustern und Funktionen von Apoptose- und Proliferationsereignissen während der Frühentwicklung des Nervensystems beschäftigen (KN 525/1-1, KN 525/1-2 mit BR 1185/41). Bisherige Schwerpunkte dieser Forschungsprojekte befassten sich mit dem Rhombenzephalon (Knabe et al. 2004), mit neurogenen Plakoden (Washausen et al. 2005, Knabe et al. 2009) sowie mit dem Rückenmark (Scheffel 2009).

Die Klassifikation der Embryonen stammt aus Vorarbeiten zur Morphogenese des Vorderhirns (Knabe und Kuhn 1998, 1999, Knabe et al. 2000). Diese Klassifikation wurde auch in der vorliegenden Arbeit übernommen (Tab. 1).

Tab. 1: Verwendete Embryonen von Tupaia belangeri

\begin{tabular}{|c|c|c|c|c|c|c|}
\hline Phase & $\mathbf{E T}$ & $\begin{array}{l}\text { Somiten- } \\
\text { paare }\end{array}$ & $\begin{array}{l}\text { Nummer des } \\
\text { Embryos }\end{array}$ & $\begin{array}{c}\text { Fixierung, } \\
\text { Einbettung, } \\
\text { Färbung }\end{array}$ & $\begin{array}{l}\text { Schnitt- } \\
\text { dicke }\end{array}$ & Verfahren \\
\hline \multirow{3}{*}{$\begin{array}{l}\text { 1: V-förmige Evagination } \\
\text { der Augenanlage }\end{array}$} & 12 & 14 & Bat. 1396D/B & $\mathrm{G} / \mathrm{P}, \mathrm{A}, \mathrm{H}$ & $2 \mu \mathrm{m}$ & LM \\
\hline & 13 & 13 & DPZ 754/5B & $\mathrm{G} / \mathrm{P}, \mathrm{A}, \mathrm{H}$ & $1 \mu \mathrm{m}$ & $\mathrm{LM} / 2 \mathrm{D}$ \\
\hline & 13 & 14 & DPZ 754/1A & $\mathrm{G} / \mathrm{P}, \mathrm{A}, \mathrm{H}$ & $1 \mu \mathrm{m}$ & $\mathrm{LM} / 2 \mathrm{D} / 3 \mathrm{D}$ \\
\hline \multirow[t]{3}{*}{ 2: Augenbläschen } & 13 & 19 & DPZ 948/1B & $\mathrm{G} / \mathrm{P}, \mathrm{A}, \mathrm{H}$ & $1 \mu \mathrm{m}$ & LM \\
\hline & 13 & 19 & DPZ 948/8A & $\mathrm{G} / \mathrm{P}, \mathrm{A}, \mathrm{H}$ & $1 \mu \mathrm{m}$ & $\mathrm{LM} / 2 \mathrm{D} / 3 \mathrm{D}$ \\
\hline & 13 & 22 & Bat. 1566/B & $\mathrm{G} / \mathrm{P}, \mathrm{A}, \mathrm{A} / \mathrm{M}$ & $1 \mu \mathrm{m}$ & $\mathrm{LM} / 2 \mathrm{D}$ \\
\hline \multirow{2}{*}{$\begin{array}{l}\text { 3: Beginnende Invagination } \\
\text { des Augenbläschens }\end{array}$} & 14 & 27 & DPZ 870/9B & $\mathrm{G} / \mathrm{P}, \mathrm{A}, \mathrm{H}$ & $1 \mu \mathrm{m}$ & LM \\
\hline & 15 & 30 & DPZ 623/9B & $\mathrm{G} / \mathrm{P}, \mathrm{A}, \mathrm{H}$ & $1 \mu \mathrm{m}$ & $\mathrm{LM} / 2 \mathrm{D} / 3 \mathrm{D}$ \\
\hline \multirow{2}{*}{$\begin{array}{l}\text { 4: Vorangeschrittene } \\
\text { Invagination }\end{array}$} & 15 & 31 & DPZ 743/1A & $\mathrm{G} / \mathrm{P}, \mathrm{A}, \mathrm{H}$ & $1 \mu \mathrm{m}$ & $\mathrm{LM} / 2 \mathrm{D} / 3 \mathrm{D}$ \\
\hline & 15 & 32 & DPZ 743/4B & G/P, GMA, HE & $3 \mu \mathrm{m}$ & LM \\
\hline $\begin{array}{l}\text { 5: Weit fortgeschrittene } \\
\text { Invagination }\end{array}$ & 16 & n. b. & DPZ 5061/C & $\mathrm{G} / \mathrm{P}, \mathrm{A}, \mathrm{H}$ & $1 \mu \mathrm{m}$ & $\mathrm{LM} / 3 \mathrm{D}$ \\
\hline
\end{tabular}

2D, zweidimensionale Rekonstruktion; 3D, dreidimensionale Rekonstruktion; A, Araldit; A/M, Azur II/Methylenblau; Bat., Battelle-Institut, Frankfurt/Main; DPZ, Deutsches Primatenzentrum, Göttingen; E, Eosin; ET, Embryonaltag; G, Glutaraldehyd; GMA, Glycolmetacrylat (Kulzer); H, Hämatoxylin nach Heidenhain; LM, Lichtmikroskopie; n.b., nicht bestimmbar (Ende der Schnittserie im mittleren Lumbalbereich); P, Paraformaldehyd. 


\section{3. Anfertigung von Semidünnschnittserien}

Gravide Muttertiere wurden nach geltender deutscher Rechtsprechung durch intraperitoneale Injektion einer Überdosis Pentobarbital (Nembutal $\left.{ }^{\circledR}\right)$ getötet. Anschließend wurden die Muttertiere mit Macrodex und 0,15\%igem Procainhydrochlorid (Novocain ${ }^{\circledR}$ ) arteriell perfundiert und mit einem Gemisch aus 4\%igem Glutaraldehyd-/3\%igem Paraformaldehyd-Phosphatpuffer ( $\mathrm{pH}$ 7,3) fixiert. Zusätzlich wurden kleinere Embryonen in utero, größere Embryonen nach Entnahme aus dem Uterus mit dem gleichen Fixans immersionsfixiert. Anschließend wurden die Embryonen in Araldit $\mathbb{R}$ (Serva, Heidelberg, Deutschland) eingebettet. Araldit ${ }^{\circledR}$ zeichnet sich gegenüber Paraffin durch einen wesentlich stärkeren Aushärtungsgrad aus und kann deshalb, wie für unsere Zwecke erforderlich, wesentlich dünner geschnitten werden (für die Lichtmikroskopie: $1 \mu \mathrm{m}$, „semidünn“) als das üblicherweise verwendete Paraffin. Zur Anfertigung einer Semidünnschnittserie wurde die Anschnittfläche des Aralditblockes durch maschinelles Abtragen des Harzes so weit „getrimmt“, dass ein pyramidenförmiger Stumpf entstand. Durch wiederholtes Trimmen während des Schneideprozesses wurde die Anschnittfläche stets möglichst klein gehalten, um die Schnittherstellung zu erleichtern und um das Risiko von Schnittstauchungen oder -zerreißungen zu minimieren. Im Regelfall wurden aufeinander folgende Serienschnitte alternierend auf zwei Sets von Objektträgern platziert. Nur eine der entstandenen Teilserien wurde gefärbt und als „Arbeitsserie“ genutzt. Die zweite, vorerst ungefärbte „Referenzserie“ wird, wie unten beschrieben, zur Gewinnung von Referenzpunkten für die Ausrichtung der Serienschnitte beim Aufbau der dreidimensionalen Rekonstruktionen eingesetzt (Knabe et al. 2002).

\section{4. Diagnose apoptotischer und mitotischer Zellen}

Die Schnitte der Arbeitsserie wurden zur Routinebefundung mit Hämatoxylin nach Heidenhain gefärbt (Romeis 1989). Diese Färbung lässt sowohl das Chromatin als auch die Zellmembranen markant hervortreten. Folglich können sowohl apoptotische Körper als auch Mitosen gut identifiziert werden (Abb. 1).

Apoptose ist eine Form des programmierten Zelltods, die einerseits im Rahmen physiologischer Entwicklungsprozesse, andererseits aber auch im Verlauf pathologischer Prozesse häufig zu beobachten ist (zur Übersicht: Kerr et al. 1972, Sanders und Wride 1995, Fadeel und Orrenius 2005). Zunächst wurde eine scharfe Trennung zwischen apoptotischen und nekrotischen Zelltodereignissen postuliert. Anschließend wurden gemeinsame Triggerfaktoren und Aktivatoren für Apoptose- und Nekroseprozesse nachgewiesen (Leist und Nicotera 1997). Aktuell wird angenommen, dass Apoptose und Nekrose als Extreme eines „Kontinuums von Zelltodformen“ aufzufassen sind (Leist und 
Nicotera 1997, Leist et al. 1997). Viele dieser Zelltodformen sind weder strukturell noch biochemisch vollständig charakterisiert. Daher ist die Diagnose „Apoptose“ erst dann zu stellen, wenn sie durch mehrere voneinander unabhängige Nachweismethoden bestätigt worden ist (zur Übersicht: Sanders und Wride 1995, Hardy 1999, Huppertz et al. 1999, Stadelmann und Lassmann 2000).

Der Apoptoseprozess lässt sich in eine reversible „Initiationsphase“ und eine irreversible „Exekutionsphase“ unterteilen (Huppertz et al. 1999). In die Initiationsphase treten Zellen nach Ligandengesteuerter Aktivierung spezifischer Rezeptoren (z. B. Tumornekrosefaktor-Rezeptor-1, Fas-Rezeptor) und anschließender Bildung eines Signalkomplexes (death-inducing signaling complex, DISC: Kischkel et al. 1995) ein, wobei DISC die „Initiator-Caspasen“ (Caspase 8, 9 und/oder 10) aktiviert. Schon diese Initiator-Caspasen leiten strukturelle Veränderungen der Zellmembran ein, in deren Folge die betroffene Zelle den Kontakt zu ihren Nachbarzellen verliert. Hierauf schließt sich ein als „blebbing“ bezeichnetes, blasenartiges Vorwölben und Zurückziehen der Zellmembran an (Sanders und Wride 1995, Häcker 2000). Überwiegen jetzt pro-apoptotische Mitglieder der b-cell-lymphoma-2-(bcl-2)-Familie (z. B. bad, bax), gibt die betroffene Zelle mitochondriale Proteine (z. B. Cytochrom C) ins Zytoplasma ab, die ihrerseits die „Exekutions-Caspasen“ (Caspase 3, 6 und/oder 7) aktivieren ( $\mathrm{Li}$ et al. 1997, Granville et al. 1998). An diesem Punkt tritt die Zelle in die Exekutionsphase ein, die durch die Spaltung zahlreicher Enzyme und Bestandteile des Zytoskeletts gekennzeichnet ist. Mikroskopisch sind nun randständige, oft ringförmige Kondensationen des Kernchromatins sichtbar (Sanders und Wride 1995, Knabe und Kuhn 1998, Goping et al. 1999, Häcker 2000, Knabe et al. 2004). Die anschließende Fragmentierung der DNS lässt sich elektrophoretisch als typische „DNS-Leiter“ nachweisen (Wyllie 1980, Wyllie et al. 1980, zur Übersicht: Earnshaw 1995). Die entstandenen Kernfragmente sowie die anfangs strukturell intakten übrigen Zellorganellen werden jeweils von einer Zellmembran umgeben und rufen das charakteristische histologische Bild dichter, glatt begrenzter ,apoptotischer Körper“ hervor (Abb. 1B). Apoptotische Körper haben einen mittleren Durchmesser von 2 bis $6 \mu \mathrm{m}$ (Sanders und Wride 1995). Sie liegen zunächst frei im Interstitium, werden aber innerhalb weniger Minuten bis Stunden von phagozytierenden Nachbarzellen (Abb. 1B) oder eingewanderten ,professionellen Phagozyten“ (Rabinovitch 1995) aufgenommen und komplett abgebaut (Kerr et al. 1972, Earnshaw 1995, Rabinovitch 1995, Sanders und Wride 1995, Knabe und Kuhn 1999, Häcker 2000, Parnaik et al. 2000, Erwig und Henson 2008). Im Unterschied zu den flächig ausgedehnten Nekrosen treten apoptotische Zelluntergänge einzeln, das heißt umgeben von zahlreichen intakten Nachbarzellen auf (zur Übersicht: Kerr et al. 1987, Sanders und Wride 1995; Abb. 1A, B). Trotz der skizzierten strukturellen Unterschiede zwischen Nekrosen und Apoptosen, die in Semidünnschnitten prägnant hervortreten (Abb. 1B), überprüfen wir strukturell diagnostizierte Apoptosemuster durch die TUNEL-(terminal deoxynucleotidyl transferase (TdT)-mediated deoxyuridine triphosphate (dUTP)-biotin nick-end labeling)-Methode 
(Gavrieli et al. 1992) sowie immunhistochemisch mit Antikörpern gegen die aktivierte Form von Caspase 3, die als Exekutions-Caspase eine Schlüsselposition in der Apoptose-Kaskade einnimmt (Nicholson et al. 1995, Schlegel et al. 1996, Urase et al. 1998, zur Übersicht: Cohen 1997). Systematische Tests an den auch im Rahmen der vorliegenden Arbeit eingesetzten Semidünnschnitten haben gezeigt, dass alle drei Verfahren praktisch identische Apoptosemuster nachweisen (Knabe et al. 2004).

Auch mitotische Zellen lassen sich in Hämatoxylin nach Heidenhain gefärbten Semidünnschnitten anhand der kondensierten Chromatinfäden optimal diagnostizieren (Knabe und Kuhn 1998, Washausen et al. 2005, Knabe et al. 2009, Scheffel 2009; Abb. 1D). Für die dreidimensionalen Rekonstruktionen wurden einheitlich alle in der Prometaphase, Metaphase, Anaphase oder Telophase befindlichen Zellen markiert (Abb. 1D). Allerdings muss bei der vergleichenden Beurteilung publizierter Daten zum Vorkommen von Proliferationsereignissen, wie im Falle der Apoptosen, beachtet werden, dass jede Methode Limitationen hat und jeweils nur bestimmte Ausschnitte des untersuchten zellulären Prozesses abbildet (Alison 1995, Leong et al. 1995, Iatropoulos und Williams 1996).

\section{II. $5 . \quad$ Dreidimensionale Rekonstruktionen}

\section{5.1 Grundlagen}

Die dreidimensionale Erfassung großer Organanlagen bei gleichzeitiger Darstellung innerhalb dieser Organanlagen ablaufender zellulärer Prozesse auf Einzelzellniveau ist für die Bearbeitung zahlreicher entwicklungsbiologischer Fragestellungen hilfreich (Knabe et al. 2002, Süss et al. 2002). Dies gilt in besonderem Maße auch für die vorliegende Arbeit zur Morphogenese der Somiten sowie für die thematisch komplementäre Vorgängerarbeit über die Frühentwicklung des Rückenmarks (Scheffel 2009). In beiden Fällen müssen Morphogeneseprozesse beinahe entlang der gesamten kraniokaudalen Körperachse beurteilt werden. Derartig ausgedehnte Untersuchungsgebiete können nur lichtmikroskopisch erfasst werden. Dagegen erfolgt der strukturelle Nachweis apoptotischer Zellen optimalerweise am Transmissionselektronenmikroskop. Als „Mittelweg“ wählten wir die lichtmikroskopische Analyse von Semidünnschnittserien (Schnittdicke $=1 \mu \mathrm{m}$; x100 Objektiv, Immersionsöl). Hierdurch ist einerseits gewährleistet, dass das ausgedehnte Untersuchungsgebiet vollständig erfasst wird. Andererseits können apoptotische Körper (Knabe und Kuhn 1998, Goping et al. 1999) wie auch Mitosen individuell identifiziert werden. Das zur Datenakquisition erforderliche Hochauflösungsscansystem wurde in Zusammenarbeit mit der Firma ZEISS (Göttingen, Deutschland) entwickelt (KN 525/1-1). Die in der vorliegenden Arbeit gezeigten dreidimensionalen Rekonstruktionen wurden mit Hilfe des in Kooperation mit der TU Chemnitz etablierten Rekonstruktions- 
systems hergestellt (Knabe et al. 2002, Süss et al. 2002, Brunnett et al. 2003, Kienel et al. 2007).

Dreidimensionale Rekonstruktionen können sowohl mit Vektor-basierten Systemen als auch mit Voxel-basierten Verfahren erstellt werden. Für die von unserer Arbeitsgruppe verfolgten Fragestellungen erwies sich das Vektor-basierte System AutoCAD 2000i® (Autodesk, München, Deutschland) als optimal geeignet (Süss et al. 2002). Erstens können auch in Vektor-basierten Systemen „kleine“ zelluläre Ereignisse unabhängig von den großen Oberflächen embryonaler Konturen (z. B. ungegliedertes paraxiales Mesoderm oder Neuralrohr) rekonstruiert werden. Zweitens können in Vektor-basierten Systemen Oberflächen auch dann rekonstruiert werden, wenn - beispielsweise zur Reduktion von Scanzeiten - nur eine Auswahl der Serienschnitte in festgelegten Rekonstruktionsintervallen zur Verfügung steht. In Vorarbeiten erwies sich ein Standardintervall von $8 \mu \mathrm{m}$ als besonders geeignet für die Rekonstruktion von Apoptosemustern (Knabe et al. 2002, Süss et al. 2002, Washausen et al. 2005, Scheffel 2009). Hierdurch ist einerseits eine hinreichend genaue Rekonstruktion embryonaler Basiskonturen gewährleistet. Andererseits werden numerische Überrepräsentationen zellulärer Ereignisse - bei im Durchmesser 2 bis $6 \mu \mathrm{m}$ großen apoptotischen Körpern (Sanders und Wride 1995) - weitestgehend vermieden. Ein weiterer entscheidender Vorteil Vektor-basierter Systeme besteht darin, dass der benötigte Speicherplatz gegenüber Voxel-basierten Rekonstruktionssystemen deutlich geringer ist (Süss et al. 2002).

\section{II. $5.2 \quad$ Ausstattung des Scan- und Rekonstruktionssystems}

Tab. 2: Ausstattung des Scan- und Rekonstruktionssystems

\section{Scansystem}

\begin{tabular}{lll}
\hline Mainboard & GA-8IPE1000-G & G.B.T Technology, Hamburg, DE \\
Prozessor & $3.0 \mathrm{GHz}$ Pentium 4 & $\begin{array}{l}\text { Intel, Leixlip, IE } \\
\text { Festplattenspeicher }\end{array}$ \\
Arbeitsspeicher & Seagate Technology, München, DE \\
Grafikkarte & 2 GB DDR RAM & \\
Betriebssystem & 256 MB PowerColor Radeon 9600 Pro & Tul Corporation, Amsterdam, NL \\
Digitalkamera & Windows 2000 & Microsoft, Berlin, DE \\
& Axiocam HR & ZEISS, Göttingen, DE \\
& Basisauflösung (Pixel): z 1300x1030 & \\
Max. Auflösung (Pixel): 3900x3090 & \\
2/3 Zoll CCD-Farbsensor & ZEISS, Göttingen, DE \\
Scantisch & Axioskop 2 MOT & Märzhäuser, Wetzlar, DE \\
Scansoftware & SCAN 65x50 & \\
\hline
\end{tabular}


Rekonstruktionscomputer 1

\begin{tabular}{|c|c|c|}
\hline Mainboard & A8N-E & Asus, Ratingen, DE \\
\hline Prozessor & 2.2 GHz Athlon 64 3500+ & AMD, München, DE \\
\hline Festplattenspeicher & $\begin{array}{l}300 \text { GB: ST3300831AS } \\
120 \text { GB: WD1200BB } \\
1000 \text { GB: HD103SJ }\end{array}$ & $\begin{array}{l}\text { Seagate Technology, München, DE } \\
\text { Western Digital, Lake Forest, CA, USA } \\
\text { Samsung Electronics, Schwalbach/Ts., DE }\end{array}$ \\
\hline Arbeitsspeicher & 2 GB DDR RAM & \\
\hline Grafikkarte & 256 MB Radeon HD 2400 Pro & Sapphire Technology Inc., Hongkong, CN \\
\hline Betriebssystem & Windows XP Professional & Microsoft, Berlin, DE \\
\hline Grafiksoftware & AutoCAD 2000i & Autodesk, München, DE \\
\hline Grafiktablett & Intuos A3 & Wacom, Krefeld, DE \\
\hline \multicolumn{3}{|c|}{ Rekonstruktionscomputer 2} \\
\hline Mainboard & GA-8KNXP & G.B.T Technology, Hamburg, DE \\
\hline Prozessor & $3.0 \mathrm{GHz}$ Pentium 4 & Intel, Leixlip, IE \\
\hline Festplattenspeicher & $\begin{array}{l}80 \text { GB: } 6 \text { Y080M0 } \\
200 \text { GB: } 6 \mathrm{~L} 200 \mathrm{P} 0 \\
250 \mathrm{~GB}: \mathrm{SP} 2514 \mathrm{~N} \\
\text { 1000 GB: HD103SJ }\end{array}$ & $\begin{array}{l}\text { Maxtor EMEA, Massy Cedex, FR } \\
\text { Samsung Electronics, Schwalbach/Ts., DE }\end{array}$ \\
\hline Arbeitsspeicher & 2.0 GB DDR RAM & \\
\hline Grafikkarte & 128 MB Gigacube Radeon 9600 Pro & Info Tek Corporation, Hsin-Chu, TW \\
\hline Betriebssystem & Windows XP Professional & Microsoft, Berlin, DE \\
\hline Grafiksoftware & AutoCAD 2000i & Autodesk, München, DE \\
\hline Grafiktablett & Intuos A3 & Wacom, Krefeld, DE \\
\hline
\end{tabular}

\section{5.3 Datenakquisition}

Die Schnitte der Arbeitsserie wurden mit dem Hochauflösungsscansystem „Huge image“ (Knabe et al. 2002, Süss et al. 2002) eingescannt. Hierzu wurde eine digitale Kamera (Axiocam HR, Zeiss, Göttingen, Deutschland; maximale Auflösung: 3900 x 3090 Pixel) an einem Lichtmikroskop (Axioskop 2 MOT®, Zeiss) angebracht, das über einen Objekttisch verfügt, der sowohl in der z-Achse als auch in der x- und y-Achse motorisiert ist (SCAN 65x50, Märzhäuser, Wetzlar, Deutschland). Bei maximaler lichtmikroskopischer Auflösung (x100-Objektiv, Immersionsöl, numerische Apertur = 1,3) werden Einzelbilder der Kamera zeilenweise aufgenommen und anschließend zu einem am Monitor befundbaren Gesamtbild fusioniert („ImageProcessor“, Prof. Dr. G. Brunnett, TU Chemnitz, Deutschland). Die Gesamtbilder werden primär als 8 bit-Graustufenbilder im TIFF-(Tagged Image File Format)-Format gespeichert, zur schnelleren Befundung aber in das JPEG-(Joint Photographic Experts Group)-Format konvertiert. Um den beim Hochauflösungsscannen besonders hohen Zeitaufwand (Süss et al. 2002) zu senken, werden die Semidünnschnittserien nicht komplett, sondern auszugsweise in einem festgelegten Intervall eingescannt. Beim Scannen selbst unternimmt das System nur dann Fokussierungsversuche, wenn sich tatsächlich Strukturen (Varianz der Grau- 
stufen > 50) im Blickfeld der Kamera befinden. Weitere Zeitersparnis wird dadurch erreicht, dass aufeinander folgende strukturhaltige Einzelbilder lediglich in (frei wählbaren) Intervallen neu fokussiert werden. Detaillierte Angaben zu den skizzierten Scanparametern sowie zum automatisierten Umgang mit Schnittartefakten (Stauchungszonen, Farbstoffniederschläge etc.) finden sich in Süss et al. (2002).

Die Bilder der hochaufgelöst eingescannten histologischen Schnitte werden zur Befundung am Monitor in AutoCAD 2000i ${ }^{\circledR}$ geladen. Dabei ist der individuelle Skalierungsfaktor eines Bildes zu berücksichtigen, der sich aus der Multiplikation der Bildbreite (Pixel) mit der Auflösung des Bildes $(\mu \mathrm{m} /$ Pixel) errechnet. Die Konturen großer embryonaler Strukturen werden mit Hilfe eines Grafiktabletts (Intuos A3®, Wacom, Krefeld, Deutschland) als Polylinien vektorisiert (Knabe et al. 2002). Dagegen werden zelluläre Ereignisse als Kugeln kodiert. Polylinien und kugelförmig repräsentierte zelluläre Ereignisse werden in benutzerdefinierten „Layern“ gespeichert (z. B. „Außenwand der Somiten“ oder „Apoptosen innerhalb des Somitenepithels“). Anschließend werden alle an einem Serienschnitt erhobenen Vektordaten gemeinsam als „Block“ abgelegt.

\section{5.4 Aufbau der Rekonstruktionen}

Anders als bei optischen Schnittverfahren gehen bei der Anfertigung histologischer Schnittserien entscheidende Informationen über die ursprüngliche räumliche Ausrichtung („Orientierung“) der anatomischen Strukturen verloren. Eine Möglichkeit, dieses Problem anzugehen, besteht darin, die vektorisierten Schnitte nach Embryo-internen Referenzpunkten („best-fit“) auszurichten. Stehen hierbei rechts-links-symmetrische Organanlagen (Somitenpaare) und Mittellinienstrukturen (Chorda dorsalis) zur Verfügung, liefert diese Methode bei ideal transversal geschnittenen Embryonen und nachfolgender Korrektur anhand von Fotografien des ungeschnittenen Embryos akzeptable Ergebnisse. Allerdings werden junge Embryonen häufig in utero fixiert und geschnitten, um Beschädigungen zu verhindern. In solchen Fällen weicht die Schnittrichtung von der optimalen transversalen Schnittebene fast immer ab. Der resultierende Kippungswinkel kann allerdings relativ einfach berechnet und kompensatorisch als Ansichtswinkel in AutoCAD 2000i ${ }^{\circledR}$ eingeführt werden (Süss et al. 2002).

Besser sind jedoch Verfahren zur Schnittausrichtung, die sich an Embryo-externen Referenzstrukturen orientieren. Solche externen Referenzstrukturen sind beispielsweise die Konturen des Einbettungsblockes, die bei der Färbung von Schnitten zwar verloren gehen (Arbeitsserie), am ungefärbten Einzelschnitt (Referenzserie) jedoch gut erkennbar sind. Angesichts der Tatsache, dass korrespondierende Schnitte der Arbeits- und der Referenzserie mit einer Schnittdicke von nur $1 \mu \mathrm{m}$ unmittelbar aufeinander folgen, können vektorisierte anatomische Strukturen der Arbeitsserie in 
AutoCAD 2000i ${ }^{\circledR}$ mühelos mit vektorisierten Konturen des Einbettungsblockes (Referenzserie) zu „Hybridschnitten“ fusioniert werden, die anschließend mit allen notwendigen Informationen in die Rekonstruktionen eingehen. Eine detaillierte Beschreibung dieses von unserer Arbeitsgruppe etablierten Verfahrens findet sich in Knabe et al. (2002).

Aufgrund des beim Schneiden der histologischen Serie wiederholt notwendigen pyramidenförmigen Trimmens des Einbettungsblockes kommt der Aufbau der oben beschriebenen Hybridschnitte in AutoCAD 2000i ${ }^{\circledR}$ immer dann ins Stocken, wenn benachbarte Pyramidenstümpfe aneinander stoßen. An solchen Schnittstellen kann ohne bedeutsame Qualitätseinbuße auf Embryo-interne Referenzpunkte zurückgegriffen werden (Knabe et al. 2002).

Innerhalb der Pyramidenstümpfe ist die Ausrichtung der Serienschnitte in der x- und y-Achse durch das „,best-fit“ der Blockkonturen vorgegeben. Auch die z-Position jedes Einzelschnittes ist durch die Abfolge der Schnittserie festgelegt. Hierbei haben wir allerdings individuelle Schwankungen der Schnittdicke, die bei Semidünnschnitten bekanntermaßen sehr gering sind (Dørup et al. 1983), nicht berücksichtigt. Um Schrumpfungs- oder Stauchungsartefakte einzelner Serienschnitte aufdecken und korrigieren zu können, werden die Hybridschnitte beim Aufbau des Rekonstruktionsstapels in verschiedenen Ansichtsfenstern aus fünf Blickwinkeln überprüft: linke Körperseite, rechte Körperseite, Ventralansicht, Dorsalansicht und Aufsicht. Dank dieser Kontrollmaßnahmen können auch Fehlpositionierungen in der $\mathrm{x}$ - und $\mathrm{y}$-Achse sowie Rotationsartefakte nachträglich ausgebessert werden.

Zur Visualisierung rekonstruierter Oberflächen haben unsere informatischen Kooperationspartner zunächst einen von Boissonat (1988) entwickelten Triangulationsalgorithmus modifiziert (Brunnett et al. 2003). Hierbei erfolgt die Generierung von Oberflächen in drei Arbeitsschritten. Zuerst werden in zwei benachbarten Schnittebenen die jeweils von den Konturpunkten umschlossenen Flächen in sogenannte „Delaunay-Dreiecke“ mit maximal großen Winkeln unterteilt. Im zweiten Arbeitsschritt werden Kanten und Ecken dieser Delaunay-Dreiecke zu drei verschiedenen Klassen von Tetraedern verbunden, die den Raum zwischen den zwei benachbarten Schnittebenen überbrücken. Abschließend werden diejenigen Tetraeder, die die embryonale Oberfläche ungenau oder fehlerhaft beschreiben, durch einen Algorithmus „entlarvt“ und eliminiert. Bei der Rekonstruktion verzweigter Oberflächen sind weitergehende Korrekturmechanismen erforderlich (Brunnett et al. 2003). Eine umfangreiche Beschreibung des zweiten von der informatischen Arbeitsgruppe entwickelten Algorithmus zur Oberflächengenerierung findet sich in Kienel et al. (2007). Für die Nachbearbeitung mathematisch generierter Oberflächen stehen zahlreiche Glättungshilfen des Rekonstruktionssystems (,smoothing“, Prof. Dr. G. Brunnett, TU Chemnitz) zur Verfügung. 
Dreidimensional rekonstruierte Oberflächen sowie rekonstruierte zelluläre Ereignisse können wir in nahezu beliebigen Kombinationen darstellen (Kienel et al. 2007). Darüber hinaus besteht die Möglichkeit, Rekonstruktionen beliebig um die drei Hauptachsen zu drehen, stufenlos zu vergrößern oder zu verkleinern sowie mit Hilfe dreier Lichtquellen optimal auszuleuchten. Besonders komplizierte, im Inneren des Embryos ablaufende Prozesse können, zusätzlich zur standardmäßigen Verwendung stufenlos regelbarer Transparenz und Reflexionsgrade, durch Einführung künstlicher Schnittebenen visualisiert werden.

\section{6. Fotografische Dokumentation}

Alle Mikrofotografien wurden mit dem Scansystem „Huge Image“ aufgenommen. Bei diesen Aufnahmen wurde eine „shading correction“ in KS400 (ZEISS) durchgeführt, um jegliches Hintergrundrauschen auszuschließen (Süss et al. 2002). Im Bedarfsfall wurden Schärfe und Kontrast der Fotografien in Photo-Paint (Corel $\mathrm{GmbH})$ in geringen Grenzen angepasst. Gleiches gilt für die mit Hilfe von „Vision“ (Prof. Dr. G. Brunnett, TU Chemnitz) erstellten dreidimensionalen Rekonstruktionen. 


\section{ERGEBNISSE}

\section{1. Morphogenese der Somiten}

\section{1.1 Grundlagen und Nomenklatur}

Somiten gliedern sich in kraniokaudaler Richtung aus dem paraxialen Mesoderm ab. Nach Ordahl (1993) wird der zuletzt abgegliederte Somit als „SI“, der jeweils zuvor abgegliederte Somit als „SI+x“ angesprochen. Pourquié und Tam (2001) dehnten diese Zählung auf prospektive Somiten aus. „S0“ ist kranial von SI abgegliedert, hängt aber kaudal noch mit dem paraxialen Mesoderm zusammen. Kaudal von S0 schließen sich „S-I+x“ an, deren Identität durch segmentspezifische Genexpressionsmuster bereits festgelegt ist (zur Übersicht: Rawls et al. 2000, Tam et al. 2000). Deshalb geben wir, in Anlehnung an Pourquié und Tam (2001) sowie Venters et al. (2008), die Positionen prospektiver Somiten nach Schätzungen an, denen die kraniokaudale Ausdehnung von SI zugrunde liegt.

Um mögliche Beiträge von Apoptose- und Proliferationsereignissen zur Abgliederung und Differenzierung von Somiten bei Tupaia belangeri aufdecken zu können, wurden dreidimensionale Rekonstruktionen von Embryonen der Phasen 1 bis 5 durchgeführt (zur Klassifikation s. Material und Methoden, S. 9). Diese Rekonstruktionen schließen auch das intermediäre Mesoderm und das Seitenplattenmesoderm ein. Zur Erleichterung der Befunderhebung wurden zusätzlich die in Vorarbeiten rekonstruierten Anlagen von Gehirn und Rückenmark, der Spinal- und Hirnnerven mit ihren Ganglien sowie der Chorda dorsalis eingefügt (Knabe et al. 2004, 2009, Washausen et al. 2005, Scheffel 2009). Beispielsweise sind für die Identifikation von Okzipitalsomiten zunächst die Rhombomere und die aus den Rhombomeren 1, 2, 4, 6 und 7 sowie aus dem Rückenmark auswandernden Neuralleistenzellströme relevant. Bei älteren Embryonen stellen die aus Neuralleistenzellen hervorgegangenen Hirn- und Spinalnervenganglien wichtige topografische Bezugspunkte dar.

\section{1.2 Okzipitalsomiten}

Bei menschlichen Embryonen liegt die Grenze zwischen Okzipital- und Zervikalregion kaudal des vierten Somiten (O’Rahilly und Müller F 2007). Begründet wird diese Festlegung damit, dass nur kaudal des vierten Somiten (zervikale) Spinalganglien ausgebildet werden. Außerdem entspringen zwischen dem vierten Somiten und dem kranial des ersten Somiten lokalisierten Rhombomer 7 (R7) sämtliche Wurzeln des N. hypoglossus aus dem Neuralrohr.

Im Phase-1-Embryo DPZ 754/1A von Tupaia belangeri sind Formationen von Neuralleistenzellen, aus denen Spinalganglien hervorgehen werden, erst kaudal des vierten Somiten nachweisbar. Der kraniale Rand des ersten Somiten projiziert auf den kaudalen Rand von R7. Demnach verfügt dieser 
Embryo, wie menschliche Embryonen (Müller F und O'Rahilly 2003, O'Rahilly und Müller F 2007), über 4 Okzipitalsomiten. Der erste Okzipitalsomit (O1) ist kleiner als alle kaudal folgenden Somiten. O2 ist auf der linken Körperseite doppelt ausgebildet. Die Ganglienanlage des N. glossopharyngeus liegt seitlich von R6. Dorsolateral von R6 und R7 finden sich mittelliniennah zahlreiche Neuralleistenzellen.

Auch der zweite Phase-1-Embryo DPZ 754/5B sowie die Phase-2-Embryonen DPZ 948/8A (Abb. 2A) und DPZ 948/1B verfügen über vier Okzipitalsomitenpaare. Die Ganglienanlagen des N. glossopharyngeus sowie andeutungsweise des N. vagus sind abgrenzbar.

In den Embryonen der Phasen 3 (DPZ 623/9B) und 4 (DPZ 743/1A: Abb. 2B) ist zwischen dem kranialsten Somiten und R7 (Höhe: N. vagus) die vorbestehende Position von O1 unbesetzt. O1 ist demnach bereits „aufgelöst“. In die entstandene Lücke projiziert die oberste Wurzel des N. hypoglossus. Die drei tieferen Wurzeln des N. hypoglossus weisen enge Lagebeziehungen zu O2, O3 beziehungsweise O4 auf. Die Anlage des ersten zervikalen Spinalganglions liegt kaudal von O4 und ist, wie beim Menschen (O'Rahilly und Müller F 2003, 2007), kleiner als alle kaudal folgenden Spinalganglienanlagen (Abb. 2B).

Auch der rekonstruierte Phase-5-Embryo DPZ 5061/C (Abb. 2C) besitzt lediglich drei paarige Okzipitalsomiten (O2 bis O4). In DPZ 5061/C sind die vier Wurzeln des N. hypoglossus bereits zu einem Strang vereinigt, dem sich auch schon Fasern aus den ersten beiden zervikalen Spinalnerven angelagert haben (Abb. 2C).

\section{1.3 Derivate des Mesoderms}

Im Folgenden wird für jeden dreidimensional rekonstruierten Embryo ein Überblick über den Entwicklungsstand der Somiten, der Chorda dorsalis, des intermediären Mesoderms sowie des Seitenplattenmesoderms gegeben. Hierbei werden die Abkürzungen Z: Zervikalsomit, T: Thorakalsomit, L: Lumbalsomit, S: Sakralsomit und K: Kokzygealsomit eingeführt.

Der Phase-1-Embryo DPZ 754/1A besitzt 14 Somitenpaare (O1 bis T2). Der prospektive (p) Somit pT3 hängt kaudal noch mit dem ungegliederten Mesoderm zusammen und entspricht daher S0 (Abb. 3A). Die aus dem axialen Mesoderm abgeleitete Chorda dorsalis endet in Höhe von S-VI (Abb. 3A, D). Dagegen ist die aus dem intermediären Mesoderm hervorgehende Urniere erst kranial von S-I/S-II abgrenzbar (Abb. 3A, D). Deshalb hängen die gemeinsam rekonstruierten Abschnitte des ungegliederten paraxialen und intermediären Mesoderms auf beiden Körperseiten zwischen S-II und S-VI zusammen (Abb. 3A). Beide Formationen sind kaudal der Chorda dorsalis über das axiale 
Mesoderm U-förmig miteinander verbunden (Abb. 3A). Kaudal von S-VI ist das ungegliederte axiale Mesoderm strangartig verdichtet und kann weder gegen das Neuroektoderm noch gegen das Entoderm abgegrenzt werden: „chordoneurales Scharnier“ („chordoneural hinge“: Pasteels 1943, Cambray und Wilson V 2002, Müller F und O’Rahilly 2004; Abb. 3E).

An die beschriebene U-förmige Mesodermformation schließt sich lateral das Seitenplattenmesoderm an, das bei DPZ 754/1A (Phase 1: Abb. 3) und DPZ 948/8A (Phase 2) vom kaudalen Ende des Embryos aufwärts bis etwa zur Herzanlage rekonstruiert wurde. Der Boden des von Somato- und Splanchnopleura begrenzten Zölomspaltes findet sich auf Höhe der Allantois (Abb. 3F). Kaudal von SII ist die Somatopleura wesentlich dicker und auskragender als die Splanchnopleura (Abb. 3E). Kranial von SII gleichen sich Somato- und Splanchnopleura in Bezug auf beide Parameter zunehmend aneinander an (Abb. 3D). Außerdem nähern sich hier die lateralen Abschnitte beider Seitenplatten aneinander an und schließen die Pleuroperikardhöhle in Höhe Z4 (linke Körperseite) beziehungsweise Z7 (rechte Körperseite) nach lateral ab (Abb. 3B, C).

Der Phase-2-Embryo DPZ 948/8A verfügt über 19 Somitenpaare (O1 bis T7, pT8 = S0). Die Urniere ist kranial von S-II abgrenzbar. Die Chorda dorsalis endet in Höhe von S-VI. Das chordoneurale Scharnier geht kaudal in die Schwanzknospe über. Die zum Entwicklungsstand des Seitenplattenmesoderms erhobenen Befunde entsprechen weitgehend den im Phase-1-Embryo DPZ 754/1A nachgewiesenen Verhältnissen.

Die rekonstruierten Embryonen der Phasen 3 (DPZ 623/9B) und 4 (DPZ 743/1A) verfügen über 30 $(\mathrm{O} 2$ bis $\mathrm{L} 6, \mathrm{pS} 1=\mathrm{S} 0)$ beziehungsweise 31 Somitenpaare $(\mathrm{O} 2$ bis $\mathrm{S} 1, \mathrm{pS} 2=\mathrm{S} 0)$. Die Chorda dorsalis endet in Höhe S-IV. Alle ungegliederten kaudalen Mesodermabschnitte bilden, wie in den Phasen 1 und 2, eine U-förmige Formation, an deren Scheitelpunkt sich die Schwanzknospe befindet. Ventrale Abschnitte dieser U-förmigen Formation werden, im Gegensatz zu dem dorsal von ihnen lokalisierten ungegliederten paraxialen Mesoderm, als „ventrales Mesoderm“ bezeichnet (Goldman et al. 2000; s. Kap. III.2.1 und Abb. 19).

Die Schnittserie des Phase-5-Embryos DPZ 5061/C endet in Höhe von L2. Alle rekonstruierbaren Somiten (26 Paare) sind bereits in Sklerotom, Dermomyotom und Myotom untergliedert. Tabelle 3 fasst den Entwicklungsstand aller rekonstruierten Embryonen zusammen. 
Tab. 3: Entwicklungsstand der dreidimensional rekonstruierten Embryonen von Tupaia belangeri (I)

\begin{tabular}{cccccc}
\hline Phase & $\begin{array}{c}\text { Nummer } \\
\text { des } \\
\text { Embryos }\end{array}$ & ET & $\begin{array}{c}\text { Somiten- } \\
\text { paare }\end{array}$ & S0 & $\begin{array}{c}\text { Okzipital- } \\
\text { somiten }\end{array}$ \\
\hline 1 & DPZ 754/1A & 13 & $\mathrm{O} 1-\mathrm{T} 2(14)$ & $\mathrm{pT} 3$ & $\mathrm{O} 1-\mathrm{O} 4$ \\
2 & $\mathrm{DPZ} 948 / 8 \mathrm{~A}$ & 13 & $\mathrm{O} 1-\mathrm{T} 7(19)$ & $\mathrm{pT} 8$ & $\mathrm{O} 1-\mathrm{O} 4$ \\
3 & $\mathrm{DPZ} 623 / 9 \mathrm{~B}$ & 14 & $\mathrm{O} 2-\mathrm{L} 6(30)$ & $\mathrm{pS} 1$ & $\mathrm{O} 2-\mathrm{O} 4$ \\
4 & $\mathrm{DPZ} 743 / 1 \mathrm{~A}$ & 15 & $\mathrm{O} 2-\mathrm{S} 1(31)$ & $\mathrm{pS} 2$ & $\mathrm{O} 2-\mathrm{O} 4$ \\
5 & $\mathrm{DPZ} 5061 / \mathrm{C}$ & 16 & $\mathrm{O} 2-\mathrm{L} 2\left(26^{*}\right)$ & - & $\mathrm{O} 2-\mathrm{O} 4$ \\
\hline
\end{tabular}

ET, Embryonaltag; L, Lumbalsomit; O, Okzipitalsomit; p, prospektiver Somit; S, Sakralsomit; S0, in Abgliederung begriffener Somit; T, Thorakalsomit; Z, Zervikalsomit; *, Ende der Schnittserie von DPZ 5061/C.

\section{1.4 Bildung intersomitischer Spalten}

Die zur Befunderhebung überwiegend eingesetzten dreidimensionalen Rekonstruktionen basieren auf der Analyse von Semidünnschnittserien im $8 \mu \mathrm{m}$-Intervall. Um noch exaktere Aussagen über den Stand der intersomitischen Spaltbildung machen zu können, haben wir den zwischen S0 und S-I entstehenden Spalt zusätzlich grafisch im $2 \mu \mathrm{m}$-Intervall rekonstruiert (Abb. 4). Die Erstellung solcher zweidimensionalen Rekonstruktionen wurde durch den Umstand erschwert, dass die Schnittebene der Serie praktisch niemals mit der Ebene des entstehenden intersomitischen Spaltes zusammenfällt (Abb. 4A). Deshalb wurde zunächst eine Schablone entworfen, die eine Aufsicht auf den hypothetisch vollständigen Spalt S0/S-I darstellt (Abb. 4B). Die Form dieser Schablone entspricht dem Umriss kranialer Abschnitte von S-I, den wir durch Einführung künstlicher Schnittebenen in unsere dreidimensionalen Rekonstruktionen ermitteln können. Innerhalb der Schablone wurden anschließend, getrennt für jeden Serienschnitt, alle bereits existierenden Spaltabschnitte grün, noch nicht durch einen Spalt getrennte Zonen dagegen magentafarben markiert (Abb. 4B).

Im Phase-1-Embryo DPZ 754/1A sind am Übergang S0/S-I sowohl dorsolateral als auch ventromedial Spaltanteile ausgebildet, die durch eine weitgehend spaltfreie Zone voneinander getrennt werden (Abb. 5C). Auf der rechten Körperseite ist diese Zone solide, linksseitig dagegen von diskreten Spaltanteilen durchbrochen. Diese Befunde legen den Schluss nahe, dass die Bildung intersomitischer Spalten bei Tupaia belangeri dorsolateral und ventromedial unabhängig voneinander einsetzt.

Diese Arbeitshypothese wurde an weiteren fünf Embryonen (Phasen 1 bis 4) überprüft (Abb. 5A, B, D-F). Unter der Annahme, dass interindividuelle Unterschiede hinsichtlich des Ausmaßes bereits etablierter Spaltanteile einen zeitlichen Ablauf widerspiegeln, haben wir eine hypothetische Sequenz der Spaltbildung zusammengestellt. Alle „Frühstadien“ (Abb. 5A-C) weisen, wie der zuerst betrachtete Phase-1-Embryo DPZ 754/1A (Abb. 5C), voneinander getrennte dorsolaterale und ven- 
tromediale Spaltanteile auf. Die „Spätstadien“ (Abb. 5D-F) lassen die Interpretation zu, dass die Spaltbildung einerseits von dorsolateral, andererseits von ventromedial nach zentral fortschreitet. Mit Ausnahme der rechten Körperseite von DPZ 754/5B (Abb. 5E), erreicht die Spaltbildung ventrolaterale Positionen zuletzt.

\section{1.5 Spalt-assoziierte Grenzzellen}

In neu gebildeten Somiten sind die Epithelzellen radiär auf das im Zentrum liegende Somitozöl ausgerichtet (Abb. 6A). Ihre Apizes sind schmal, ihre kerntragenden basalen Abschnitte vergleichsweise breit. Wie dieser hoch geordnete Epithelverband im Einzelnen aus dem ungegliederten paraxialen Mesoderm hervorgeht und, mehr noch, wie die zugrunde liegende mesenchymal-epitheliale Transition (MET) mit der intersomitischen Spaltbildung zusammenhängt, ist bei weitem nicht vollständig verstanden.

Der Versuch einer Beantwortung dieser Fragen durch strukturelle Analysen von Semidünnschnittserien wird durch mehrere Hindernisse erschwert. Erstens ist die MET am Übergang S0/S-I, wie die Spaltbildung auch, bei allen untersuchten Tupaia-Embryonen unterschiedlich weit vorangeschritten. Zweitens ist die standardisierte Festlegung des Epithelialisierungsgrades stellenweise unmöglich. Drittens hängt die Vergleichbarkeit des Epithelialisierungsgrades von Zellgruppen, die bei verschiedenen Embryonen an identischen Positionen auftreten, erheblich von der jeweils vorliegenden Schnittebene $a b$.

Auf der Grundlage von Transplantationsversuchen in Kombination mit molekulargenetischen Untersuchungen haben Sato et al. (2002) postuliert, dass beim Haushuhn spezifische Grenzzellpopulationen im Bereich des sich bildenden intersomitischen Spaltes auftreten. Unsere an Tupaia belangeri erhobenen Befunde sprechen dafür, dass solche Grenzzellen tatsächlich existieren.

Diese Grenzzellen weisen epitheliale Charakteristika auf (Abb. 6B-D): Sie sind langgestreckt und Fortsatz-arm. Ihre Längsachsen sind aber nicht radiär auf das künftige Somitenzentrum, sondern parallel zum entstehenden intersomitischen Spalt ausgerichtet, den sie häufig in kettenartiger Anordnung flankieren. Am Übergang S0/S-I treten solche Grenzzellen entweder auf nur einer Seite des Spaltes (überwiegend bei S-I) oder beidseits des Spaltes auf (Abb. 6B-D). Alternativ finden sich Stapel von meist zwei oder drei Grenzzellen ,innerhalb“ des eben erkennbaren Spaltes (Abb. 6B, D). Spalt-assoziierte Grenzzellen, die möglicherweise kausal mit der Spaltbildung am Übergang S0/S-I im Zusammenhang stehen, fanden wir bei allen untersuchten Embryonen der Phasen 1 bis 4 (DPZ 754/1A, DPZ 754/5B, DPZ 948/8A, Bat. 1566/B, DPZ 623/9B, DPZ 743/1A). 
Mit der Hypothese, dass Grenzzellen an der Initiierung der Spaltbildung beteiligt sein könnten, sind auch die am Übergang S-I/S-II an den Tupaia-Embryonen DPZ 754/1A (Phase 1) und DPZ 948/8A (Phase 2) exemplarisch erhobenen Befunde vereinbar. So wird der in DPZ 754/1A ausschließlich ventromedial zwischen S-I und S-II nachweisbare Spalt kranial und kaudal von kettenförmig beziehungsweise in Stapeln angeordneten Grenzzellen flankiert (Abb. 6E). Auch in DPZ 948/8A ist der zwischen S-I und S-II entstehende Spalt auf ventromediale Positionen begrenzt. Verglichen mit DPZ 754/1A ist die mediolaterale Ausdehnung dieses Spaltes sogar noch geringer. Passend zu unserer Arbeitshypothese treten auch hier vereinzelt bereits Spalt-assoziierte Grenzzellen auf.

Interessanterweise wird der weitgehend vollständig ausgebildete Spalt S0/S-I des Phase-1-Embryos DPZ 754/5B lediglich von vereinzelt auftretenden Grenzzellen flankiert. Auch am Übergang SI/S0 (Abb. 6F) nimmt die Zahl von Grenzzellen, verglichen mit den analysierten Übergängen S0/S-I (Abb. 6B-D), immer weiter ab. Diese Beobachtungen stützen die Anschlusshypothese, dass die Anwesenheit von Grenzzellen nach Etablierung des intersomitischen Spaltes nicht mehr erforderlich ist.

Zwischen dem Auftreten von Grenzzellen und dem Stand der MET bestehen sowohl am Übergang S0/S-I als auch, in abgeschwächter Form, am Übergang S-I/S-II zeitliche und räumliche Zusammenhänge. Insbesondere fällt auf, dass Spalt-assoziierte Grenzzellverbände an der Grenze S0/S-I sowie S-I/S-II grundsätzlich aus palisadenartig angeordneten, senkrecht auf das Neuralrohr stehenden Formationen Epithel-ähnlicher Zellen in der medialen Wand von S-I hervorzugehen scheinen (Abb. 6B-E). Auf eine umfassende räumliche Charakterisierung des Epithelialisierungsprozesses wird im Rahmen der vorliegenden Arbeit verzichtet. 

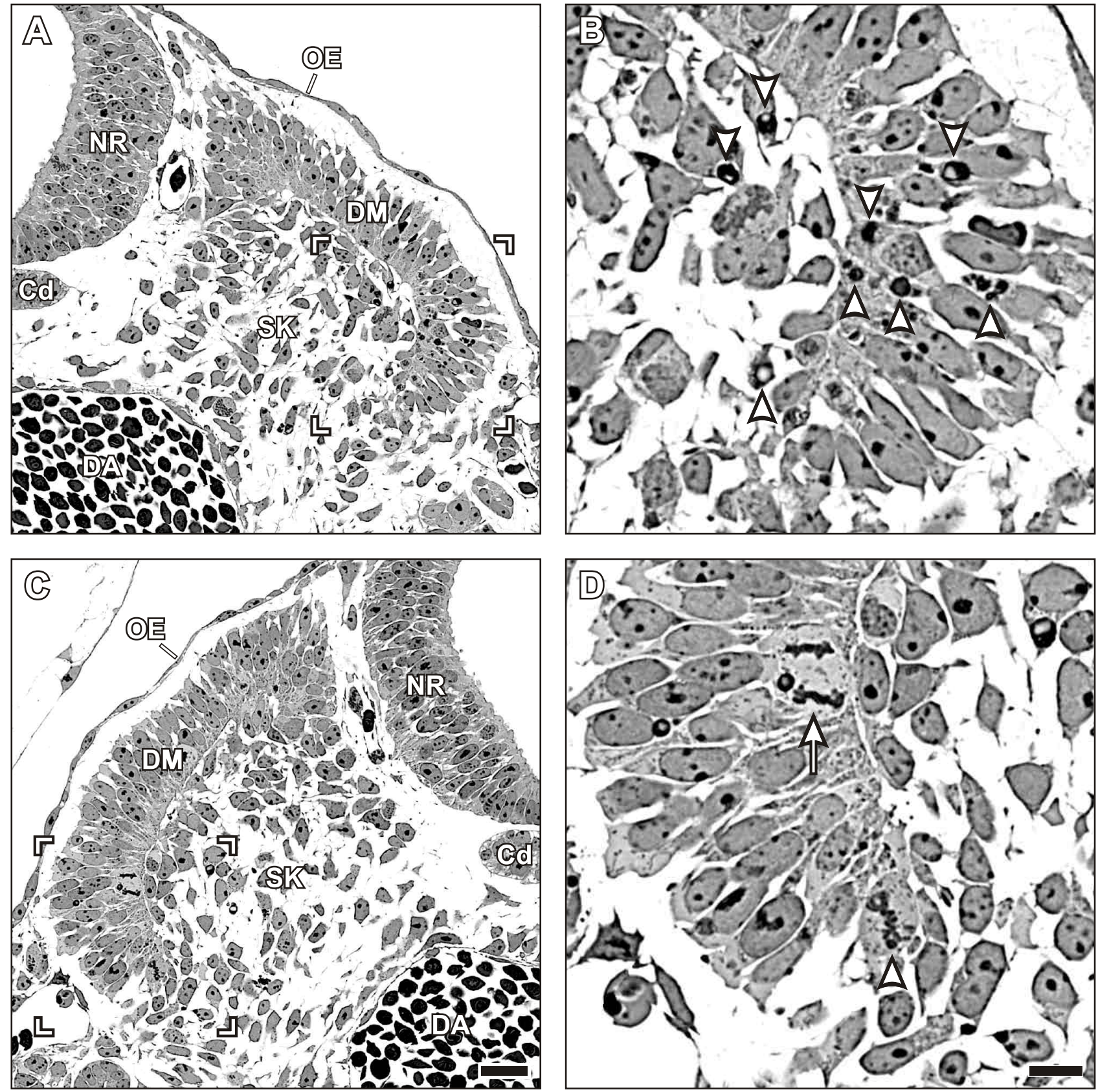

Abb. 1: Tupaia belangeri, Diagnose apoptotischer $(\mathbf{A}, \mathbf{B})$ und mitotischer $(\mathbf{C}, \mathbf{D})$ Zellen in Semidünnschnitten $(1 \mu \mathrm{m}$, Hämatoxylin/Heidenhain; Phase 3, DPZ 623/9B). Apoptotische Körper (Pfeilköpfe in B: Detail, Rahmen in A) im Dermomyotom und Sklerotom des 3. rechtsseitigen Lumbalsomiten sowie Mitosen (D: Detail, Rahmen in C) im Dermomyotom des 1. linksseitigen Lumbalsomiten. Mitotische Zellen wurden in der Prometaphase, Metaphase (Pfeilkopf in D), Anaphase (Pfeil in D) und Telophase rekonstruiert. Cd, Chorda dorsalis; DA, dorsale Aorta; DM, Dermomyotom; NR, Neuralrohr; SK, Sklerotom; OE, Oberflächenektoderm. Maßstäbe: $\mathbf{A}, \mathbf{C}=25 \mu \mathrm{m} ; \mathbf{B}, \mathbf{D}=10 \mu \mathrm{m}$. 


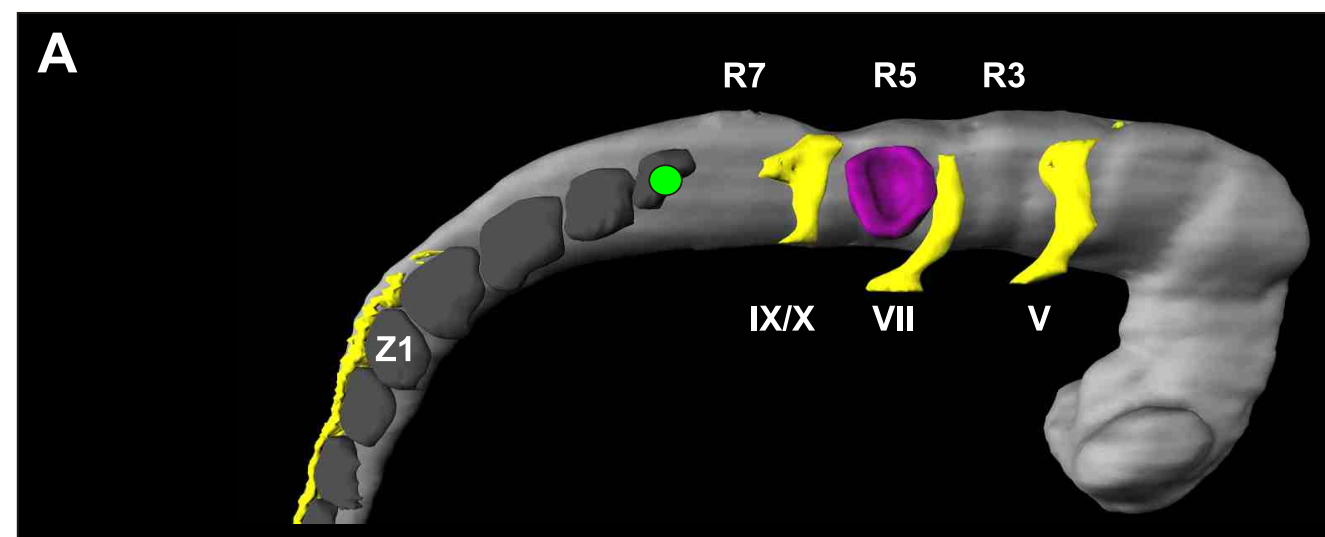

B

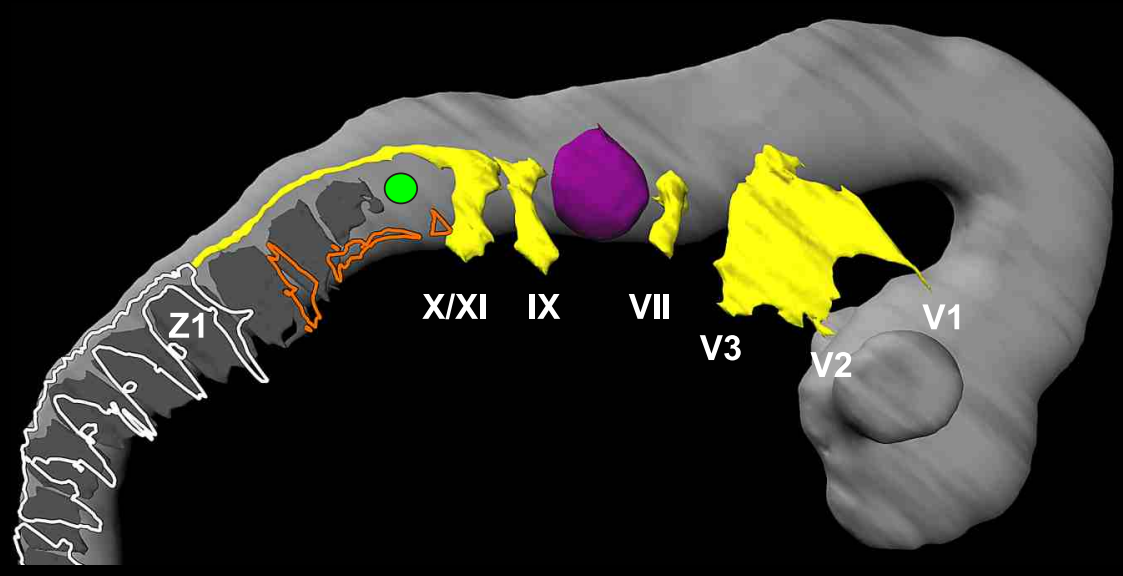

C

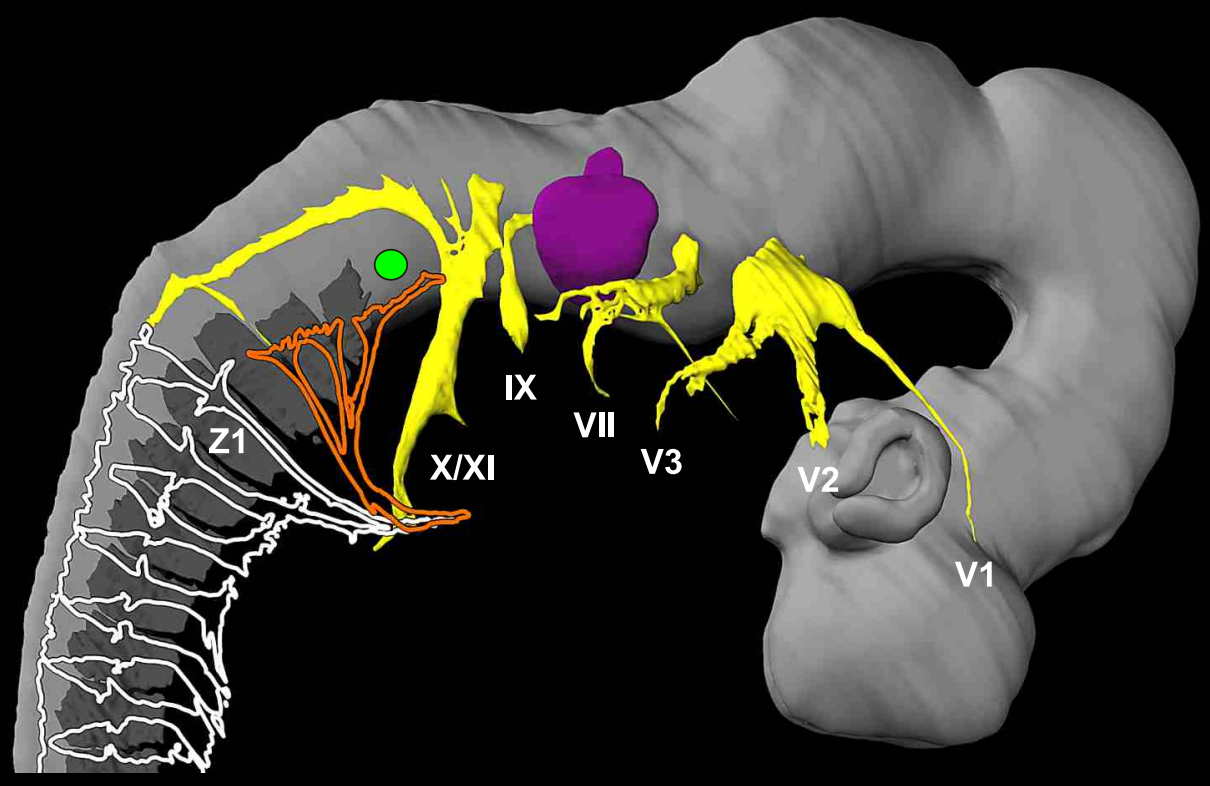

Abb. 2: Tupaia belangeri, 4 Okzipitalsomiten. Seitansichten dreidimensionaler Rekonstruktionen (A: Phase 2, DPZ 984/8A; B: Phase 4, DPZ 743/1A; C: Phase 5, DPZ 5061/C). In den Phasen 1 und 2 (A) ist der 1. Okzipitalsomit (grüner Punkt auf Dunkelgrau) kleiner als alle kaudal folgenden Somiten (dunkelgrau). Er liegt kaudal von Rhombomer (R) 7 (R7). Bandartige dorsale Formationen emigrierender Neuralleistenzellen (gelb) sind zervikal, aber nicht okzipital nachweisbar. In den Phasen 3, 4 (B) und 5 (C) ist der 1. Okzipitalsomit aufgelöst. Beachte die kranialen Wurzeln des N. hypoglossus (orange) in Höhe der vorbestehenden Position des 1. Okzipitalsomiten (grüner Punkt). Anlagen von Spinalganglien und Spinalnerven (weiß) treten in Höhe des N. hypoglossus nicht auf. Hellgrau, Neuralanlage; magenta, Ohrvesikel; V, N. trigeminus; V1, N. ophthalmicus; V2, N. maxillaris; V3, N. mandibularis; VII, N. facialis; IX, N. glossopharyngeus; $X, N$. vagus; XI, N. accessorius; Z1, Zervikalsegment 1 . Maßstäbe $=100 \mu \mathrm{m}$. 



Abb. 3: Tupaia belangeri, Ventralansicht des dreidimensional rekonstruierten Mesoderms (grau in A), Phase 1, DPZ 754/1A, 14 Somitenpaare sowie repräsentative Semidünnschnitte (1 $\mu \mathrm{m}$, Hämatoxylin/Heidenhain; B-F: rote Schnittebenen in A). S0 (in Abgliederung begriffener Somit) hängt kaudal mit der U-förmigen Formation des noch ungegliederten, überwiegend mesenchymalen Mesoderms ( $\mathrm{mM}$ in E, F) zusammen. Kaudal der Chorda dorsalis (Cd in A, D) ist das Mesoderm zum ,,chordoneuralen Scharnier“" (Pfeilköpfe in E) verdichtet. Der Zölomspalt (ZS in D) reicht kaudal bis in Höhe der Allantois (weißer Stern in F) und mündet kranial in die Pleuroperikardhöhle (schwarzer Stern in B, C). In Höhe der Herzanlage (HA in B) sind die Pleuroperikardhöhlen beider Körperseiten miteinander verbunden (Pfeil in A). AE, Amnionepithel; DA, dorsale Aorten; EN, Entoderm; N, Nierenanlage; NF, Neuralfalten; NP, Neuralplatte; NR, Neuralrohr; OE, Oberflächenektoderm; SII, abgegliederter Somit 2; S-II, prospektiver Somit 2; S-VI, prospektiver Somit 6; SM, Somatopleura; SP, Splanchnopleura; Z8, Zervikalsomit 8. Maßstäbe $=50 \mu \mathrm{m}$. 

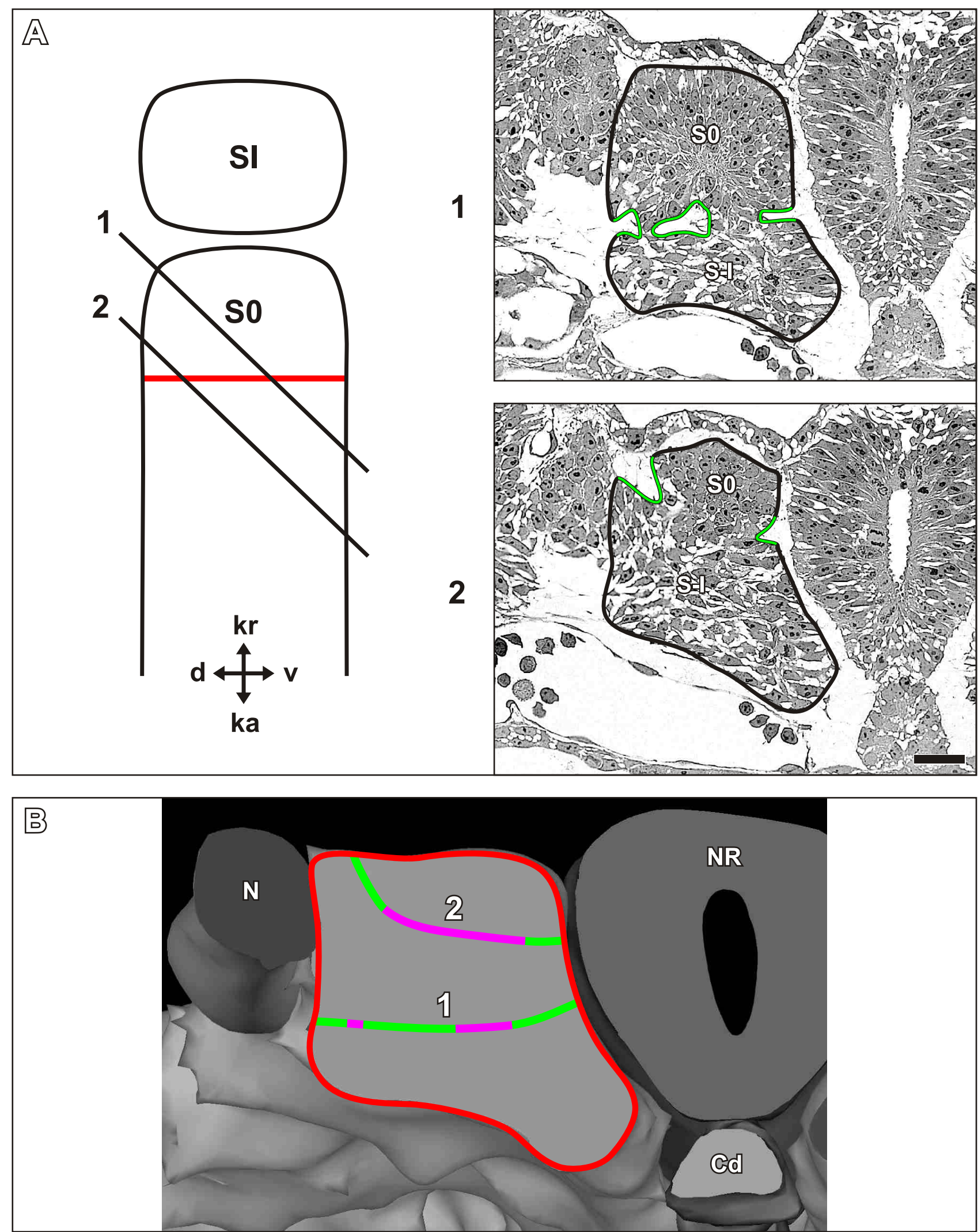

Abb. 4: Tupaia belangeri, zweidimensionale Rekonstruktion des entstehenden intersomitischen Spaltes zwischen dem in Abgliederung begriffenen Somiten S0 und dem ersten prospektiven Somiten S-I anhand von Semidünnschnitten (1 $\mu$ m, Hämatoxylin/Heidenhain; Phase 1, DPZ 754/1A). A: Linke Spalte: Seitansicht des ungegliederten paraxialen Mesoderms (schwarzer Umriss) sowie des zuletzt abgegliederten Somiten SI; Positionen des entstehenden Spaltes S0/S-I (rot) sowie der Schnittebenen 1 und 2 (schwarze Linien). Rechte Spalte: Zunächst werden bereits ausgebildete Spaltanteile (grün) einzeln in allen Serienschnitten ermittelt. B: Danach werden die Positionen bereits ausgebildeter Spaltanteile (grün) sowie noch fehlender Spaltanteile (magenta) in die Schablone des Spaltes S0/S-I (roter Umriss) übertragen. Cd, Chorda dorsalis; d, dorsal; N, Nierenanlage; ka, kaudal; NR, Neuralrohr; kr, kranial; v, ventral. Maßstab $=25 \mu \mathrm{m}$. 

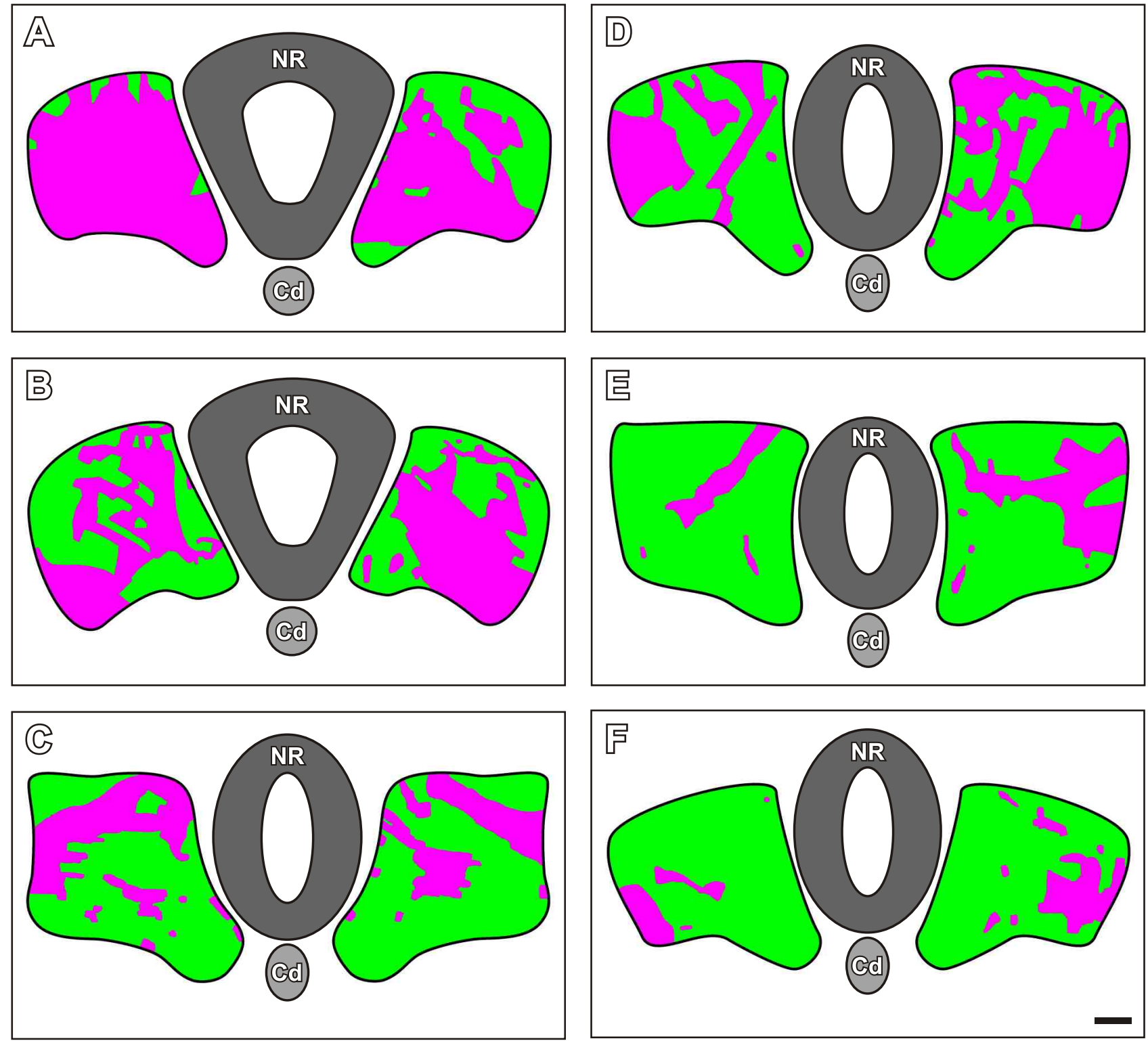

Abb. 5: Tupaia belangeri, zweidimensionale Rekonstruktionen des entstehenden intersomitischen Spaltes zwischen dem in Abgliederung begriffenen Somiten S0 und dem ersten prospektiven Somiten S-I der Embryonen DPZ 623/9B (A), DPZ 743/1A(B), DPZ 754/1A(C), DPZ 948/8A(D), DPZ 754/5B (E) und Bat. 1556/B (F). Rekonstruiert wurden bereits existierende Spaltanteile (grün) sowie die Position noch ausstehender Spaltanteile (magenta). Die Gruppierung der Embryonen ist unabhängig von ihrem Entwicklungsalter und berücksichtigt ausschließlich das zwischen $\mathbf{A}$ und $\mathbf{F}$ zunehmende Ausmaß bereits existierender Spaltanteile. Offenbar setzt die Spaltbildung dorsolateral und ventromedial nahezu gleichzeitig ein (A-C). Danach setzt sie sich von diesen beiden Seiten nach zentral fort (D-F). Ventrolaterale Spaltanteile bilden sich zuletzt (Ausnahme: rechte Körperseite DPZ 754/5B in E). NR, Neuralrohr; Cd, Chorda dorsalis. Maßstab $=25 \mu \mathrm{m}$. 

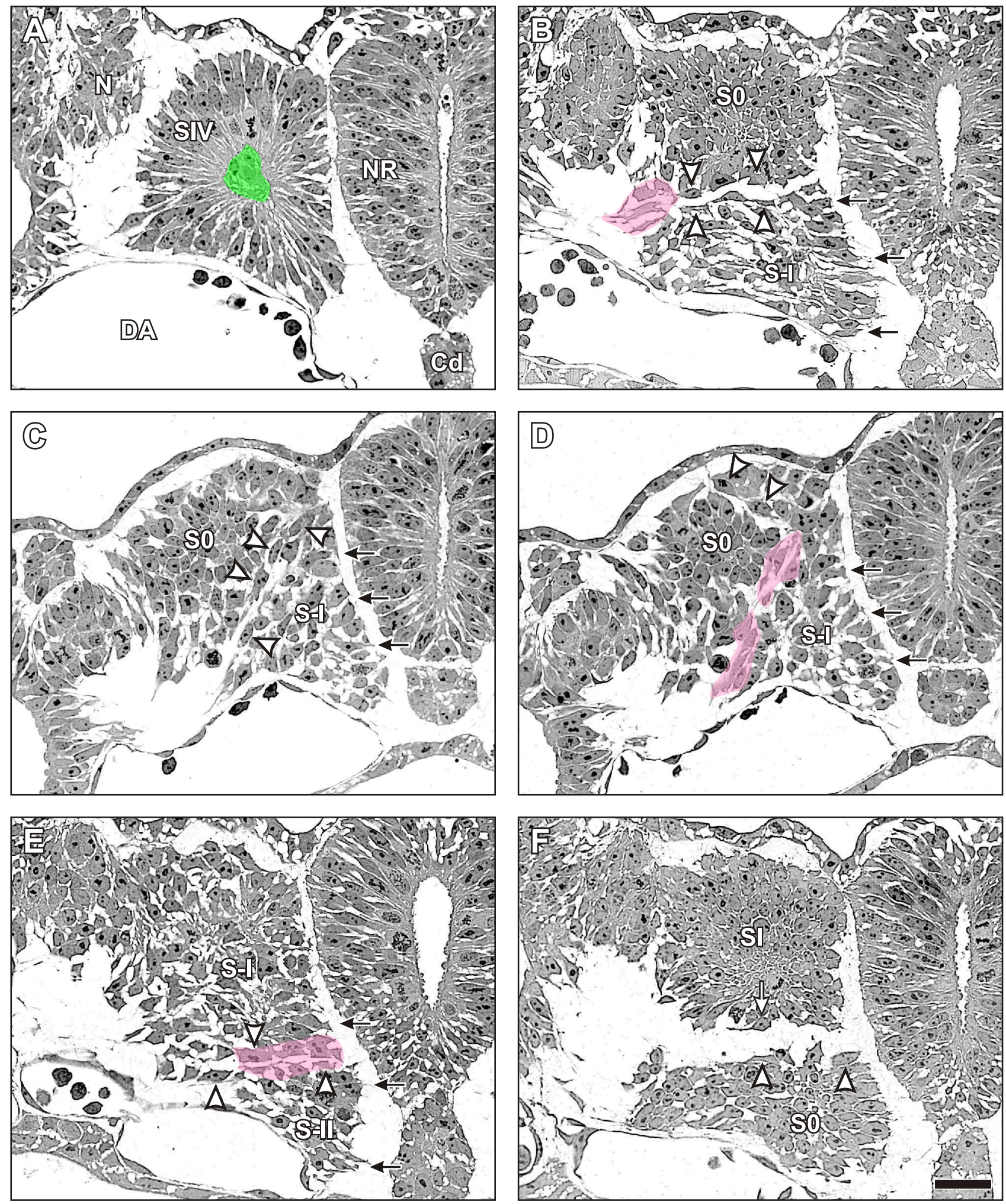

Abb. 6: Tupaia belangeri, möglicher Beitrag von „Grenzzellen“ zur Bildung des intersomitischen Spaltes, Semidünnschnitte (1 $\mu \mathrm{m}$, Hämatoxylin/Heidenhain). A, B, E, F: Phase 1, DPZ 754/1 A. C, D: Phase 2, DPZ 948/8A. A: In neu abgegliederten Somiten sind die Epithelzellen radiär auf das Somitozöl (grün) ausgerichtet. B-E: Langgestreckte, Fortsatzarme Grenzzellen (Pfeilköpfe) sind dagegen kettenartig, ein- oder beidseitig parallel zu bereits existierenden Anteilen des intersomitischen Spaltes zwischen dem in Abgliederung begriffenen Somiten S0 und dem ersten prospektiven Somiten S-I (B-D) angeordnet. Medial gehen Grenzzellformationen in palisadenartig angeordnete, Epithel-ähnliche Zellformationen über (schwarze Pfeile). Grenzzellstapel (rosa, B, D: S0/S-I, E: S-I/S-II) finden sich dort, wo die Bildung des intersomitischen Spaltes höchstwahrscheinlich unmittelbar bevorsteht. F: Im voll etablierten intersomitischen Spalt SI/S0 sind mutmaßliche Grenzzellen nur noch vereinzelt nachweisbar (Pfeilköpfe). Beachte auch strukturelle Hinweise auf Grenzzellen, die möglicherweise in das Somitenepithel integriert werden (weißer Pfeil). Cd, Chorda dorsalis; DA, dorsale Aorten; N, Nierenanlage; NR, Neuralrohr; SIV, abgegliederter Somit 4. Maßstab $=25 \mu \mathrm{m}$. 


\section{1.6 Sklerotom}

Verglichen mit epithelialen Organanlagen sind die durch epithelial-mesenchymale Transition (EMT) entstehenden Sklerotome nach strukturellen Kriterien schwieriger abgrenzbar. Dies gilt insbesondere für die fortgeschrittene Sklerotomentwicklung. Zu Beginn hängen jedoch alle aus einem Somiten hervorgehenden Sklerotomzellen als Gruppe zusammen (Abb. 7). Außerdem ist das „frühe" Sklerotom durch weitgehend zellfreie Gewebespalten von seinen Nachbarorganen getrennt (Abb. 7B-D). Es verfügt über eine ventromediale Ausziehung („chordaler Fortsatz“: Williams 1910, Abb. 7A-C) und, kurz darauf, über einen zweiten ,aortalen Fortsatz“ (Williams 1910, Abb. 7A). Bei der Erstellung dreidimensionaler Rekonstruktionen wurden die Somitozölzellen, in Anlehnung an Langman und Nelson (1968) sowie Huang et al. (1994, 1996), in die Sklerotommarkierung einbezogen (Abb. 7D).

Bei der dreidimensionalen Rekonstruktion fortgeschrittener Sklerotome ist die Abgrenzung gegen benachbarte Organanlagen (Oberflächenektoderm, Neuralrohr, Chorda dorsalis, dorsale Aorten, Entoderm, Dermomyotom, Nierenanlagen) meistens problemlos möglich (Abb. 8). Dagegen muss die Grenzziehung zwischen mesenchymalen Zellverbänden des Sklerotoms und mesenchymalen Zellverbänden anderer Herkunft, beispielsweise am Übergang zur Extremitätenknospe, mehr oder weniger willkürlich erfolgen (Abb. 8). Ein besonders schwieriges Problem stellen in dieser Hinsicht Gruppen von Neuralleistenzellen dar (Abb. 8), die ausschließlich die kranialen Sklerotomhälften durchwandern und/oder besiedeln (Tupaia belangeri: Knabe et al. 2004, Scheffel 2009, Tab. 4; zur Übersicht: Krull 2001). In solchen Fällen ist die Zuordnung von Apoptosen und Mitosen zu einem bestimmten Zelltyp nach strukturellen Kriterien unmöglich.

Bei der dreidimensionalen Rekonstruktion von Sklerotomen sowie bei der Interpretation von Apoptose- und Proliferationsmustern wurden vier der insgesamt acht von Christ et al. (2004) definierten Subdomänen des Sklerotoms besonders berücksichtigt (Abb. 8B). Die ventrale Subdomäne geht aus dem „chordalen Fortsatz“ (Williams 1910) hervor und umschließt die Chorda dorsalis. Die laterale Subdomäne entwickelt sich aus dem ,aortalen Fortsatz“(Williams 1910) und liegt im Winkel zwischen Aorta dorsalis, Zölomhöhle und Dermomyotom. Die zentrale Subdomäne befindet sich zwischen Dermomyotom und Neuralrohr. Die dorsale Subdomäne spannt sich zwischen dorsalen Abschnitten des Neuralrohres und dem Oberflächenektoderm aus. Neuralleistenzellen wandern über die dorsale in die zentrale Subdomäne ein. Die aus ihrer Aggregation hervorgehenden Spinalganglien liegen zwischen Neuralrohr und dorsomedialer Dermomyotomhälfte, und ragen deshalb sowohl in die dorsale Subdomäne als auch in die dorsale Hälfte der zentralen Subdomäne hinein (Abb. 8B, Tab. 4). 
Tab. 4: Neuralleistenzelldelamination bei Embryonen von Tupaia belangeri (Knabe et al. 2004, Scheffel 2009)

\begin{tabular}{cccc}
\hline Phase & Nummer des Embryos & $\begin{array}{c}\text { Starke Delamination von } \\
\text { Neuralleistenzellen }\end{array}$ & Spinalganglienanlagen \\
\hline 1 & DPZ 754/1A & O1 - Z8 & - \\
2 & DPZ 948/8A & Z6 - T7 & - \\
3 & DPZ 623/9B & L4 - L6 $1-\mathrm{T} 6 / \mathrm{T} 7$ \\
4 & DPZ 743/1A & L1/L2 - S1 & Z1 - T6/T7 \\
5 & DPZ 5061/C & - & Z1 - L3* \\
\hline
\end{tabular}

ET, Embryonaltag; L, Lumbalsomit; O, Okzipitalsomit; S, Sakralsomit; T, Thorakalsomit; Z, Zervikalsomit; *, Spinalganglienanlage von L3 unvollständig (Ende der Schnittserie von DPZ 5061/C)

Bei dem Phase-1-Embryo DPZ 754/1A hat die Sklerotombildung zwischen O1 und Z4 eingesetzt (Abb. 7A-D). Um den Entwicklungsfortschritt von Strukturen, die im Gradienten von kranial nach kaudal entstehen, im Detail aufzeigen zu können, werden im Folgenden grundsätzlich zunächst die weniger weit entwickelten kaudalen Segmente und erst danach die reiferen kranialen Segmente beschrieben. Demnach gehen Sklerotomzellen zunächst aus ventromedialen und, bezogen auf seine kraniokaudale Ausdehnung, zentralen Abschnitten des Somiten hervor (Z4, Abb. 7A, D). In Z3 hat sich die vorbestehende ventromediale EMT nach kranial und kaudal ausgedehnt (Abb. 7A). Z2 bildet nicht nur ventromedial, sondern auch ventrolateral Sklerotomzellen. Wie im Falle der ventromedialen EMT von Z4 setzt auch die ventrolaterale EMT von Z2, bezogen auf seine kraniokaudale Ausdehnung, zentral ein (Abb. 7A). Eine vollständig von medial nach lateral durchgehende Front auswandernder Sklerotomzellen findet sich erstmals in O4 (Abb. 7A). Allerdings ist hier die ventrolaterale EMT noch immer auf zentrale Somitenabschnitte begrenzt. Dieser „Entwicklungsrückstand" wird in $\mathrm{O} 3$ weitgehend (Abb. 7A, B), in $\mathrm{O} 2$ (rechte Körperseite) und O1 vollständig aufgeholt (Abb. 7A). Die beiden Partner des auf der linken Körperseite doppelt ausgebildeten O2 weisen Unterschiede hinsichtlich des Stands der Sklerotombildung auf (Abb. 7A). Nur der mediale Partner besitzt eine von kranial nach kaudal durchgehende Sklerotomfront. Dagegen beschränkt sich die EMT im kleineren lateralen Partner auf zentrale Somitenabschnitte (Abb. 7A).

Der am Beispiel des Phase-1-Embryos DPZ 754/1A detailliert beschriebene formale Ablauf der Sklerotombildung trifft auch für alle anderen untersuchten Tupaia-Embryonen zu (Abb. 7E-G, Tab. 5). So verfügt der Phase-2-Embryo DPZ 948/8A bereits zwischen O1 und Z8 über Sklerotome, die sowohl aus ventromedialen als auch aus ventrolateralen Somitenabschnitten hervorgegangen sind (Abb. 7E). Weniger weit entwickelt sind die Sklerotome T2 und T3. Im Phase-3-Embryo DPZ 623/9B besitzen bereits O2 bis L2 vollständig ausgebildete, L3 weitgehend vollständig ausgebildete Sklerotome (Abb. 7F). Dagegen erhalten die Sklerotome von L4 überwiegend ventromedialen Zell- 
zuzug. Im Phase-4-Embryo DPZ 743/1A finden sich vollständig ausgebildete Sklerotome zwischen O2 und L3. L4 verfügt über weitgehend vollständige Sklerotome (Abb. 7G). In L5 der linken Körperseite steht nur noch die Bildung kaudolateraler Sklerotomabschnitte bevor, während sich auf der rechten Körperseite die EMT noch auf ventromediale Somitenabschnitte beschränkt.

Tab. 5: Entwicklungsstand der dreidimensional rekonstruierten Embryonen von Tupaia belangeri (II)

\begin{tabular}{ccccccl}
\hline Phase & $\begin{array}{c}\text { Nummer } \\
\text { des } \\
\text { Embryos }\end{array}$ & ET & $\begin{array}{c}\text { Somiten- } \\
\text { paare }\end{array}$ & S0 & $\begin{array}{c}\text { Okzipital- } \\
\text { somiten }\end{array}$ & Sklerotome \\
\hline 1 & DPZ 754/1A & 13 & $\mathrm{O} 1-\mathrm{T} 2(14)$ & $\mathrm{pT} 3$ & $\mathrm{O} 1-\mathrm{O} 4$ & $\mathrm{O} 1-\mathrm{Z} 4$ \\
2 & $\mathrm{DPZ} 948 / 8 \mathrm{~A}$ & 13 & $\mathrm{O} 1-\mathrm{T} 7(19)$ & $\mathrm{pT} 8$ & $\mathrm{O} 1-\mathrm{O} 4$ & $\mathrm{O} 1-\mathrm{T} 3$ \\
3 & $\mathrm{DPZ} \mathrm{623/9B}$ & 14 & $\mathrm{O} 2-\mathrm{L} 6(30)$ & $\mathrm{pS} 1$ & $\mathrm{O} 2-\mathrm{O} 4$ & $\mathrm{O} 2-\mathrm{L} 4$ \\
4 & $\mathrm{DPZ} \mathrm{743/1A}$ & 15 & $\mathrm{O} 2-\mathrm{S} 1(31)$ & $\mathrm{pS} 2$ & $\mathrm{O} 2-\mathrm{O} 4$ & $\mathrm{O} 2-\mathrm{L} 5$ \\
5 & $\mathrm{DPZ} \mathrm{5061/C}$ & 16 & $\mathrm{O} 2-\mathrm{L} 2\left(26^{*}\right)$ & - & $\mathrm{O} 2-\mathrm{O} 4$ & - \\
\hline
\end{tabular}

ET, Embryonaltag; L, Lumbalsomit; O, Okzipitalsomit; p, prospektiver Somit; S, Sakralsomit; S0, in Abgliederung begriffener Somit; T, Thorakalsomit; Z, Zervikalsomit; *, Ende der Schnittserie von DPZ 5061/C.

\section{1.7 Dermomyotom und Myotom}

Als Dermomyotom wird die dorsale Hälfte des Somiten bezeichnet, die nach Abschluss der der Sklerotombildung zugrunde liegenden EMT zunächst epithelial verbleibt. Dermomyotome weisen eine nach ventromedial gerichtete Konkavität auf, die in vier Lippen ausläuft (Abb. 9). Die dorsomediale Lippe (DML) ist führend bei der Hervorbringung des epaxialen Myotoms. Dagegen stammt das hypaxiale Myotom, das in der Rumpfregion zusätzlich zum epaxialen Myotom vorkommt, vorrangig aus der ventrolateralen Lippe (VLL). Histologisch bestehen Myotome aus spindelförmigen, in mehreren Lagen parallel zueinander ausgerichteten Zellen, die über reichlich helles Zytoplasma und auffällig helle Kerne verfügen (Abb. 9B, C).

Epaxiale Myotome sind erstmals im Phase-2-Embryo DPZ 948/8A nachweisbar (O1 bis O3, Abb. 9A, B). In O3 ist das epaxiale Myotom zwischen kranialer Lippe und DML ausgespannt und füllt etwa das mediale Drittel der Konkavität des Dermomyotoms aus (Abb. 9A). In O2 nimmt das epaxiale Myotom bereits die mediale Hälfte dieser Konkavität ein und erreicht auch die kaudale Lippe (Abb. 9A). Der (sehr kleine) Somit O1 enthält nur wenige Myotomzellen (Abb. 9A). Sie liegen in Nachbarschaft zur DML.

De-epithelialisierende Abschnitte der VLL treten in solchen Dermomyotomen früh auf, die kein hypaxiales Myotom hervorbringen (zur Übersicht: Fischel 1895, Christ et al. 2007). Im Phase-2- 
Embryo DPZ 948/8A finden sich de-epithelialisierende Abschnitte der VLL in O2 (kranial) und, stärker nach kaudal ausgedehnt, auch in O1 (Abb. 9A).

Bei Embryonen der Phasen 3 (DPZ 623/9B: Abb. 9D) und 4 (DPZ 743/1A: Abb. 9E) sind Myotome bereits zwischen $\mathrm{O} 2$ und $\mathrm{T} 9$ beziehungsweise zwischen $\mathrm{O} 2$ und $\mathrm{T} 10$ ausgebildet. Zwischen Z8 und T8 (Phase 4: T9) wird die von vier intakten, das heißt noch nicht de-epithelialisierenden Lippen begrenzte Konkavität des Dermomyotoms vollständig vom Myotom ausgefüllt (Abb. 9C-E). Aus der Analyse von T9 beziehungsweise T10 (Phase 4) geht hervor, dass das epaxiale Myotom zuerst medial zwischen kranialer Lippe und DML entsteht (Abb. 9A, B, D, E). Bei beiden Embryonen hat die De-epithelialisierung der VLL innerhalb und oberhalb von Z7 massiv eingesetzt (DPZ 623/9B: Abb. 10A; DPZ 743/1A: Abb. 10B). Innerhalb jedes einzelnen Segmentes schreitet sie von kranial nach kaudal und, zeitgleich, von der VLL zu zentralen Dermomyotomabschnitten fort. Die DML wird zuletzt erreicht (Abb. 10A-C).

Im teilrekonstruierten Phase-5-Embryo DPZ 5061/C sind Myotome zwischen O2 und L2 (Serienabbruch) vorhanden (Abb. 11A). Epaxiale und hypaxiale Myotome sind zwischen Z8 und mindestens T13 unterscheidbar. Die in den kranialen Segmenten O2 bis Z7 von der VLL zum zentralen Dermomyotom sowie zur DML fortschreitende De-epithelialisierung (Phasen 2 bis 4) ist weitestgehend abgeschlossen (Abb. 11A). Die De-epithelialisierung derjenigen Dermomyotome, aus denen - kaudal von Z7 - sowohl epaxiale als auch hypaxiale Myotome hervorgehen, erfolgt nach einem anderen Muster. Hier setzt die De-epithelialisierung im zentralen Dermomyotom ein (Phase 4, DPZ 743/1A: Abb. 10B, D; Phase 5, DPZ 5061/C: Abb. 11). Von hier schreitet sie einerseits zur VLL, andererseits zur DML fort, erreicht aber die VLL deutlich früher als die DML (Phase-5-Embryo DPZ 5061/C: Abb. 11A). Tabelle 6 fasst abschließend den Entwicklungsstand aller rekonstruierten Embryonen zusammen.

Tab. 6: Entwicklungsstand der dreidimensional rekonstruierten Embryonen von Tupaia belangeri (III)

\begin{tabular}{ccccccccc}
\hline Phase & $\begin{array}{c}\text { Nummer } \\
\text { des } \\
\text { Embryos }\end{array}$ & ET & $\begin{array}{c}\text { Somiten- } \\
\text { paare }\end{array}$ & S0 & $\begin{array}{c}\text { Okzipital- } \\
\text { somiten }\end{array}$ & Sklerotome & Myotome & $\begin{array}{c}\text { de-ep. } \\
\text { Dermo- } \\
\text { myotome }\end{array}$ \\
\hline 1 & DPZ 754/1A & 13 & $\mathrm{O} 1-\mathrm{T} 2(14)$ & $\mathrm{pT} 3$ & $\mathrm{O} 1-\mathrm{O} 4$ & $\mathrm{O} 1-\mathrm{Z} 4$ & - & - \\
2 & $\mathrm{DPZ} \mathrm{948/8A}$ & 13 & $\mathrm{O} 1-\mathrm{T} 7(19)$ & $\mathrm{pT} 8$ & $\mathrm{O} 1-\mathrm{O} 4$ & $\mathrm{O} 1-\mathrm{T} 3$ & $\mathrm{O} 1-\mathrm{O} 3$ & $\mathrm{O} 1-\mathrm{O} 2$ \\
3 & $\mathrm{DPZ} 623 / 9 \mathrm{~B}$ & 14 & $\mathrm{O} 2-\mathrm{L} 6(30)$ & $\mathrm{pS} 1$ & $\mathrm{O} 2-\mathrm{O} 4$ & $\mathrm{O} 2-\mathrm{L} 4$ & $\mathrm{O} 2-\mathrm{T} 9$ & $\mathrm{O} 2-\mathrm{T} 1$ \\
4 & $\mathrm{DPZ} 743 / 1 \mathrm{~A}$ & 15 & $\mathrm{O} 2-\mathrm{S} 1(31)$ & $\mathrm{pS} 2$ & $\mathrm{O} 2-\mathrm{O} 4$ & $\mathrm{O} 2-\mathrm{L} 5$ & $\mathrm{O} 2-\mathrm{T} 10$ & $\mathrm{O} 2-\mathrm{T} 2$ \\
5 & $\mathrm{DPZ} \mathrm{5061/C}$ & 16 & $\mathrm{O} 2-\mathrm{L} 2(26 *)$ & - & $\mathrm{O} 2-\mathrm{O} 4$ & - & $\mathrm{O} 2-\mathrm{L} 2 *$ & $\mathrm{O} 2-\mathrm{L} 2 *$ \\
\hline
\end{tabular}

ET, Embryonaltag; de-ep., de-epithelialisierte; L, Lumbalsomit; O, Okzipitalsomit; p, prospektiver Somit; S, Sakralsomit; S0, in Abgliederung begriffener Somit; T, Thorakalsomit; Z, Zervikalsomit; *, Ende der Schnittserie von DPZ 5061/C. 

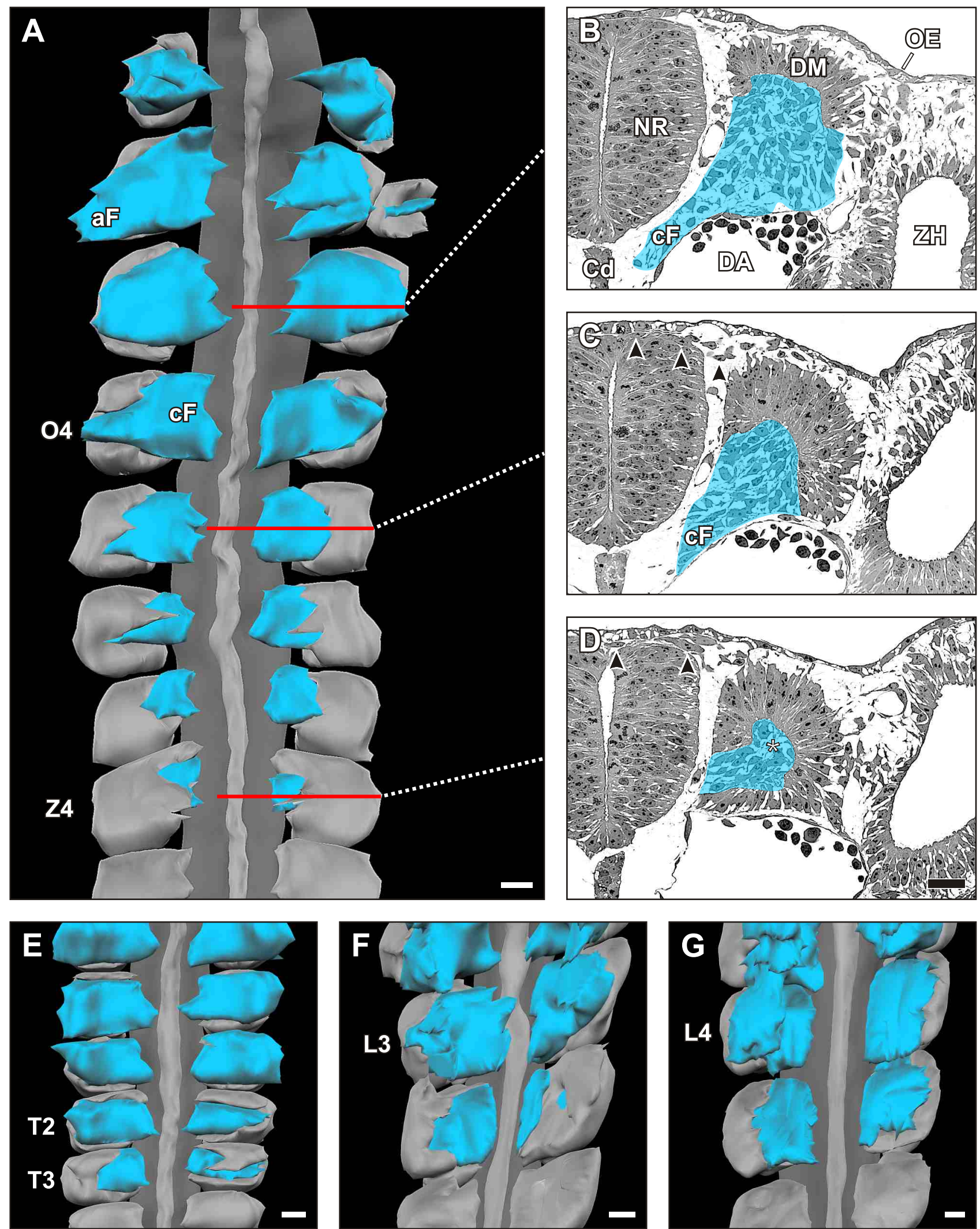

Abb. 7: Tupaia belangeri, beginnende Sklerotomentwicklung, Ventralansichten dreidimensionaler Rekonstruktionen (A: Phase 1, DPZ 754/1A; E: Phase 2, DPZ 948/8A; F: Phase 3, DPZ 623/9B; G: Phase 4, DPZ 743/1A) sowie repräsentative Semidünnschnitte (1 $\mu \mathrm{m}$, Hämatoxylin/Heidenhain; B-D: rote Schnittebenen in A). A-D: Die Sklerotombildung (blau) durch epithelial-mesenchymale Transition setzt ventromedial (C, D) und zentral ein (4. Zervikalsomit (Z4) in A, 3. Thorakalsomit (T3) in E) und dehnt sich anschließend zunächst lokal nach kranial und kaudal aus (A, E-F). Erst danach werden auch ventrolaterale Somitenabschnitte (B), wiederum zentral zuerst, in die Sklerotombildung einbezogen (4. Okzipitalsomit (O4) in A, T2 in E, 3. Lumbalsomit (L3) in F, L4 in G). Am „frühen“ Sklerotom wird ein ventromedialer „,chordaler Fortsatz“ (cF in A-C) von einem ventrolateralen ,,aortalen Fortsatz" (aF in A) unterschieden. Beachte die dorsal aus dem Neuralrohr (NR) auswandernden Neuralleistenzellen (Pfeilköpfe in C, D). Cd, Chorda dorsalis; DA, dorsale Aorta; DM, Dermomyotom; OE, Oberflächenektoderm; Stern, Somitozöl; ZH, Zölomhöhle. Maßstäbe = $25 \mu \mathrm{m}$. 



Abb. 8: Tupaia belangeri, fortgeschrittene Sklerotomentwicklung, Semidünnschnitte (1 $\mu \mathrm{m}$, Hämatoxylin/Heidenhain). A: Phase 2, DPZ 948/8A, 2. Zervikalsomit: Die Sklerotome (SK, blau) sind zunehmend schwieriger (blau, transparent) gegen die Ströme einwandernder Neuralleistenzellen (lila) sowie gegen Mesenchymzellen des Seitenplattenmesoderms (Stern) abgrenzbar. B: Phase 3, DPZ 623/9B, 5. Zervikalsomit: Fortgeschrittene Sklerotome werden in zentrale (1), laterale (2), ventrale (3) und dorsale (4) Subdomänen unterteilt (Christ et al. 2004). Die Spinalganglien (SG, lila) ragen von der dorsalen in die zentrale Subdomäne hinein. A, unpaare Aorta; Cd, Chorda dorsalis; DA, dorsale Aorten; DM, Dermomyotom; EN, Entoderm; NR, Neuralrohr; OE, Oberflächenektoderm; ZH, Zölomhöhle. Maßstäbe $=50 \mu \mathrm{m}$. 

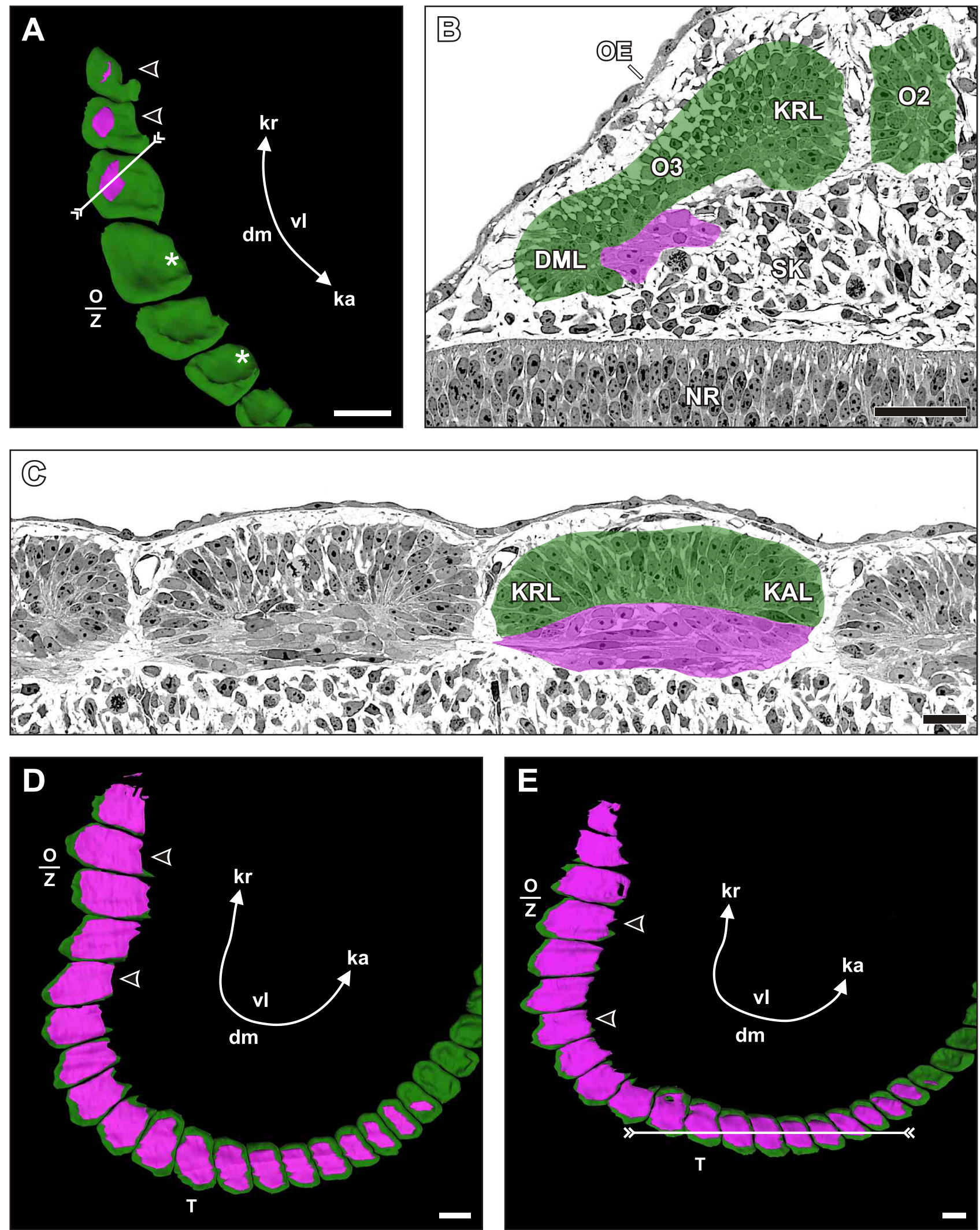

Abb. 9: Tupaia belangeri, Medialansichten dreidimensional rekonstruierter Dermomyotome und Myotome (A, D, E) sowie repräsentative Semidünnschnitte (1 $\mu \mathrm{m}$, Hämatoxylin/Heidenhain; B, C). A, B (Phase 2, DPZ 948/8A, linke Körperseite): Erste Myotomzellen (magenta, in Okzipitalsomit (O) 1 bis O3) sind zwischen kranialer Lippe (KRL) und dorsomedialer Lippe (DML) der Dermomyotome (grün) lokalisiert (Schnittebene B: weiße Linie in A; vergleiche auch Thorakalsomit (T) 9 in D und T10 in E). Die De-epithelialisierung der ventrolateralen Lippe (VLL, Sterne in A) beginnt kranial (Pfeilköpfe in A). C: Später sind die Konkavitäten der Dermomyotome mit Myotomzellen ausgefüllt, die sich zwischen KRL und kaudaler Lippe des Dermomyotoms (KAL) ausspannen (Schnittebene C: weiße Linie in E). D (Phase 3, DPZ 623/9B: linke Körperseite), E (Phase 4, DPZ 743/1A, gespiegelte rechte Körperseite): In Dermomyotomen, die kein hypaxiales Myotom ausbilden werden (O2 bis Zervikalsomit (Z) 7), ist die VLL weitgehend de-epithelialisiert (Pfeilköpfe in A, D, E). dm, dorsomedial; ka, kaudal; kr, kranial; NR, Neuralrohr; OE, Oberflächenektoderm; SK, Sklerotom; vl, ventrolateral. Maßstäbe: $\mathbf{A}, \mathbf{D}, \mathbf{E}=100 \mu \mathrm{m} ; \mathbf{B}, \mathbf{C}=20 \mu \mathrm{m}$. 

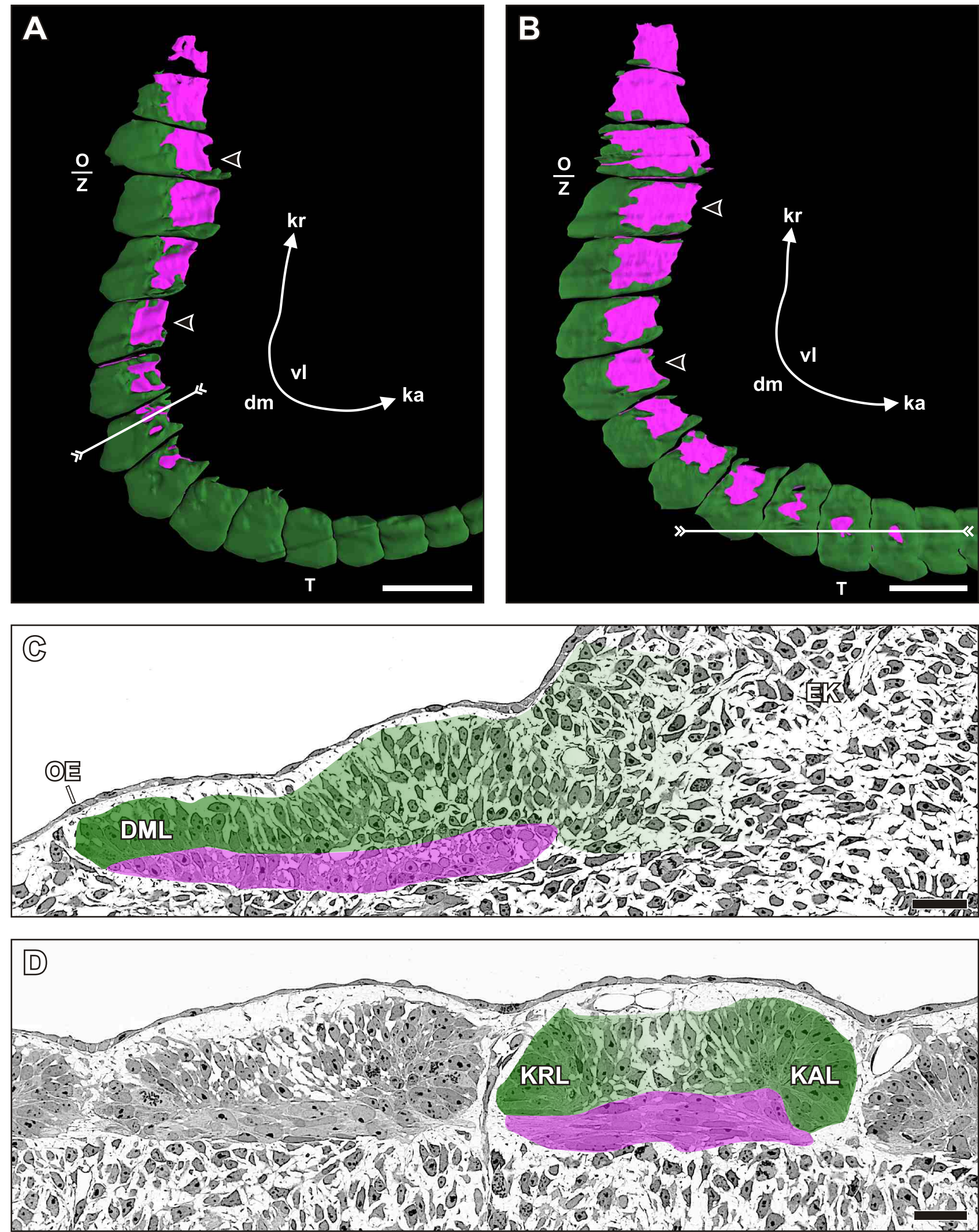

Abb. 10: Tupaia belangeri, Lateralansichten dreidimensional rekonstruierter Dermomyotome und Myotome (A, B) sowie Semidünnschnitte (1 $\mu \mathrm{m}$, Hämatoxylin/Heidenhain; C, D). In Lateralansichten ist das Myotom (magenta) dort einsehbar, wo sich solide Abschnitte des Dermomyotoms (grün) durch De-epithelialisierung bereits aufgelöst haben (grün, transparent in C, D). In denjenigen Dermomyotomen, aus denen nur ein epaxiales Myotom hervorgehen wird (Okzipitalsomit (O) 2 bis Zervikalsomit (Z) 7), schreitet die De-epithelialisierung von der ventrolateralen Lippe (Pfeilköpfe in A und B) in Richtung dorsomediale Lippe (DML) fort (C: gespiegelter Serienschnitt, Schnittebene: weiße Linie in A: rechte Körperseite, Phase 3, DPZ 623/9B). Dagegen findet sich ein zentraler Beginn der De-epithelialisierung in solchen Dermomyotomen, die zusätzlich auch ein hypaxiales Myotom hervorbringen werden (D: Schnittebene: weiße Linie in B: gespiegelte linke Körperseite, Phase 4, DPZ 743/1A). dm, dorsomedial; EK, Extremitätenknospe; ka, kaudal; kr, kranial; OE, Oberflächenektoderm; T, thorakal; vl, ventrolateral; Maßstäbe: $\mathbf{A}, \mathbf{B}=250 \mu \mathrm{m} ; \mathbf{C}, \mathbf{D}=25 \mu \mathrm{m}$. 

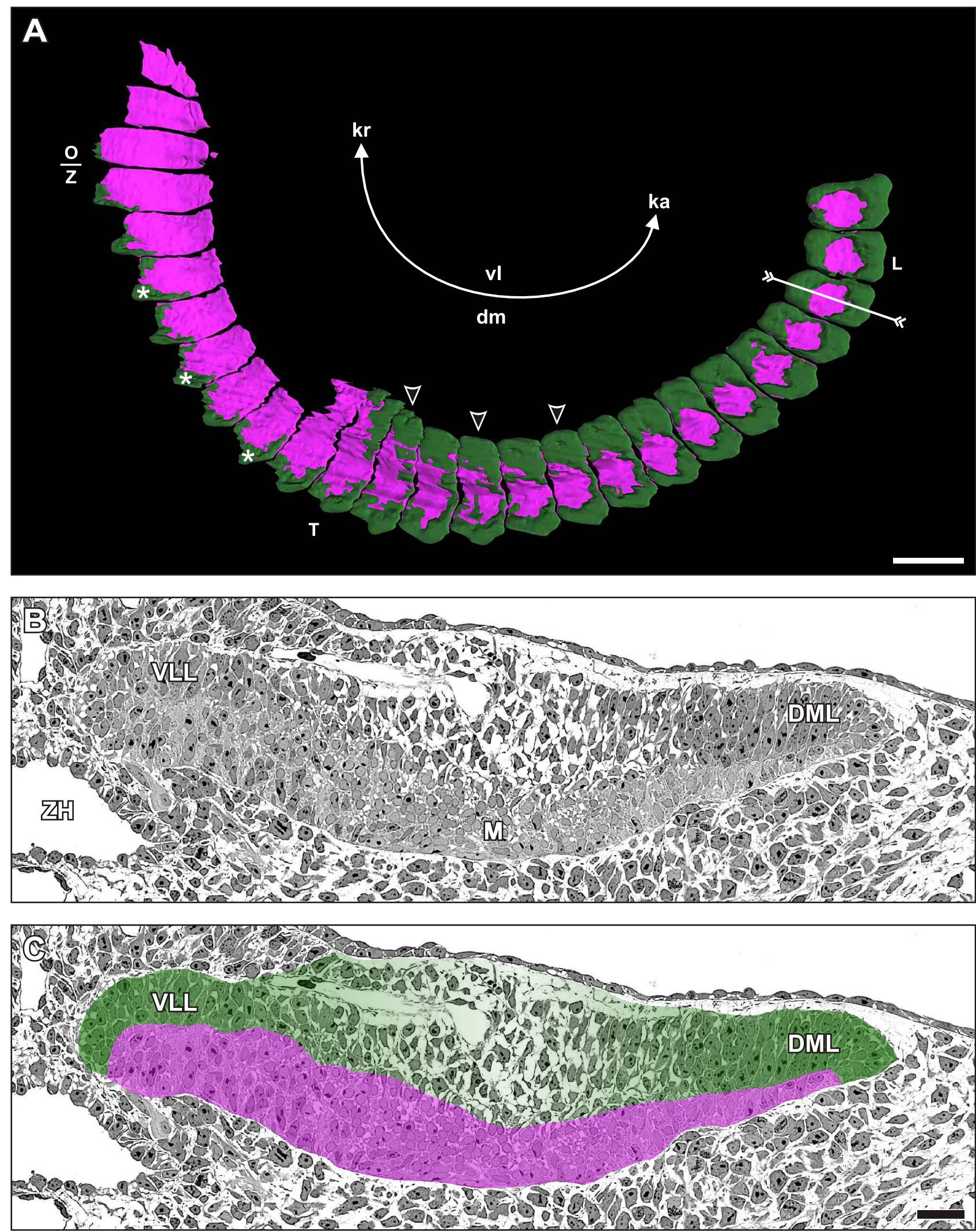

Abb. 11: Tupaia belangeri, Lateralansicht dreidimensional rekonstruierter Dermomyotome und Myotome (Phase 5, DPZ 5061/C, rechte Körperseite, Okzipitalsomit (O) 2 bis Lumbalsomit (L) 2, Ende der Schnittserie, A) sowie Semidünnschnitt (1 $\mu \mathrm{m}$, Hämatoxylin/Heidenhain; Schnittebene B, C: weiße Linie in A, Höhe: Thorakalsomit (T) 13). Bei denjenigen Dermomyotomen (grün), die sowohl ein epaxiales als auch ein hypaxiales Myotom (M, magenta) ausbilden (Zervikalsomit (Z) 8 bis mindestens T13 in A), setzt die De-epithelialisierung zentral ein und dehnt sich, in der Rekonstruktion von kaudal nach kranial sichtbar, zunehmend in Richtung auf die ventrolaterale Lippe (VLL, Pfeilköpfe in A) und, etwas verzögert, auf die dorsomediale Lippe (DML) aus. Ansichtsbedingt sind nur hier Myotome einsehbar. VLL und DML bleiben vorerst epithelial. Die Dermomyotome O2 bis Z7 bilden dagegen kein hypaxiales Myotom aus. Sie sind mit Ausnahme von Teilen der DML (Sterne in A) fast vollständig de-epithelialisiert. dm, dorsomedial; ka, kaudal; kr, kranial; vl, ventrolateral; ZH, Zölomhöhle. Maßstäbe: $\mathbf{A}=250 \mu \mathrm{m} ; \mathbf{B}, \mathbf{C}=25 \mu \mathrm{m}$. 


\section{2. Apoptose- und Proliferationsereignisse}

In den von unserer Arbeitsgruppe bisher durchgeführten, überwiegend neuroembryologisch ausgerichteten Vorarbeiten hatte sich wiederholt gezeigt, dass Muster und Funktionen von Apoptose- und Proliferationsereignissen besser verstanden werden können, wenn Organanlagen über den eigentlichen engeren Zielbereich hinaus rekonstruiert werden. Aus diesem Grund beschränkt sich die vorliegende Arbeit über die Morphogenese der Somiten bei Tupaia belangeri nicht auf die Dokumentation zellulärer Prozesse innerhalb des paraxialen Mesoderms, sondern schließt auch Parallelbefunde innerhalb des entstehenden Seitenplattenmesoderms, intermediären Mesoderms sowie der als Signalzentrum für die Somitendifferenzierung bedeutsamen Chorda dorsalis ein. Die als Grundlage der Befundung angefertigten Rekonstruktionen förderten zutage, dass auch sehr komplex gestaltete Apoptose- und Proliferationsmuster in den meisten Fällen bilateral symmetrisch auf beiden Körperseiten auftreten. Deshalb werden Apoptose- und Proliferationsereignisse im Folgenden nur dann für jede Körperseite getrennt beschrieben, wenn hierbei tatsächlich gravierende Unterschiede festzustellen waren.

\section{2.1 Apoptose im Seitenplattenmesoderm und im ungegliederten Mesoderm}

In kaudalen Abschnitten aller rekonstruierten Embryonen finden sich vorübergehend zusammenhängende U-förmige Formationen noch ungegliederter Mesodermabschnitte. In den Phasen 1 und 2 setzen sich diese Formationen aus axialem, paraxialem und intermediärem Mesoderm zusammen (Abb. 3). Seitlich gehen sie in das Seitenplattenmesoderm über. In den Phasen 3 und 4 ist die Schwanzregion erheblich weiter entwickelt. Deshalb bilden hier axiales, paraxiales und ventrales Mesoderm die Grundlage der zusammenhängenden Mesodermformation, die das Entodermrohr kranial nur seitlich flankiert, weiter kaudal dagegen zusätzlich auch ventral umfasst (Abb. 19).

Im Phase-1-Embryo DPZ 754/1A (Übersicht: Abb. 12) tritt eine erste Häufung apoptotischer Zellen am Boden des Zölomspaltes auf (Abb. 13A). Sie setzt sich kranial als „Band“ apoptotischer Zellen mindestens bis S-VII und, lückenhafter, bis S-V (rechts) beziehungsweise S-VI (links) fort. Der Schwerpunkt dieses Bandes liegt am Übergang zwischen Somato- und Splanchnopleura einerseits und intermediärem Mesoderm andererseits (Abb. 13A). Unterhalb der Einmündung der Pleuroperikardhöhle in den Zölomspalt finden sich verstreute Seitenplattenapoptosen, rechtsseitig in größerer Zahl als linksseitig, praktisch ausschließlich in (überwiegend medialen Abschnitten) der Somatopleura (Abb. 13B). Oberhalb der Einmündung der Pleuroperikardhöhle in den Zölomspalt treten Seitenplattenapoptosen dagegen sowohl in der Somatopleura als auch in der Splanchnopleura auf. Sie sind Cluster-artig angeordnet, wobei die kraniokaudalen Positionen dieser Cluster in der Somato- und Splanchnopleura vielfach, aber nicht immer, übereinstimmen (Abb. 13B). Zwei weitere 
Apoptosehäufungen des Phase-1-Embryos DPZ 754/1A finden sich einerseits innerhalb des chordoneuralen Scharniers (S-VI bis S-IX), andererseits kaudal des chordoneuralen Scharniers gleichfalls mittelliniennah und ventral der Neuralplatte (Abb. 13A). In den „Schenkeln“ der oben beschriebenen U-förmigen Formation, die die Chorda dorsalis kranial von S-VI bilateral symmetrisch flankieren, sind Apoptosen überwiegend, aber insgesamt in geringer Zahl, im paraxialen Mesoderm lokalisiert (Abb. 13B). Einige dieser apoptotischen Zellen liegen tatsächlich in der Position prospektiver intersomitischer Spalten. Ein streng kausaler Zusammenhang zwischen dem Auftreten von Apoptose und der Bildung intersomitischer Spalten erscheint jedoch unwahrscheinlich.

Auch im Phase-2-Embryo DPZ 948/8A (Übersicht: Abb. 15) findet sich eine Häufung apoptotischer Zellen am Boden des Zölomspaltes, die sich kranialwärts auf die Übergangszone zwischen Somatopleura, Splanchnopleura und intermediärem Mesoderm fortsetzt und etwa in Höhe S-III (rechte Körperseite: Abb. 16D) beziehungsweise S-I (linke Körperseite: Abb. 16F) endet. Der in Phase 1 vorbestehende bandartige Charakter dieser Apoptosehäufung ist im Phase-2-Embryo etwas weniger deutlich ausgeprägt (Abb. 16D, F). Hierfür ist unter anderem das, verglichen mit Phase 1, erhöhte Vorkommen zusätzlicher kaudaler Seitenplattenapoptosen verantwortlich. Oberhalb von S-III weist die Verteilung apoptotischer Zellen in den Seitenplatten diskrete Unterschiede auf. In der Somatopleura sind sie, bei insgesamt moderaten Zahlen, annähernd regellos verteilt (Abb. 17A, C). Dagegen finden sich in der Splanchnopleura zwei angedeutete Häufungen (Abb. 17A, C): (1) zwischen Z1 und dem kranialen Vornierenpol, (2) parallel zu mindestens der kranialen Hälfte der Urniere. Diese letztgenannten Apoptosen nehmen insofern eine Sonderstellung ein, als sie, teilweise oder gänzlich, mit zwei anderen Apoptosehäufungen überlappen (Abb. 17A, C). Weitgehend vollständig ist die Überlappung mit Apoptosen in medialen Abschnitten der Somatopleura. Eine erhebliche Teilüberlappung besteht mit Apoptosen innerhalb der Urnierenanlage (Abb. 17A, C). Es liegt daher nahe, diese letztgenannten Apoptosehäufungen (Schwerpunkt: Z8/T1 bis T6/T7) funktionell mit der Entstehung von Nephrostomata in Verbindung zu bringen. Bandartig aufgereihte Apoptosen, die die weiter kranial liegende Vorniere eliminieren, werden dagegen nicht systematisch von Seitenplattenapoptosen begleitet (Abb. 17A, C). Die im Phase-1-Embryo DPZ 754/1A einerseits innerhalb, andererseits kaudal des chordoneuralen Scharniers vorbestehenden Apoptosefoki finden sich - bei insgesamt höheren Zellzahlen - auch im Phase-2-Embryo DPZ 948/8A wieder (Abb. 18D). Allerdings liegt der mittelliniennahe, kaudal des chordoneuralen Scharniers in der Schwanzknospe lokalisierte Apoptosefokus im Phase-2-Embryo in größerer Entfernung von der Neuralanlage (Abb. 18G). Die Verteilung apoptotischer Zellen im ungegliederten paraxialen Mesoderm entspricht qualitativ und quantitativ den im Phase-1-Embryo beschriebenen Verhältnissen (Abb. 18D, G). 
Im Phase-3-Embryo DPZ 623/9B (Übersicht: Abb. 20) wird das chordoneurale Scharnier, wie in den Phasen 1 und 2, von einer Apoptosehäufung durchzogen (Abb. 20A). Verglichen mit den rekonstruierten jüngeren Embryonen ist diese Apoptosehäufung jetzt deutlich massiver. Sie läuft breitbasig im Mesoderm der Schwanzknospe aus (Abb. 20A, D). Das Muster der zweiten Apoptosehäufung, die vollständig in ventralen Abschnitten des ventralen Mesoderms liegt, ist komplizierter aufgebaut (Abb. 20A, D). Im Zentrum dieser Figur steht ein Mittellinienfokus (Höhe: S-IV, kaudales Ende der Chorda dorsalis; Abb. 20D). Dieser Fokus ist, bilateral symmetrisch, mit paramedian lokalisierten Apoptosebändern „verbunden“, die kranial bis S-I aufsteigen und kaudal (mit tendenziell abnehmender Dichte) in der Schwanzknospe auslaufen (Abb. 20A, D). Oberhalb des Mittellinienfokus liegen Entoderm und Oberflächenektoderm einander an (Abb. 20A, D; vergleiche Abb. 19). Unterhalb dieses Fokus werden beide Blätter, wie im Bereich des Fokus selbst, durch Mesoderm voneinander getrennt. Auch in diesen kaudalen Abschnitten des ventralen Mesoderms lassen sich überwiegend mittelliniennah - Apoptosen nachweisen. Verglichen mit dem Mittellinienfokus ist ihre Zahl deutlich niedriger (Abb. 20A, D). Wie in den Phasen 1 und 2 sind auch im Phase-3-Embryo DPZ 623/9B apoptotische Zellen im ungegliederten paraxialen Mesoderm rar (Abb. 20A).

Im ungegliederten kaudalen Mesoderm des Phase-4-Embryos DPZ 743/1A (Übersicht: Abb. 21) ist die Zahl apoptotischer Zellen, wie in allen anderen rekonstruierten mesodermalen Kompartimenten auch, erheblich niedriger als im zuvor besprochenen Phase-3-Embryo DPZ 623/9B. Dennoch lässt sich auch im Phase-4-Embryo ein Apoptoseherd im chordoneuralen Scharnier nachweisen (Abb. 21A). Von den vorbestehenden, paramedian im ventralen Mesoderm auf- und absteigenden Apoptosebändern sind nur die kranialen und kaudalen Enden „erhalten“ (Abb. 21A, D). Dementsprechend ist die Verbindung dieser Bänder zum ventralen Mittellinienfokus weniger markant als im Phase-3Embryo. Auch unterhalb des Mittellinienfokus ist das Aufkommen apoptotischer Zellen im mittelliniennahen ventralen Mesoderm des Phase-4-Embryos erheblich niedriger als im Phase-3-Embryo (Abb. 21A, D). Passend zu den am Phase-3-Embryo erhobenen Vorbefunden ist das ungegliederte paraxiale Mesoderm des Phase-4-Embryos praktisch frei von apoptotischen Zellen (Abb. 21A).

\section{2.2 Proliferation im Seitenplattenmesoderm und im ungegliederten Mesoderm}

Verglichen mit der sowohl im Seitenplattenmesoderm als auch im ungegliederten kaudalen Mesoderm überwiegend fokalen oder bandartigen Anordnung apoptotischer Zellen, treten proliferierende Zellen generell zahlreicher und tendenziell homogener verteilt in diesen Organanlagen auf. Dennoch können, nicht selten unter Zuhilfenahme der Apoptosemuster, regionale Unterschiede im Proliferationsverhalten aufgezeigt werden. 
Solche Unterschiede bestehen beispielsweise zwischen den beiden Seitenplatten. In der Somatopleura des Phase-1-Embryos DPZ 754/1A ist die Verteilung mitotischer Zellen entlang ihrer gesamten kraniokaudalen Ausdehnung annähernd homogen (Abb. 14). Passend hierzu überstreichen funktionell wahrscheinlich als Korrektiv wirkende - Apoptoseereignisse, trotz ihres kranial eher fokalen Charakters, ebenfalls die gesamte kraniokaudale Achse (Abb. 13). Dass mitotische und apoptotische Ereignisse tatsächlich quantitativ korreliert auftreten, zeigt sich noch deutlicher bei der Analyse der Splanchnopleura. Hier besteht kranial (Höhe: O2) ein Proliferationsmaximum, dessen kaudale Grenze mit dem kranialen Pol der Vorniere zusammenfällt (Abb. 14B). Im Bereich dieses Proliferationsmaximums finden sich mehrere Cluster apoptotischer Zellen (Abb. 13B). Kaudal des Proliferationsmaximums sind mitotische Zellen zwar weiterhin homogen in der Splanchnopleura verteilt (Abb. 14B). Allerdings geht ihre Zahl, parallel zu dem fast vollständigen Fehlen apoptotischer Zellen, deutlich zurück. Fokal konzentrierte Mitosehäufungen innerhalb des Seitenplattenmesoderms finden sich erst wieder am kaudalen Ende des Embryos (Abb. 14A). Sie kolokalisieren ausgiebig mit den am Boden des Zölomspaltes beziehungsweise am Übergang von Somato- und Splanchnopleura ausgebildeten Apoptosefoki (Abb. 13A). Dagegen kolokalisieren Mitosen lediglich mit der kaudalen Hälfte der das chordoneurale Scharnier durchziehenden, mittelliniennahen Apoptosehäufung (Abb. 13A, 14A). Die im ungegliederten paraxialen Mesoderm zahlreich und überwiegend homogen auftretenden Mitosen sind nicht gänzlich regellos angeordnet (Abb. 14B). Stattdessen finden sich sporadisch Ballungen mitotischer Zellen, die, bezogen auf die kraniokaudale Achse, durch Mitose-ärmere Zonen voneinander getrennt erscheinen. Zwingende Hinweise auf eine prospektiv segmentale, die künftigen intersomitischen Spalten respektierende Anordnung mitotischer Mesodermzellen finden sich aber nicht.

Auch in der Splanchnopleura des Phase-2-Embryos DPZ 948/8A erstreckt sich ein kranial mindestens bei Z1 (Rekonstruktionsgrenze der Seitenplatten) beginnendes Proliferationsmaximum nach kaudal bis zum kranialen Vornierenpol (Abb. 17D, F). Kaudal hiervon ist die Zahl der Mitosen, bei gleichbleibend homogener Verteilung, niedriger (Abb. 17D, F). Wie im Phase-1-Embryo DPZ 754/1A kolokalisiert das kraniale Proliferationsmaximum mit einer diskreten Häufung apoptotischer Zellen (Abb. 17A, C, D, F). In den kaudalen, verdickten Abschnitten der Somatopleura sind dagegen sowohl die Apoptosen als auch die vergleichsweise zahlreicher vorhandenen Mitosen homogen verteilt (Abb. 16G, I). In Höhe der Pleuroperikardhöhle sowie kranialer Abschnitte des Zölomspaltes ist die Mehrzahl der Seitenplattenmitosen, anders als im Phase-1-Embryo, lateral positioniert (Abb. 17D, F). Hierdurch bleibt beim Phase-2-Embryo die Übergangszone zwischen Somatound Splanchnopleura auch im Bereich der möglicherweise mit der Bildung von Nephrostomata assoziierten Apoptosehäufung weitgehend von mitotischen Zellen ausgespart (Abb. 17A, C, D, F). Deutlicher als im Phase-1-Embryo ist das kaudale Ende des Phase-2-Embryos, der bereits über eine 
Schwanzknospe verfügt, durch ein starkes Mitoseaufkommen in allen Organanlagen charakterisiert (Abb. 15B). Deshalb kolokalisieren Mitosen mit allen in dieser Region aufgezeigten Apoptosehäufungen: (1) am Boden des Zölomspaltes (Abb. 16) und, in dessen kranialer Verlängerung, in der Übergangszone zwischen Somatopleura, Splanchnopleura und intermediärem Mesoderm (Abb. 17), (2) im chordoneuralen Scharnier und hier nicht, wie in Phase 1, nur in dessen kaudaler Hälfte, sondern entlang seiner gesamten kraniokaudalen Ausdehnung (Abb. 18), (3) mittelliniennah kaudal des chordoneuralen Scharniers (Abb. 18). Unter den zahlreichen Mitosen im ungegliederten paraxialen Mesoderm finden sich auch Aggregationen mitotischer Zellen (Abb. 18F, I), die, wie die umstrittenen Somitomere (zur Übersicht: Keynes und Stern 1988, Gossler und Hrabě de Angelis 1998), auf den ersten Blick eine bereits vorhandene segmentale Gliederung repräsentieren könnten. Fehlende bilaterale Symmetrie sowie die mangelhafte Respektierung der Positionen künftiger intersomitischer Spalten sprechen jedoch, wie in Phase 1, gegen eine solche Interpretation.

Hinsichtlich der Proliferationsmuster bei Embryonen unserer Phasen 3 und 4 ist Folgendes festzustellen. Die im chordoneuralen Scharnier vorbestehende Mitosehäufung (Phasen 1 und 2) ist auch im Phase-3-Embryo DPZ 623/9B (Abb. 20B) sowie im Phase-4-Embryo DPZ 743/1A (Abb. 21B) als (kleiner) Cluster nachweisbar, der sich, wie in Phase 2, über die gleichfalls vollständig von Apoptosen durchzogene kraniokaudale Ausdehnung des chordoneuralen Scharniers erstreckt. Strukturell vom kaudalen Ende des chordoneuralen Scharniers kaum abgrenzbar, kolokalisieren auch in der Schwanzknospe Apoptose- und Mitosehäufungen (DPZ 623/9B: Abb. 20C, F; DPZ 743/1A: Abb. 21C, F).

Auch im ventralen Mesoderm weist der Phase-3-Embryo DPZ 623/9B charakteristische Apoptoseund Proliferationsmuster auf, die sich, wenn auch in abgeschwächter Form, im Phase-4-Embryo DPZ 743/1A wiederfinden. Die kraniale Hälfte der in Phase 3 am Übergang S0/S-I beginnenden Apoptosehäufung überlappt ausgiebig mit einem Feld homogen verteilter Mitoseereignisse (Abb. 20C, F). Kaudal hiervon weicht das Mitosefeld, unter weitgehender Aufgabe der Kolokalisation mit apoptotischen Zellen, etwas nach dorsal zurück, so dass die am ventralen Rand des ventralen Mesoderms abwärts ziehende Apoptosehäufung nur noch minimal mit Mitoseereignissen überlappt (Abb. 20C). Die Mitose- und Apoptosemuster im ungegliederten paraxialen Mesoderm des Phase-3(Abb. 20A-C) beziehungsweise des Phase-4-Embryos (Abb. 21A-C) entsprechen weitestgehend den für die Phasen 1 und 2 beschriebenen Verhältnissen. 


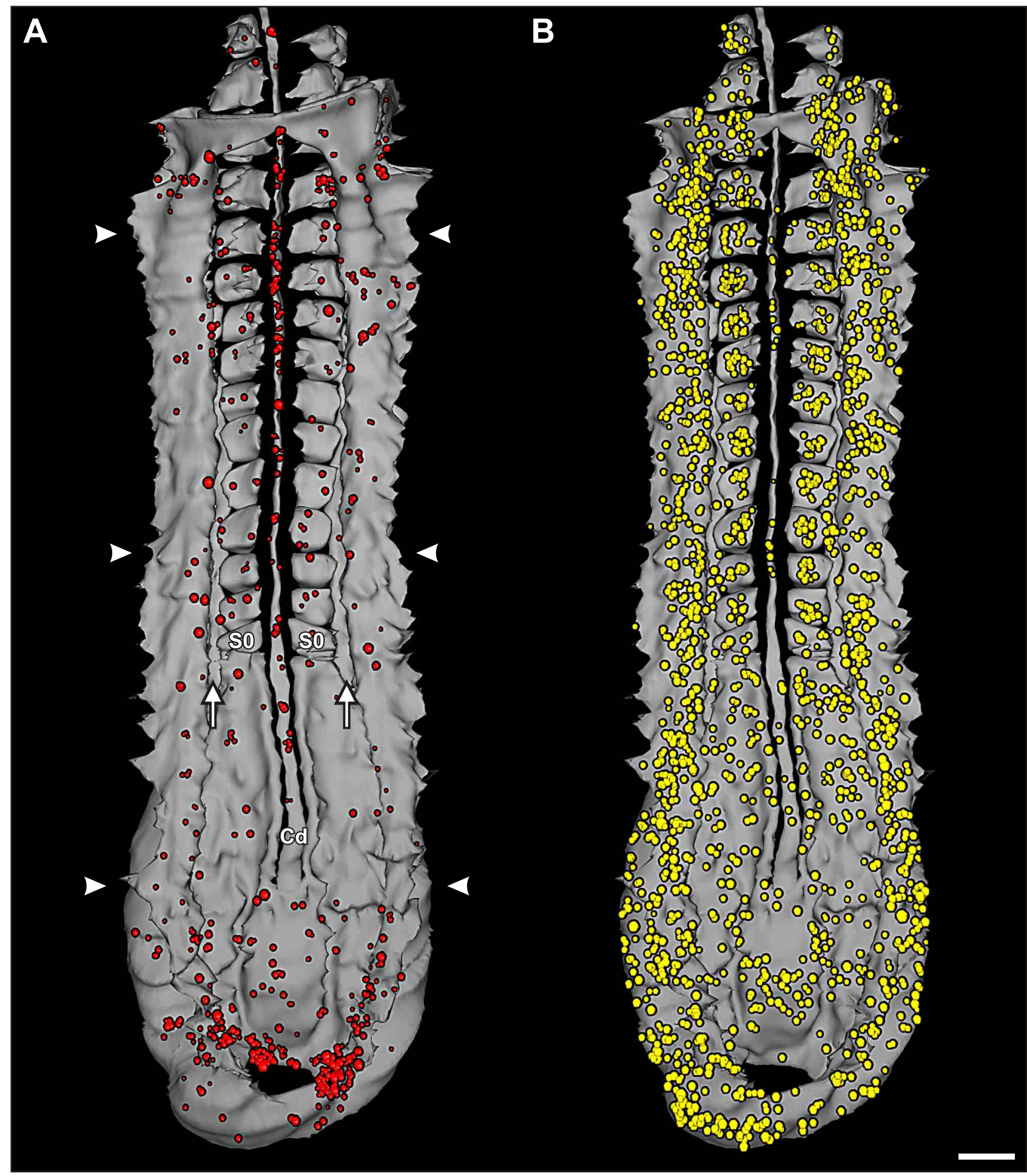

Abb. 12: Tupaia belangeri, Ventralansichten dreidimensionaler Rekonstruktionen (Übersichten) sämtlicher Apoptosen (A: rot, Radius 4fach) und Mitosen (B: gelb, Radius 2fach) im Mesoderm (grau) des Phase-1-Embryos DPZ 754/1A. Rekonstruiert wurden zelluläre Ereignisse in der Chorda dorsalis $(\mathrm{Cd})$, in den Somiten einschließlich des in Abgliederung begriffenen Somiten S0, in den lateral anschließenden Nierenanlagen (Pfeile), in den Seitenplatten (Pfeilköpfe) sowie in ungegliederten kaudalen Mesodermabschnitten. Weitere Erläuterungen im Text sowie in den nachfolgenden Abbildungen. $\mathrm{Maßstab}=100 \mu \mathrm{m}$. 

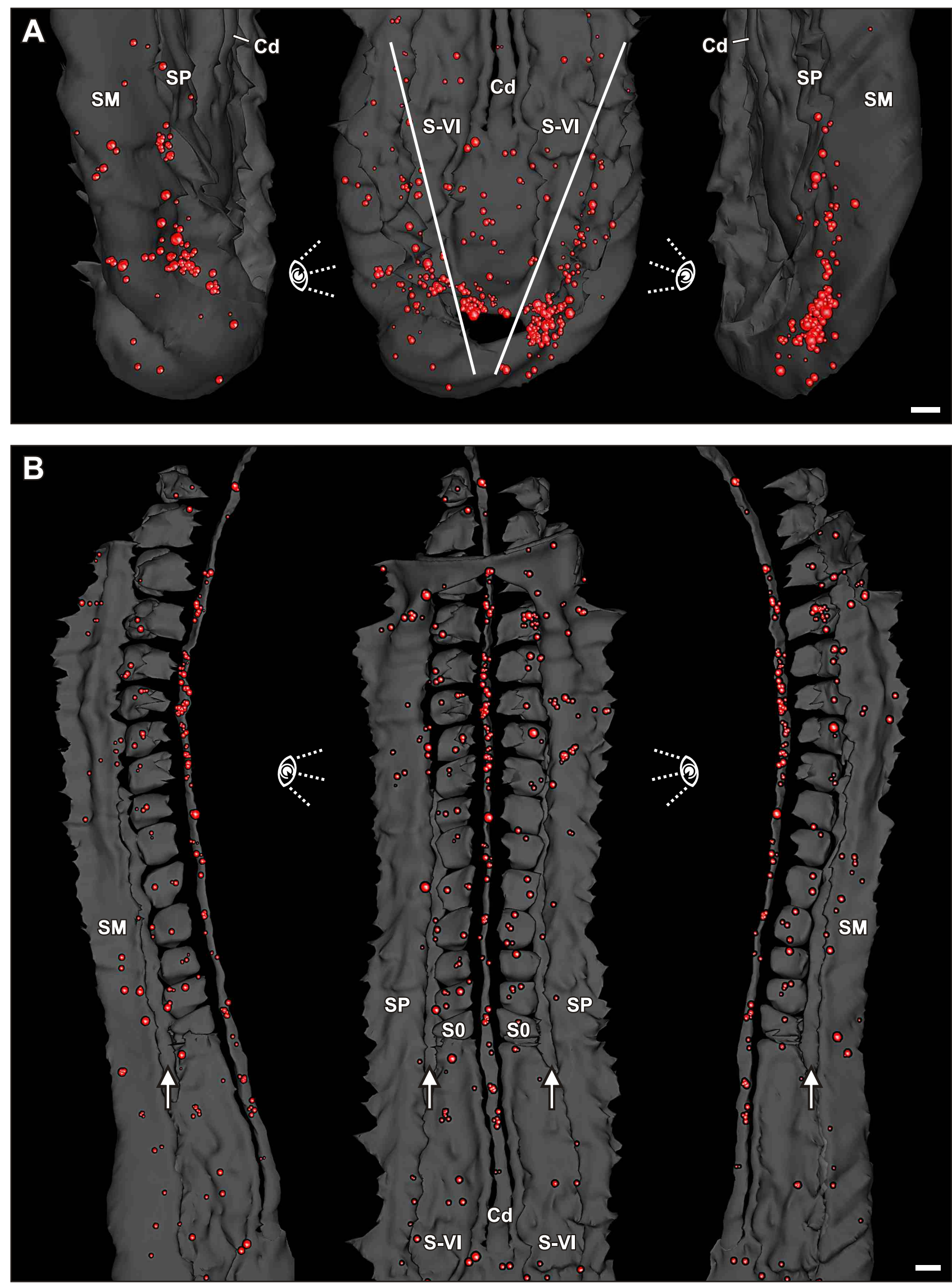

Abb. 13: Tupaia belangeri, dreidimensionale Rekonstruktionen von Apoptosen (rot, Radius 4 fach) im Mesoderm (grau), Phase 1, DPZ 754/1A. A: Kaudaler Pol. Mitte: Ventralansicht, links: Einblick (Augensymbole) in rechten Zölomspalt, rechts: Einblick in linken Zölomspalt. Bandförmige Apoptosezone am Übergang von Somatopleura (SM) und Splanchnopleura (SP). Überlagerungsartefakte durch benachbarte Apoptosen wurden durch Einführung virtueller Schnittebenen (weiße Linien) ausgeschlossen. B: Apoptosen in Splanchnopleura (Mitte: Ventralansicht), in rechtsseitiger (linke Spalte) und linksseitiger Somatopleura (rechte Spalte) sowie in ungegliedertem Mesoderm, Somiten, Chorda dorsalis (Cd) und Nierenanlagen (Pfeile). S0, in Abgliederung begriffener Somit; S-VI, prospektiver Somit 6. Maßstäbe $=50 \mu \mathrm{m}$. 

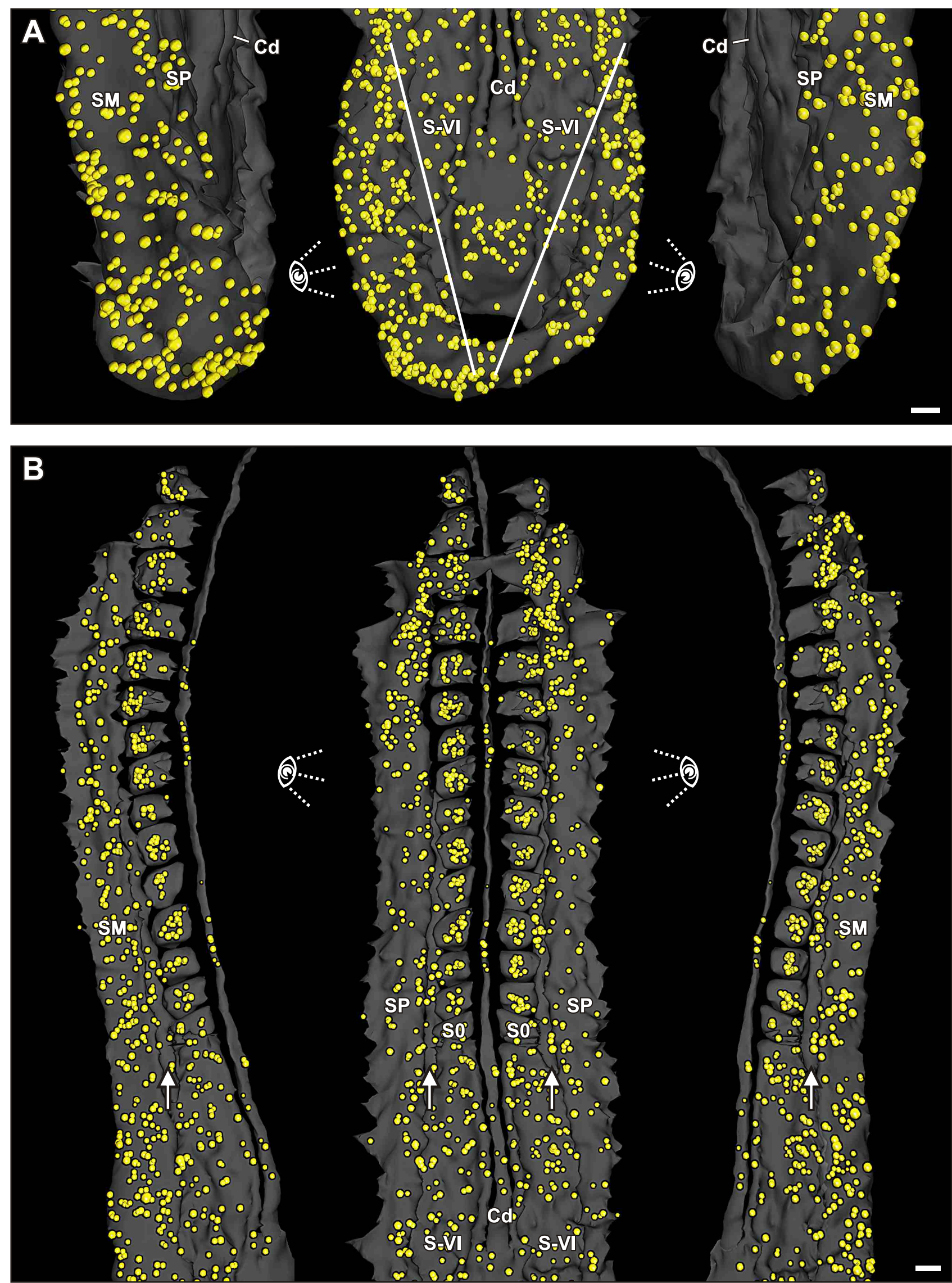

Abb. 14: Tupaia belangeri, dreidimensionale Rekonstruktionen von Mitosen (gelb, Radius 2 fach) im Mesoderm (grau), Phase 1, DPZ 754/1A. A: Kaudaler Pol. Mitte: Ventralansicht, links: Einblick (Augensymbole) in rechten Zölomspalt, rechts: Einblick in linken Zölomspalt. Zur Befundung des Seitenplattenmesoderms wurden Überlagerungsartefakte durch Mitosen in angrenzenden Mesodermabschnitten durch Einführung virtueller Schnittebenen (weiße Linien) ausgeschlossen. B: Mitosen in Splanchnopleura (SP, Mitte: Ventralansicht), in rechtsseitiger (linke Spalte) und linksseitiger Somatopleura (SM, rechte Spalte) sowie in ungegliedertem Mesoderm, Somiten, Chorda dorsalis (Cd) und Nierenanlagen (Pfeile). S0, in Abgliederung begriffener Somit; S-VI, prospektiver Somit 6. Maßstäbe $=50 \mu \mathrm{m}$. 


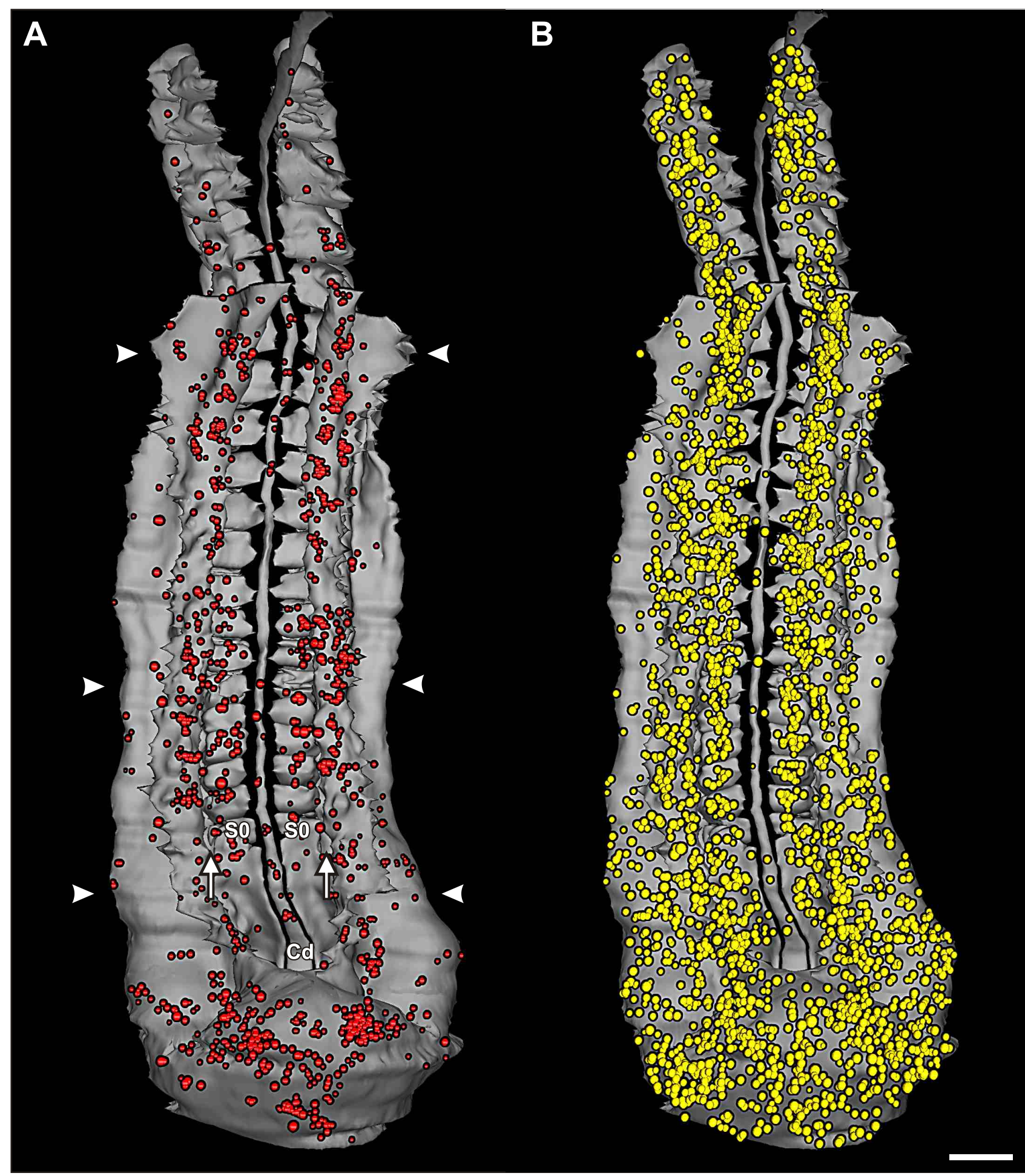

Abb. 15: Tupaia belangeri, Ventralansichten dreidimensionaler Rekonstruktionen (Übersichten) sämtlicher Apoptosen (A: rot, Radius 4fach) und Mitosen (B: gelb, Radius 2fach) im Mesoderm (grau) des Phase-2-Embryos DPZ 948/8A. Rekonstruiert wurden zelluläre Ereignisse in der Chorda dorsalis $(\mathrm{Cd})$, in den Somiten einschließlich des in Abgliederung begriffenen Somiten S0, in den lateral anschließenden Nierenanlagen (Pfeile), in den Seitenplatten (Pfeilköpfe) sowie in ungegliederten kaudalen Mesodermabschnitten. Weitere Erläuterungen im Text sowie in den nachfolgenden Abbildungen. $\mathrm{Ma} ß \mathrm{stab}=100 \mu \mathrm{m}$. 

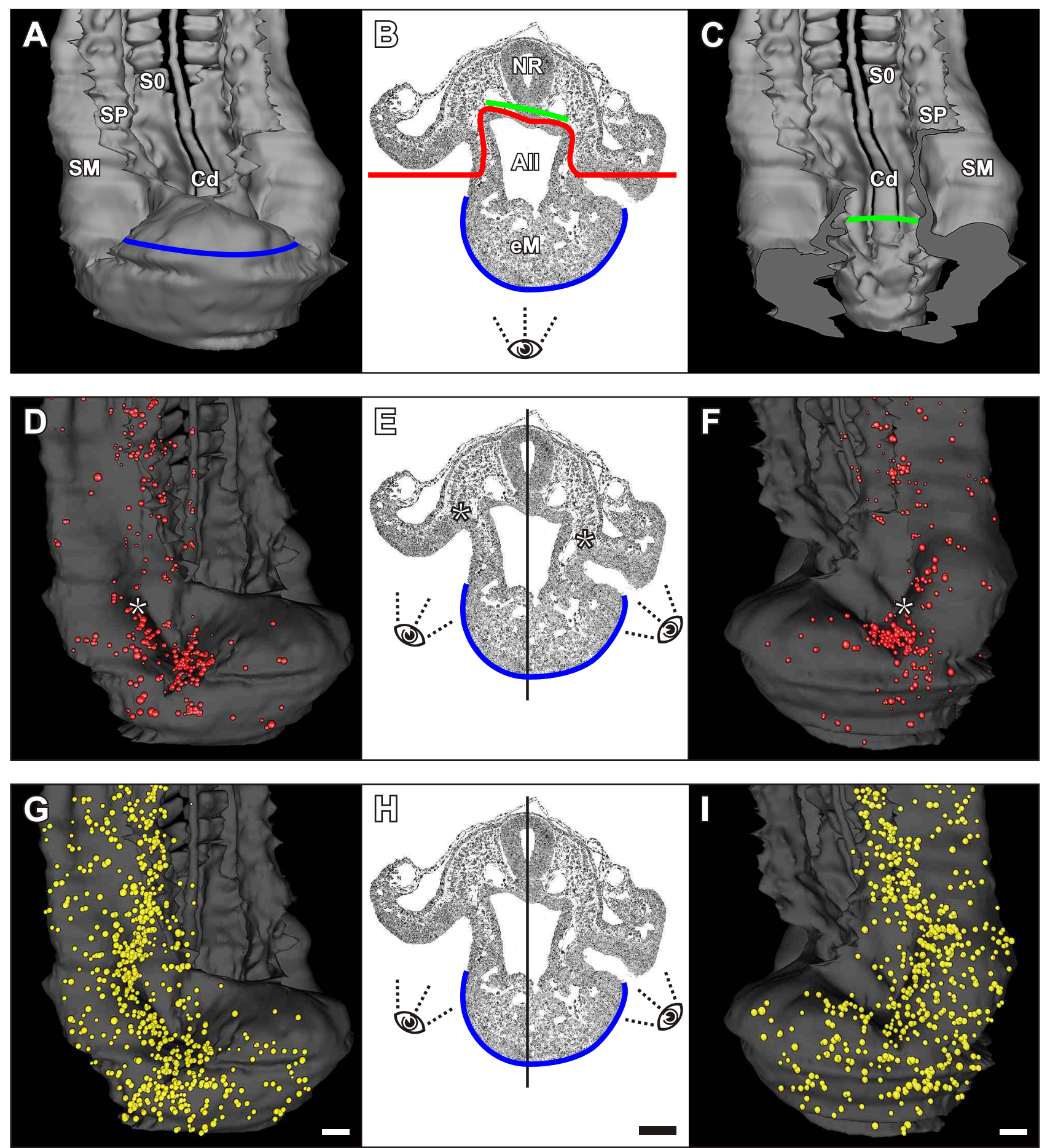

Abb. 16: Tupaia belangeri, dreidimensionale Rekonstruktionen (A, D, G und C, F, I) zellulärer Ereignisse im Mesoderm (grau in A, C; grau, transparent in D, F, G, I) des Phase-2-Embryos DPZ 948/8A, kaudaler Pol, sowie ein farbkodierter Semidünnschnitt (1 $\mu \mathrm{m}$, Hämatoxylin/Heidenhain; B, E, H) zur Erläuterung der topografischen Verhältnisse. A: Die in der Ventralansicht sichtbare Vorwölbung (blaue Linie: A, B, E, H) ,beinhaltet“" extraembryonales Mesoderm (eM) und Allantois (All). Ungegliedertes Mesoderm und Chorda dorsalis (Cd) werden sichtbar (grüne Linie: B, C), wenn auch die Allantois virtuell ausgeschlossen wird (Schnittführung: rote Linie in B). D, F: Apoptosen (rot, Radius 4fach) und G, I: Mitosen (gelb, Radius 1,5fach) im rechtsseitigen (D, G) und linksseitigen (F, I) Mesoderm (Seitenkodierung: schwarze Linie in E, F). Das im Phase-1-Embryo vorbestehende Apoptoseband am Übergang von Somatopleura (SM) und Splanchnopleura (SP) persistiert (Sterne in D-F). Augensymbole in der mittleren Spalte zeigen an, aus welcher Ansicht die Rekonstruktion in rechter und linker Bildspalte betrachtet wird. NR, Neuralrohr; S0, in Abgliederung begriffener Somit. Maßstäbe $=50 \mu \mathrm{m}$. 

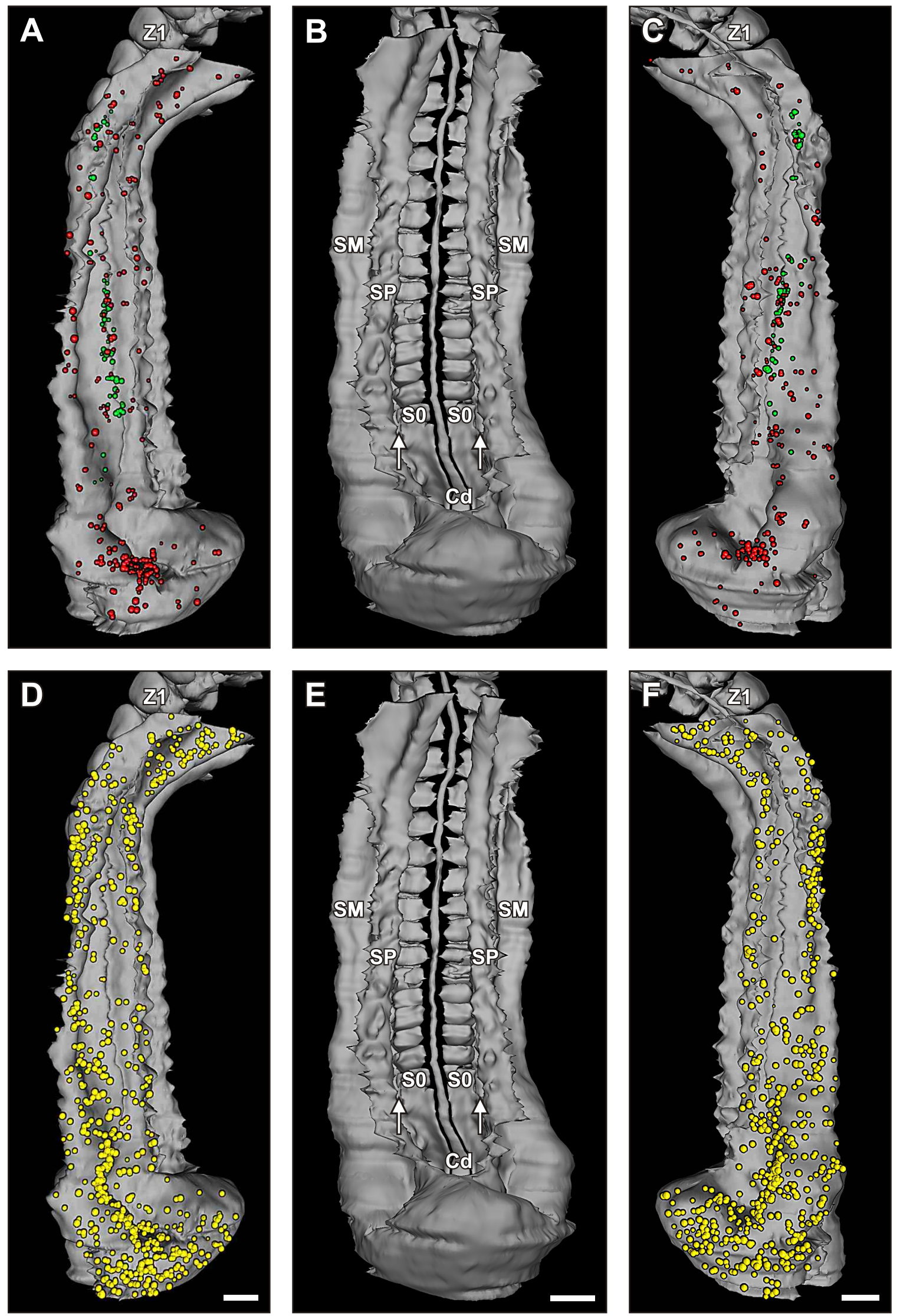

Abb. 17: Tupaia belangeri, dreidimensionale Rekonstruktionen des Seitenplattenmesoderms (A-F) mit Apoptosen (rot, Radius 4fach: A, C) und Mitosen (gelb, Radius 2 fach: D, F) sowie Apoptosen in den Nierenanlagen (grün, Radius 4 fach in A, C) des Phase-2-Embryos DPZ 948/8A. B, E: Ventralansicht des Mesoderms (grau); A, D: Einblick in den rechten Zölomspalt; C, F: Einblick in den linken Zölomspalt. Beachte die Apoptosehäufungen (rot) am Übergang von Somatopleura (SM) und Splanchnopleura (SP), die mit Apoptosehäufungen (grün) in der Nierenanlage überlappen. Cd, Chorda dorsalis; Pfeile, Nierenanlagen; S0, in Abgliederung begriffener Somit; Z1, Zervikalsomit 1. Maßstäbe $=100 \mu \mathrm{m}$. 

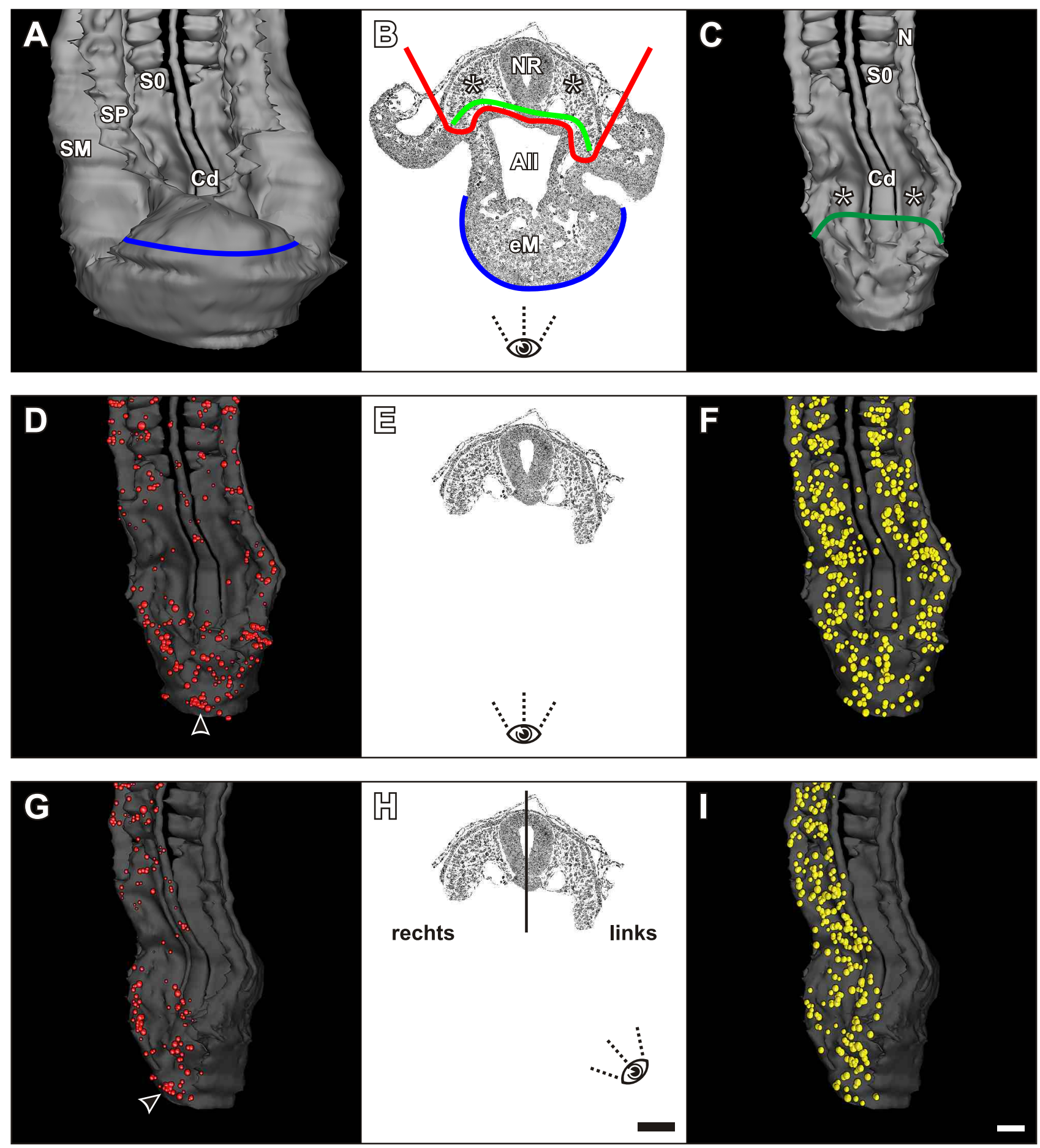

Abb. 18: Tupaia belangeri, dreidimensionale Rekonstruktionen des Mesoderms (grau in A, C; grau, transparent in D, F, G, I) des Phase-2-Embryos DPZ 948/8A, kaudaler Pol, sowie ein farbkodierter Semidünnschnitt als Orientierungshilfe (1 $\mu \mathrm{m}$, Hämatoxylin/Heidenhain; B, E, H). Die in der Ventralansicht sichtbare Vorwölbung (blaue Linie: A, B) ,beinhaltet“" extraembryonales Mesoderm (eM) und Allantois (All). Ungegliedertes Mesoderm (Sterne in B, C) und Chorda dorsalis (Cd) werden sichtbar (grüne Linie: B, C), wenn auch die Allantois virtuell ausgeschlossen wird (Schnittführung: rote Linie in B). Ventralansichten (D, F) und Schrägansichten $(\mathbf{G}, \mathbf{I})$ von Apoptosen (rot, Radius 4fach: D, G) und Mitosen (gelb, Radius 1,5fach: F, I) im ungegliederten Mesoderm (D, F) sowie - nach Ausschaltung separat kodierter zellulärer Ereignisse der linken Körperseite (Grenze in $\mathbf{H}$ : schwarze Linie) - überlagerungsfrei auf der rechten Körperseite (G, I). Beachte die ventrale Apoptosehäufung im kaudalen ungegliederten Mesoderm (Pfeilkopf in D, G). N, Nierenanlagen; NR, Neuralrohr; S0, in Abgliederung begriffener Somit; SM, Somatopleura; SP, Splanchnopleura. Maßstäbe $=50 \mu \mathrm{m}$. 


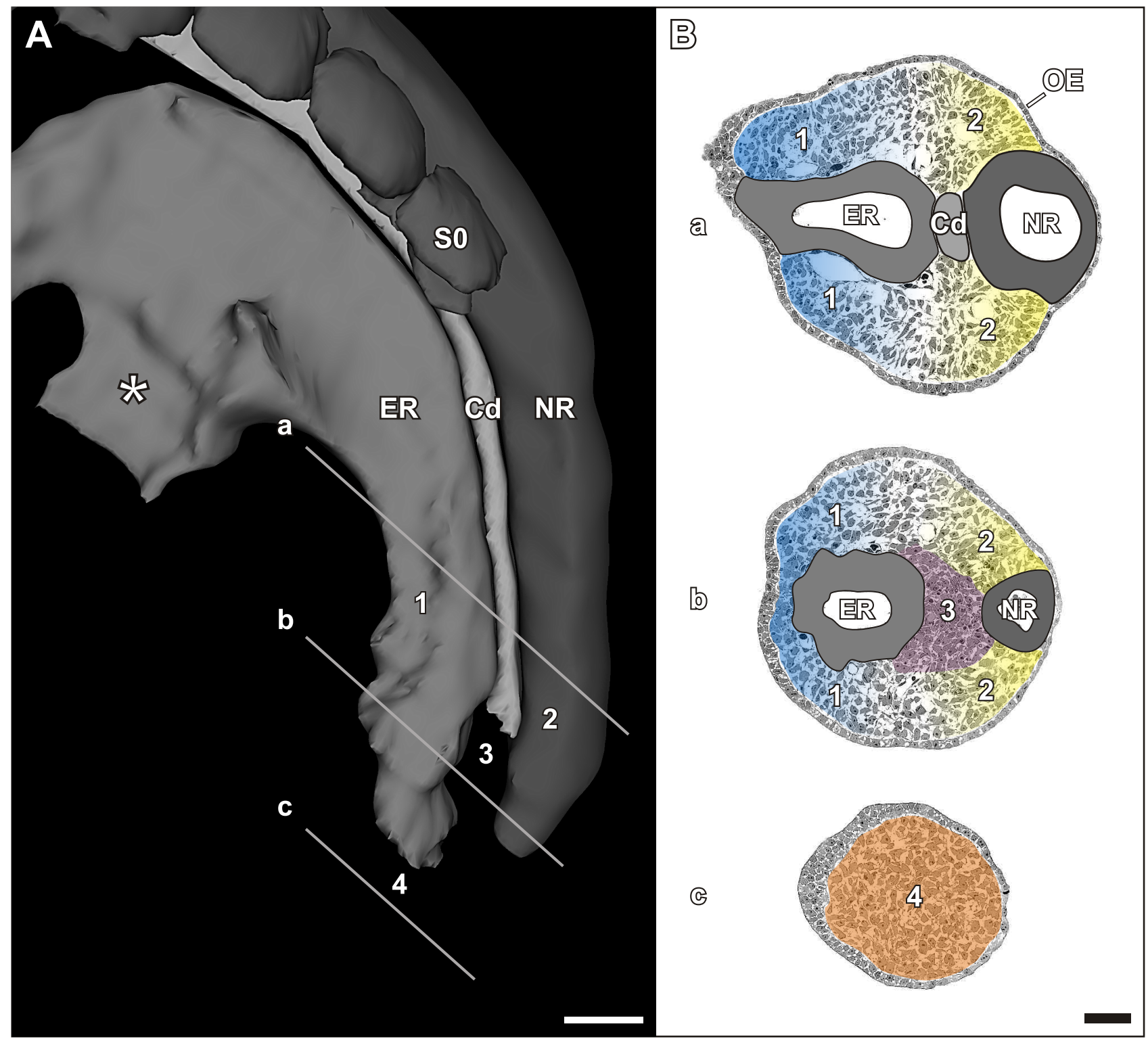

Abb. 19: Tupaia belangeri, Lateralansicht der dreidimensional rekonstruierten Schwanzregion des Phase-3-Embryos DPZ 623/9B (A) sowie repräsentative kolorierte Semidünnschnitte (1 $\mu \mathrm{m}$, Hämatoxylin/Heidenhain; B: a-c, Schnittebenen: weiße Linien in A). Ventrales Mesoderm (1, blau), paraxiales Mesoderm (2, gelb), chordoneurales Scharnier (3, lila) und das Mesoderm der Schwanzknospe (4, orange) bilden eine zusammenhängende Formation (A, B). Nur in kranialen Abschnitten der Schwanzregion liegen Oberflächenektoderm (OE) und Entodermrohr (ER) eng aneinander (B: a). Cd, Chorda dorsalis; NR, Neuralrohr; S0, in Abgliederung begriffener Somit; Stern, Abgang der Allantois aus dem Entodermrohr. Maßstäbe $=50 \mu \mathrm{m}$. 

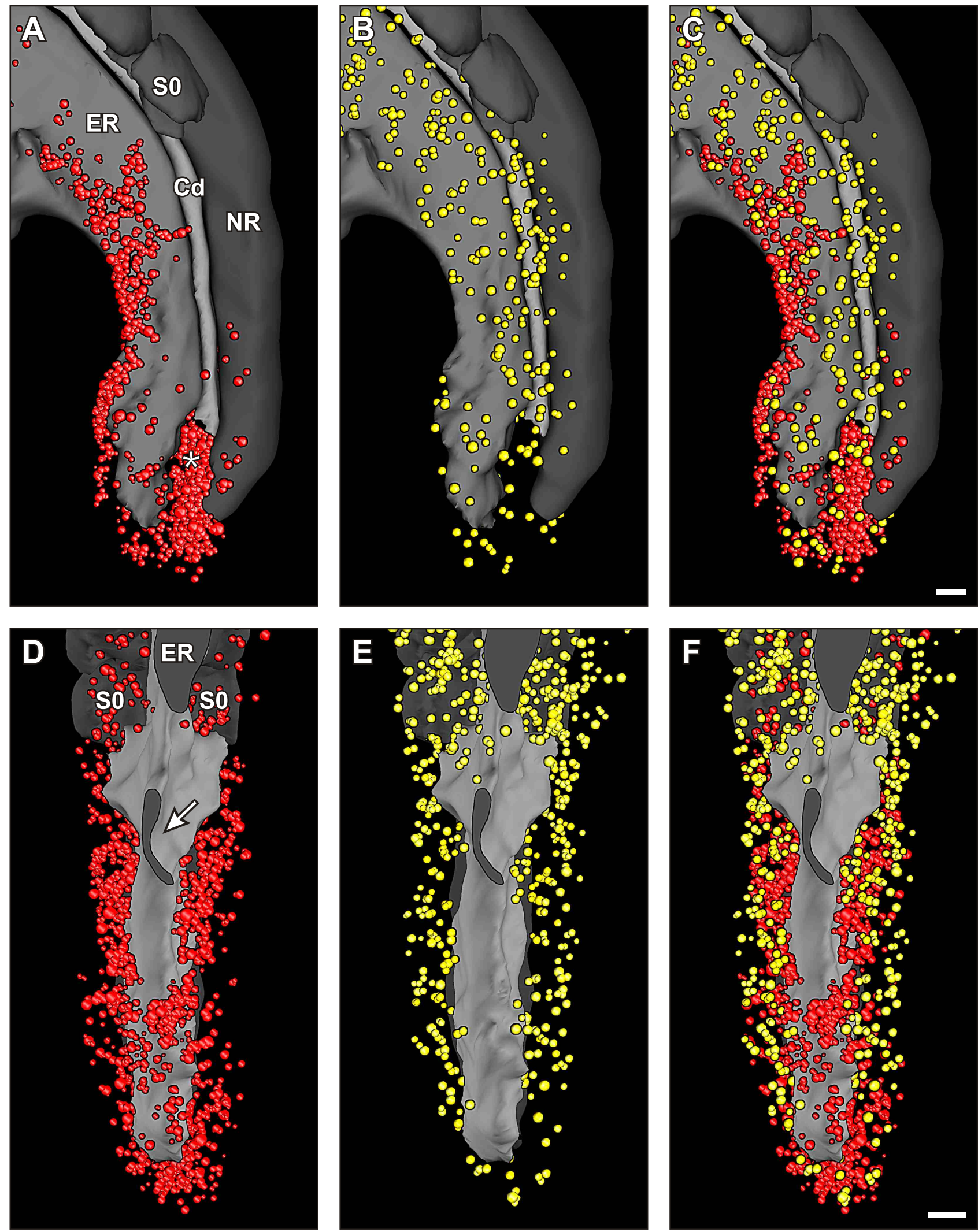

Abb. 20: Tupaia belangeri, dreidimensionale Rekonstruktionen von Apoptosen (rot, Radius 4fach) und Mitosen (gelb, Radius 1,5fach) im ungegliederten Mesoderm der Schwanzregion des Phase-3-Embryos DPZ 623/9B. A-C: Lateralansichten, D-F: Ventralansichten. In D-F ist der Übergang von Entodermrohr (ER) und Allantois virtuell ,abgeschnitten“ (Pfeil in D). Häufungen apoptotischer Zellen finden sich in ventralem Mesoderm, chordoneuralem Scharnier (Stern) und Schwanzknospe, überlagern aber nur zum Teil mit Mitosehäufungen (B, C, E, F; Details siehe Text). Beachte das weitgehende Fehlen von Apoptosen im paraxialen Mesoderm (A) seitlich von Chorda dorsalis (Cd) und Neuralrohr (NR). S0, in Abgliederung begriffener Somit. Maßstab $=50 \mu \mathrm{m}$. 

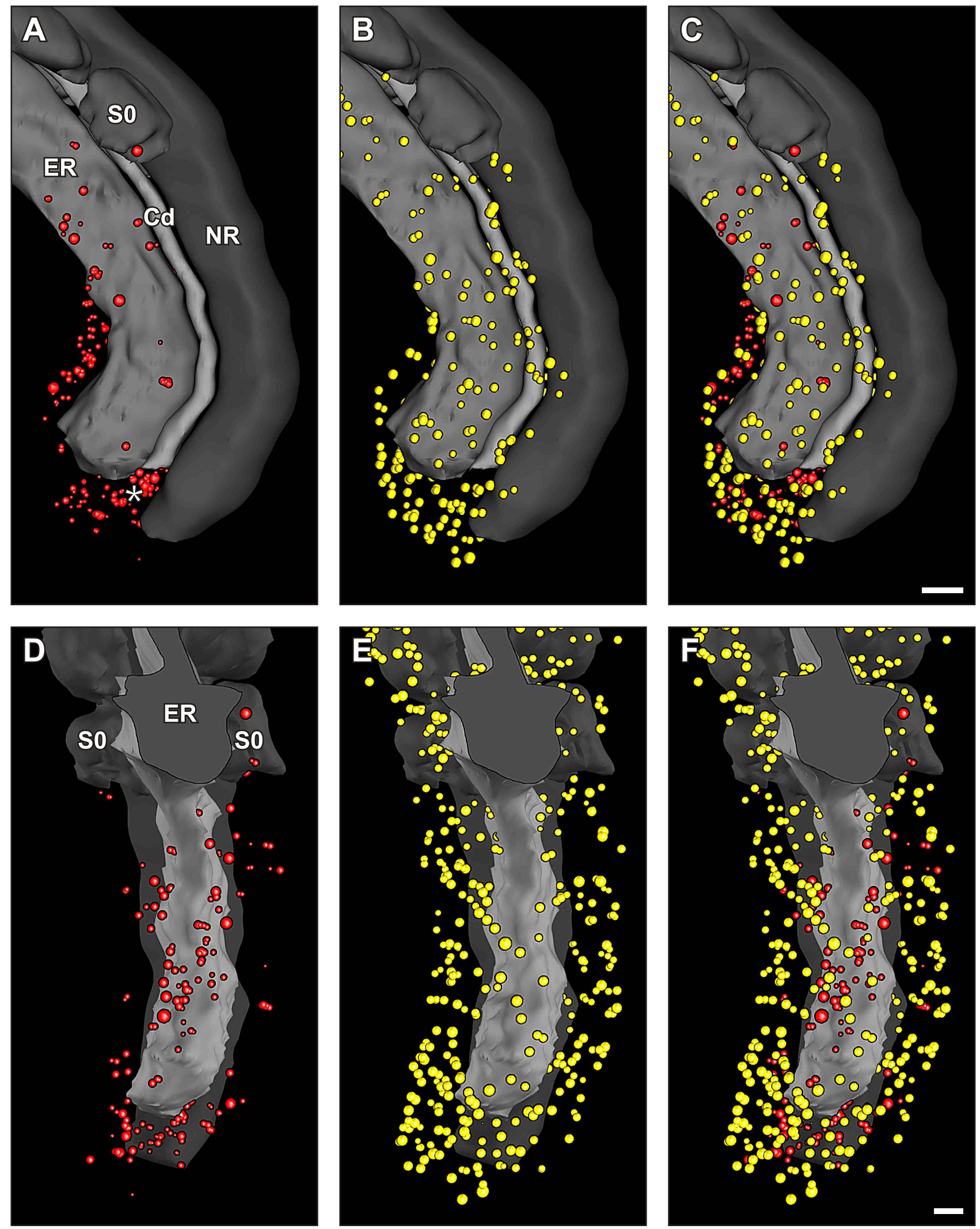

Abb. 21: Tupaia belangeri, dreidimensionale Rekonstruktionen von Apoptosen (rot, Radius 4fach) und Mitosen (gelb, Radius 1,5fach) im ungegliederten Mesoderm der Schwanzregion des Phase-4-Embryos DPZ 743/1A. A-C: Lateralansichten, D-F: Ventralansichten. In D-F sind kraniale Abschnitte des Entodermrohres (ER) virtuell ,abgeschnitten“. Wie im Phase-3-Embryo DPZ 623/9B (vergleiche Abb. 20A, D), quantitativ aber deutlich geringer ausgeprägt, finden sich Apoptosehäufungen in ventralem Mesoderm, chordoneuralem Scharnier (Stern) und Schwanzknospe. Wiederum treten im paraxialen Mesoderm seitlich von Chorda dorsalis (Cd) und Neuralrohr (NR) zahlreiche mitotische, aber nur vereinzelt apoptotische Zellen auf(A-C). S0, in Abgliederung begriffener Somit. Maßstab $=50 \mu \mathrm{m}$. 


\section{2.3 Apoptose und Proliferation in der Chorda dorsalis}

Bei Tupaia belangeri eilt die Entwicklung der Chorda dorsalis der Abgliederung von Somiten voraus (s. Kap. III.1.3 und Abb. 3). Dementsprechend projiziert das kaudale Ende der Chorda dorsalis nacheinander auf die prospektiven Somiten pT9 (Phase 1, DPZ 754/1A), pL2 (Phase 2, DPZ 948/8A), pK2 (Phase 3, DPZ 623/9B) und pK3 (Phase 4, DPZ 743/1A). Der auf das Vorkommen von Apoptose- und Proliferationsereignissen untersuchte Abschnitt der Chorda dorsalis reicht von der Okzipitalregion bis zu ihrem jeweiligen kaudalen Ende (Abb. 22).

In der Chorda dorsalis des Phase-1-Embryos DPZ 754/1A finden sich Mitosehäufungen zwischen Z1 und Z4, Z7 und T1 sowie zwischen pT4 und pT7 (Abb. 22B). Alle proliferierenden Abschnitte werden von Apoptosen überlappt, die zahlreich und beinahe durchgehend von O3 bis pT6 nachweisbar sind.

Im Phase-2-Embryo DPZ 948/8A treten Mitosen zwischen Z5 und T7 zwar durchgehend, aber nicht sehr zahlreich auf (Abb. 22B). Ihre Häufigkeit nimmt kaudal von pT9 zu und erreicht ein Maximum zwischen pT13 und pL2. Auch die Apoptosehäufungen (Z1 bis Z5, viel ausgeprägter zwischen T3 und pT10 und abgeschwächt zwischen pL1 und pL2) sind, verglichen mit Phase 1, nach kaudal verlagert. Kolokalisationen zwischen Proliferations- und Apoptoseereignissen bestehen zwischen T3 und pT10 sowie zwischen pL1 und pL2.

Wie im Phase-2-Embryo DPZ 948/8A sind Mitosen auch in kranialen Abschnitten der Chorda dorsalis des Phase-3-Embryos DPZ 623/9B nur noch spärlich nachweisbar (O3 bis T7, Abb. 22A, B). Ihre Häufigkeit nimmt jedoch zwischen T9 und pK2 erheblich zu. Apoptosen treten nahezu in der gesamten Chorda dorsalis zahlreich auf. Allerdings ist ihre Zahl kaudal erheblich höher als kranial. Dementsprechend überlappen Apoptoseereignisse sowohl mit Mitose-armen kranialen als auch mit Mitose-reichen kaudalen Abschnitten.

In der Chorda dorsalis des Phase-4-Embryos DPZ 743/1A sind Proliferationsereignisse kranial rar (O3 bis T4, Abb. 22B). Von T5 abwärts nimmt ihre Zahl jedoch bis zum Erreichen eines Maximums (pS1 bis pK3) zu. Apoptosehäufungen bestehen zwischen $\mathrm{O} 1$ und T1, T9 und T11 und, besonders ausgeprägt, zwischen L2 und pK3.

Die schematisierte Zusammenfassung dieser Ergebnisse (Abb. 22B) zeigt, dass die Chorda dorsalis von Tupaia belangeri im untersuchten Entwicklungszeitraum von einer rasch in kraniokaudaler Richtung ablaufenden Proliferationswelle durchsetzt wird. Begleitet wird diese Proliferationswelle 
von einer etwas träger fortschreitenden ersten Apoptosewelle, der, bei minimal erhaltener Basisproliferation, ab Phase 3 offenbar eine zweite kraniokaudale Apoptosewelle folgt.

\section{2.4 Apoptose und Proliferation in den epithelialen Somiten}

Über alle vier rekonstruierten Entwicklungsphasen hinweg lässt sich für das Auftreten von Mitosen und Apoptosen in solchen Somiten, die noch nicht in Sklerotom und Dermomyotom untergliedert sind, Folgendes festhalten (Abb. 23): (1) Innerhalb des Epithels liegen Apoptosen fast grundsätzlich basal, Mitosen dagegen apikal. (2) Die Zahl apoptotischer Zellen ist deutlich niedriger als die Zahl mitotischer Zellen. (3) Spalt-assoziierte Apoptosen, die auf das Absterben intersomitischer Grenzzellen (s. Kap. III.1.5) hinweisen könnten, kommen zwar vor, stellen aber keinen regelmäßig auftretenden Befund dar. (4) Innerhalb des Somitozöls treten nur sporadisch Apoptosen oder Mitosen auf.

\section{2.5 Apoptose im Sklerotom}

In den Sklerotomen des Phase-1-Embryos DPZ 754/1A (Somiten O1 bis Z4) kommen Apoptosen zwischen O1 und O4 vor (Abb. 24B). Sie liegen tendenziell häufiger in der kranialen, bereits von Neuralleistenzellen durchwanderten Sklerotomhälfte (vergleiche Scheffel 2009, Tab. 4). Ihre Zahl ist mit Ausnahme von O4 (linke Körperseite, laterale Sklerotomhälfte) äußerst gering (Abb. 24B). Im Phase-2-Embryo DPZ 948/8A finden sich Häufungen apoptotischer Zellen bereits in den Sklerotomen von O4 bis Z7 sowie von T1 (linke Körperseite, Abb. 24E). Mit wenigen Ausnahmen liegen auch diese apoptotischen Zellen in lateralen Abschnitten der Sklerotome.

Beginnend mit Phase 3 (DPZ 623/9B) sind die in den Sklerotomen nachgewiesenen Apoptosemuster komplexer als zuvor, dehnen sich aber, wie bisher, von kranial nach kaudal aus (O2 bis L3, Abb. 25A). Es persistiert die Konzentration apoptotischer Zellen auf die laterale Hälfte (T9 bis L1) beziehungsweise auf die laterale Subdomäne der Sklerotome (O2 bis T8, Abb. 25A). Hinzu kommen jetzt apoptotische Zellen in der nahe benachbarten ventralen Subdomäne (Abb. 25B). Okzipital sind beide Häufungen praktisch nicht voneinander trennbar. Zwischen Z1 und T3 treten jedoch apoptotische Zellen in den beiden Subdomänen als weitgehend separate Häufungen hervor (Abb. 25B). Dass auch die Etablierung der ventralen Apoptosehäufung einem kraniokaudalen Gradienten folgt, wird durch zwei Befunde unterstrichen. Erstens nimmt die Zahl apoptotischer Zellen in der ventralen Subdomäne in kraniokaudaler Richtung ab (Abb. 25B). Zweitens kommen Häufungen apoptotischer Zellen kaudal von T3 praktisch nicht vor.

Im Phase-3-Embryo DPZ 623/9B ist die Zahl apoptotischer Zellen in den dorsalen Subdomänen der Sklerotome erheblich niedriger als in den lateralen und ventralen Subdomänen (Abb. 25A). Die kombinierte Rekonstruktion apoptotischer Zellen in Neuralleistenzellströmen, Spinalganglienanla- 
gen (Scheffel 2009) sowie in allen nicht von diesen beiden Kompartimenten eingenommenen Abschnitten der dorsalen Subdomäne des Sklerotoms zeigt, dass die Zahl dieser dorsalen Apoptoseereignisse zwischen $\mathrm{O} 2$ und T2/T3 kontinuierlich abnimmt (Abb. 25A). Die zentrale Subdomäne des Sklerotoms enthält praktisch keine Apoptosen (Abb. 25A).

Verglichen mit dem Phase-3-Embryo DPZ 623/9B (Abb. 25A) ist die Zahl apoptotischer Körper in den Sklerotomen des Phase-4-Embryos DPZ 743/1A (Abb. 26A) deutlich geringer (2665 versus 608 apoptotische Körper). Nichtsdestoweniger finden sich auch im Phase-4-Embryo Apoptosehäufungen in der lateralen (O4 bis T13, Abb. 26A) und ventralen Subdomäne (O4 bis Z8, Abb. 26B). Die kombinierte Rekonstruktion apoptotischer Zellen in Neuralleistenzellströmen, Spinalganglienanlagen und dorsalen Subdomänen der Sklerotome zeigt (wiederum) einen von kranial nach kaudal fortschreitenden Gradienten (Z1 bis T7, Abb. 26A). Anders als im Phase-3-Embryo (Abb. 25A) ist eine sichere Abgrenzung solcher Apoptoseereignisse von weiter kaudal ablaufenden Zelleliminationen, die ebenfalls dorsal, aber parallel zur hier noch immer starken Delamination von Neuralleistenzellen auftreten (T9 bis L5, vergleiche Scheffel 2009, Tab. 4), nicht möglich (Abb. 26A). In zentralen Subdomänen der Sklerotome des Phase-4-Embryos DPZ 743/1A treten praktisch keine Apoptosen auf (Abb. 26A).

\section{2.6 Proliferation im Sklerotom}

Die Rekonstruktion des Phase-1-Embryos DPZ 754/1A zeigt, dass die Sklerotomentwicklung von Anfang an durch das Auftreten von Mitosen unterstützt wird (O1 bis Z4, Abb. 24C). Diese Mitosen treten vor allem in zentralen Abschnitten der entstehenden Sklerotome auf. Ihre Zahl nimmt von kranial nach kaudal ab (Abb. 24C). Parallel zum kraniokaudalen Fortschritt der Sklerotombildung weitet sich auch das Vorkommen von Mitosen auf immer weiter kaudal liegende Sklerotome aus (Phase 2, DPZ 948/8A: O1 bis T2, Abb. 24F; Phase 3, DPZ 623/9B: O2 bis L4, Abb. 25C; Phase 4, DPZ 743/1A: O2 bis L5, Abb. 26C). Dabei bleibt die bevorzugte Lokalisation dieser zahlreichen Mitosen in zentralen Subdomänen der Sklerotome erhalten.

Beginnend mit Phase 3 treten zusätzliche, aber vergleichsweise bescheidenere Mitosehäufungen in den ventralen Subdomänen der Sklerotome auf. Sie sind zunächst zwischen O4 und Z7 (Phase 3, DPZ 623/9B: Abb. 25D), danach bereits zwischen O3 und T1 (Phase 4, DPZ 743/1A: Abb. 26D) nachweisbar, schreiten also wiederum in kraniokaudaler Richtung fort.

Eine dritte Häufung mitotischer Zellen, die quantitativ etwa in der Mitte zwischen dem Mitoseaufkommen in zentralen beziehungsweise in ventralen Subdomänen der Sklerotome liegt, findet sich frühestens in den dorsalen Subdomänen der Sklerotome des Phase-3-Embryos DPZ 623/9B (Abb. 
25C). Die kombinierte Rekonstruktion mitotischer Zellen in Neuralleistenzellströmen, Spinalganglienanlagen (Scheffel 2009) und in den nicht von diesen beiden Kompartimenten eingenommenen Abschnitten der dorsalen Subdomänen belegt, dass diese Mitoseereignisse sich, wie die zugehörigen dorsalen Apoptoseereignisse auch, von kranial nach kaudal ausdehnen (Phase 3, DPZ 623/9B: O2 bis T6, Abb. 25C; Phase 4, DPZ 743/1A: O2 bis L2, Abb. 26C). Ihre Abgrenzung gegen weiter kaudal liegende dorsale Mitoseereignisse, die mit der Delamination von Neuralleistenzellen in Verbindung stehen (vergleiche Scheffel 2009, Tab. 4), ist weder in Phase 3 noch in Phase 4 zweifelsfrei möglich.

Zusammenfassend besteht der hervorstechendste Unterschied hinsichtlich der Subdomänen-spezifischen Verteilung apoptotischer und mitotischer Ereignisse in den Sklerotomen darin, dass die Apoptosen überwiegend in der lateralen und ventralen Subdomäne (Abb. 27A), die Mitosen dagegen überwiegend in der zentralen Subdomäne anzutreffen sind (Abb. 27B). 


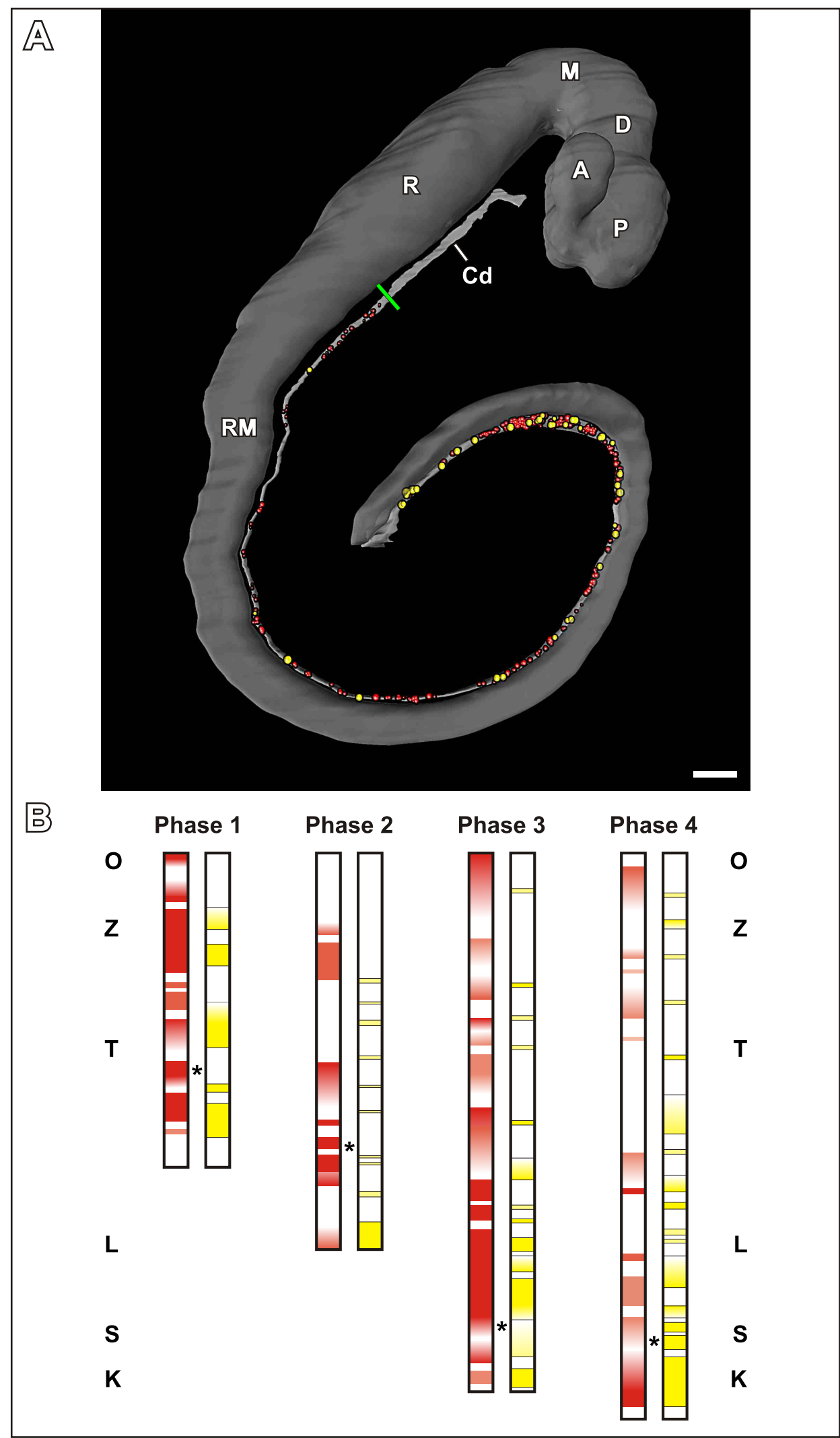

Abb. 22: Tupaia belangeri. A: Seitansicht der dreidimensionalen Rekonstruktion von Apoptosen (rot, Radius 5 fach) und Mitosen (gelb, Radius 3fach) in der Chorda dorsalis (Cd) des Phase-3-Embryos DPZ 623/9B, Befundung zwischen Okzipitalregion (obere Grenze: grüne Linie) und kaudalem Ende der Chorda dorsalis. B: Schema: Apoptosen (mit zunehmender Häufigkeit von rosa zu rot) und Mitosen (mit zunehmender Häufigkeit von blassgelb zu gelb) in der Chorda dorsalis von Embryonen der Phasen 1 (DPZ 754/1A), 2 (DPZ 948/8A), 3 (DPZ 623/9B) und 4 (DPZ 743/1A). Auf eine kraniokaudale Proliferationswelle mit eng assoziierter erster Apoptosewelle (Phase 1 bis 4) folgt eine zweite Apoptosewelle (Beginn: Phase 3). A, Augenbläschen; D, Dienzephalon; K, kokzygeal; L, lumbal; M, Mesenzephalon; O, okzipital; P, Prosenzephalon; R, Rhombenzephalon; RM, Rückenmarksanlage; S, sakral; Stern, Position des in Abgliederung begriffenen Somiten S0; T, thorakal; Z, zervikal. Maßstab $=100 \mu \mathrm{m}$. 

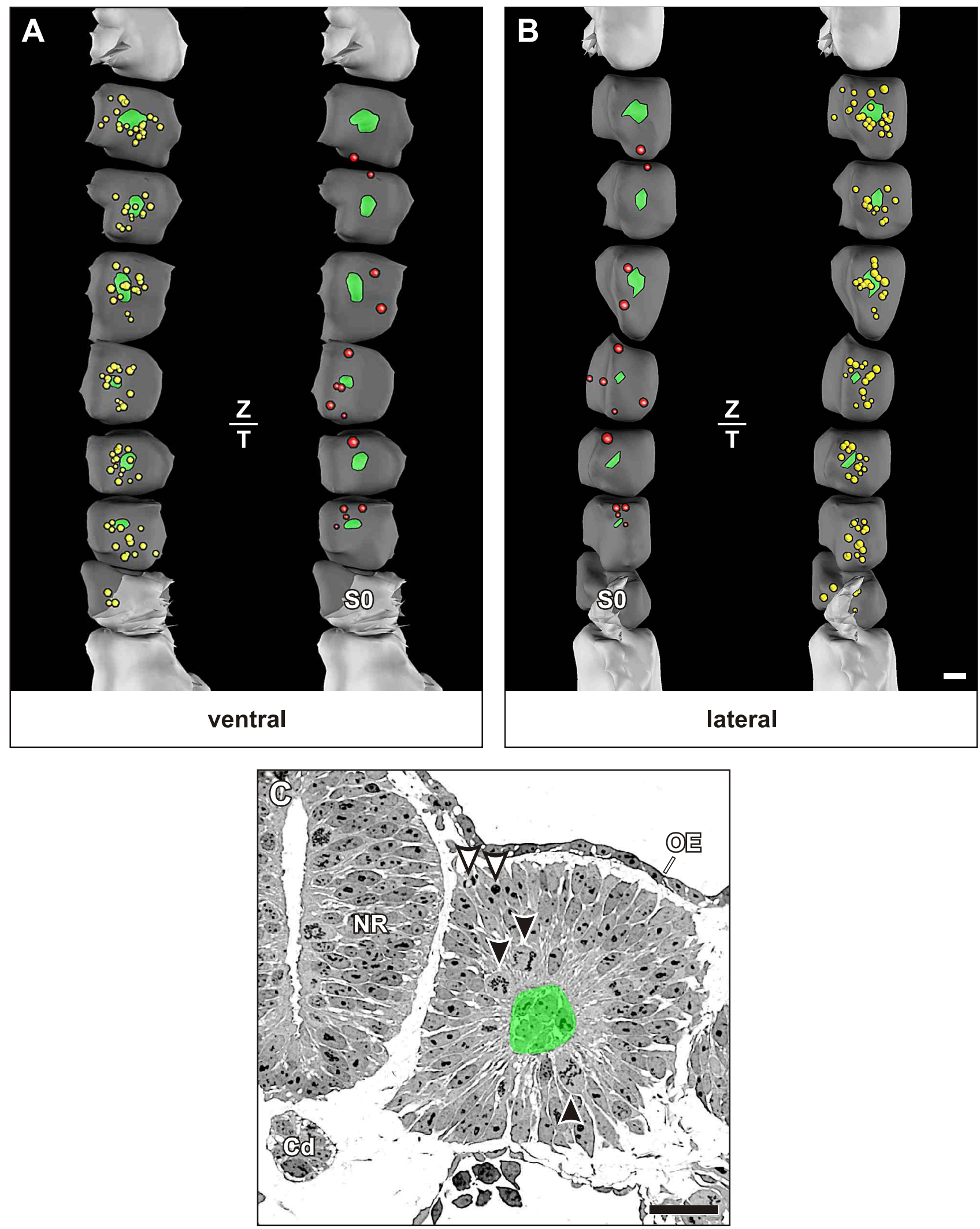

Abb. 23: Tupaia belangeri, Ventral-(A) und Lateralansichten (B) dreidimensional rekonstruierter Apoptosen (rot, Radius 3 fach) und Mitosen (gelb, Radius $1 \mathrm{fach}$ ) in vollständig epithelialen Somiten (grau, transparent, linke Körperseite, Phase 1, DPZ 754/1A); (C) Kolorierter Semidünnschnitt (1 $\mu$ m, Hämatoxylin/Heidenhain; Phase 2, DPZ 948/8A). Apoptosen sind rar und überwiegend randständig im Somitenepithel angeordnet (A, B, weiße Pfeilköpfe in C). Die zahlreichen Mitosen finden sich dagegen überwiegend zentral (A, B, schwarze Pfeilköpfe in C), nahe des Somitozöls (grün). Cd, Chorda dorsalis; NR, Neuralrohr; OE, Oberflächenektoderm; T, thorakal; S0, in Abgliederung begriffener Somit; Z, zervikal. Maßstäbe $=25 \mu \mathrm{m}$. 

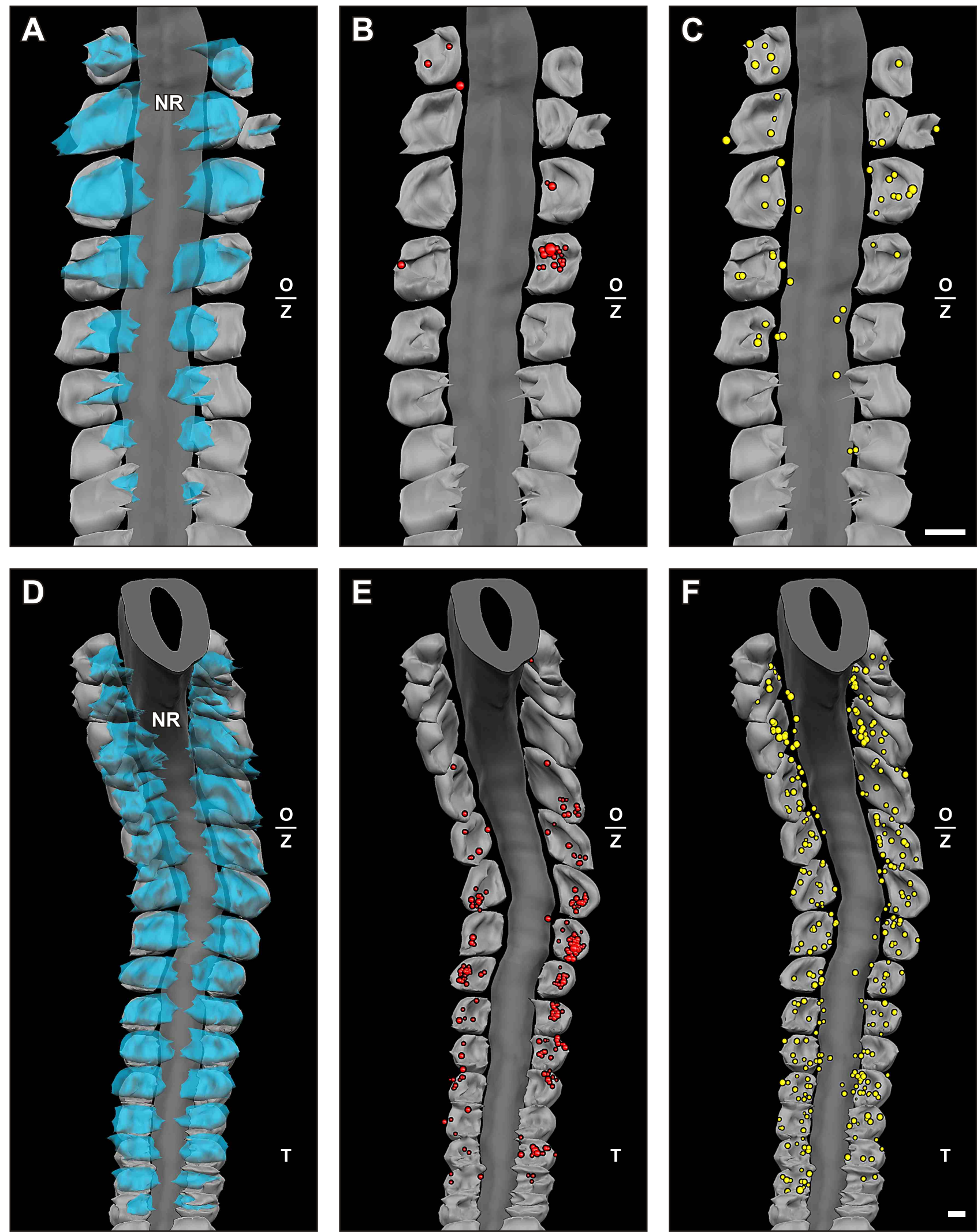

Abb. 24: Tupaia belangeri, dreidimensionale Rekonstruktionen von Apoptosen (rot, Radius 4fach) und Mitosen (gelb, Radius 1,5fach) im Sklerotom (A, D: hellblau; B, C, E, F: Sklerotommarkierung ausgeblendet) von Embryonen der Phasen 1 (DPZ 754/1A, A-C) und 2 (DPZ 984/8A, D-F). Apoptosen treten zunächst spärlich (B, Phase 1), dann zahlreicher (E, Phase 2) überwiegend in der lateralen Sklerotomhälfte auf. Dagegen sind Mitosen von Anfang an zahlreich vorhanden $(\mathbf{C}$, F). In D-F wurde das Neuralrohr (NR) virtuell geschnitten. Hellgrau, Dermomyotom; O, okzipital; T, thorakal; Z, zervikal. Maßstäbe $=50 \mu \mathrm{m}$. 

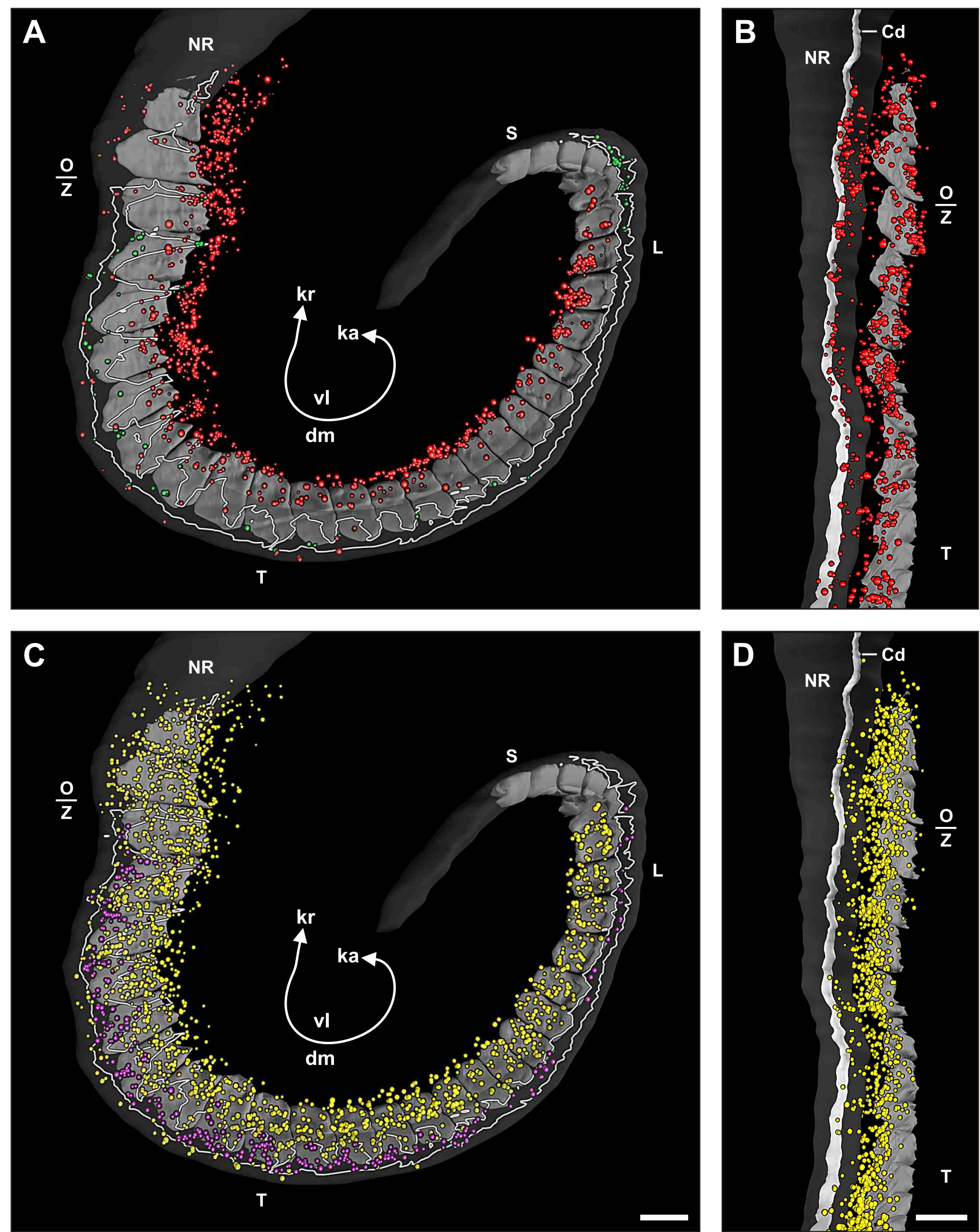

Abb. 25: Tupaia belangeri, dreidimensionale Rekonstruktionen von Apoptosen (Radius 5fach) und Mitosen (Radius 2 fach) im Sklerotom, linke Körperseite, Phase 3, DPZ 623/9B. A: Medialansicht: Apoptosehäufungen (rot) finden sich in der lateralen Subdomäne (Okzipitalsomit (O) 2 bis Thorakalsomit (T) 8) beziehungsweise in der lateralen Sklerotomhälfte (T9 bis Lumbalsomit (L) 1). Dagegen sind Apoptosen in der dorsalen Subdomäne (rot) sowie in Spinalganglienanlagen (grün in weißer Umrandung) rar. B: Ventralansicht: Weitere Apoptosehäufungen in der lateralen und ventralen Subdomäne (O2 bis T3). C: Medialansicht: Mitosen (gelb) treten besonders zahlreich in der zentralen Subdomäne auf. Beachte auch Mitosen (lila) unter migrierenden Neuralleistenzellen beziehungsweise in Spinalganglienanlagen. D: Ventralansicht: Mitosehäufungen in der ventralen Subdomäne (Höhe: O4 bis Zervikalsomit (Z) 7). Cd, Chorda dorsalis; dm, dorsomedial; ka, kaudal; kr, kranial; NR, Neuralrohr (grau, transparent); S, sakral; vl, ventrolateral. Maßstäbe $=100 \mu \mathrm{m}$. 

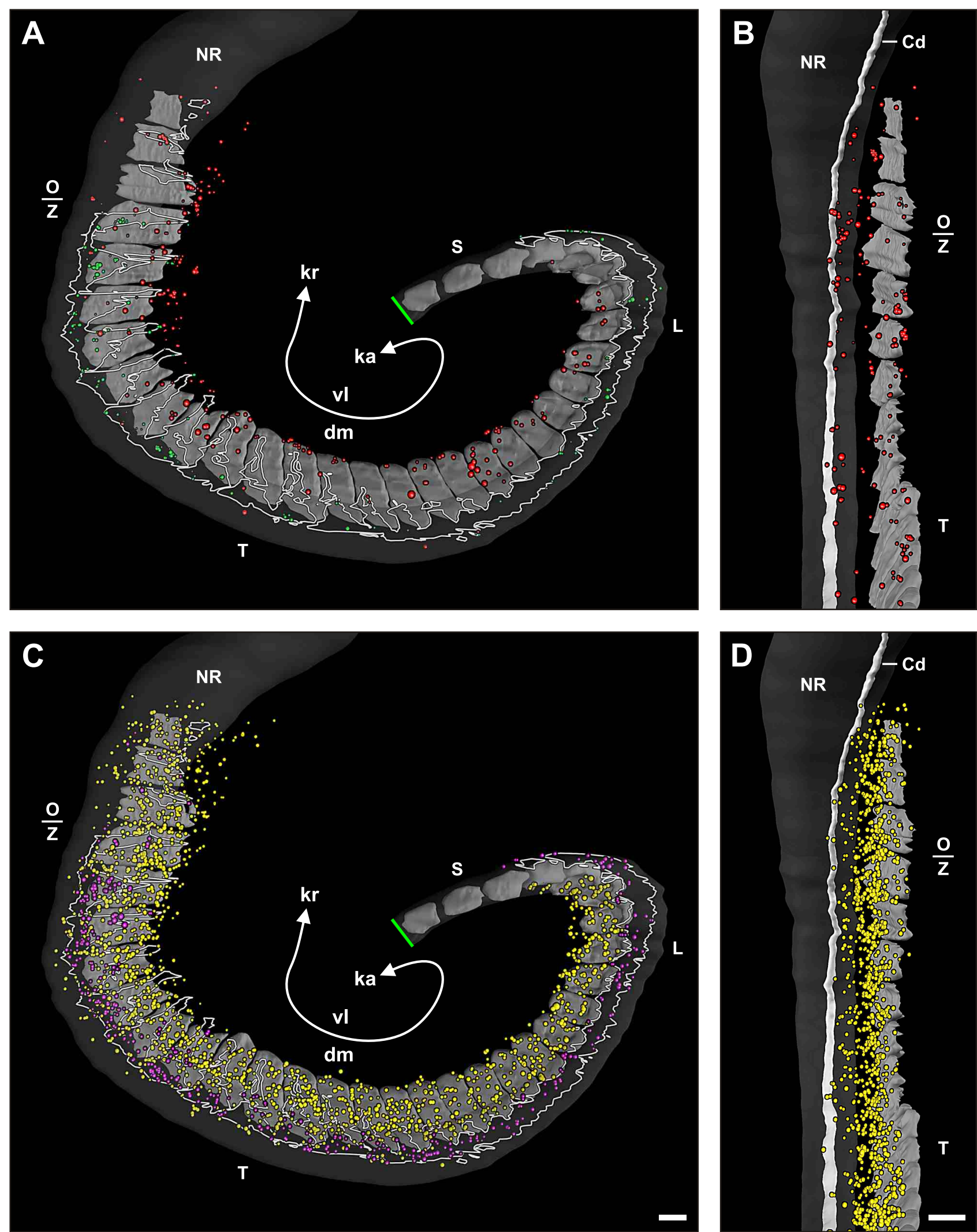

Abb. 26: Tupaia belangeri, dreidimensionale Rekonstruktionen von Apoptosen (Radius 5fach) und Mitosen (Radius 2 fach) im Sklerotom, linke Körperseite, Phase 4, DPZ 743/1A. A: Medialansicht: Apoptosehäufungen (rot) finden sich in der lateralen Subdomäne (Okzipitalsomit (O) 4 bis Thorakalsomit (T) 13). Dagegen sind Apoptosen in der dorsalen Subdomäne (rot) sowie in Spinalganglienanlagen (grün in weißer Umrandung) rar. B: Ventralansicht: Weitere Apoptosehäufungen in der lateralen und ventralen Subdomäne (O4 bis Zervikalsomit (Z) 8). C: Medialansicht: Mitosen (gelb) treten besonders zahlreich in der zentralen Subdomäne auf. Beachte auch Mitosen (lila) unter migrierenden Neuralleistenzellen beziehungsweise in Spinalganglienanlagen. D: Ventralansicht: Mitosehäufungen in der ventralen Subdomäne (Höhe: O3 bis T1). Verglichen mit DPZ 623/9B ist das Apoptosemuster gleichartig, aber quantitativ erheblich schwächer ausgebildet. Das Neuralrohr wurde kaudal des Sakralsomiten (S) 2 virtuell geschnitten (grüne Linie in A, C). Cd, Chorda dorsalis; dm, dorsomedial; ka, kaudal; kr, kranial; L, lumbal; NR, Neuralrohr (grau, transparent); vl, ventrolateral; Z, zervikal. Maßstäbe $=100 \mu \mathrm{m}$. 

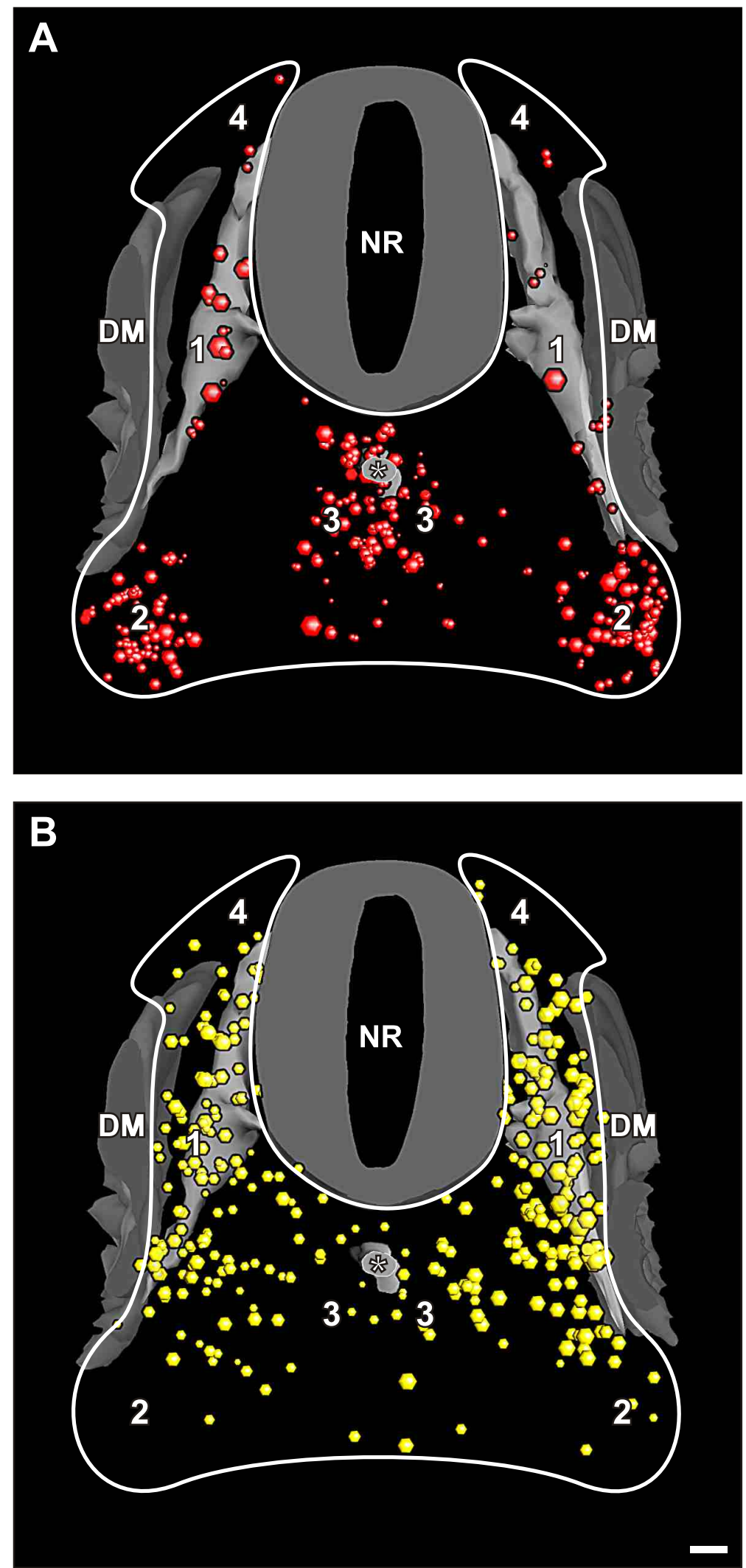

Abb. 27: Tupaia belangeri, Verteilungsmuster von Apoptosen (rot, Radius 4fach, A) und Mitosen (gelb, Radius 1,5fach, B) in den Subdomänen des Sklerotoms (weißer Umriss). Aufsicht auf dreidimensional rekonstruierte zelluläre Ereignisse in Höhe des ersten zervikalen Sklerotoms von DPZ 623/9B (Phase 3) - durch Einführung künstlicher Schnittebenen aus der Gesamtrekonstruktion ,,isoliert“. A: Apoptosen sind in der lateralen (2) und ventralen Subdomäne (3) zahlreich, in der dorsalen (4) und zentralen Subdomäne (1) vergleichsweise rar. B: Dagegen häufen sich Mitosen besonders in der zentralen Subdomäne. DM, Dermomyotom; hellgrau, Spinalganglienanlage; NR, Neuralrohr; Stern, Chorda dorsalis. $\mathrm{Maßstab}=50 \mu \mathrm{m}$. 


\section{2.7 Apoptose im Dermomyotom}

Im Phase-1-Embryo DPZ 754/1A sind Apoptosen in jungen Dermomyotomen, die nur angedeutete Lippen aufweisen (Z1 bis Z4), wie zuvor im Epithel der Somiten, bevorzugt basal lokalisiert. Die Zahl dieser Apoptosen ist gering und nimmt, bei gleichzeitig angedeuteter Konzentration auf die Lippen, in den Dermomyotomen von O1 bis O4 sogar noch ab (Abb. 28B).

In den jungen Dermomyotomen (T1 bis T3) sowie in den epithelialen Somiten des Phase-2-Embryos DPZ 948/8A nimmt die Zahl apoptotischer Zellen, verglichen mit dem Phase-1-Embryo DPZ 754/1A, merklich zu (Abb. 28E). Beibehalten wird die überwiegend basale, ansonsten aber regellose Anordnung apoptotischer Zellen, die erst kranial von T2 eine Bevorzugung der Dermomyotomlippen erkennen lässt. Allerdings geht die Zahl apoptotischer Zellen in diesen kranialen Dermomyotomen wiederum erheblich zurück (Abb. 28E).

In den Dermomyotomen des Phase-3-Embryos DPZ 623/9B sind die Apoptosemuster bilateral symmetrisch, rechtsseitig aber massiver als auf der linken Körperseite ausgebildet. Der Phase-4-Embryo DPZ 743/1A ist dem Phase-3-Embryo DPZ 623/9B hinsichtlich des Entwicklungsstandes außerordentlich nahe. Die Apoptosemuster beider Embryonen weisen überwiegend, aber keineswegs ausnahmslos, hohe Übereinstimmungen auf. Quantitativ stehen die auf beiden Körperseiten des Phase4-Embryos gefundenen Apoptosemuster hinter den im Phase-3-Embryo nachweisbaren Apoptosemustern zurück (1683 versus 5830 apoptotische Körper). Um die aus den genannten Gründen selbst mit Hilfe dreidimensionaler Rekonstruktionen schwierig durchführbare Analyse dieser Apoptosemuster (Abb. 29) zu erleichtern und nicht zuletzt auch, um Überinterpretationen von Einzelbefunden zu vermeiden, haben wir die in den Dermomyotomen der Phase-3- und Phase-4-Embryonen nachgewiesenen Apoptose- und Proliferationsmuster zusätzlich schematisch zusammengefasst und einander gegenüber gestellt (Abb. 30). Mit Hilfe dieser Schemata werden im Folgenden übereinstimmende oder abweichende Befunde aus den Phasen 3 und 4 erläutert, mit Folgebefunden im Phase-5-Embryo DPZ 5061/C (Abb. 31) verglichen und in der Diskussion zusammenhängend bewertet.

Ein möglicher Zusammenhang zwischen der De-epithelialisierung des Dermomyotoms und dem Auftreten von Apoptoseereignissen lässt sich zunächst kranial von Z8 aufzeigen (Abb. 30). Hier schreitet die De-epithelialisierung in den Phasen 3 und 4 von ventral nach dorsal voran. Diesem Deepithelialisierungsprozess geht, allerdings unter Auslassung der VLL, eine gleichfalls von ventral nach dorsal fortschreitende Apoptosewelle voraus. 
Aus diesem Befund ergeben sich zwei Anschlussfragen. Zunächst müsste überprüft werden, ob auch weit kaudal lokalisierte Dermomyotome, die, wie die eben betrachteten Dermomyotome kranial von Z8, nur epaxiale Myotome entwickeln werden, ähnliche zeitlich-räumliche Zusammenhänge zwischen ihrer De-epithelialisierung und dem Auftreten von Apoptoseereignissen aufweisen. Diese Frage kann mit Hilfe des aktuell verfügbaren Untersuchungsmaterials nicht geklärt werden. Die zweite Frage befasst sich mit dem Problem, ob Myoblasten, die sich kranial von Z8 von der VLL ableiten, einer „,apoptotischen Selektion“ unterzogen werden. Aus den bisher angefertigten Rekonstruktionen geht hervor, dass myoblastische Vorläuferzellen kranial von Z8 nicht innerhalb der VLL (Abb. 28B, E; 30), sondern erst nach Verlassen der VLL, das heißt während der Wanderung zu ihren Zielgebieten, apoptotisch selektioniert werden (Daten nicht gezeigt).

Im Gegensatz zu myoblastischen Vorläuferzellen kranial von Z8 werden Vorläuferzellen mutmaßlich hypaxialer Myoblasten, die in der Rumpfregion durch De-epithelialisierung aus der VLL hervorgehen, offenbar bereits innerhalb der VLL eliminiert (Abb. 29A, 30). Apoptoseereignisse in der VLL, die hierfür verantwortlich sein könnten, finden sich sowohl im Phase-3-Embryo DPZ 623/9B als auch im Phase-4-Embryo DPZ 743/1A mindestens zwischen Z8 und L1 (Abb. 30). Allerdings bildet sich diese Apoptosehäufung in der VLL in dem Maße zurück, in dem Vorläuferzellen in das hypaxiale Myotom integriert werden (Phase 5, DPZ 5061/C: Abb. 31A). Auch im Rumpfbereich durchläuft die VLL demnach eine, verglichen mit Dermomyotomen oberhalb von Z8, späte „Apoptose-freie“" Phase. Aus den Rekonstruktionen geht nicht hervor, ob und in welchem Ausmaß auch in dieser späten Phase Myoblasten aus der VLL hervorgehen. Daher bleibt ungeklärt, ob die abschließende De-epithelialisierung der VLL und des zentralen Dermomyotoms durch Auswanderung von Myoblasten und/oder Vorläuferzellen der Dermisanlage erfolgt.

In den Dermomyotomen der Phase-3- und Phase-4-Embryonen finden sich kaudal von Z7 zusätzliche Apoptosehäufungen, die der De-epithelialisierung des zentralen Dermomyotoms vorangehen (Abb. 30). Sie erstrecken sich mindestens bis T7 (Phase 3, DPZ 623/9B) beziehungsweise T13 (Phase 4, DPZ 743/1A). Im Phase-3-Embryo DPZ 623/9B sind diese Apoptosefoki zunächst auf das Zentrum jüngerer Dermomyotome beschränkt (T7), dehnen sich aber praktisch auf das gesamte zentrale Dermomyotom aus (Z8 bis T5). Da die De-epithelialisierung des zentralen Dermomyotoms zentrifugal abläuft, gehen Apoptoseereignisse dieser De-epithelialisierung grundsätzlich voraus (vergleiche Phase 3, DPZ 623/9B: Abb. 30 und Phase 5, DPZ 5061/C: Abb. 31A). Zwei Einschränkungen müssen allerdings gemacht werden. Erstens ist das sequenzielle Auftreten von Apoptose und De-epithelialisierung in dem insgesamt „Apoptose-ärmeren“ Phase-4-Embryo DPZ 743/1A nur bedingt nachvollziehbar, weil Apoptosen hier, neben regelhaft vorhandenen Herden in der VLL, lediglich fokal in zentralen Abschnitten des zentralen Dermomyotoms auftreten (Abb. 30). Zweitens 
ist der Entwicklungssprung zwischen den Phasen 3 und 4 einerseits und der Phase 5 andererseits zu groß, um Latenz- oder Überlappungszeiten zwischen Apoptose und De-epithelialisierung enger eingrenzen zu können.

Zeitliche und räumliche Zusammenhänge zwischen dem Auftreten von Apoptoseereignissen und Entwicklungsprozessen der DML wurden bisher lediglich für Dermomyotome kranial von Z8 betrachtet (Phasen 3 und 4: Abb. 30). Hier, und auch im Phase-5-Embryo DPZ 5061/C (Abb. 31A), gehen Apoptoseprozesse der De-epithelialisierung der DML voraus. Dagegen finden sich im Rumpfbereich der rekonstruierten Embryonen der Phase 2 (DPZ 948/8A; Abb. 28D), Phase 4 (DPZ 743/1A: Abb. 30) und der Phase 5 (DPZ 5061/C: Abb. 31) sowohl vor (Phasen 2 und 4) als auch nach Etablierung des epaxialen Myotoms (Phase 5) praktisch keine oder höchstens einige wenige Apoptoseereignisse in der DML. Es ist aber nicht auszuschließen, dass die De-epithelialisierung der DML im Rumpfbereich erst im Anschluss an Phase 5 von Apoptosehäufungen eingeleitet und/oder begleitet wird. Außerdem zeigt mindestens der Phase-3-Embryo DPZ 623/9B sporadisch Apoptosen in der DML thorakaler Dermomyotome (Abb. 30). Der gravierendste Unterschied zwischen den hinsichtlich ihres Entwicklungsstandes besonders nahen Embryonen der Phasen 3 und 4 (DPZ 743/1A) besteht jedoch darin, dass nur der Phase-3-Embryo DPZ 623/9B über massive Apoptosevorkommen in der DML und/oder in dorsalen Abschnitten des zentralen Dermomyotoms verfügt (T13 bis L4, Abb. 30).

\section{2.8 Proliferation im Dermomyotom}

In jüngeren Dermomyotomen (Phase 1, DPZ 754/1A: Z1 bis Z4, Abb. 28C; Phase 2, DPZ 948/8A: T1 bis T3, Abb. 28F) sind die Mitosen, wie zuvor in den epithelialen Somiten, zahlreich und überwiegend zentral konzentriert. In reiferen Dermomyotomen der Phase-1- und Phase-2-Embryonen treten Mitosen - einschließlich des im Phase-1-Embryo DPZ 754/1A linksseitig doppelt ausgebildeten Somiten O2 - bevorzugt in den Dermomyotomlippen auf (Abb. 28C, F).

Auch in den Dermomyotomen von Embryonen der Phasen 3 (DPZ 623/9B) und 4 (DPZ 743/1A) sind mitotische Zellen zunächst zentral und anschließend zunehmend Lippen-betont angeordnet (Abb. 30). Allerdings verfügen diese beiden Embryonen, im Gegensatz zu Embryonen der Phasen 1 und 2, über eine große Zahl von Dermomyotomen, aus deren Lippen bereits Myotome hervorgegangen sind. Insofern können die in den Dermomyotomen nachweisbaren Proliferationsmuster der Phase-3- und Phase-4-Embryonen besser als in den jüngeren Embryonen daraufhin überprüft werden, inwieweit sie mit konkurrierenden Modellen zur Myotomentwicklung „vereinbar“ sind. 
Zur Erleichterung dieser Analyse wurden die rekonstruierten Proliferationsmuster zusätzlich in schematischer Form zusammengefasst (Abb. 30). Hierbei zeigte sich, dass der unmittelbar vor Beginn der Myotomentstehung (Phase 3, DPZ 623/9B: T9; Phase 4, DPZ 743/1A: T10) erfolgende Umschwung von zentrischen zu Lippen-betonten Mitosehäufungen zunächst bevorzugt die DML und VLL erfasst. Anschließend treten, teils hiermit überlappend, teils alternativ hierzu, Mitosehäufungen auch in kranialen und/oder kaudalen Dermomyotomlippen auf. Wiederum kranial hiervon treten Lippen-betonte Mitosehäufungen zugunsten einer eher diffusen Verteilung von Mitosen zurück. Solche diffusen Proliferationsmuster behalten - kranial von Z8 - auch die noch epithelialen Abschnitte der bereits im Prozess der De-epithelialisierung stehenden Dermomyotome bei. Auch in den noch erhaltenen Dermomyotomabschnitten des Phase-5-Embryos DPZ 5061/C sind zahlreiche, diffus verteilte Mitosen nachweisbar (Abb. 31B).

\section{2.9 Apoptose und Proliferation im Myotom}

Häufungen von Apoptosen und/oder Mitosen in den Myotomen finden sich erstmals im Phase-3Embryo DPZ 623/9B (Abb. 32A). In den rekonstruierten Embryonen der Phasen 3 und 4 (DPZ 743/1A: Abb. 32B) sind zwischen O2 und T9 beziehungsweise T10 überwiegend epaxiale Myotome ausgebildet. Häufungen apoptotischer Zellen treten fast ausschließlich in der ventralen Hälfte dieser Myotome auf. Ihre Zahl nimmt von kaudal nach kranial zu.

Der Phase-5-Embryo DPZ 5061/C (Abb. 32C) besitzt neben epaxialen (O2 bis L2) auch hypaxiale Myotome (Z8 bis mindestens T13). Innerhalb der epaxialen Myotome sind Apoptosehäufungen, wie in den Phasen 3 (DPZ 623/9B: Abb. 32A) und 4 (DPZ 743/1A: Abb. 32B), mehrheitlich ventral lokalisiert, brechen aber, anders als in den Phasen 3 und 4, in mehreren zervikalen Myotomen weit nach dorsal aus. Insgesamt nimmt die Zahl apoptotischer Zellen in den epaxialen Myotomen des Phase-5-Embryos DPZ 5061/C zwischen T9 und O2 in kranialer Richtung zu. In den hypaxialen Myotomen des Phase-5-Embryos DPZ 5061/C sind nur vereinzelt Apoptosen nachweisbar.

In den Myotomen der rekonstruierten Embryonen der Phasen 3 (DPZ 623/9B: Abb. 32A) und 4 (DPZ 743/1A: Abb. 32B) steigt die Zahl mitotischer Zellen tendenziell von kaudal nach kranial an, ist aber insgesamt noch sehr gering. Mitotische Zellen treten bevorzugt in der Peripherie der Myotome, das heißt in enger Nachbarschaft zu den Lippen der Dermomyotome auf. Auch im Phase-5-Embryo DPZ 5061/C (Abb. 32C) nimmt die Zahl mitotischer Zellen in den epaxialen Myotomen (L2 bis O2) in kranialer Richtung zu. Insbesondere in den rein epaxialen Myotomen von O2 bis Z7 sind diese Mitosen, im Gegensatz zu den überwiegend ventral konzentrierten Apoptosen, mehrheitlich dorsal anzutreffen. In den hypaxialen Myotomen steht die hohe Proliferationsrate in starkem Kontrast zu dem minimalen Apoptoseaufkommen (Abb. 32C). 

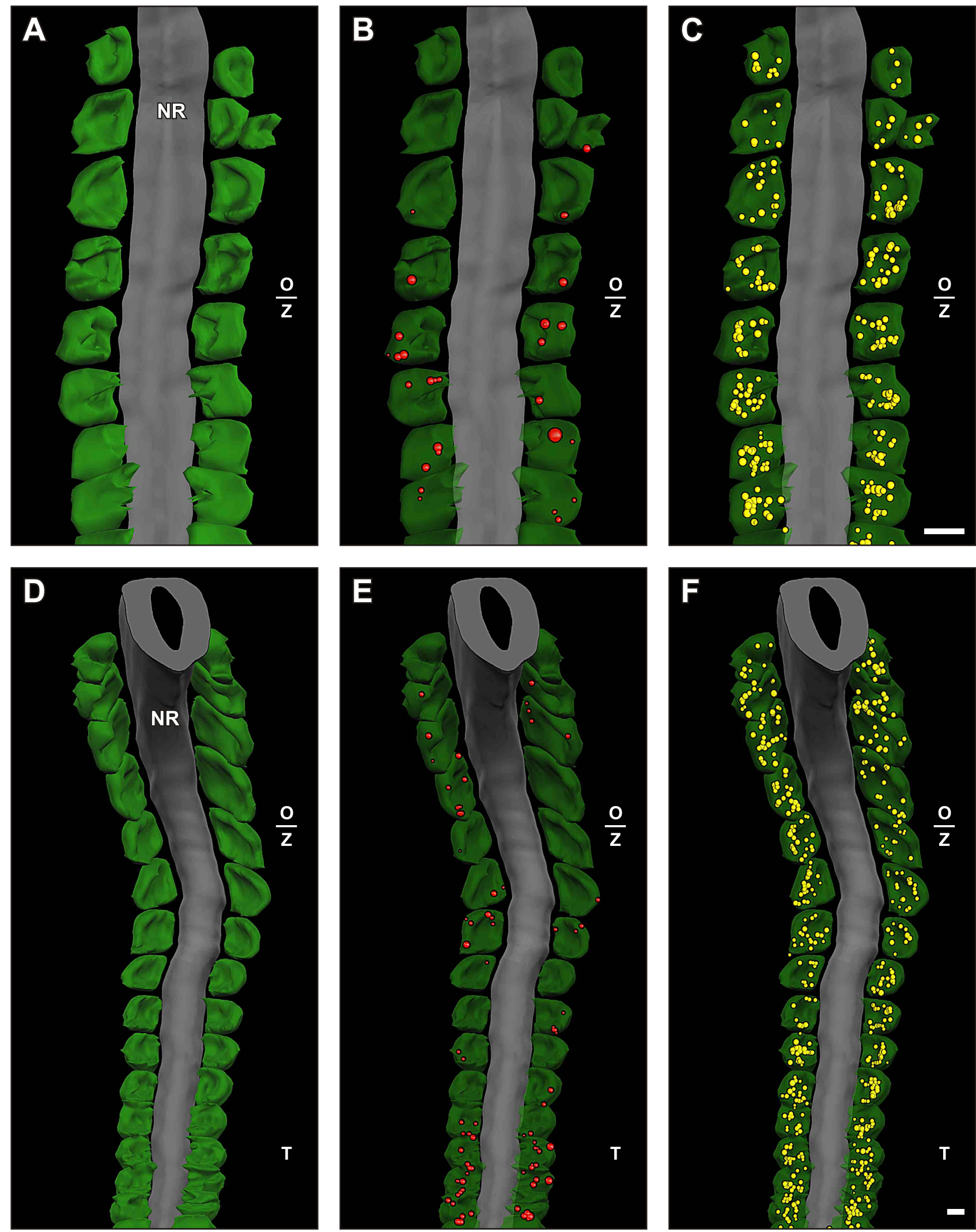

Abb. 28: Tupaia belangeri, dreidimensionale Rekonstruktionen von Apoptosen (rot, Radius 4fach) und Mitosen (gelb, Radius 1,5fach) im Dermomyotom (A, D: grün, B, C, E, F: grün, transparent) von Embryonen der Phasen 1 (DPZ 754/1A, A-C) und 2 (DPZ 948/8A, D-F). Apoptosen sind in ,jungen“ Dermomyotomen (B: Zervikalsomit (Z) 1 bis Z4, E: Thorakalsomit (T) 1 bis T3) regellos angeordnet, in ,reiferen“ Dermomyotomen (A: Okzipitalsomit (O) 1 bis O4, C: O1 bis Z8) - bei abnehmender Zahl - auf die Lippen des Dermomyotoms konzentriert. Tendenziell ähnlich sind die Mitosen in ,jungen“"Dermomyotomen (C: Z1 bis Z4, F: T1 bis T3) überwiegend zentral, und in ,reiferen“"Dermomyotomen, wie die Apoptosen, vorrangig in den Lippen der Dermomyotome lokalisiert. In D-F wurde das Neuralrohr (NR) virtuell geschnitten. Maßstäbe $=50 \mu \mathrm{m}$. 

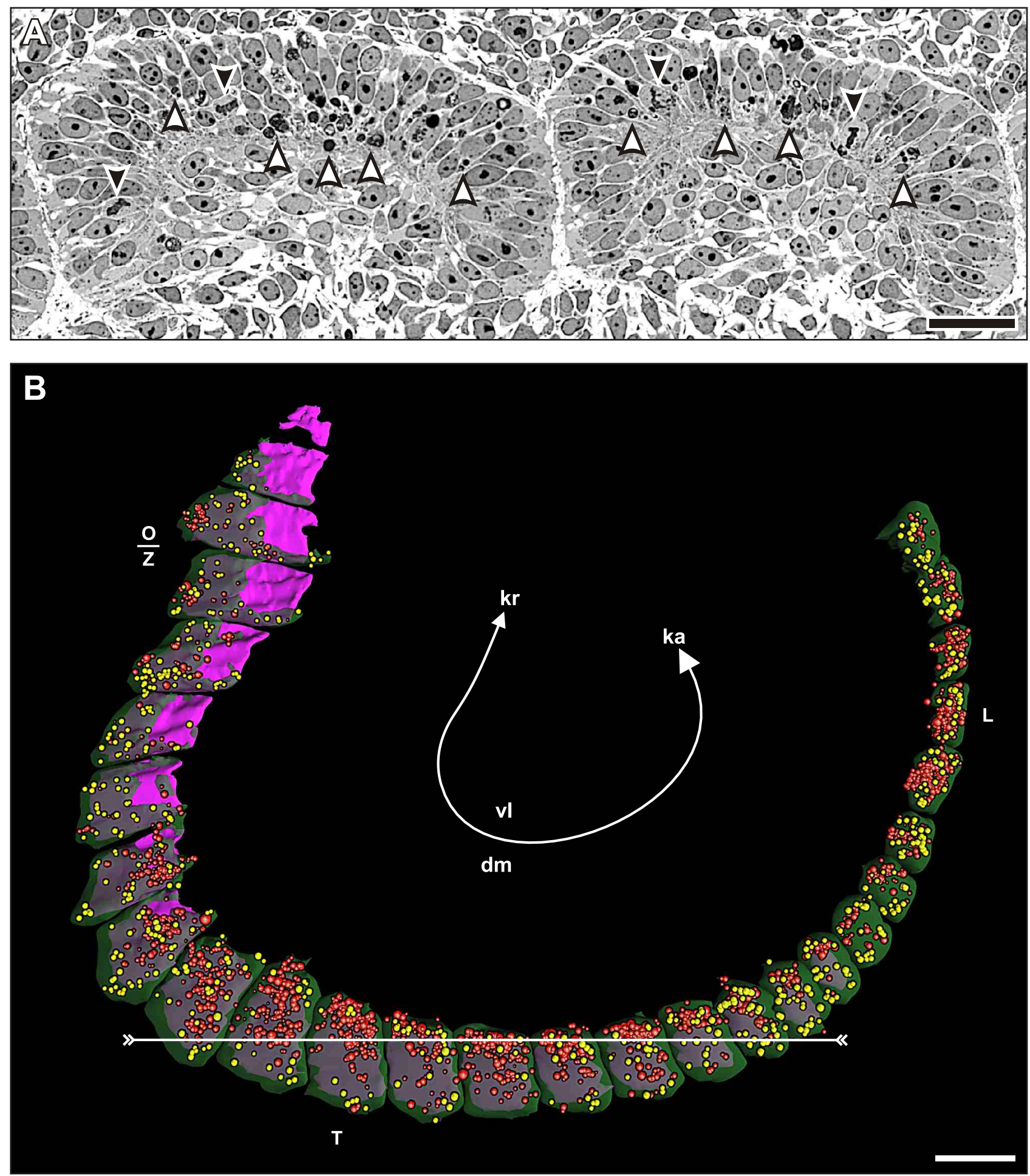

Abb. 29: Tupaia belangeri, Apoptosen und Mitosen im Dermomyotom, Phase 3, DPZ 623/9B. A: Semidünnschnitt (1 $\mu \mathrm{m}$, Hämatoxylin/Heidenhain; Schnittebene: weiße Linie in B). Apoptotische Körper (weiße Pfeilköpfe) sowie Mitosen (schwarze Pfeilköpfe) in der ventrolateralen Lippe der thorakalen (T) Dermomyotome 3 und 4. B: Lateralansicht dreidimensional rekonstruierter Apoptosen (rot, Radius 4fach) und Mitosen (gelb, Radius 1,5fach) in den Dermomyotomen (grün, transparent) und Myotomen (magenta) der rechten Körperseite zur Übersicht. Für die detaillierte und schematisierte Auswertung siehe Abb. 30. dm, dorsomedial; ka, kaudal; kr, kranial; L, lumbal; O, okzipital; vl, ventrolateral; Z, zervikal. Maßstäbe: $\mathbf{A}=25 \mu \mathrm{m} ; \mathbf{B}=100 \mu \mathrm{m}$. 


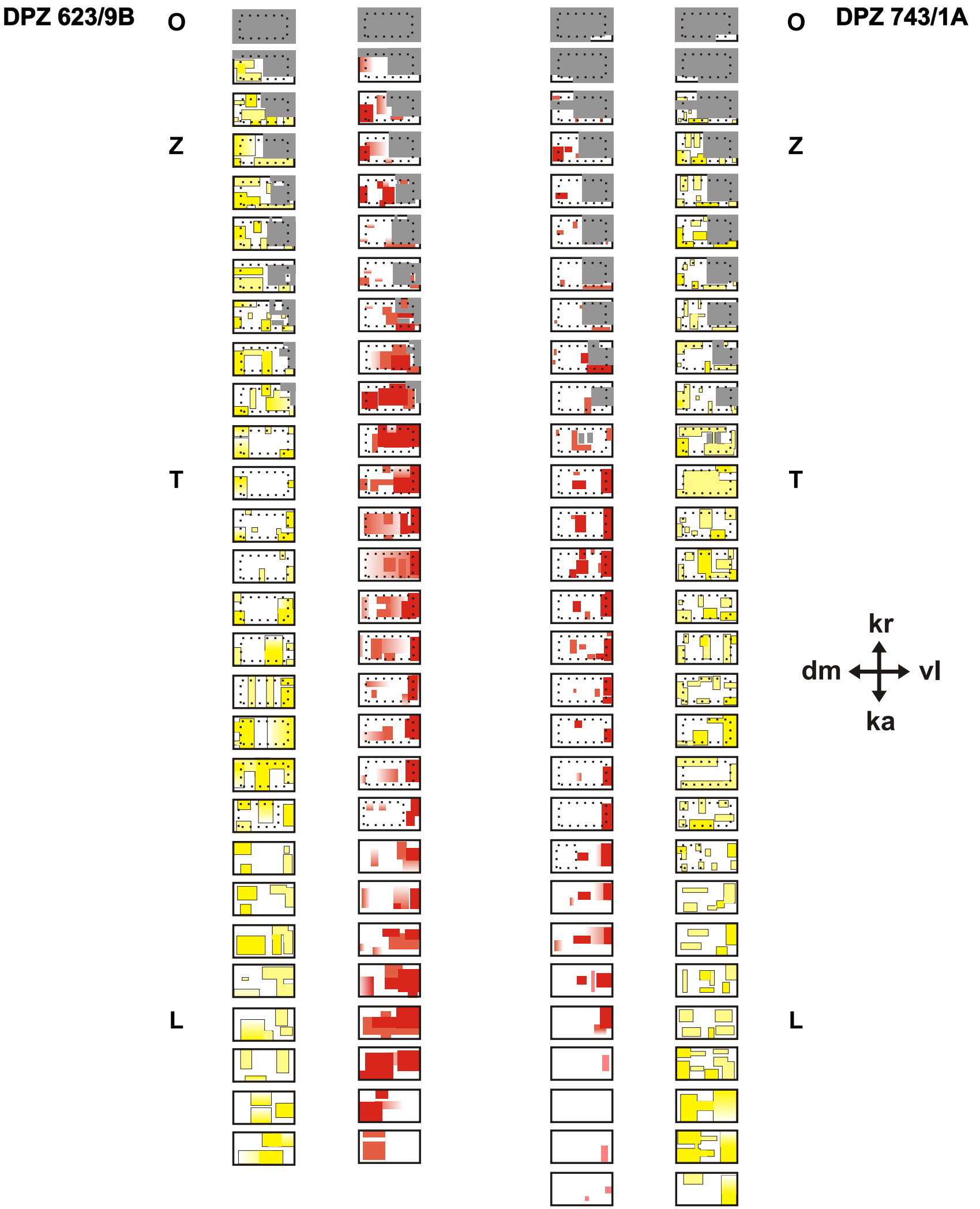

Abb. 30: Tupaia belangeri, Verteilung von Apoptosen (mit zunehmender Häufigkeit von rosa zu rot) und Mitosen (mit zunehmender Häufigkeit von blassgelb zu gelb) in den Dermomyotomen (schwarz umrandete Rechtecke) der rechten Körperseite des Phase-3-Embryos DPZ 623/9B (linke Spalte) und des Phase-4-Embryos DPZ 743/1A (rechte Spalte). Die detaillierte Befunddarstellung im Haupttext unterscheidet zwischen Dermomyotomen, aus denen entweder epaxiale und hypaxiale Myotome (Zervikalsomit (Z) 8 bis mindestens Thorakalsomit (T) 13) oder ausschließlich epaxiale Myotome (Okzipitalsomit (O) 2 bis Z7) hervorgehen. Beachte den Fortschritt der De-epithelialisierung (grau) der Dermomyotome sowie den Entwicklungsstand der Myotome (gepunktete Rechtecke). dm, dorsomedial; ka, kaudal; kr, kranial; L, lumbal; $\mathrm{vl}$, ventrolateral. 


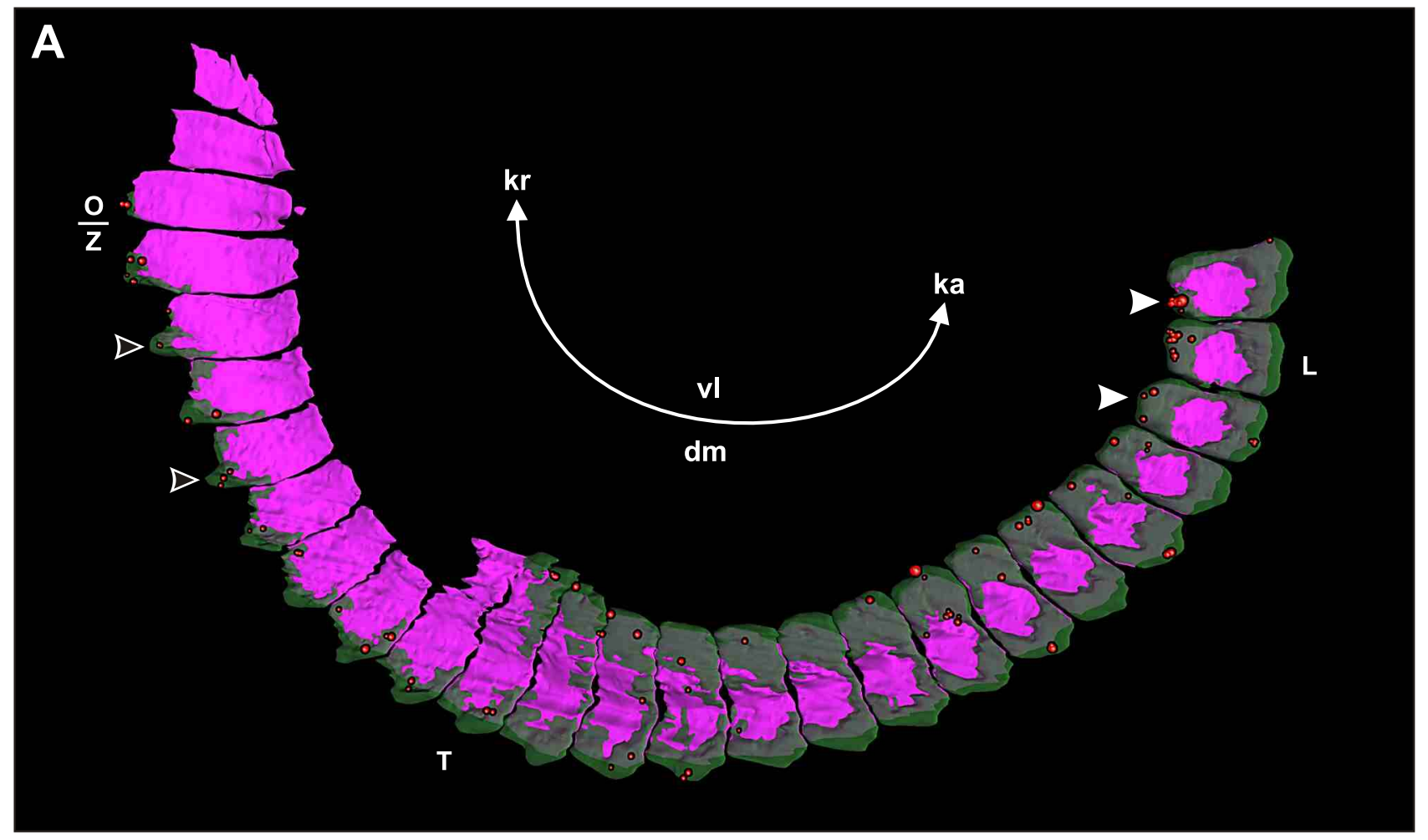

B

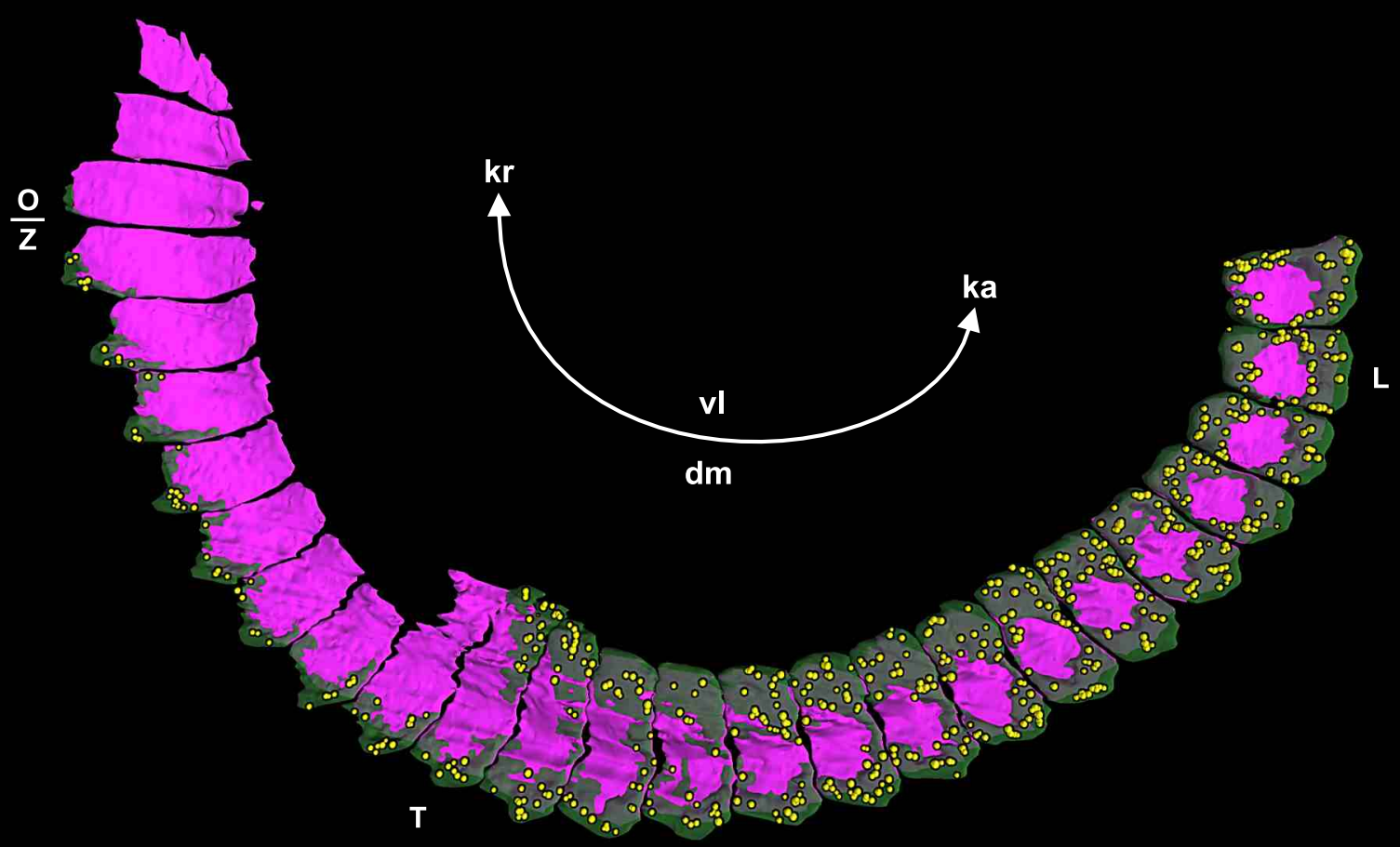

Abb. 31: Tupaia belangeri, Lateralansichten dreidimensionaler Rekonstruktionen von Apoptosen (rot, Radius 5fach, A) und Mitosen (gelb, Radius 2fach, B) in Dermomyotomen (grün, transparent) des Phase-5-Embryos DPZ 5061/C der rechten Körperseite (Okzipitalsomit (O) 2 bis Lumbalsomit (L) 2: Ende der Schnittserie). A: Diskrete Apoptosehäufungen finden sich (1) in der dorsomedialen Lippe (offene Pfeilköpfe) kranialer Dermomyotome (O4 bis Thorakalsomit (T) 1), (2) in der ventrolateralen Lippe (weiße Pfeilköpfe) kaudaler Dermomyotome (T10 bis L2) sowie (3) unmittelbar angrenzend an zentrale De-epithelialisierungszonen der Dermomyotome T8 bis T12. B: Verglichen mit den Apoptosen, finden sich Mitosen deutlich zahlreicher in allen (noch) epithelial verbliebenen Dermomyotomabschnitten. dm, dorsomedial; ka, kaudal; kr, kranial; magenta, Myotome; vl, ventrolateral; Z, zervikal. Maßstab $=250 \mu \mathrm{m}$. 

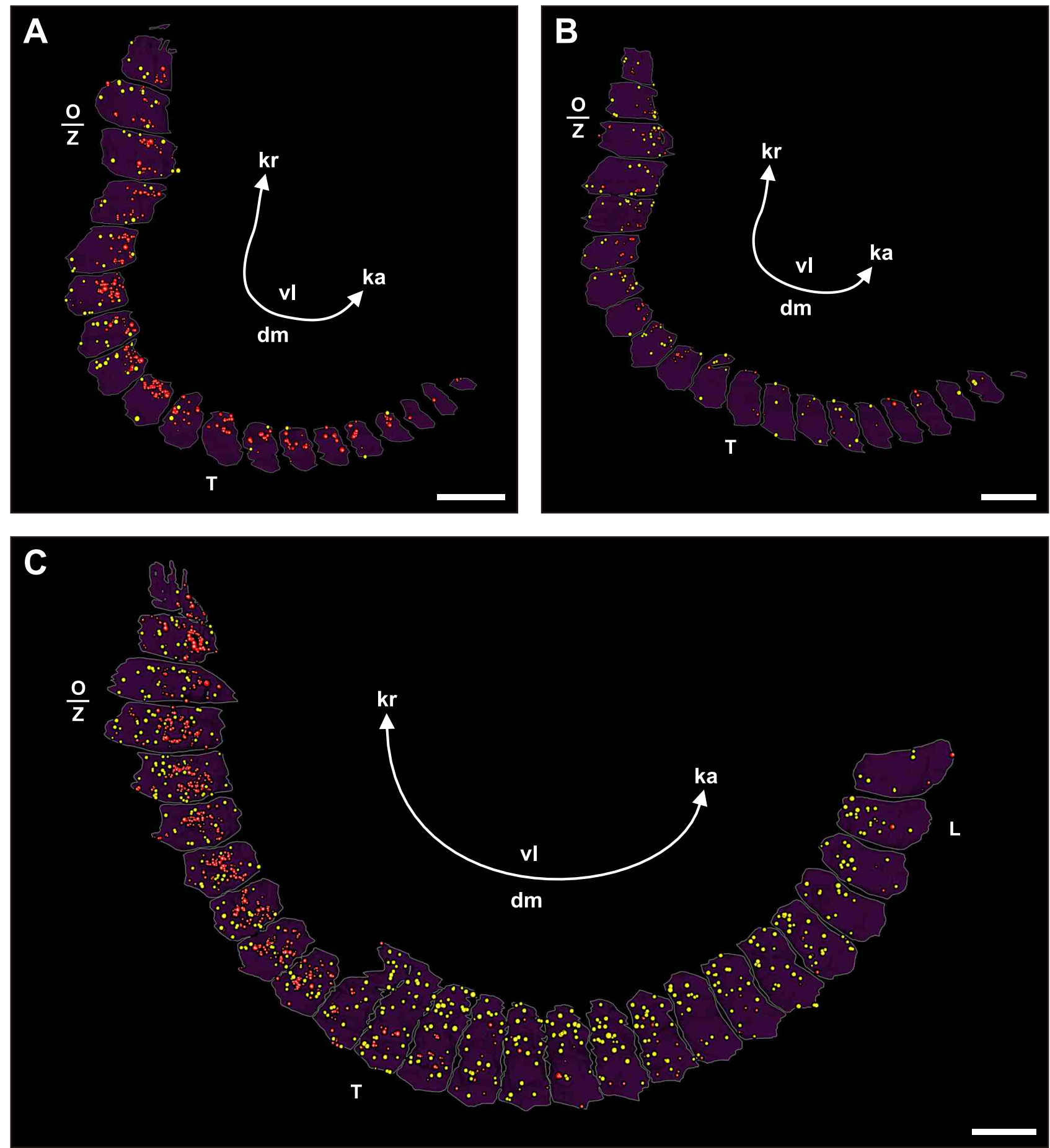

Abb. 32: Tupaia belangeri, Medialansichten dreidimensionaler Rekonstruktionen von Apoptosen (rot, Radius 5 fach) und Mitosen (gelb, Radius 2fach) in Myotomen (magenta, transparent) der linken Körperseite von Embryonen der Phasen 3 (DPZ 623/9B: A), 4 (DPZ 743/1A: B) und 5 (DPZ 5061/C: C). A, B: In den (in Phase 3 und 4 noch durchgehend dominierenden) epaxialen Myotomen steigt die Zahl apoptotischer und mitotischer Zellen von kaudal nach kranial an. Apoptosen sind vorrangig in der ventralen Myotomhälfte, Mitosen überwiegend an den Myotomrändern lokalisiert. C: In den hypaxialen Myotomen des Phase-5-Embryos (Zervikalsomit (Z) 8 bis mindestens Thorakalsomit (T) 13) treten Apoptosen praktisch nicht, Mitosen aber sehr zahlreich auf. In den epaxialen Myotomen nimmt die Zahl von Apoptosen und Mitosen, wie in den Phasen 3 (A) und 4 (B), von kaudal nach kranial zu. Die Apoptosen sind (wiederum) vorrangig in der ventralen Hälfte, die Mitosen (jetzt) dagegen überwiegend in der dorsalen Hälfte epaxialer Myotome lokalisiert. dm, dorsomedial; ka, kaudal; kr, kranial; L, lumbal; O, okzipital; vl, ventrolateral. Maßstäbe $=200 \mu \mathrm{m}$. 


\section{DISKUSSION}

\section{1. Methodische Rahmenbedingungen}

Für die Erhebung von Befunden zur Morphogenese der Somiten verwenden viele Arbeitsgruppen whole-mount-Techniken, bei denen Embryonen spezifisch vorbehandelt und anschließend im Ganzen fotografiert und analysiert werden. Durch Anwendung solcher Techniken, die zudem den Vorteil einer relativ raschen Durchführbarkeit haben, konnten erhebliche Fortschritte bei der Entschlüsselung und Dokumentation der Expressionsmuster von Genen, die in die Somitogenese eingreifen, erzielt werden (Palmeirim et al. 1997, Saga et al. 1997). Auch embryonale Fehlbildungen von Somiten und ihren Derivaten können, sofern ihr Phänotyp nicht allzu diskret ist, am whole mount rasch an einer großen Zahl von Individuen nachgewiesen werden (Burgess et al. 1996, Chiang et al. 1996, Asakura und Tapscott 1998). Die Beantwortung der Fragestellungen der vorliegenden Arbeit verlangte jedoch eine andere Herangehensweise. Beispielsweise sollte die Bildung intersomitischer Spalten auf Einzelzellniveau analysiert und die Position von Apoptosen oder Mitosen im paraxialen Mesoderm möglichst exakt (und ohne störende Überprojektionen) bestimmt werden. Darüber hinaus sollten auch räumlich ausgedehntere Organanlagen im intermediären Mesoderm sowie in den Seitenplatten auf Einzelzellniveau analysiert und im Zusammenhang mit der Morphogenese der Somiten dargestellt werden. Solche Fragestellungen können mit Hilfe des von unserer Arbeitsgruppe etablierten und in Vorarbeiten erfolgreich eingesetzten dreidimensionalen Rekonstruktionssystems „Huge Image“ (Knabe et al. 2002, 2009, Süss et al. 2002, Washausen et al. 2005, Scheffel 2009) optimal bearbeitet werden.

Für den Nachweis proliferierender oder apoptotischer Zellen steht mittlerweile eine Vielzahl von Methoden für die Routinediagnostik zur Verfügung. Ihr Spektrum reicht von Struktur-basierten Ansätzen bis hin zur Anwendung biochemischer Verfahren (zur Übersicht: Alison 1995, Iatropoulos und Williams 1996, Stadelmann und Lassmann 2000, Shtilbans et al. 2010). Die vorliegende Arbeit benötigt hochauflösende Techniken zur Struktur-basierten zellulären Diagnose nicht nur für die Identifikation von apoptotischen und proliferierenden Zellen, sondern bereits auch bei der Erhebung der basalen anatomischen Verhältnisse in den untersuchten Organanlagen. Beispielsweise ist es zwingend erforderlich, zwischen epithelialen und mesenchymalen Zellverbänden sicher unterscheiden zu können. Aus diesen Gründen kamen die routinemäßig in histologischen Laboren eingesetzten Einbettungs- und Schneideverfahren zur Herstellung von Paraffinschnittserien von Anfang an nicht in Betracht. Stattdessen verwenden wir extrem dünne Serienschnitte (Schnittdicke $=1 \mu \mathrm{m}$ ), deren Ausgangsmaterial für die Transmissionselektronenmikroskopie eingebettet wurde, die aber lichtmikroskopisch bei maximaler Auflösung analysiert werden können. Hierdurch ist einerseits sichergestellt, dass zelluläre Befunde mit der erforderlichen Präzision erhoben werden können. An- 
dererseits erlaubt der lichtmikroskopische Zugang, im Gegensatz zur Transmissionselektronenmikroskopie, die Analyse räumlich ausgedehnter Organanlagen.

\section{2. Segmentierung des paraxialen Mesoderms}

\section{2.1 Okzipitalsomiten}

Die Kenntnis der segmentalen Identität von Somiten ist nicht nur für die formale Beschreibung der Somitogenese wünschenswert, sondern, wie im Falle anderer metamer gegliederter Strukturen auch, Ziel eigenständiger und in hohem Maße interessanter Forschungsprojekte. Im Rahmen der vorliegenden Arbeit, die sich erstmals detailliert mit der Morphogenese der Somiten bei Tupaia belangeri auseinandersetzt, musste deshalb zunächst die Frage geklärt werden, wie viele Okzipitalsomiten maximal ausgebildet werden. Bei anderen Tiermodellen wird nicht nur diese Frage, sondern auch das Schicksal okzipitaler Somiten kontrovers diskutiert (Hunter 1935, Arey 1938, Reiter 1944, Hamilton und Hinsch 1956, Sensenig 1957, Hazelton 1970, Schemainda 1979, Müller F und O’Rahilly 1994, 2003, Huang et al. 1997, 2000).

Beim Haushuhn sind übereinstimmend maximal fünf Okzipitalsomiten nachgewiesen worden (Hazelton 1970, Noden 1983, Lim et al. 1987, Christ et al. 1988, Christ und Wilting 1992, Couly et al. 1993, Huang et al. 2000). Gleiches gilt für die Wachtel (Wilting et al. 1995). Im Gegensatz hierzu sollen sowohl Eidechsen (van Bemmelen 1889) als auch zahlreiche Säugetiere lediglich über vier Okzipitalsomiten verfügen (Labormaus: Kessel und Gruss 1991, Lufkin et al. 1992; Laborratte: Butcher 1929, Fukiishi und Morriss-Kay 1992; Hamster: Shedden und Wiley 1987; Kaninchen: Hunter 1935; Katze: Bates 1948). Auch bei menschlichen Embryonen sollen maximal vier Okzipitalsomiten vorkommen (Sensenig 1957, O’Rahilly und Müller F 1984, 2003, Müller F und O'Rahilly 1986, 2003). Abweichend hiervon postulieren allerdings sowohl Reiter (1944) als auch Christ und Wilting (1992) die Existenz von fünf Okzipitalsomiten.

Folgende in der Literatur beschriebene Kriterien, die nach Auffassung der Autoren dafür sprechen, dass (nur) vier Okzipitalsomiten existieren, sind auch bei Tupaia-Embryonen erfüllt (Abb. 2): (1) In der Okzipitalregion werden keine Spinalganglien ausgebildet (Kaninchen: Hunter 1935; Mensch: Müller F und O’Rahilly 1980, 1994, O’Rahilly und Müller F 1984, 2007). (2) Die erste zervikale Spinalganglienanlage ist kleiner als alle kaudal folgenden Spinalganglienanlagen (Mensch: O’Rahilly und Müller F 2003, 2007). (3) Der erste okzipitale Somit (O1) liegt unmittelbar kaudal von Rhombomer 7 (Mensch: O’Rahilly und Müller F 1984, Müller F und O'Rahilly 2003), das heißt auf Distanz zum otischen Primordium (Laborratte: Fukiishi und Morriss-Kay 1992; Mensch: 
Blechschmidt 1961, Müller F und O’Rahilly 2003). Abweichend hiervon liegt O1 beim Haushuhn (fünf Okzipitalsomiten!) unmittelbar kaudal des otischen Primordiums (Lim et al. 1987, Lumsden 1990, Huang et al. 1997). (4) O1 ist kleiner als alle kaudal folgenden Somiten (Eidechse: van Bemmelen 1889; Haushuhn: Williams 1910, Huang et al. 1997; Katze: Bates 1948; Mensch: Arey 1938, Sensenig 1957). (5) Von O2 abwärts nimmt die Größe der übrigen Okzipitalsomiten zu (Haushuhn: Platt 1889; Laborratte: Butcher 1929; Kaninchen: Hunter 1935; Mensch: Sensenig 1957). Auf Grund dieser zahlreichen Übereinstimmungen mit anderen bisher untersuchten Wirbeltieren gehen wir davon aus, dass Embryonen von Tupaia belangeri über maximal vier Okzipitalsomiten verfügen.

Ein weiteres Problem bei der Beurteilung von Okzipitalsomiten besteht darin, dass das Schicksal von O1 nicht vollständig geklärt ist. Demnach sind Sklerotom, Dermomyotom und Myotom von O1 bei menschlichen Embryonen strukturell ebenso lange nachweisbar wie bei den übrigen Okzipitalsomiten (O'Rahilly und Müller F 1984, Müller F und O'Rahilly 2003). Andere Autoren vertreten die Auffassung, dass sich O1 frühzeitig ,auflöst“ und beschreiben dieses Phänomen wechselnd als „disappearance“ (Laborratte: Butcher 1929; Haushuhn: Huang et al. 1997), „dedifferentiation“ (Mensch: Arey 1938), „dispersion“ (Haushuhn: Hamilton und Hinsch 1956) oder „disintegration“ (Wachtel: Wilting et al. 1995).

Aussagen über das Schicksal von Zellen des ersten okzipitalen Somiten können wir bei Tupaia belangeri bisher nicht machen. Bei Tupaia belangeri ,zerfällt“ O1 zwischen den Phasen 2 (19-Somitenstadium) und 3 (30-Somitenstadium). Bei anderen Spezies finden sich teils übereinstimmende, teils abweichende Angaben über den Zeitpunkt dieses „Zerfalls“: 6- bis 10-Somitenstadium (Kaninchen: Hunter 1935), 7-Somitenstadium (Lachmöwe: Rex 1905), 9-Somitenstadium (Laborratte: Butcher 1929), 10-Somitenstadium (Wachtel: Wilting et al. 1995), 10- bis 20-Somitenstadium (Mensch: Arey 1938), 19- bis 20-Somitenstadium (Mensch: Sensenig 1957), 30-Somitenstadium (Haushuhn: Hamilton und Hinsch 1956).

\section{2.2 Bildung intersomitischer Spalten}

In vielen Vorarbeiten, die sich schwerpunktmäßig mit den molekularen Mechanismen der Somitogenese befassen (zur Übersicht: Cinquin 2007, Dequéant und Pourquié 2008, Aulehla und Pourquié 2010, Gibb et al. 2010), wird der Prozess der intersomitischen Spaltbildung nicht im zellulären Detail untersucht. Passend zu der Erkenntnis, dass die „segmentation clock“ ein Segment nach dem anderen „gebiert“, wird vereinfachend angenommen, dass ein intersomitischer Spalt lediglich oberhalb des in Entstehung befindlichen Somiten S0 existiert (Pourquié und Tam 2001). Diejenigen Vorarbeiten, die sich eingehender mit dem formalen Ablauf der intersomitischen Spaltbildung aus- 
einandersetzen, kommen zu durchaus unterschiedlichen Ergebnissen. So vertreten Wilson PA et al. (1989) die Auffassung, dass die Spaltbildung bei Xenopus laevis von lateral nach medial fortschreitet. Bei verschiedenen Vertretern der Familie der Karpfenfische (Cyprinidae) läuft die intersomitische Spaltbildung möglicherweise unterschiedlich ab. Bei der Prachtbarbe (Barbus conchonius) beginnt sie zentral und dehnt sich anschließend nach medial und lateral aus (Wood und Thorogood 1994). Beim Zebrafisch (Danio rerio) beginnt sie dagegen, wie bei Xenopus laevis, offenbar lateral (Stickney et al. 2000, Barrios et al. 2003). Auch die für das Haushuhn vorgelegten Befunde sind insofern widersprüchlich, als der Beginn der Spaltbildung einerseits dorsolateral (Lipton und Jacobson 1974), andererseits medial angegeben wird (Kulesa und Fraser 2002). Untersuchungen zur Bildung intersomitischer Spalten bei Säugetieren wurden bisher lediglich für die Labormaus publiziert. Hier schreitet die Spaltbildung von medial nach lateral fort (Tam et al. 1982).

Diese teils übereinstimmenden, teils widersprüchlichen, teils lückenhaften Vorbefunde zum Ablauf der Bildung intersomitischer Spalten (zur Übersicht: Kulesa et al. 2007) veranlassten uns, die Spaltbildung bei Tupaia belangeri anhand lückenloser Semidünnschnittserien zu analysieren. Hierbei stellte sich heraus, dass S0, der definitionsgemäß vollständig durch einen Spalt von SI getrennt ist, kaudal keineswegs durchgehend mit dem ungegliederten paraxialen Mesoderm in Verbindung steht. Stattdessen finden sich auch hier bereits intersomitische Spaltanteile. Allerdings ist der Stand der Spaltbildung selbst in dreidimensionalen Rekonstruktionen, die wir standardmäßig im $8 \mu \mathrm{m}$-Intervall durchführen, nicht immer vollständig beurteilbar. Deshalb haben wir das Analyseintervall auf $2 \mu \mathrm{m}$ verkleinert und zusätzliche zweidimensionale Rekonstruktionen angefertigt (Abb. 4). Hierdurch konnten wir zeigen, dass die Spaltbildung bei Tupaia belangeri an zwei einander gegenüber liegenden Positionen gleichzeitig einsetzt: ventromedial und dorsolateral. Von diesen beiden Ausgangspositionen weitet sich der Spalt auf zentrale und - wahrscheinlich zuletzt - auf ventrolaterale Abschnitte des paraxialen Mesoderms aus (Abb. 5).

Vergleicht man die an Tupaia belangeri erhobenen Befunde mit den vermeintlich widersprüchlichen Vorbefunden anderer Arbeitsgruppen, lassen sich mindestens einige dieser „Widersprüche“ unter Einbeziehung methodischer Gesichtspunkte auflösen. Beispielsweise fällt auf, dass sämtliche Autoren, die die Bildung intersomitischer Spalten mittels Auflichtmikroskopie in der Dorsalansicht untersucht haben, einen lateralen Beginn der Spaltbildung favorisieren (Xenopus laevis: Wilson PA et al. 1989; Zebrafisch: Stickney et al. 2000; Haushuhn: Lipton und Jacobson 1974). Die von Tupaia belangeri angefertigten zweidimensionalen Rekonstruktionen zeigen, dass eine der beiden Startpositionen dorsolateral lokalisiert ist und dass die zweite, ventromediale Startposition bei ausschließlicher Betrachtung von dorsal höchstwahrscheinlich übersehen worden wäre (Abb. 5A-C). Daher ist es nicht ausgeschlossen, dass auch das Haushuhn, Xenopus laevis und/oder der Zebrafisch 
eine zweite, ventromediale Spaltinitialisierungszone besitzen.

Diejenigen Arbeitsgruppen, die die Spaltbildung live mittels Konfokal- oder Nomarski-DIC-Mikroskopie in frontal geführten optischen Schnittebenen beobachtet haben, kommen zu unterschiedlichen Ergebnissen. Demnach beginnt die Bildung intersomitischer Spalten beim Haushuhn medial (Kulesa und Fraser 2002), bei der Prachtbarbe dagegen zentral (Wood und Thorogood 1994). Alternativ erlauben die von Barrios et al. (2003) zur Verfügung gestellten Videos den Schluss, dass die Spaltbildung beim Zebrafisch lateral einsetzt. Die kritische Würdigung dieser zweiten Befundserie erfordert eine Spezies-spezifische Besprechung.

Beim Zebrafisch stimmen die einerseits durch konfokale Mikroskopie (Barrios et al. 2003), andererseits auflichtmikroskopisch (Stickney et al. 2000) erhobenen Befunde dahingehend überein, dass die Bildung intersomitischer Spalten lateral beginnt. Diese Übereinstimmung ist umso „verständlicher“", als der Befundung in beiden Fällen Dorsalansichten zugrunde lagen. Im Umkehrschluss bedeutet dies, dass eine mögliche zweite, ventromedial lokalisierte Initialisierungszone, die wir bei Tupaia belangeri nachweisen konnten (Abb. 5), mit hoher Wahrscheinlichkeit in beiden Fällen übersehen worden wäre. Ob eine solche zweite Spaltinitialisierungszone auch beim Zebrafisch existiert, muss durch Anschlussuntersuchungen geklärt werden.

Angesichts der Tatsache, dass der laterale Beginn der intersomitischen Spaltbildung beim Zebrafisch durch zwei unabhängige Methoden übereinstimmend festgestellt worden ist, hätten wir erwartet, dass auch bei anderen Mitgliedern derselben Familie (Karpfenfische, Cyprinidae) prinzipiell identische Befunde erhoben werden. Stattdessen setzt die Spaltbildung bei der Prachtbarbe offenbar zentral ein (Wood und Thorogood 1994). Befundet wurde jeweils in zwei frontalen Schnittebenen, die durch die dorsale beziehungsweise ventrale Hälfte des paraxialen Mesoderms gelegt worden waren. Darüber hinaus stellen die Autoren fest (S. 157), dass zentrale Spaltinitialisierungszonen (,,centres“) ,generally first appear across the entire dorso-ventral axis of the paraxial mesenchyme at a distance from the notochord, (...)“. Die vergleichende Würdigung legt den Schluss nahe, dass die Spaltbildungssequenzen bei Tupaia belangeri und mindestens einem Teil der Karpfenfische unterschiedlich sind. Beim Haushuhn hatten Lipton und Jacobson (1974) mittels dorsaler Auflichtmikroskopie festgestellt, dass die Bildung intersomitischer Spalten lateral beginnt. Zusätzlich fanden diese Autoren in Sagittalschnitten, wie zuvor bereits auch Platt (1889), früh entstehende dorsale Spaltabschnitte. Dagegen sprechen sich Kulesa und Fraser (2002) auf der Grundlage konfokal beurteilter Frontalebenen für einen medialen Beginn der Spaltbildung aus. Ob die Bildung intersomitischer Spalten auch beim Haushuhn, wie die hier am Beispiel von Tupaia belangeri vorgestellten Befunde nahelegen, von zwei entgegengesetzten Fronten gleichzeitig dorsolateral und ventromedial 
einsetzt, muss durch Anschlussuntersuchungen geklärt werden.

Die von Kulesa und Fraser (2002) publizierten Untersuchungen werfen noch einen weiteren interessanten Aspekt auf. Demnach scheint die (im Regelfall stillschweigend vorausgesetzte) Annahme, dass sich ein „statischer“ intersomitischer Spalt plan in der transversalen Ebene erstreckt, für das Haushuhn nicht zuzutreffen. Stattdessen wird die Spaltbildung von Zellbewegungen begleitet, die im Zentrum des paraxialen Mesoderms von kaudal nach kranial, in peripheren Abschnitten des paraxialen Mesoderms dagegen von kranial nach kaudal gerichtet sind. Hieraus resultiert in Momentaufnahmen ein kaudal kugelförmiger Somit S0 („ball“), der komplementär in den unterlagernden, konkav zur Pfanne (,,socket“) eingezogenen Somiten S-I eingesenkt ist (Kulesa und Fraser 2002). Bisher ist nicht bekannt, ob die Somitogenese auch bei anderen Wirbeltieren einem solchen „balland-socket"-Modell folgt. Sollte dies der Fall sein, müsste bei der Beurteilung von Befunden in nur einer Schnittebene bedacht werden, dass der beim Haushuhn beschriebene, unerwarteterweise temporär bogige Verlauf des intersomitischen Spaltes nur in wenigen günstigen Fällen erfasst werden kann. Einschränkungen ergäben sich aber auch für solche Befunde, die, wie im vorliegenden Fall am Beispiel von Tupaia belangeri, auf der Grundlage zwei- oder dreidimensionaler Rekonstruktionen erhoben worden sind. Diese letztgenannten Einschränkungen beruhen aber nicht auf prinzipiellen Projektions-bedingten Darstellungsschwierigkeiten der Methode, sondern auf der Tatsache, dass auch sehr detailgetreue Rekonstruktionen lediglich Momentaufnahmen eines biologischen Prozesses einfangen können. Um wirklich zu beweisen (oder auszuschließen), dass „ball-and-socket“Konfigurationen bei Tupaia belangeri vorkommen, hätte eine den Rahmen der vorliegenden Arbeit sprengende Zahl von Embryonen rekonstruiert werden müssen.

Wie oben bereits dargelegt, könnte das für Tupaia belangeri vorgeschlagene „Zwei-Fronten-Modell“ (Abb. 5), unabhängig von der „,ball-and-socket“-Problematik, auch bei anderen Wirbeltieren für die Bildung intersomitischer Spalten relevant sein. Zur Überprüfung dieser Arbeitshypothese sind Folgeuntersuchungen erforderlich, die die Spaltbildung auch bei anderen Wirbeltieren dreidimensional erfassen. In diese Untersuchungen sollten auch Mesodermabschnitte kaudal von S-I einbezogen werden. Bei Tupaia belangeri setzt die Spaltbildung am Übergang S-I/S-II offenbar ventromedial ein (Abb. 6E). Wir können daher nicht ausschließen, dass das „Zwei-Fronten-Modell“ nicht strikt simultan, sondern mit geringer zeitlicher Verzögerung sukzessiv abläuft.

Das vorgeschlagene „Zwei-Fronten-Modell““ wird durch experimentelle Befunde anderer Arbeitsgruppen zusätzlich gestützt. So führt die Inaktivierung des in ventralen Abschnitten des paraxialen Mesoderms exprimierten Adhäsionsmoleküls paraxiales Protocadherin (PAPC) bei der Labormaus zu einer Unterdrückung der Spaltbildung in ventralen, nicht aber in dorsalen Abschnitten des par- 
axialen Mesoderms (Rhee et al. 2003). Auch die Entfernung der Chorda dorsalis bei Hühnerembryonen führt zu Störungen im Ablauf der Somitenbildung (Resende et al. 2010). Interessanterweise besteht diese Störung in einer Verzögerung des Segmentierungsprozesses. Die am Beispiel von Tupaia belangeri erhobenen Befunde könnten dazu beitragen, diese Verzögerung zu erklären. Bei Tupaia belangeri geht die Spaltbildung von zwei (offenbar voneinander unabhängigen) dorsolateralen und ventromedialen Spaltinitialisierungszonen aus (Abb. 5). Unter Berücksichtigung aller Signalzentren, die nach aktuellem Kenntnisstand Einfluss auf die Morphogenese der Somiten nehmen (zur Übersicht: Marcelle et al. 2002), könnten Spalt-induzierende Faktoren bei Tupaia belangeri einerseits von der Chorda dorsalis, andererseits vom dorsalen Oberflächenektoderm abgegeben werden. Vorausgesetzt, dass beispielsweise die vom Oberflächenektoderm gebildeten Faktoren in der Lage wären, dorsal beginnende, letztlich aber vollständige intersomitische Spalten zu induzieren, so würde der „Wegfall“ des zweiten, jeweils gegenüber liegenden Signalzentrums (hier: die von Resende et al. (2010) bei Hühnerembryonen entfernte Chorda dorsalis) hypothetisch zu einer verlangsamten, aber doch vollständigen Segmentierung des paraxialen Mesoderms führen.

\section{2.3 Grenzzellen und mesenchymal-epitheliale Transition (MET)}

Offensichtlich existiert ein enger zeitlicher Zusammenhang zwischen der Segmentierung und der mesenchymal-epithelialen Transition (MET) des paraxialen Mesoderms. Weniger klar ist, ob und inwiefern kausale Zusammenhänge zwischen beiden Prozessen bestehen. Diese Wissenslücke beruht unter anderem darauf, dass Zellen, die die MET durchlaufen, strukturell und molekular schwierig zu klassifizieren sind. Nicht mehr vollständig mesenchymale, sondern bereits „Epithel-ähnliche“ Vorläuferzellen sind sowohl beim Haushuhn (Christ et al. 1972, Duband et al. 1987, Jacob et al. 1991, Schmidt et al. 2001) als auch bei der Labormaus (Tam et al. 1982) nachgewiesen worden. Solche Epithel-ähnlichen Zellen unterscheiden sich demnach von Mesenchymzellen dadurch, dass sie wenige Fortsätze sowie elongierte, bereits parallel zueinander ausgerichtete Zellkörper besitzen. Der zwischen Epithel-ähnlichen Zellen zunächst noch verbleibende Interzellularraum vermindert sich mit zunehmender epithelialer Differenzierung.

Bellairs (1979) vermutete als Erste, dass ein Zusammenhang zwischen MET und Segmentierung des paraxialen Mesoderms besteht. Ihre rasterelektronenmikroskopischen Aufnahmen von Hühnerembryonen belegen, dass „elongated cells“ zunächst dorsal und erst verzögert auch ventral im zusammenhängenden paraxialen Mesoderm auftreten. Diese Beobachtung führte zu der Vermutung, dass der dorsale Beginn der MET „,may be related to the fact that segmentation starts dorsally“ (S. 235).

Im unsegmentierten paraxialen Mesoderm der Prachtbarbe beobachteten Wood und Thorogood 
(1994) unter Einsatz der Nomarski-DIC-Mikroskopie, dass Zellgruppen mit „a “palisade” appearance of the nuclei“" (S. 153) zuallererst medial auftreten. Angesichts der Tatsache, dass die Bildung intersomitischer Spalten bei der Prachtbarbe zentral beginnt (Wood und Thorogood 1994), besteht für einen kausalen Zusammenhang zwischen MET und Spaltbildung kein Anhalt. Stattdessen vermuten die Autoren, dass die beobachteten palisadenartig angeordneten Zellen die Abgliederung der Chorda dorsalis gegen das paraxiale Mesoderm unterstützen. Bei Tupaia belangeri eilt die Abgliederung der Chorda dorsalis dem Auftreten palisadenartig angeordneter Epithel-ähnlicher Zellen in medialen Abschnitten des unsegmentierten paraxialen Mesoderms um mehrere Segmenthöhen voraus (vergleiche Abb. 3 und 6). Deshalb ist ein kausaler Zusammenhang zwischen der MET des paraxialen Mesoderms und der Abgliederung der Chorda dorsalis hier eher unwahrscheinlich.

Das erste definitive Postulat eines Zusammenhanges zwischen der Bildung intersomitischer Spalten und der MET des paraxialen Mesoderms formulierten Kulesa und Fraser (2002). Mittels konfokalmikroskopischer Technik weisen diese Autoren am Beispiel des Haushuhns nach, dass radiär auf das Zentrum von S0 ausgerichtete Epithelzellen zunächst aufseiten des Spaltes SI/S0 sowie in der dem Neuralrohr zugewandten medialen Wand von S0 auftreten. Erst danach dehnt sich die MET innerhalb von S0 nach kaudal aus. Kulesa und Fraser dokumentieren darüber hinaus (2002, Videos im Supplement, von den Autoren unkommentiert), dass radiär auf das Zentrum von S0 ausgerichtete Epithelzellen in engem zeitlichen und räumlichen Zusammenhang mit der Spaltbildung S0/S-I auftreten. Vergleichbare Epithelzellen kommen zu diesem Zeitpunkt in kranialen Abschnitten von S-I nicht vor. Auch bei Tupaia belangeri finden sich radiär angeordnete Zellen mit epithelialem Charakter zahlreich in kaudalen Abschnitten von S0, sehr viel seltener dagegen in kranialen Abschnitten von S-I (Abb. 6B-D). Zusätzlich konnten wir bei Tupaia belangeri erstmals Populationen Epithel-ähnlicher „Grenzzellen“ strukturell identifizieren, die an der Bildung intersomitischer Spalten beteiligt sein könnten. Solche parallel zur Spaltebene ausgerichteten, teils die Spaltposition „,vorwegnehmenden“, teils den eben gebildeten Spalt flankierenden Grenzzellen existieren nicht nur am Übergang S0/S-I (Abb. 6B-D), sondern auch, weniger deutlich ausgeprägt, ,eine Etage“ tiefer (SI/S-II: Abb. 6E) beziehungsweise höher (SI/S0: Abb. 6F).

Experimentelle Hinweise darauf, dass die Bildung intersomitischer Spalten tatsächlich durch spezifische, strukturell allerdings noch nicht identifizierte Populationen von Grenzzellen unterstützt wird, liegen bereits vor. Sato et al. (2002) implantierten Wachtelzellen, die aus der prospektiven Spaltbildungszone S-I/S-II gewonnen wurden, in zentrale Abschnitte prospektiver Somiten von Hühnerembryonen. Unter dem Einfluss der transplantierten Zellen entstanden künstliche Spalten auch in solchen Positionen, die bei ungestörter Entwicklung niemals einen ,intersomitischen Spalt“ ausbilden würden. Hierbei treten transplantierte Wachtelzellen entweder nur kaudal oder zusätzlich 
auch kranial eines solchen induzierten Spaltes auf. Ausschließlich kranial des induzierten Spaltes auftretende Wachtelzellen wurden dagegen nicht beobachtet. Deshalb postulierten Sato et al. (2002) die Existenz regulatorisch dominanter, Spalt-induzierender „posterior border cells“, die, möglicherweise unter Mitwirkung von lunatic fringe, auch Eigenschaften einer postulierten zweiten, an der Spaltbildung beteiligten Zellgruppe (,,anterior border cells“) bestimmen sollen. Inwieweit die bei Tupaia belangeri strukturell dokumentierten mutmaßlichen Grenzzellen ein Pendant solcher „posterior border cells“ und/oder ,anterior border cells“ darstellen, muss durch Folgeuntersuchungen geklärt werden. Gleiches gilt für die Einordnung der schon 1981 bei der Labormaus in der Position prospektiver intersomitischer Spalten beschriebenen, transversal orientierten Zellgruppen (Tam 1981). Diese als mesenchymal klassifizierten Zellen sind in derb strukturierten Bündeln angeordnet und unterscheiden sich daher erheblich von den bei Tupaia belangeri nachgewiesenen Formationen filigraner Grenzzellen (Abb. 6).

Hinsichtlich der Herkunft der bei Tupaia belangeri in der Position intersomitischer Spalten nachgewiesenen mutmaßlichen Grenzzellen sind noch viele Fragen offen. Zeigen können wir bisher, dass solche Grenzzellformationen auf Höhe des Spaltes S0/S-I mit Formationen Epithel-ähnlicher Zellen in Verbindung stehen, die frühzeitig in der medialen Wand von S-I nachweisbar sind. Grenzzellen könnten sich von solchen medialen Epithelzellen ableiten. Darüber hinaus könnte der skizzierte Befund einen Schlüssel zur Klärung der Frage liefern, durch welche Morphogeneseprozesse die MET und die Segmentierung des paraxialen Mesoderms miteinander gekoppelt sind. Wir vermuten, dass die bei Tupaia belangeri in S-I beobachtete Konstellation kranialer Grenzzellen und Epithel-ähnlicher medialer Somitenzellen (Abb. 6B-D) dem am Beispiel des Haushuhns dokumentierten frühzeitigen Auftreten ausdifferenzierter Epithelzellen in kraniomedialen Abschnitten von S0 vorausgeht (Kulesa und Fraser 2002). Passend zu dieser Hypothese finden sich auch beim Haushuhn Gruppen Epithel-ähnlicher Zellen in der medialen Wand von S-I (Kulesa und Fraser 2002: Abb. 3, S. 992, beziehungsweise Video 4 im Supplement).

Folgeuntersuchungen werden sich auch mit dem Schicksal der bei Tupaia belangeri dokumentierten Grenzzellen auseinandersetzen. Der vorläufige Befund, dass im Bereich des intersomitischen Spaltes SI/S0 nicht nur parallel zum Spalt angeordnete Grenzzellen und radiär auf das künftige Somitenzentrum ausgerichtete Epithelzellen, sondern auch „Zwischenformen“ vorkommen (Abb. 6F), spricht dafür, dass mindestens ein Teil der postulierten Grenzzellen sich zu typischen, radiär ausgerichteten Epithelzellen des Somiten umgruppiert. Unter Würdigung der separat diskutierten Apoptosebefunde kommt - zusätzlich oder alternativ - in Betracht, dass mindestens ein Teil der Grenzzellen nach erfolgter Spaltbildung apoptotisch eliminiert wird. 


\section{2.4 Apoptosemuster}

Schon die frühesten systematischen Untersuchungen zum Vorkommen von Zelltod während der Embryonalentwicklung förderten zutage, dass abgestorbene Zellen häufig im Rahmen von Abschnürungs-, Aushöhlungs- oder Verschmelzungsprozessen auftreten (Ernst 1926, Glücksmann 1951). Allerdings darf das mittlerweile umfangreich dokumentierte Auftreten von (programmiertem) Zelltod im Rahmen der frühen Embryonalentwicklung nicht darüber hinwegtäuschen, dass schlüssige Beweise für einen kausalen „,mechanischen“ Beitrag solcher Zelltodereignisse zu den oben beispielhaft skizzierten Morphogeneseprozessen bis zum heutigen Tage weitgehend ausstehen. Eine ausgiebige Erörterung dieser Problematik am Beispiel der besonders kontrovers diskutierten Funktionen von Apoptoseereignissen bei der Fusion der Neuralfalten verfasste Scheffel (2009).

Hinsichtlich möglicher Beiträge von Apoptoseereignissen zur Abgliederung von Somiten aus dem paraxialen Mesoderm lässt sich in der Literatur Folgendes eruieren. Bei Hühnerembryonen der Hamburger-Hamilton-(HH)-Stadien (Hamburger und Hamilton 1951) HH10 und HH13 haben Jeffs und Osmond (1992) das Vorkommen von Apoptosen im unsegmentierten paraxialen Mesoderm mittels whole-mount-Vitalfärbungen untersucht. Wie später auch Hirata und Hall (2000: HH9 bis HH20), die apoptotische Zellen mit der spezifischeren TUNEL-Methode nachgewiesen haben (Gavrieli et al. 1992), finden Jeffs und Osmond (1992) nur sehr wenige apoptotische Zellen im unsegmentierten paraxialen Mesoderm. Ein Beitrag von Apoptoseprozessen zur Segmentierung des paraxialen Mesoderms ist beim Haushuhn daher unwahrscheinlich.

Beim Zebrafisch stellt sich die Beurteilung der Befundlage komplizierter dar. Hier treten, anders als beim Haushuhn, zahlreiche TUNEL-positive Apoptosen im unsegmentierten paraxialen Mesoderm auf (Cole und Ross 2001: 12 bis 22 Stunden nach Befruchtung). Allerdings ist die von den Autoren unter Verweis auf Glücksmann (1951) favorisierte morphogenetische Rolle des Zelltodes bei der Etablierung intersomitischer Spalten in dem publizierten Bildmaterial (Cole und Ross 2001: Abb. 5, S. 133) schwer nachvollziehbar, weil sich kaum Anhalt für ein bevorzugtes Auftreten von Apoptoseprozessen an den mutmaßlichen Grenzen zwischen prospektiven Somiten findet.

Die am Beispiel von Tupaia belangeri angefertigten dreidimensionalen Rekonstruktionen zeigen, dass ein Beitrag von Apoptoseereignissen zur Bildung intersomitischer Spalten auch bei dieser Primaten-nahen Spezies eher unwahrscheinlich ist (Abb. 13B, 18D, G; 20A, 21A). Nach unserer Auffassung ist hierfür schon die Zahl nachweisbarer Apoptoseereignisse zu gering. Auch eine präferenzielle Positionierung apoptotischer Zellen im Bereich prospektiver intersomitischer Spalten, die einen solchen funktionellen Zusammenhang wahrscheinlich machen würde, ist nicht gegeben. Zusätzlich haben wir überprüft, ob Spalt-assoziierte apoptotische Zellen unmittelbar nach Etablierung 
des intersomitischen Spaltes gezielt auftreten. Aber auch für diese Konstellation, die auf ein programmiertes Absterben nicht mehr benötigter Grenzzellen hinweisen könnte, fanden wir bisher keinen überzeugenden Anhalt (Abb. 23A, B).

Kausale Zusammenhänge zwischen dem Vorkommen von Zelltod und der Morphogenese des Somitozöls wurden schon frühzeitig vermutet. Entgegen der durch den Namen „Somitenhöhle“ möglicherweise geweckten Erwartungen, handelt es sich hierbei allerdings nicht um einen sekundär entstehenden Hohlraum, sondern um eine von Mesenchymzellen besiedelte zentrale Zone, deren Textur erheblich lockerer ist als diejenige des umgebenden Somitenepithels (Christ et al. 2007). Zentral im epithelialen Somiten positionierte Apoptosen, die der Etablierung des Somitozöls vorangingen, stünden daher weniger im Dienste einer „Kavitation“, sondern trügen eher zur Elimination (möglicherweise falsch spezifizierter) Vorläuferzellen bei, die beim Haushuhn offenbar wenigstens zum Teil aus dem Somitenepithel hervorgehen (Langman und Nelson 1968, Wong GK et al. 1993).

Noch geleitet von der mechanistischen Vorstellung einer Hohlraumbildung postulierte schon Ernst (1926, S. 252), dass die „Degeneration von Zellen ursächliche Bedeutung bei der Entstehung der Somitenhöhle (...)“ von Wirbeltieren haben soll. Peter (1936, S. 428) widerspricht diesem sehr weitreichenden Postulat, weil er zumindest bei Eidechsenembryonen eine solche morphogenetische Degeneration mangels Masse ,nicht anerkennen kann“. Auch beim Haushuhn (Langman und Nelson 1968, Hirata und Hall 2000) und bei Tupaia belangeri finden sich nur geringfügige Mengen apoptotischer Zellen im Zentrum der epithelialen Somiten. Insofern ist ein maßgeblicher Einfluss von Apoptoseereignissen auf die zelluläre Zusammensetzung des Somitozöls - unter Würdigung aller bisher zu dieser Fragestellung publizierten Arbeiten - eher unwahrscheinlich.

\section{2.5 Proliferationsmuster}

Mit Hilfe dreidimensionaler Rekonstruktionen wollten wir überprüfen, ob benachbarte, molekular definierte prospektive Somiten (zur Übersicht: Pourquié und Tam 2001) bereits so „autark“ sind, dass sie sich durch ihr jeweiliges Proliferationsmuster voneinander abgrenzen lassen. Gut vorstellbar wäre beispielsweise, dass Cluster mitotischer Zellen, wie in den abgegliederten Somiten (Abb. 23A), überwiegend im Zentrum prospektiver Somiten aufträten. Unsere Rekonstruktionen belegen, dass tatsächlich Cluster mitotischer Zellen im ungegliederten paraxialen Mesoderm vorkommen, die bisweilen sogar recht genau die kraniokaudale Ausdehnung eines prospektiven Somiten ausfüllen (Abb. 14B, 18F, I; 20B, 21B). Allerdings sind solche Koinzidenzen selten und im Regelfall auch nicht simultan auf beiden Körperseiten anzutreffen. Deshalb können wir die oben aufgeworfene Hypothese am Beispiel von Tupaia belangeri nicht aufrechterhalten. 
Bei der Labormaus ist der Mitoseindex (MI) im ungegliederten paraxialen Mesoderm mit Werten zwischen 4,5\% bis 11,5\% geringfügig höher als in den bereits abgegliederten Somiten (MI: 3,1\% bis 7,3\%, Tam 1981). Auch beim Haushuhn stellten Stern und Bellairs (1984) nur geringgradige, statistisch nicht signifikante Unterschiede hinsichtlich des Proliferationsverhaltens von paraxialem Mesoderm (MI: 6,5\%) und epithelialen Somiten (MI: 4,7\%) fest. Die am Beispiel von Tupaia belangeri erstellten dreidimensionalen Rekonstruktionen lassen sich ebenfalls dahingehend interpretieren, dass sich die Mitosehäufigkeiten im ungegliederten paraxialen Mesoderm und in den bereits abgegliederten Somiten kaum voneinander unterscheiden. Ein Vergleich mit aktuellen quantitativen Befunden beim Haushuhn (Venters et al. 2008) erfordert zusätzliche quantitative Untersuchungen bei Tupaia belangeri. Venters et al. (2008) fanden, dass die Gesamtzahl paraxialer Mesodermzellen linear zwischen S-VI und SVIII ansteigt und sich hierbei verdoppelt. Dagegen verdoppelt sich die Zahl mitotischer paraxialer Mesodermzellen relativ steil zwischen S-I und SI.

\section{3. Apoptose- und Proliferationsmuster in den epithelialen Somiten}

Bei der Festlegung von Zellschicksalen im embryonalen Neuroepithel kommt es entscheidend darauf an, welche Positionen (mitotische oder apoptotische) Vorläuferzellen entlang der apikobasalen Achse einnehmen (Boya und de la Rosa 2005, Latasa et al. 2009). Deswegen haben wir untersucht, ob solche regionalen Spezifika auch im Somitenepithel nachweisbar sind. Alle Vorarbeiten an anderen Wirbeltieren stimmen darin überein, dass Mitosen vorrangig apikal im Somitenepithel auftreten (Eidechse: Peter 1936; Haushuhn: Trelstad et al. 1967, Langman und Nelson 1968, Christ et al. 1972, Stern und Bellairs 1984; Laborratte: Butcher 1929; Mensch: Blechschmidt 1969). Passend hierzu nehmen auch im Somitenepithel von Tupaia belangeri Mitosen überwiegend apikale Positionen ein (Abb. 23). Voruntersuchungen über die Position von Apoptosen im Somitenepithel sind rar. Demnach treten Apoptosen beim Haushuhn (Hirata und Hall 2000) wie auch beim Zebrafisch (Cole und Ross 2001) sowohl apikal als auch basal auf. Bei Tupaia belangeri besteht dagegen ein Trend zur Basalseite des Epithels (Abb. 23). „Entwicklungsfehler“ der Vorläuferzellen, die vermutlich auch im Somitenepithel, wie im Neuroepithel, interkinetische Migrationen durchlaufen (Langman und Nelson 1968, Stern und Bellairs 1984), würden deshalb bei Tupaia belangeri bevorzugt in basalen Differenzierungszonen durch Apoptose korrigiert werden.

Anschließend haben wir orientierend untersucht, ob Apoptosen und Mitosen im Somitenepithel auch spezifische Verteilungsmuster entlang der kraniokaudalen, mediolateralen und/oder dorsoventralen Achse des Embryos aufweisen. Solche regionalen Unterschiede könnten beispielsweise für die Entstehung von Sklerotomen und Dermomyotomen bedeutsam sein. Erstaunlicherweise liegen 
$\mathrm{zu}$ dieser Frage bisher nur wenige (an Hühnerembryonen erhobene) Daten vor. Hirata und Hall (2000) stellen fest, dass Apoptosen überwiegend im ventralen Somitenepithel positioniert sind (HH11 bis HH14). Kahane et al. (1998a: Abb. 1B, S. 61) weisen mittels Bromodeoxyuridin(BrdU)-Färbungen nach, dass postmitotische Zellen frühzeitig in dorsalen Abschnitten der medialen Somitenwand auftreten, von denen sich die ersten Myotomzellen ableiten. Bei Tupaia belangeri können wir bisher keine Ortspräferenzen von Apoptosen oder Mitosen entlang der drei Hauptachsen dokumentieren (Abb. 23A, B).

Offen ist nach wie vor die Frage, inwieweit Apoptoseereignisse zum „Zerfall“ der Okzipitalsomiten beitragen. Hinweise darauf, dass sich $\mathrm{O} 1$ (und möglicherweise auch andere Okzipitalsomiten) durch programmierten Zelltod auflösen, gibt es bei Xenopus laevis (Chung et al. 1989), bei der Labormaus (Ernst 1926) sowie bei einigen weiteren Säugetierarten (Glücksmann 1951). Bei Tupaia belangeri haben wir bisher keinen Anhalt für solche apoptotischen Eliminationen. Interessanterweise deutet sich aber bei Tupaia-Embryonen der Phasen 1 und 2 ein Proliferationsminimum in den Somiten (und ihren Derivaten) kranial von O4 an (Abb. 24C, F; 28C, F). Hierdurch könnte die „Auflösung“ von Okzipitalsomiten mindestens zum Teil ,erklärt“ werden. Passend zu dieser Hypothese nimmt die Expression von pax-1, einem Mitglied der paired box-Genfamilie, das für die Aufrechterhaltung hoher Proliferationsraten notwendig ist (Wilting et al. 1994, Furumoto et al. 1999, Peters et al. 1999), in den okzipitalen Sklerotomen der Wachtel von kaudal nach kranial immer weiter ab (Wilting et al. 1995).

\section{4. Apoptose- und Proliferationsmuster in der Chorda dorsalis}

Die Chorda dorsalis greift als Signalzentrum maßgeblich in die Entwicklung von Somiten und Neuralrohr ein (zur Übersicht: Fleming et al. 2001, Stemple 2004, 2005). Deshalb wollten wir wissen, ob sich zeitliche, räumliche und funktionelle Bezüge zwischen den Proliferations- und Apoptosemustern in der Chorda dorsalis und der Entwicklung von Somiten herstellen lassen. Publizierte systematische Vorarbeiten zum Proliferationsverhalten der Chorda dorsalis liegen bisher nicht vor. Dagegen wurde das Vorkommen von Apoptoseprozessen mehrfach dokumentiert. Hierbei zeigte sich, dass die Chorda dorsalis in einem kraniokaudalen Gradienten von Apoptoseprozessen durchlaufen wird (Xenopus laevis: Hensey und Gautier 1998, Malikova et al. 2007; Zebrafisch: Cole und Ross 2001; Haushuhn: Hirata und Hall 2000).

Auch bei Tupaia belangeri wird die Chorda dorsalis von einer kraniokaudalen Apoptosewelle durchsetzt (Abb. 22B). Dieser Apoptosewelle eilt eine Proliferationswelle voraus. Allerdings ist der 
„Gangunterschied“ beider Wellen gering, so dass Apoptose- und Proliferationsereignisse häufig simultan auftreten. Überlappende Maxima finden sich in der Übergangszone zwischen prospektiven und abgegliederten Somiten (Abb. 22B). In Folgearbeiten wollen wir klären, wie sich diese Überlappungszone zu den Expressionsmustern von sonic hedgehog und noggin verhält, weil diese Gene beim Haushuhn sowohl die Geschwindigkeit, mit der Somiten abgegliedert werden (Resende et al. 2010), als auch die weitere Differenzierung dieser Somiten beeinflussen (Fan und Tessier-Lavigne 1994, Fan et al. 1995, McMahon et al. 1998, zur Übersicht: Marcelle et al. 2002, Yusuf und BrandSaberi 2006).

In der Chorda dorsalis von Tupaia belangeri existiert noch eine zweite Apoptosewelle (Abb. 22B). Diese zweite, gleichfalls kraniokaudal fortschreitende Apoptosewelle setzt im Phase-3-Embryo DPZ 623/9B ein und ist im Phase-4-Embryo DPZ 743/1A erstmals eindeutig von der ersten Apoptosewelle abgrenzbar. Sie durchläuft die in diesem Zeitraum kaum noch proliferierende Chorda dorsalis genau dann, wenn die Bodenplatte des Neuralrohrs, deren Entwicklung von Signalen der Chorda dorsalis abhängt, gerade etabliert ist (Scheffel 2009). Wir vermuten, dass die erste Apoptosewelle, gemeinsam mit der sie begleitenden Proliferationswelle, der Etablierung kompetenter Chordazellen dient, die ihrerseits die Differenzierung der Bodenplatte bewirken. Danach könnte die zweite Apoptosewelle diejenigen Chordazellen auslöschen, die für die weitere Differenzierung der Bodenplatte nicht mehr „benötigt“ werden. Passend hierzu vermuten auch Cole und Ross (2001), dass Apoptoseprozesse beim Zebrafisch diejenigen Chordazellen aussortieren, die für die Induktion des Neuroektoderms erforderlich waren. Bei Tupaia belangeri könnte die zweite Apoptosewelle auBerdem mit der „Vakuolisierung“ der Chorda dorsalis in Verbindung stehen, die bei Xenopus laevis die Aufrichtung des Embryos unterstützen soll (Malikova et al. 2007). Cole und Ross (Zebrafisch: 2001) vermuten, dass solche Apoptoseereignisse diejenigen Chordazellen eliminieren, die keine Vakuolen bilden. Andererseits führt die Überexpression des Apoptose-inhibierenden bcl-2-Proteins bei Xenopus laevis zu einer weitgehenden Unterdrückung der Vakuolisierung (Malikova et al. 2007).

\section{IV. $5 . \quad$ Sklerotom}

\section{5.1 Sequenz der Sklerotombildung}

Es herrscht weitgehend Einigkeit darüber, dass das Sklerotom bei Amnioten durch epithelial-mesenchymale Transitionen (EMT) aus ventralen Abschnitten des Somiten hervorgeht (zur Übersicht: Dockter 2000, Christ et al. 2004, 2007). Nach strukturellen Kriterien gehen auch bei Tupaia belangeri mesenchymale Sklerotomzellen aus epithelialen Somitenzellen hervor (Abb. 7). Strukturelle und molekulare Charakteristika, die zur Klassifizierung mesenchymaler und epithelialer Zellen he- 
rangezogen werden, sind jedoch noch immer nicht verbindlich aufeinander abgestimmt (Shook und Keller 2003). Insofern wundert es nicht, dass Ostrovsky et al. (1988) auf der Basis von Expressionsanalysen (Laminin, Fibronektin, Aktin) zu dem Schluss kommen, dass Sklerotomzellen der Labormaus zu keinem Zeitpunkt ihrer Entwicklung epithelialen Charakter haben - eine Ansicht, die Gossler und Hrabĕ de Angelis (1998) unter strukturellen Gesichtspunkten kategorisch ablehnen.

Spezifischere Angaben zum zeitlichen und räumlichen Ablauf der Sklerotombildung sind rar. Bei Hühnerembryonen beginnt sie in ventrolateralen Abschnitten des Somiten (Teillet et. al. 1987: Abb. 4B, S. 334; Kahane et al. 1998a: Abb. 1B, S. 61). Bei Tupaia belangeri setzt die EMT dagegen ventromedial und zentral ein, dehnt sich anschließend aber nicht sofort nach ventrolateral, sondern zunächst nach kranial und kaudal aus. Erst in dieser Phase werden ventrolaterale Somitenabschnitte von der EMT erfasst, die auch hier zentral beginnt und sich anschließend nach kranial und kaudal ausdehnt (Abb. 7).

Kandidatengene, die bei Tupaia belangeri in die Sklerotombildung eingreifen könnten, sind noggin und bone morphogenetic protein-4 (BMP-4). Bei Huhn- und Mausembryonen wird BMP-4 vom Seitenplattenmesoderm (Jones et al. 1991, Pourquié et al. 1996, Schmidt et al. 1998), noggin von der Chorda dorsalis gebildet (Hirsinger et al. 1997, McMahon et al. 1998). Noggin induziert die Expression von pax-1 in denjenigen Abschnitten des Somiten, die das Sklerotom hervorbringen werden (McMahon et al. 1998, Dockter 2000). Unter experimentellen Bedingungen antagonisiert noggin die Expression von BMP-4 (Zimmerman et al. 1996) und BMP-4 die von noggin induzierte pax-1-Expression (McMahon et al. 1998). Die Sklerotombildung setzt - höchstwahrscheinlich nach dem hier erstmals am Beispiel von Tupaia belangeri im Detail dargestellten Ablaufplan - ein, sobald das von lateral einwirkende BMP-4-Signal durch noggin ,überwunden“ ist (McMahon et al. 1998).

\section{IV. $5.2 \quad$ Apoptosemuster}

Prinzipiell sind Zelltodereignisse (Jacobson W 1932, Glücksmann 1934a, 1951) im Sklerotom verschiedener Amnioten bereits mehrfach beobachtet und beschrieben worden. Systematische Analysen solcher Zelltodmuster sind jedoch aus guten Gründen rar. So hebt bereits Bardeen (1905) hervor, dass „The outlines of the condensed tissue are not so sharp in nature as it is necessary to make them in a model of this kind“ (S. 165). Bei der Identifikation apoptotischer und mitotischer Zellen kommen weitere Schwierigkeiten hinzu. Die kraniale Sklerotomhälfte wird nämlich von Neuralleistenzellen durchwandert und zum Teil auch besiedelt (Haushuhn: Keynes und Stern 1984, Rickmann et al. 1985; Labormaus: Serbedzija et al. 1990; Mensch: O’Rahilly und Müller F 2007; Tupaia belangeri: Knabe et al. 2004, Scheffel 2009). Selbst innerhalb der aus Neuralleistenzellen hervorge- 
gangenen Spinalganglien müssen apoptotische Zellen differenzialdiagnostisch gegen Sklerotomabkömmlinge im Endo- und Perineurium abgegrenzt werden (Halata et al. 1990). Dementsprechend wird die Frage, ob im Sklerotom nachgewiesene apoptotische Zellen von der Neuralleiste oder tatsächlich vom Sklerotom abstammen, am Beispiel des Haushuhns seit längerem kontrovers diskutiert. Jeffs und Osmond (1992) gehen davon aus, dass es sich bei der Mehrzahl aller abgestorbenen Zellen, die sie (1) innerhalb (überwiegend kranialer Abschnitte) des Sklerotoms, (2) zwischen Neuralrohr und Sklerotom sowie (3) zwischen Oberflächenektoderm und Dermomyotom mittels Nilblausulfat-Färbung fanden, um wandernde Neuralleistenzellen handelt. Identifiziert wurden diese Neuralleistenzellen anhand des von ihnen inkorporierten Farbstoffes DiI, der zuvor in das Lumen des Neuralrohres eingebracht worden war. Die von Jeffs und Osmond (1992) publizierte Auffassung wird sowohl von Sanders (1997) als auch von Cotrina et al. (2000) vehement bestritten. Auf der Grundlage von Doppelmarkierungsversuchen kommen beide Arbeitsgruppen zu dem Schluss, dass Apoptoseprozesse innerhalb des Sklerotoms überwiegend Sklerotomzellen eliminieren. Darüber hinaus hebt Sanders (1997) hervor, dass Apoptoseereignisse, die mit Hilfe der TUNEL-Methode spezifischer und sensitiver als mittels Nilblausulfat-Färbung (Jeffs und Osmond 1992) detektiert werden können, nicht nur in kranialen, sondern auch in kaudalen Abschnitten der Sklerotome zahlreich vorkommen.

Bei Tupaia belangeri ist das Vorkommen von Apoptosehäufungen nicht, wie von Jeffs und Osmond (1992) für das Haushuhn festgestellt, auf die kraniale Hälfte des Sklerotoms beschränkt, sondern bezieht explizit auch dessen kaudale Hälfte ein (Abb. 24B, E; 25A, B; 26A, B). Unter der Annahme, dass Neuralleistenzellen bei Tupaia belangeri, wie bei allen anderen bisher untersuchten Amnioten auch (Krull 2001), die kaudale Hälfte des Sklerotoms meiden, sollte es sich bei den in der kaudalen Hälfte der Sklerotome zahlreich nachgewiesenen apoptotischen Zellen tatsächlich um Sklerotomzellen handeln. Dagegen können wir nur spekulieren, dass Apoptoseereignisse auch in den kranialen Sklerotomhälften von Tupaia belangeri, wie beim Haushuhn (Sanders 1997, Cotrina et al. 2000), mehrheitlich Sklerotomzellen auslöschen.

Sanders (1997) legte zwar systematische Untersuchungen über das Vorkommen von Apoptoseereignissen im Sklerotom des Haushuhns vor, kommentierte die funktionelle Bedeutung seiner Befunde jedoch zurückhaltend. Auch die vorliegende Arbeit fokussiert auf die Erfassung von Apoptosemustern und nicht auf funktionsorientierte Experimente. Hypothetisch könnte eine erste Funktion von Apoptoseereignissen im Sklerotom darin bestehen, solche Zellen auszusortieren, die die EMT „fehlerhaft" durchlaufen haben und Defekte aufweisen. Bei Tupaia belangeri finden sich sowohl im Epithel von Somiten (Abb. 23A, B), bei denen der Beginn der EMT unmittelbar bevorsteht, als auch unter den mesenchymalen Zellen derjenigen Sklerotome, deren Zellzuzug aus lateralen Somi- 
tenabschnitten noch unvollständig ist (Abb. 24B, E; 25A, 26A), außerordentlich wenige apoptotische Zellen. Ähnlich niedrige Apoptosezahlen teilten Jeffs und Osmond (1992) sowie Sanders (1997) für das Haushuhn mit. Offenbar sind „Korrekturen“ fehlerhaft spezifizierter Sklerotomzellen in der Frühphase der EMT kaum erforderlich.

Verglichen mit diesen frühen Sklerotomen nimmt die Zahl apoptotischer Zellen in den „fortgeschritteneren“ Sklerotomen bei Tupaia belangeri erheblich zu (Abb. 24B, E; 25A, B; 26A, B). Zusätzlich erfolgt eine Konzentration apoptotischer Zellen an drei Orten (Abb. 27A): (1) in der lateralen Hälfte beziehungsweise in der lateralen Subdomäne des Sklerotoms, (2) in der ventralen Subdomäne, die die Chorda dorsalis umfasst und (3), sehr viel diskreter, in der dorsalen Subdomäne des Sklerotoms. Der Vergleich dieser Befunde mit Vorbefunden aus der Literatur ist schwierig. Erstens verwenden beinahe alle an diesem Problem interessierten Arbeitsgruppen unterschiedliche Termini bei der Beschreibung verschiedener Sklerotomabschnitte. Zweitens geht die Position apoptotischer Zellen in vielen Fällen nicht eindeutig aus den zur Verfügung gestellten Abbildungen hervor.

Beispielsweise findet Sanders (1997) beim Haushuhn Apoptosehäufungen, die er ganz überwiegend dem „,ventral sclerotome“ zuordnet. Den Vergleich mit den an Tupaia belangeri erhobenen Befunden können wir aber nur so weit führen, dass ventrale Apoptoseereignisse auch in den Sklerotomen eines Säugetieres vorkommen. Ob allerdings die beim Haushuhn beschriebenen Apoptosehäufungen, wie bei Tupaia belangeri, in der ventralen Subdomäne, in der gleichfalls nach ventral gerichteten lateralen Subdomäne oder sogar in diesen beiden Subdomänen lokalisiert sind, bleibt offen. Hirata und Hall (2000) übernehmen den von Sanders (1997) geprägten Begriff „,ventral sclerotome“, um die Lage der auch von ihnen beim Haushuhn nachgewiesenen Apoptosehäufungen zu bezeichnen. Anhand des beigefügten Bildmaterials (Hirata und Hall 2000: Abb. 6F, S. 762) entspricht diese Apoptosehäufung am ehesten den bei Tupaia belangeri in der lateralen Subdomäne des Sklerotoms vorgefundenen Apoptoseereignissen (Abb. 25A, 26A, 27A). Angesichts der Tatsache, dass auch bei der Labormaus Apoptoseereignisse in ,,ventrolateral regions“ des Sklerotoms auftreten (Furumoto et al. 1999, S. 27), stellen Apoptoseereignisse in der lateralen Subdomäne des Sklerotoms offenbar einen gemeinsamen Nenner aller bisher untersuchten Spezies dar.

Entgegen der zunächst vertretenen Ansicht, dass Zelltodereignisse, die in der lateralen Subdomäne des Sklerotoms an der Spitze auswachsender Nerven auftreten (Theiler 1958, Tosney und Landmesser 1985), dazu dienen, Raum für auswachsende Nerven zu schaffen (Tosney und Landmesser 1985), wiesen Tosney et al. (1988) experimentell nach, dass solche Zelltodereignisse unabhängig von einwachsenden Nervenfasern auftreten. Auch bei Tupaia belangeri finden sich Apoptosehäufungen in der lateralen Subdomäne nicht nur, wie bei der Labormaus (Theiler 1958) und beim 
Haushuhn (Tosney und Landmesser 1985), an der Spitze auswachsender Nervenfasern, sondern bereits deutlich vor dem Einwachsen von Spinalnerven oder ihren Ästen (Abb. 25A, 26A, 27A). In der ventralen Subdomäne des Sklerotoms finden sich sowohl bei der Labormaus (Theiler 1958, Furumoto et al. 1999) als auch bei Tupaia belangeri Apoptosehäufungen (Abb. 25B, 26B, 27A), die mit der Entwicklung der Perichordalscheide in Beziehung stehen könnten.

Übereinstimmend treten auch im dorsalen Sklerotom beziehungsweise in der dorsalen Subdomäne beim Haushuhn (Hirata und Hall 2000) und bei Tupaia belangeri Apoptosehäufungen auf (Abb. 25A, 26A, 27A). Hirata und Hall (2000) vermuten, dass es sich bei diesen apoptotischen Zellen um Neuralleistenzellen handelt. Möglicherweise passend hierzu sind Apoptosen im dorsalen Sklerotom von Tupaia belangeri nicht nur außerhalb der von Neuralleistenzellen gebildeten Spinalganglien, sondern, parallel zu deren Reifungsfortschritt, zunehmend auch innerhalb dieser Ganglien lokalisiert (Abb. 25A, 26A, 27A).

Die zentrale Subdomäne des Sklerotoms bleibt bei allen untersuchten Embryonen von Tupaia belangeri weitgehend frei von Apoptoseereignissen (Abb. 27A). Im Gegensatz hierzu geht aus drei zu dieser Frage Stellung beziehenden Untersuchungen an Vögeln hervor, dass Apoptosehäufungen auch in heute der zentralen Subdomäne zugeschlagenen Abschnitten des Sklerotoms auftreten (Wellenpapagei: Ernst 1926; Haushuhn: Homma et al. 1994: Abb. 12A, C, S. 389; Cotrina et al. 2000: Abb. 6A, B, S. 332).

\section{5.3 Proliferationsmuster}

Wie bei allen anderen bisher untersuchten Säugetieren einschließlich des Menschen sowie beim Haushuhn finden sich auch in den Sklerotomen von Tupaia belangeri zahlreiche proliferierende Zellen (Jacobson W 1932, Glücksmann 1934a, Blechschmidt 1957, Langman und Nelson 1968, Shapiro 1992, Köhler et al. 2005; Tupaia belangeri: Abb. 24C, F; 25C, D; 26C, D). Häufigkeitsunterschiede zwischen Mitose-reichen kaudalen und Mitose-ärmeren kranialen Sklerotomabschnitten, die Wilting et al. (1994) sowohl beim Menschen als auch beim Haushuhn nachweisen konnten, haben wir bei den bisher untersuchten Embryonen von Tupaia belangeri in Einzelfällen, aber nicht generell beobachtet (Abb. 25, 26).

Unsere dreidimensionalen Rekonstruktionen belegen darüber hinaus, dass die Mitosehäufungen in der zentralen Subdomäne des Sklerotoms, die bei Tupaia belangeri praktisch frei von Apoptosen ist, besonders stark ausgeprägt sind (Abb. 25A, C; 26A, C; 27). Gleichartige Mitosehäufungen finden sich auch bei menschlichen Embryonen (Sensenig 1949). Außerdem exprimiert die zentrale Subdomäne des Sklerotoms bei Hühnerembryonen pax-1 (Ebensperger et al. 1995, Christ et al. 
2004), dessen Proliferations-fördernder Einfluss bei der Sklerotomentwicklung (Müller TS et al. 1996, Peters et al. 1999), aber auch im Rahmen anderer Morphogeneseprozesse nachgewiesen werden konnte (Müller TS et al. 1996, Su et al. 2001). Anders als in der zentralen Subdomäne, werden Proliferationsereignisse in der ventralen Subdomäne des Sklerotoms von Tupaia belangeri von zahlreichen Apoptosen begleitet (Abb. 25B, D; 26B, D; 27). Wir vermuten, dass das hohe Proliferationsaufkommen in der ventralen Subdomäne, wie beim Menschen (Sensenig 1949) und bei der Labormaus (Dalgleish 1985), die Entwicklung der Perichordalscheide fördert.

\section{6. Dermomyotom und Myotom}

\section{6.1 Methodische Vorbemerkungen}

Bei der dreidimensionalen Rekonstruktion der Somitenderivate mussten wir epitheliale Dermomyotome einerseits gegen mesenchymale Sklerotome, andererseits gegen Myotome abgrenzen (Abb. 9B, C). Die im Befundteil spezifizierten strukturellen Diagnosekriterien stehen in Übereinstimmung mit zahlreichen, an anderen Wirbeltierarten durchgeführten Vorarbeiten (Bardeen 1900, Williams 1910, Glücksmann 1934a, Weed 1936, Theiler 1957, Boyd 1960, Langman und Nelson 1968, Mestres und Hinrichsen 1976, Christ et al. 1983, Kaehn et al. 1988, Borman und Yorde 1994, Christ und Ordahl 1995, Denetclaw et al. 1997). Die topographische Zuordnung von Apoptose- und Proliferationsereignissen in den Dermomyotomen wird (auch) bei Tupaia belangeri dadurch erschwert, dass die Abfaltung des Embryonalkörpers bereits eingesetzt hat. Außerdem treten abschnittsweise Rotationen des Embryonalkörpers um die kraniokaudale mittlere Längsachse auf (Abb. 28D, 29B, 31). Diese „Komplikationen“ können wir dank der freien Drehbarkeit und artifiziellen Schneidbarkeit unserer dreidimensionalen Rekonstruktionen in den allermeisten Fällen ausschalten. Zur Vereinfachung der Befundpräsentation haben wir die aus den Rekonstruktionen ermittelten Apoptoseund Proliferationsmuster in übersichtlichere Schemata übertragen (Abb. 30).

\section{6.2 Morphogenese}

Für die Beurteilung von Apoptose- und Proliferationsmustern in den Dermomyotomen ist es entscheidend, den zeitlichen und räumlichen Ablauf der De-epithelialisierung der Dermomyotome genau darzustellen. Bei Tupaia belangeri beginnt die De-epithelialisierung von Dermomyotomen, die kein hypaxiales Myotom hervorbringen, an der ventrolateralen Lippe (VLL; Abb. 9A, 10A-C). Dagegen setzt die De-epithelialisierung in denjenigen Dermomyotomen, aus denen sowohl ein epaxiales als auch ein hypaxiales Myotom hervorgeht, zentral ein (Abb. 10B, D; 11). Diese beiden unterschiedlichen De-epithelialisierungsmuster sind auch bei anderen Wirbeltieren beschrieben worden (Fischel 1895, Williams 1910, Glücksmann 1934a, 1934b, Theiler 1957, Boyd 1960). Bardeen 
(1900) weicht insofern hiervon ab, als er den Beginn der De-epithelialisierung beim Schwein im Rumpfbereich nicht nur zentral, sondern auch in der kranialen Dermomyotomlippe beobachtet. Die einzigen prinzipiell abweichenden Beobachtungen publizierte Butcher (1929). Demnach beginnt die De-epithelialisierung von Dermomyotomen bei der Laborratte im Rumpfbereich zwar auch zentral, schreitet aber anschließend nach dorsal fort. Außerdem soll laut Butcher (1929) die De-epithelialisierung von Dermomyotomen oberhalb des Rumpfbereichs nicht an der VLL, sondern zentral beginnen und von dort nach ventral fortschreiten.

Unter anderem wollten wir wissen, ob sich Zusammenhänge zwischen den in den Dermomyotomen ablaufenden Apoptose- und Proliferationsereignissen und der Myotombildung aufzeigen lassen. Hier wird die Situation dadurch kompliziert, dass derzeit mindestens drei konkurrierende Modelle existieren, die die Myotombildung (beim Haushuhn) unterschiedlich erklären.

Das erste dieser drei Modelle wurde von Charles P. Ordahl und seinen Mitarbeitern etabliert. Demnach tragen Zellen aus der dorsomedialen Lippe (DML) sowie Dermomyotomzellen aus medialen Abschnitten der kranialen Lippe zur Bildung des epaxialen Myotoms bei, während die VLL - zeitverzögert - das hypaxiale Myotom hervorbringt (Denetclaw et al. 1997, Denetclaw und Ordahl 2000).

Das zweite Modell stammt von der Arbeitsgruppe um Chaya Kalcheim. Es besagt, dass die Myotomzellen in drei aufeinander folgenden Wellen aus verschiedenen Dermomyotomabschnitten abgegeben werden. Zunächst unterlagern postmitotische epaxiale Myotomzellen, die aus dorsomedialen Somitenabschnitten hervorgehen, das gesamte Dermomyotom. Sie bilden ein Gerüst für alle später hinzu tretenden Myotomzellen (Kahane et al. 1998a). Im Zuge der zweiten Welle wird das Myotom um postmitotische Myotomzellen aus der DML sowie aus der kranialen und kaudalen Lippe vermehrt (Kahane et al. 1998b). Zeitlich parallel entsteht in der Rumpfregion das hypaxiale Myotom aus Vorläuferzellen, die aus der VLL stammen (Cinnamon et al. 1999). Die dritte Welle unterscheidet sich von den beiden Vorgängerwellen dadurch, dass jetzt durchgehend mitotisch noch aktive Vorläuferzellen in das entstehende Myotom abgegeben werden: zunächst aus der kranialen und kaudalen Dermomyotomlippe (Kahane et al. 2001), anschließend auch aus dem in De-epithelialisierung begriffenen zentralen Dermomyotom (Ben-Yair et al. 2003, Ben-Yair und Kalcheim 2005).

Das dritte Modell (Gros et al. 2004, 2005; Arbeitsgruppenleiter: Christophe Marcelle) lokalisiert Vorläuferzellen des Myotoms exakt in denjenigen Positionen, die auch von Kalcheim und Mitarbeitern favorisiert werden. Allerdings existieren unterschiedliche Vorstellungen über das Migrationsverhalten der Muskelvorläuferzellen. 
Bei Tupaia belangeri gehen aus allen Dermomyotomen epaxiale Myotome hervor. Die frühesten epaxialen Myotomzellen finden sich, wie beim Haushuhn (Kaehn et al. 1988, Borman und Yorde 1994, Kahane et al. 1998a, Yang und Ordahl 2006) und bei der Laborratte (Butcher 1929), zwischen der DML und der kranialen Lippe des Dermomyotoms (Abb. 9). Hypaxiale Myotome entstehen, wie beim Haushuhn (Christ et al. 1983, Pourquié et al. 1995, Denetclaw und Ordahl 2000, Kahane et al. 2007), zeitverzögert nur im Rumpfbereich (Abb. 11). Ihre Vorläuferzellen gehen bei Tupaia belangeri, wie bei anderen Wirbeltieren, höchstwahrscheinlich aus der zunächst epithelial verbleibenden VLL hervor (Haushuhn: Williams 1910, Christ et al. 1983, Cinnamon et al. 1999, Denetclaw und Ordahl 2000, Kahane et al. 2007; Laborratte: Butcher 1929; Schwein: Bardeen 1900; Mensch: Zechel 1924; Ente und Mensch: Fischel 1895; Ente, Schwein und Mensch: Glücksmann 1934b; Haushuhn, Schwein, Meerschweinchen und Mensch: Theiler 1957).

\section{6.3 Apoptosemuster im Dermomyotom}

Bereits in der ersten Hälfte des 20. Jahrhunderts wurden Zelltodereignisse im Dermomyotom (damalige Terminologie: „Dermatom“) nachgewiesen und funktionell mit der „Auflösung“ dieses Somitenkompartiments in Verbindung gebracht (Schwein: Bardeen 1900; Vögel, Labormaus, Schwein, Meerschweinchen, Maulwurf, Fledermaus, Mensch: Glücksmann 1934a; Schwein, Mensch: Glücksmann 1934b; Labormaus: Theiler 1958). Bei Tupaia belangeri ist die Zahl apoptotischer Zellen im Dermomyotom in den Entwicklungsphasen 3 und 4 besonders hoch (Abb. 29, 30). Dieses Maximum fällt, wie im Folgenden ausgeführt, zeitlich und räumlich mit dem Beginn der Bildung hypaxialer Myotome sowie der Dermis des Rückens durch De-epithelialisierung des zentralen Dermomyotoms zusammen. Wir vermuten, dass in beiden Fällen eine „Überwachung“ und gegebenenfalls - eine gezielte Aussortierung von Vorläuferzellen stattfinden könnte. Auch in den Dermomyotomen des Haushuhns existiert in nahezu identischen Entwicklungsphasen eine vorübergehende Häufung apoptotischer Zellen (Hirata und Hall 2000: 30-Somitenstadium, HH18). Aus dem von Hirata und Hall (2000) bereit gestellten Bildmaterial geht jedoch hervor, dass beim Haushuhn, im Gegensatz zu Tupaia belangeri (Abb. 30), ein räumlicher Zusammenhang zwischen der De-epithelialisierung des zentralen Dermomyotoms und gehäuft auftretenden Apoptoseereignissen nicht existiert. Dennoch ist auch beim Haushuhn ein funktioneller Zusammenhang zwischen dem Auftreten von Apoptosen und der Dermisbildung des Rückens nicht ausgeschlossen. Aus dem von Homma et al. (1994: Abb. 12A, B, S. 389) publizierten Bildmaterial kann nämlich erschlossen werden, dass Apoptoseereignisse der De-epithelialisierung des zentralen Dermomyotoms beim Haushuhn, wie bei Tupaia belangeri (Abb. 30), unmittelbar vorausgehen. Der Unterschied zwischen beiden Spezies besteht offenbar lediglich darin, dass bei Tupaia belangeri Apoptoseereignisse im zentralen Dermomyotom auch während der De-epithelialisierung persistieren. 
Bei Tupaia belangeri treten Apoptosehäufungen nicht nur bei der De-epithelialisierung des zentralen Dermomyotoms, sondern auch bei der De-epithelialisierung der DML auf (Abb. 30, 31A). Beide Dermomyotomabschnitte tragen (beim Haushuhn) zur Bildung der Dermis bei (Olivera-Martinez et al. 2000, 2004, Ben-Yair et al. 2003, zur Übersicht: Scaal und Christ 2004). Vorausgesetzt, dass sich diese beiden Dermomyotomabschnitte bei Tupaia belangeri ähnlich verhalten, könnten unterschiedliche, für die Dermisbildung zuständige Dermomyotomabschnitte durch gleichartige, Apoptose-getriggerte Selektionsprozesse reguliert werden.

Bei Tupaia belangeri scheint auch die zweite, oben skizzierte Koinzidenz zwischen dem Auftreten von Apoptosehäufungen im Dermomyotom und der Bildung des hypaxialen Myotoms funktionelle Bedeutung zu haben, weil diese innerhalb der VLL ablaufenden Apoptosereignisse der Myotomentstehung unmittelbar vorhergehen (Abb. 30, 31A). Auch beim Haushuhn (Hirata und Hall 2000: Abb. 4H, S. 760; Abb. 6L, S. 762) kommen Apoptoseereignisse offenbar regelhaft in ventrolateralen Dermomyotomabschnitten der Rumpfregion vor. Allerdings ist die Aufklärung des exakten zeitlichen und räumlichen Zusammenhanges zwischen dem Auftreten solcher Apoptosen und der Bildung des hypaxialen Myotoms nicht Gegenstand der von Hirata und Hall (2000) vorgelegten Untersuchungen. Dennoch vermuten wir, dass Apoptosen sowohl bei Tupaia belangeri (Abb. 30, 31A) als auch beim Haushuhn Vorläuferzellen in der VLL apoptotisch aussortieren, ehe die überlebenden Vorläuferzellen das hypaxiale Myotom hervorbringen. Angesichts der Tatsache, dass bereits Rabl (1889, zitiert nach Glücksmann 1934b, S. 498) bei Pristiurus (Selachii) beobachtete, dass die der VLL entsprechenden Muskelknospen „,in der Region zwischen den Flossen (...) degenerieren“, könnten Apoptoseprozesse prinzipiell gleichartig zur Bildung des hypaxialen Myotoms von Wirbeltieren beitragen.

Außerhalb der Rumpfregion trägt die VLL nicht zur Bildung hypaxialer Myotome, sondern zur Entstehung der Muskulatur von Extremitäten, Hals und Zunge bei (Christ et al. 2007). Deshalb vermuteten wir, dass Apoptoseprozesse auch in der VLL okzipitaler und zervikaler Dermomyotome von Tupaia belangeri zu einer Selektion von Muskelvorläuferzellen beitragen könnten. Überraschenderweise treten jedoch vor der De-epithelialisierung der VLL dieser kranialen Dermomyotome praktisch keine Apoptosen in der VLL auf (Phasen 1 und 2: Abb. 28B, E). Stattdessen beobachteten wir wenig später zahlreiche Apoptoseereignisse unter migrierenden Muskelvorläuferzellen (Phasen 3 und 4: Daten nicht gezeigt). Ähnliche Apoptosehäufungen fanden sich auch beim Haushuhn (Jacob et al. 1979, Tosney und Landmesser 1985, Tosney et al. 1988, Wakamatsu et al. 1998) sowie bei der Labormaus und beim Menschen (Theiler 1958). Deshalb vermuten wir, dass die apoptotische Selektion von Muskelvorläuferzellen oberhalb beziehungsweise innerhalb der Rumpfregion „heterochron" erfolgt. 
Publizierte Hinweise auf Apoptosehäufungen in der DML, die im Zusammenhang mit der Bildung epaxialer Myotome stehen könnten, gibt es bisher nicht. Bei Tupaia belangeri fanden wir lediglich im Phase-3-Embryo DPZ 623/9B derartige Apoptosehäufungen (Abb. 30). Angesichts der Tatsache, dass vergleichbare Apoptosehäufungen bei keinem der anderen untersuchten Tupaia-Embryonen vorkommen, erscheinen weitergehende Aussagen zu diesem Komplex verfrüht.

\section{6.4 Proliferationsmuster im Dermomyotom}

Generell belegen unsere Rekonstruktionen zunächst, dass in den Dermomyotomen von Tupaia belangeri, wie bei allen anderen bisher untersuchten Spezies auch, zahlreiche Mitosen auftreten (Haushuhn: Williams 1910, Langman und Nelson 1968, Galli et al. 2008; Laborratte: Butcher 1929; Schwein: Bardeen 1900). Unsere zusätzliche Annahme, dass lokalisierte Proliferationshäufungen im Dermomyotom Hinweise auf den zeitlichen und räumlichen Ablauf der Myotombildung geben könnten, stützt sich auf die am Beispiel des Haushuhns dokumentierte Beobachtung, dass proliferierende Vorläuferzellen der DML schon vier Stunden später im Myotom nachweisbar sind (Venters und Ordahl 2002). Passend zu unserer Annahme, treten bei Tupaia belangeri isolierte Mitosehäufungen in der DML und VLL thorakaler Dermomyotome tatsächlich bereits vor der Myotombildung auf (Abb. 30). Auch bei anderen Wirbeltieren wurden vergleichbare Proliferationsfoki in diesen beiden Lippen beobachtet (Haushuhn: Köhler et al. 2005; Laborratte: Butcher 1929). Angesichts der Tatsache, dass das von der VLL gespeiste hypaxiale Myotom später als das von der DML versorgte epaxiale Myotom entsteht, erscheint es jedoch verwunderlich, dass die von mehreren Untersuchern übereinstimmend beobachteten Proliferationsmaxima gleichzeitig in der DML und VLL auftreten. Eine mögliche Erklärung für dieses Phänomen lieferten unabhängig voneinander Gros et al. (2004: Abb. 1E, S. 877) und Kahane et al. (2007: Abb. 2, S. 442). Demnach existieren in der VLL von Hühnerembryonen „early lateral myoblasts“ (Kahane et al. 2007), die die VLL nahezu zeitgleich mit der ersten Abgabe von Vorläuferzellen des epaxialen Myotoms aus der DML verlassen. Diese „early lateral myoblasts“ sind zunächst mesenchymal (Kahane et al. 2007). Mesenchymzellen sind allerdings in den nach strukturellen Kriterien diagnostizierten und rekonstruierten Myotomen von Tupaia belangeri nicht enthalten.

Nach Einsetzen der Myotombildung finden sich bei Tupaia belangeri weiterhin zahlreiche Proliferationsereignisse sowohl in der DML als auch in der VLL. Zusätzlich treten jetzt aber Mitosehäufungen in den kranialen und kaudalen Dermomyotomlippen auf (Abb. 30). Unter der Annahme, dass auch diese zusätzlichen proliferierenden Zellen in das Myotom integriert werden, wäre der Ablauf der Myotombildung bei Tupaia belangeri mit beiden erweiterten, oben skizzierten Modellen zur Myotombildung (Modell 2: Kahane et al. 1998b; Modell 3: Gros et al. 2004) vereinbar. 
Die Modelle 2 und 3 postulieren weiterhin, dass zusätzliche Myotomzellen auch aus dem in De-epithelialisierung begriffenen zentralen Dermomyotom hervorgehen (Ben-Yair et al. 2003, Ben-Yair und Kalcheim 2005, Gros et al. 2005). Wiederum unter der Annahme, dass das lokal erhöhte Proliferationsaufkommen im Dermomyotom von Tupaia belangeri der Integration hieraus erwachsender Myoblasten ins Myotom unmittelbar vorhergeht, könnte die bei Tupaia belangeri abschließend beobachtete diffuse Proliferationsaktivität im gesamten Dermomyotom auf eine weitere Übereinstimmung mit den bisher durch Befunde am Haushuhn gestützten Modellen 2 und 3 zur Myotombildung hinweisen (Abb. 30, 31B). In dieser letzten Phase könnten neben mitotisch aktiven Myotomzellen auch dermale Vorläuferzellen generiert werden.

\section{6.5 Apoptose- und Proliferationsmuster im Myotom}

Tendenziell nimmt in den Myotomen von Tupaia-Embryonen der Phasen 2 bis 5 sowohl die Zahl apoptotischer Zellen als auch die Zahl mitotischer Zellen mit der Zeit deutlich zu (Abb. 32). Ganz ähnliche Trends hinsichtlich des Zelltods (Glücksmann 1934a, 1934b, Theiler 1957, Cole und Ross 2001) oder der Proliferation (Williams 1910, Butcher 1929, Langman und Nelson 1968) fanden sich auch bei anderen Wirbeltieren in den entsprechenden Entwicklungsstadien.

Wie oben ausgeführt, stimmen die an Tupaia belangeri erhobenen Befunde mit Vorbefunden am Haushuhn dahingehend überein, dass Proliferationshäufungen im Dermomyotom zunächst in den kranialen und kaudalen Dermomyotomlippen und anschließend in den in De-epithelialisierung begriffenen zentralen Dermomyotomabschnitten auftreten. Beim Haushuhn liegen experimentelle Beweise dafür vor, dass Vorläuferzellen, die aus allen genannten Lokalisationen ins Myotom übertreten, auch in ihrer jeweiligen neuen Position proliferativ aktiv bleiben (Kahane et al. 2001, Ben-Yair et al. 2003, Ben-Yair und Kalcheim 2005, Gros et al. 2005). Die bisher an Tupaia belangeri erhobenen Befunde lassen den Schluss zu, dass ganz ähnliche Übertritte proliferativ aktiver Vorläuferzellen ins epaxiale Myotom stattfinden. Erstens liegen Mitosen innerhalb ,junger“ epaxialer Myotome vorrangig peripher, das heißt in Nachbarschaft der kranialen und kaudalen Dermomyotomlippen. Zweitens verliert sich diese Vorzugslokalisation anschließend zugunsten einer gleichmäßigeren Verteilung von Mitosen über das gesamte epaxiale Myotom, das heißt auch in Nachbarschaft mitotisch aktiver zentraler Abschnitte des in der De-epithelialisierung begriffenen Dermomyotoms (Phase 3: Abb. 32A; Phase 4: Abb. 32B). Grundsätzlich stimmt auch der rekonstruierte Phase-5-Embryo DPZ 5061/C mit diesen Trends überein, liefert aber zusätzlich den Befund, dass sich die Mitosehäufungen in den „reiferen“ hochthorakalen, zervikalen und okzipitalen Myotomen, wie beim Haushuhn (Köhler et al. 2005), zunehmend auf die dorsomediale Hälfte des epaxialen Myotoms konzentrieren (Abb. 32C). 
Apoptoseereignisse in den reiferen epaxialen Myotomen von Tupaia belangeri sind, im Unterschied zu den dorsomedial konzentrierten Mitosen, überwiegend ventrolateral anzutreffen (Abb. 32). Übereinstimmend besteht eine solche ventrolaterale Präferenz beobachteter Zelltodereignisse auch bei anderen Wirbeltieren (Ernst 1926, Glücksmann 1934a, Grim 1970, Tosney et al. 1988, Wride et al. 1994). Bisher existiert keine belastbare Erklärung für diese offenbar ubiquitär auftretende gegensätzliche Verteilung von Apoptosen und Mitosen im epaxialen Myotom. Die im Rahmen der vorliegenden Arbeit durchgeführten Simultanrekonstruktionen sämtlicher Somitenkompartimente sowie des Seitenplattenmesoderms lassen jedoch weitergehende Hypothesen zu, die im Zusammenhang mit der Diskussion der im Seitenplattenmesoderm erhobenen Befunde erörtert werden sollen. Auf eine Diskussion der hypaxialen Myotome, die in Phase 5 ein deutliches Proliferationsmaximum haben, wird verzichtet, da die hier durchgeführten Rekonstruktionen lediglich den Beginn der Entwicklung der hypaxialen Myotome erfassen.

\section{7. Apoptose- und Proliferationsmuster im Seitenplattenmesoderm}

Publizierte Untersuchungen über die Morphogenese des Seitenplattenmesoderms sowie über mögliche Beiträge durch Apoptose- und Proliferationsereignisse sind rar. Einer der Gründe hierfür ist, dass die Seitenplatten bei der Präparation häufig beschädigt werden (Funayama et al. 1999). Diese Arbeitsgruppe beschäftigte sich zunächst mit der Frage, wie Somato- und Splanchnopleura aus einer zusammenhängenden Gewebeplatte entstehen. Demnach treten beim Haushuhn zunächst vereinzelt, dann immer zahlreicher Spalten innerhalb des zusammenhängenden Zellverbandes auf, die schließlich zu einem Hohlraum konfluieren, der beide Seitenplatten voneinander trennt. Auf die naheliegende Frage, ob auch Zelltodereignisse, wie bei vielen anderen Abtrennungsprozessen im Rahmen der Embryogenese (Ernst 1926, Glücksmann 1951), zu der Spaltung des Seitenplattenmesoderms beitragen, gehen Funayama et al. (1999) nicht ein. Auch die für die vorliegende Arbeit untersuchten Embryonen von Tupaia belangeri geben hierzu nur begrenzt Auskunft, weil lediglich Embryonen unserer Phasen 1 und 2 (in geringem Umfang) noch „ungespaltenes“ Seitenplattenmesoderm besitzen. Die Auswertung dieses für die genannte Fragestellung sicher nicht repräsentativen Materials ergibt bisher keinen zwingenden Hinweis auf einen Beitrag von Apoptoseereignissen zur Aufspaltung des Seitenplattenmesoderms.

Dagegen finden sich bei Tupaia belangeri erhebliche Apoptosehäufungen am Boden des Zölomspaltes, und zwar in der Übergangszone zwischen dem Seitenplattenmesoderm und dem medial anschließenden ungegliederten Mesoderm. Diese Apoptosehäufungen setzen sich bandförmig nach kranial fort (Abb. 13, 16). Deshalb vermuten wir, dass sie Ausdruck einer „Grenzziehung“ sind, die 
das Seitenplattenmesoderm durch Elimination „falsch spezifizierter“ Vorläuferzellen vom übrigen Mesoderm trennt. Unsere dreidimensionalen Simultanrekonstruktionen belegen, dass auch andere mesodermale Apoptosehäufungen bevorzugt auf der dem Seitenplattenmesoderm zugewandten Seite auftreten: (1) in der lateralen Hälfte/Subdomäne des Sklerotoms (Abb. 24B, E; 25A, 26A), (2) in der VLL von Dermomyotomen der Rumpfregion (Abb. 29, 30), (3) unter migrierenden, von der VLL abstammenden hypaxialen Muskelvorläuferzellen (Daten nicht gezeigt) sowie (4) in der ventrolateralen Hälfte epaxialer Myotome (Abb. 32). Eine mögliche Erklärung für dieses topografisch koordinierte Auftreten von Apoptosehäufungen könnte darin bestehen, dass pro-apoptotische Faktoren vom Seitenplattenmesoderm produziert und abgegeben werden. Ein guter Kandidat hierfür ist BMP-4 (Haushuhn: Pourquié et al. 1996, Tonegawa et al. 1997, Schmidt et al. 1998, Tonegawa und Takahashi 1998; Labormaus: Jones et al. 1991), dessen pro-apoptotische Wirkung beispielsweise im embryonalen Rhombenzephalon (Graham et al. 1994) sowie in der Extremitätenknospe (Yokouchi et al. 1996) nachgewiesen worden ist. Folgeuntersuchungen bei Tupaia belangeri werden deshalb zunächst die Expressionsmuster von BMP-4 und noggin analysieren, die bei der Grenzziehung zwischen paraxialem Mesoderm und Seitenplattenmesoderm als Gegenspieler fungieren (Tonegawa et al. 1997, Tonegawa und Takahashi 1998, Wijgerde et al. 2005, Miura et al. 2006).

\section{8. Apoptose- und Proliferationsmuster am kaudalen Embryonalpol}

\section{8.1 Chordoneurales Scharnier}

Das bei Xenopus laevis (Pasteels 1943) erstbeschriebene „chordoneurale Scharnier“ bezeichnet eine kaudal der Chorda dorsalis lokalisierte, strangartig verdichtete Gewebeformation, die von der Neuralplatte beziehungsweise vom Neuralrohr nicht scharf abgrenzbar ist („chordoneural hinge“: Labormaus: Cambray und Wilson V 2002; Mensch: Müller F und O’Rahilly 2004; Tupaia belangeri: Abb. 3E). Das chordoneurale Scharnier trägt zur Bildung der Chorda dorsalis sowie ventraler Anteile des Rückenmarks bei (Xenopus laevis: Gont et al. 1993). Außerdem birgt es pluripotente Stammzellen, aus denen sämtliche Strukturen der Schwanzregion hervorgehen (Labormaus: Cambray und Wilson V 2002).

Im Schrifttum fanden wir lediglich eine einzige Untersuchung, die sich mit dem möglichen Auftreten von Apoptosen in dem chordoneuralen Scharnier befasst hat. Demnach treten Apoptosen in dem chordoneuralen Scharnier der Labormaus praktisch nicht auf (Ukita et al. 2009). Unsere dreidimensionalen Rekonstruktionen des kaudalen Embryonalpols von Tupaia belangeri belegen jedoch, dass das Ergebnis der zitierten Voruntersuchung auf keinen Fall generelle Gültigkeit für die Säugetiere beanspruchen kann. Bei Tupaia belangeri wird das chordoneurale Scharnier in allen untersuchten 
Entwicklungsphasen von zahlreichen Apoptosen durchzogen (Abb. 13A, 18D, G; 20A, 21A). Eine Erklärung für diesen Unterschied zur Labormaus können wir bisher nicht geben. Methodenbedingte Unterschiede scheiden insofern aus, als die von unserer Arbeitsgruppe häufig (und auch hier) zur strukturellen Diagnose apoptotischer Zellen eingesetzten Semidünnschnitte identische Ergebnisse zeigen, wenn wir sie, wie Ukita et al. (2009) das von ihnen verwendete Material, mit der TUNELMethode (Gavrieli et al. 1992) analysieren (Knabe et al. 2004). Nachuntersuchungen bei der Labormaus sind aber erforderlich, weil Ukita et al. (2009) nur ein einziges Entwicklungsstadium $(E 9,25)$ zur Befundung herangezogen haben.

Ukita et al. (2009) haben sich außerdem mit der proliferativen Aktivität im chordoneuralen Scharnier von Labormäusen auseinandergesetzt. Demnach ist die Proliferationsaktivität im 20-Somitenstadium $(E 9,25)$ hoch (bis zu 39\% BrdU-positive Zellen), im 35-Somitenstadium aber bereits wieder niedriger (E10,5: bis zu 24\% BrdU-positive Zellen). Die von Ukita et al. (2009) bei der Labormaus untersuchte Entwicklungsperiode entspricht bei Tupaia belangeri dem Zeitraum zwischen unseren Phasen 2 (19-Somitenstadium) und 4 (31-Somitenstadium). Hier ist die Proliferationshäufigkeit, ermittelt durch dreidimensionale Rekonstruktion strukturell identifizierter mitotischer Zellen, durchweg hoch (Abb. 18F, I; 20B, 21B). Eine Heterochronie hinsichtlich der Sequenz „hoher Proliferationsgrad geht Abfall des Proliferationsgrades voraus“"(Labormaus) scheidet höchstwahrscheinlich aus, denn auch der Phase-1-Embryo DPZ 754/1A von Tupaia belangeri verfügt über zahlreiche Mitosen, die allerdings strikt auf kaudale Abschnitte des chordoneuralen Scharniers konzentriert sind (Abb. 14A). Auch unter Berücksichtigung der verschiedenen, von Ukita et al. (2009) und unserer Arbeitsgruppe zum Nachweis proliferierender Zellen eingesetzten Methoden können wir die offensichtlichen Unterschiede zwischen Labormaus und Tupaia belangeri bisher nicht erklären. Folgeuntersuchungen an Tupaia belangeri werden sich deshalb mit der molekularen Charakterisierung des chordoneuralen Scharniers auseinandersetzen.

\section{8.2 Schwanzknospe}

Bei Tupaia belangeri ist eine Schwanzknospe erstmalig bei Embryonen der Phase 2 (19-Somitenstadium) ausgebildet. Dieser Befund steht in guter Übereinstimmung mit Vorbefunden beim Haushuhn (18-Somitenstadium, HH13: Schoenwolf 1979, Griffith et al. 1992, Ohta et al. 2007), bei der Labormaus (13- bis 20-Somitenstadium, E9,0: Schoenwolf 1984), bei der Laborratte (19- bis 21-Somitenstadium, E10,5: Gajović und Kostović-Knežević 1995) sowie beim Menschen (21- bis 29-Somitenstadium, E30: Müller F und O’Rahilly 2004). Auch unser Befund, dass apoptotische Zellen gehäuft in der Schwanzknospe von Tupaia belangeri auftreten (Abb. 18D, 20A, 21A), findet Entsprechungen bei anderen Wirbeltieren (Zebrafisch: Cole und Ross 2001; Haushuhn: Schoenwolf 1981, Mills und Bellairs 1989, Hirata und Hall 2000; Mensch: Fallon und Simandl 1978). Die funk- 
tionelle Deutung dieser in der Schwanzknospe übereinstimmend nachgewiesenen Apoptosehäufungen ist jedoch schwierig, da bis heute keine allgemein akzeptierte Vorstellung über das Schicksal von Stammzellen im chordoneuralen Scharnier einerseits, in der Schwanzknospe andererseits existiert. Diese Einschränkung gilt in vollem Unfang auch für Tupaia belangeri. Die vielfach geäußerte Auffassung, dass Apoptosehäufungen in der Schwanzknospe mit deren Rückbildung in Zusammenhang stehen könnten, ist bei „nicht-Schwanz-tragenden“ Tieren sowie, in späteren Entwicklungsstadien, auch bei „Schwanz-tragenden“ Tieren einleuchtend. Für die bisher untersuchten Embryonen von Tupaia belangeri ist dieses Argument angesichts des noch ausstehenden Auswachsens der Schwanzanlage nicht stichhaltig. Adulte Tupaia belangeri verfügen über 3 sakrale und 24 kokzygeale Wirbel (Sargis 2001).

Bei Tupaia belangeri wird das hohe Apoptoseaufkommen in der Schwanzknospe von einem gleichfalls hohen Mitoseaufkommen begleitet (Abb. 18F, 20B, 21B). Auch in der Schwanzknospe der Labormaus findet sich eine hohe proliferative Aktivität (Tam 1981, Tam et al. 1982), während in der Schwanzknospe des ,nicht-Schwanz-tragenden“ Haushuhns nur sehr wenige Proliferationsereignisse auftreten (Mills und Bellairs 1989).

\section{8.3 Ventrales Mesoderm}

Das dritte, am kaudalen Embryonalpol gesondert angesprochene Kompartiment ist das „,ventrale Mesoderm“, das sämtliche lateral des paraxialen Mesoderms lokalisierten Mesodermabschnitte umfasst, die in der Schwanzregion nach ventral verlagert sind. Bei Tupaia belangeri durchsetzen Apoptosehäufungen die gesamte kraniokaudale Ausdehnung des ventralen Mesoderms, konzentrieren sich kaudal aber zunehmend auf ventrale Unterabschnitte dieses Kompartiments (Phase 3: Abb. 20; Phase 4: Abb. 21). Kolokalisationen mit Mitosen finden sich überwiegend in der kranialen Hälfte der Schwanzanlage. In der kaudalen Hälfte sind Proliferationsereignisse dagegen vorrangig in dorsalen Unterabschnitten des ventralen Mesoderms lokalisiert, „meiden“ also die durch Apoptosehäufungen charakterisierten ventralen Unterabschnitte.

Auch bei anderen Wirbeltieren wurden Apoptosehäufungen im ventralen Mesoderm beobachtet (Haushuhn: Schoenwolf 1981, Sanders et al. 1986, Mills und Bellairs 1989, Miller und Briglin 1996; Laborratte: Gajović und Kostović-Knežević 1995; Mensch: Fallon und Simandl 1978). Bisher ist allerdings in keinem Fall bekannt, welche Funktion diese Apoptoseereignisse haben. Einen Schlüssel zur Lösung dieser Frage könnte die Vermutung liefern, dass Überreste des Primitivstreifens in das Oberflächenektoderm der ventralen Schwanzanlage integriert werden und auch in dieser Position weiterhin Mesodermzellen generieren (Haushuhn: Liu et al. 2004; Labormaus: Schoenwolf 1984, Wilson V und Beddington 1996; Laborratte: Gajović und Kostović-Knežević 1995; Mensch: 
Müller F und O’Rahilly 2004). Sofern eine solche Integration des Primitivstreifens in das Oberflächenektoderm bei Tupaia belangeri stattfindet, könnten apoptotische Zellen, die wir in den untersuchten Embryonen der Phasen 2 bis 4 unmittelbar unterhalb des Oberflächenektoderms im ventralen Mesoderm fanden, Ausdruck einer „Selektion“ aktuell generierter Mesodermzellen sein. Ein ganz ähnlicher „Aussortierungsprozess“ könnte sogar bereits im Phase-1-Embryo DPZ 754/1A stattfinden. Hier liegt die Apoptosehäufung in kaudaler Verlängerung des chordoneuralen Scharniers und ventral der Neuralplatte (Abb. 13A). Wie bei anderen Wirbeltieren auch, ist die Neuralplatte in dieser Region kaum gegen das Mesoderm abgrenzbar (Haushuhn: Schoenwolf 1979, Knezevic et al. 1998; Labormaus: Tam et al. 1982; Mensch: Müller F und O’Rahilly 2004; Tupaia belangeri: Abb. 3F) und tatsächlich gehen aus dieser Übergangszone, mindestens bei der Labormaus, Mesodermzellen hervor (Tam et al. 1982, Cambray und Wilson V 2002). 


\section{ZUSAMMENFASSUNG}

Die erfolgreiche Entschlüsselung molekularer Mechanismen, die der periodischen Abgliederung von Somiten aus dem paraxialen Mesoderm zugrunde liegen, hat unser Wissen über fundamentale Entwicklungsprinzipien des Wirbeltierembryos entscheidend vorangebracht. Weitergehender Forschungsbedarf besteht einerseits bezüglich des detailgenauen Ablaufes dieser „molekularen Uhr“, andererseits zu der Frage, wie regulatorische Vorgaben im Rahmen der Somitogenese auf struktureller Ebene umgesetzt werden. Die vorliegende Arbeit untersucht die Morphogenese von Somiten und ihren Derivaten am Beispiel von Tupaia belangeri (Scandentia). Im Zentrum steht die Frage, inwieweit zeitlich und räumlich gerichtet ablaufende Apoptose- und Proliferationsereignisse zu diesen Morphogeneseprozessen beitragen.

Untersucht wurden Embryonen des 12. bis 16. Embryonaltages. Methodisch standen dreidimensionale Rekonstruktionen nach Semidünnschnitten im Vordergrund, die bei maximaler lichtmikroskopischer Auflösung optimale Voraussetzungen für die strukturelle Diagnostik apoptotischer und proliferierender Zellen sowie mesenchymal-epithelialer Transitionen bieten. Das Computer-gestützte Rekonstruktionssystem wurde in DFG-geförderten Vorarbeiten von der AG Neuroembryologie (Göttingen, jetzt Münster) in Kooperation mit der TU Chemnitz etabliert.

Feinanalysen der intersomitischen Spaltbildung mittels zusätzlicher zweidimensionaler Rekonstruktionen im $2 \mu \mathrm{m}$-Intervall förderten zunächst zutage, dass viele der bisher auf unterschiedlicher methodischer Basis publizierten, vermeintlich widersprüchlichen Modelle zur Spaltbildung miteinander vereinbar sein könnten. Bei Tupaia belangeri existieren nämlich zwei offenbar voneinander unabhängige Spaltinitialisierungszonen, die nahezu gleichzeitig in ventromedialen und dorsolateralen Abschnitten des ungegliederten paraxialen Mesoderms auftreten. Unter der Voraussetzung, dass Nachuntersuchungen bei Haushuhn und Labormaus ähnliche oder identische Spaltinitialisierungszonen identifizieren sollten, ließen sich die bisher publizierten, experimentell induzierten Störungen im Ablauf der intersomitischen Spaltbildung hypothetisch erklären.

Anschließend haben wir untersucht, ob sich strukturelle Korrelate für „Grenzzellen“ finden lassen, deren Existenz und „Spalt-bildende-Funktion“ auf der Grundlage von Wachtel-Huhn-Transplantationsexperimenten vor kurzem postuliert worden ist. Tatsächlich fanden wir bei Tupaia belangeri Epithel-ähnliche, meist kettenartig aneinander gereihte Zellen, die insbesondere am kaudalen Ende des aktuell in Abgliederung begriffenen Somiten den Spalt flankieren, in Form von Stapeln „ausfüllen“ oder seine künftige Position vorwegnehmen. Im Vorgriff auf Folgeuntersuchungen, mit deren Hilfe der Ablauf der mesenchymal-epithelialen Transitionen im paraxialen Mesoderm umfassend 
dreidimensional rekonstruiert werden soll, legen unsere Befunde die Vermutung nahe, dass sich die Grenzzellen von früh etablierten medialen Epithelzellen des prospektiven Somiten ableiten.

Für eine etwaige apoptotische Elimination „nicht mehr benötigter“ mutmaßlicher Grenzzellen liefern unsere dreidimensionalen Rekonstruktionen keinen überzeugenden Anhalt. Auch ein gezielter, in der Literatur mehrfach postulierter Beitrag von Apoptosen zur Bildung oder Konfiguration des Somitozöls ist bei Tupaia belangeri unwahrscheinlich. Schließlich spielen bei der Abgliederung von Somiten offenbar weder Apoptosen, deren abtrennende mechanische Funktionen häufig diskutiert, aber niemals bewiesen wurden, noch Segmentgrenzen-respektierende Mitose-Cluster eine herausragende Rolle.

In den vollständig epithelialen Somiten von Tupaia belangeri treten Mitosen, wie bei anderen Wirbeltieren, überwiegend apikal auf. Dagegen zeigen die Apoptosen eine bisher nicht dokumentierte basale Lagepräferenz. Entgegen der in der Literatur mehrheitlich vertretenen Auffassung erfolgt die Rückbildung der insgesamt vier bei Tupaia belangeri identifizierten Okzipitalsomiten wahrscheinlich nicht durch massive Apoptose, sondern beruht eher auf einem Rückgang der Proliferationsrate.

Der Nachweis einer im Detail neuartigen Sequenz, mit der Somitenzellen bei Tupaia belangeri durch epithelial-mesenchymale Transition ins Sklerotom integriert werden, ist für Folgearbeiten zur genetischen Regulation dieses Prozesses bedeutungsvoll. Die Sklerotombildung setzt ventromedial ein, schreitet nach kranial und kaudal, und erst dann nach ventrolateral fort, gefolgt wiederum von kranialen und kaudalen Ergänzungen. In der Frühphase der Sklerotombildung sind Apoptosen rar, treten aber anschließend, wie bei anderen Wirbeltieren, gehäuft in der lateralen Subdomäne des Sklerotoms auf. Bei Tupaia belangeri überlappen außerdem, möglicherweise die Bildung der Perichordalscheide fördernde, Apoptose- und Proliferationsmaxima in der ventralen Subdomäne des Sklerotoms. In der zentralen Subdomäne steht ein weiteres Proliferationsmaximum einem Apoptoseminimum gegenüber.

Bei Tupaia belangeri beginnt die De-epithelialisierung der Dermomyotome im Rumpfbereich zentral, in Segmenten dagegen, die kein hypaxiales Myotom ausbilden, in der ventrolateralen Lippe. Weiterhin übereinstimmend mit anderen Wirbeltieren stammen die Vorläuferzellen epaxialer Myotome aus der dorsomedialen Lippe, die des hypaxialen Myotoms aus der ventrolateralen Lippe des Dermomyotoms. Proliferationsmaxima unter Vorläuferzellen des Myotoms finden sich zunächst isoliert in der dorsomedialen und ventrolateralen Lippe, dann in allen vier Lippen und schließlich diffus im Dermomyotom. Die Sequenz ihres Auftretens ist mit den gegenwärtig diskutierten Modellen zur Myotomentstehung vereinbar. Apoptosemaxima, die während der De-epithelialisierung in 
der dorsomedialen Lippe sowie in zentralen Abschnitten der Dermomyotome des Rumpfbereichs auftreten, nehmen offenbar eine Selektion unter Vorläuferzellen der Dermis vor. Auch der Bildung hypaxialer Myotome gehen Apoptosehäufungen in der ventrolateralen Lippe voraus. Dagegen werden Vorläuferzellen der Extremitätenmuskeln nicht in der ventrolateralen Lippe, sondern möglicherweise erst während ihrer Wanderung zu den Zielgebieten apoptotisch „selektioniert“.

In den Myotomen von Tupaia belangeri nimmt die Zahl mitotischer wie auch apoptotischer Zellen, wie bei anderen Wirbeltieren, mit dem Entwicklungsfortschritt zu. Auch die präferenzielle Ausbildung von Proliferationsmaxima in dorsomedialen und von Apoptosemaxima in ventrolateralen Myotomabschnitten ist offenbar eine Konstante bei Vertretern aller Wirbeltierklassen.

Mit Hilfe unserer speziell für die Untersuchung großer Organanlagen entwickelten Rekonstruktionsmethode konnten wir Simultanrekonstruktionen des paraxialen und intermediären Mesoderms, des Seitenplattenmesoderms sowie der Chorda dorsalis von Tupaia belangeri durchführen. Auffälligster Befund war hier, dass bandförmig angeordnete Apoptoseereignisse offenbar eine „Grenzziehung“ zwischen dem Seitenplattenmesoderm und den medial benachbarten Mesodermabschnitten vornehmen. Außerdem postulieren wir die Existenz pro-apoptotischer Faktoren im Seitenplattenmesoderm, die benachbarte Apoptosehäufungen (1) in der lateralen Subdomäne des Sklerotoms, (2) in der ventrolateralen Lippe von Dermomyotomen des Rumpfes, (3) unter migrierenden, aus der ventrolateralen Lippe des Dermomyotoms stammenden Vorläuferzellen der Extremitätenmuskeln sowie (4) in der ventrolateralen Hälfte epaxialer Myotome verursachen könnten.

Am kaudalen Embryonalpol besitzt Tupaia belangeri im Untersuchungszeitraum drei weitere Orte hohen Apoptoseaufkommens: (1) das chordoneurale Scharnier, das bei der Labormaus keine Apoptosehäufungen aufweist, (2) die Schwanzknospe und (3) das „ventrale Mesoderm“. Die funktionelle Relevanz von Apoptosehäufungen in der frühen Schwanzknospe ist unklar, sofern, wie bei Tupaia belangeri, ein Schwanz ausgebildet wird. Apoptosehäufungen im ventralen Mesoderm könnten mit der „Selektion“ von Mesodermzellen befasst sein, die, möglicherweise auch bei Tupaia belangeri, aus den in das Oberflächenektoderm der Schwanzregion inkorporierten Resten des Primitivstreifens emigrieren.

Schließlich belegen unsere dreidimensionalen Rekonstruktionen erstmals, dass die Chorda dorsalis nicht nur von einer, sondern sogar von zwei dicht aufeinander folgenden Apoptosewellen in kraniokaudaler Richtung durchlaufen wird. Nur die erste Apoptosewelle wird von einer deutlichen, minimal vorauseilenden Proliferationswelle begleitet. Unter Einbeziehung unserer Vorarbeiten zur Entwicklung des Rückenmarks (Scheffel 2009) vermuten wir, dass Chordazellen, die die Differenzie- 
rung der Bodenplatte steuern, durch die erste Apoptosewelle „ausgewählt“ und, nach Etablierung der Bodenplatte, durch die zweite Apoptosewelle eliminiert werden. Postulate, denenzufolge Apoptoseereignisse zur Vakuolisierung der Chorda dorsalis beitragen, können wir für Tupaia belangeri weder bekräftigen noch widerlegen. 


\section{LITERATURVERZEICHNIS}

Alison MR (1995): Assessing cellular proliferation: What's worth measuring? Hum Exp Toxicol $\underline{14}$, 935-944

Amako Y, Tsukiyama-Kohara K, Katsume A, Hirata Y, Sekiguchi S, Tobita Y, Hayashi Y, Hishima T, Funata N, Yonekawa H, et al. (2010): Pathogenesis of hepatitis C virus infection in Tupaia belangeri. J Virol 노, 303-311

Andrade RP, Palmeirim I, Bajanca F (2007): Molecular clocks underlying vertebrate embryo segmentation: A 10-year-old hairy-go-round. Birth Defects Res C Embryo Today $\underline{81}$, 65-83

Arey LB (1938): The history of the first somite in human embryos. Contrib Embryol Carneg Inst 27, 233-269

Asakura A, Tapscott SJ (1998): Apoptosis of epaxial myotome in Danforth's short-tail (Sd) mice in somites that form following notochord degeneration. Dev Biol 203, 276-289

Aulehla A, Pourquié O (2010): Signaling gradients during paraxial mesoderm development. Cold Spring Harb Perspect Biol $\underline{2}$, a000869

Bagnall KM, Sanders EJ, Berdan RC (1992): Communication compartments in the axial mesoderm of the chick embryo. Anat Embryol 186, 195-204

Bardeen CR (1900): The development of the musculature of the body wall in the pig, including its histogenesis and its relations to the myotomes and to the skeletal and nervous apparatus. Johns Hopkins Hosp Rep 9, 367-399

Bardeen CR (1905): The development of the thoracic vertebrae in man. Am J Anat $\underline{4}, 163-174$

Barrios A, Poole RJ, Durbin L, Brennan C, Holder N, Wilson SW (2003): Eph/Ephrin signaling re- 
gulates the mesenchymal-to-epithelial transition of the paraxial mesoderm during somite morphogenesis. Curr Biol $\underline{13}, 1571-1582$

Bates MN (1948): The early development of the hypoglossal musculature in the cat. Am J Anat $\underline{83}$, $329-355$

Bellairs R (1979): The mechanism of somite segmentation in the chick embryo. J Embryol Exp Morphol 51, 227-243

Ben-Yair R, Kalcheim C (2005): Lineage analysis of the avian dermomyotome sheet reveals the existence of single cells with both dermal and muscle progenitor fates. Development $\underline{132}$, 689-701

Ben-Yair R, Kahane N, Kalcheim C (2003): Coherent development of dermomyotome and dermis from the entire mediolateral extent of the dorsal somite. Development $\underline{130}, 4325-4336$

Blechschmidt E (1957): Die Entwicklungsbewegungen der Somiten und ihre Bedeutung für die Gliederung der Wirbelsäule. Z Anat Entwicklungsgesch 120, 150-172

Blechschmidt E: Die vorgeburtlichen Entwicklungsstadien des Menschen. Eine Einführung in die Humanembryologie; Karger, Basel, Freiburg i.B., London, New York 1961

Blechschmidt E (1969): Differenzierungen im kinetischen Feld (Entstehungsbedingungen der Metamerie). Acta Anat $\underline{73}, 351-371$

Boissonat JD (1988): Shape reconstruction from planar cross sections. Comput Vision Graph Image Proc $\underline{44}, 1-29$

Borman WH, Yorde DE (1994): Analysis of chick somite myogenesis by in situ confocal microscopy of desmin expression. J Histochem Cytochem $\underline{42}, 265-272$ 
Boya P, de la Rosa EJ (2005): Cell death in early neural life. Birth Defects Res C Embryo Today $\underline{75}$, 281-293

Boyd JD: Development of striated muscle; in: The structure and function of muscle; hrsg. v. Bourne GH, Academic Press, New York 1960, 63-85

Brand-Saberi B, Christ B (2000): Evolution and development of distinct cell lineages derived from somites. Curr Top Dev Biol $\underline{48}, 1-42$

Brand-Saberi B, Wilting J, Ebensperger C, Christ B (1996): The formation of somite compartments in the avian embryo. Int J Dev Biol $\underline{40}, 411-420$

Bremer CM, Bung C, Kott N, Hardt M, Glebe D (2009): Hepatitis B virus infection is dependent on cholesterol in the viral envelope. Cell Microbiol 11, 249-260

Brunnett G, Vančo M, Haller C, Washausen S, Kuhn H-J, Knabe W: Visualization of cross sectional data for morphogenetic studies; in: GI-Edition - Lecture Notes in Informatics, Informatik 2003 Innovative Informatikanwendung, P-34; hrsg. v. Dittrich K, König W, Oberweis A, Rannenberg K, Wahlster W; Köllen, Bonn 2003, 354-359

Burgess R, Rawls A, Brown D, Bradley A, Olson EN (1996): Requirement of the paraxis gene for somite formation and musculoskeletal patterning. Nature $\underline{384}, 570-573$

Butcher EO (1929): The development of the somites in the white rat (Mus norvegicus albinus) and the fate of the myotomes, neural tube, and gut in the tail. Am J Anat $\underline{44}, 381-439$

Cambray N, Wilson V (2002): Axial progenitors with extensive potency are localised to the mouse chordoneural hinge. Development $\underline{129}, 4855-4866$

Cao J, Yang E-B, Su J-J, Li Y, Chow P (2003): The tree shrews: Adjuncts and alternatives to primates as models for biomedical research. J Med Primatol 32, 123-130 
Chaffer CL, Thompson EW, Williams ED (2007): Mesenchymal to epithelial transition in development and disease. Cells Tissues Organs 185, 7-19

Chiang C, Litingtung Y, Lee E, Young KE, Corden JL, Westphal H, Beachy PA (1996): Cyclopia and defective axial patterning in mice lacking Sonic hedgehog gene function. Nature $\underline{383}, 407-413$

Christ B, Wilting J (1992): From somites to vertebral column. Ann Anat 174, 23-32

Christ B, Ordahl CP (1995): Early stages of chick somite development. Anat Embryol 191, 381-396

Christ B, Jacob HJ, Jacob M (1972): Experimentelle Untersuchungen zur Somitenentstehung beim Hühnerembryo. Z Anat Entwicklungsgesch 138, 82-97

Christ B, Jacob HJ, Jacob M (1979): Über die Gestaltungsfunktionen der Somiten bei der Entwicklung der Körperwand von Hühnerembryonen. Verh Anat Ges $\underline{73}$, 509-518

Christ B, Jacob M, Jacob HJ (1983): On the origin and development of the ventrolateral abdominal muscles in the avian embryo. An experimental and ultrastructural study. Anat Embryol 166, 87-101

Christ B, Jacob HJ, Seifert R: Über die Entwicklung der zervikookzipitalen Übergangsregion; in: Neuroorthopädie; hrsg. v. Hohmann D, Kügelgen B, Liebig K, Springer, Berlin, Heidelberg 1988, $13-22$

Christ B, Schmidt C, Huang R, Wilting J, Brand-Saberi B (1998): Segmentation of the vertebrate body. Anat Embryol 197, 1-8

Christ B, Huang R, Wilting J (2000): The development of the avian vertebral column. Anat Embryol $\underline{202}, 179-194$

Christ B, Huang R, Scaal M (2004): Formation and differentiation of the avian sclerotome. Anat 
Embryol 208, 333-350

Christ B, Huang R, Scaal M (2007): Amniote somite derivatives. Dev Dyn 236, 2382-2396

Chung H-M, Neff AW, Malacinski GM (1989): Autonomous death of amphibian (Xenopus laevis) cranial myotomes. J Exp Zool 251, 290-299

Cinnamon Y, Kahane N, Kalcheim C (1999): Characterization of the early development of specific hypaxial muscles from the ventrolateral myotome. Development $\underline{126}, 4305-4315$

Cinquin O (2007): Understanding the somitogenesis clock: What's missing? Mech Dev 124, 501517

Cohen GM (1997): Caspases: The executioners of apoptosis. Biochem J $\underline{326}$, 1-16

Cole LK, Ross LS (2001): Apoptosis in the developing zebrafish embryo. Dev Biol 240, 123-142

Correira KM, Conlon RA (2000): Surface ectoderm is necessary for the morphogenesis of somites. Mech Dev $\underline{\text { 91, }}$ 19-30

Cotrina ML, González-Hoyuela M, Barbas JA, Rodríguez-Tébar A (2000): Programmed cell death in the developing somites is promoted by nerve growth factor via its p75(NTR) receptor. Dev Biol $\underline{228}, 326-336$

Couly GF, Coltey PM, Le Douarin NM (1993): The triple origin of skull in higher vertebrates: A study in quail-chick chimeras. Development $\underline{117}, 409-429$

Dalgleish AE (1985): A study of the development of thoracic vertebrae in the mouse assisted by autoradiography. Acta Anat 122, 91-98 
Day-Brown JD, Wei H, Chomsung RD, Petry HM, Bickford ME (2010): Pulvinar projections to the striatum and amygdala in the tree shrew. Front Neuroanat $\underline{4}, 143$

Denetclaw WF Jr, Ordahl CP (2000): The growth of the dermomyotome and formation of early myotome lineages in thoracolumbar somites of chicken embryos. Development $\underline{127}, 893-905$

Denetclaw WF Jr, Christ B, Ordahl CP (1997): Location and growth of epaxial myotome precursor cells. Development $\underline{124}, 1601-1610$

Dequéant M-L, Pourquié O (2008): Segmental patterning of the vertebrate embryonic axis. Nature Rev Genet $\underline{9}, 370-382$

Dietrich S (1999): Regulation of hypaxial muscle development. Cell Tissue Res $\underline{296}, 175-182$

Dietrich S, Schubert FR, Healy C, Sharpe PT, Lumsden A (1998): Specification of the hypaxial musculature. Development 125, 2235-2249

Diogo R, Wood BA, Aziz MA, Burrows A (2009): On the origin, homologies and evolution of primate facial muscles, with a particular focus on hominoids and a suggested unifying nomenclature for the facial muscles of the Mammalia. J Anat 215, 300-319

Dockter JL (2000): Sclerotome induction and differentiation. Curr Top Dev Biol 4ㄹ, 77-127

Dørup J, Andersen GK, Maunsbach AB (1983): Electron microscope analysis of tissue components identified and located by computer-assisted 3-D reconstructions: Ultrastructural segmentation of the developing human proximal tubule. J Ultrastruct Res $\underline{85}, 82-94$

Duband J-L, Dufour S, Hatta K, Takeichi M, Edelman GM, Thiery JP (1987): Adhesion molecules during somitogenesis in the avian embryo. J Cell Biol 104, 1361-1374 
Earnshaw WC (1995): Nuclear changes in apoptosis. Curr Opin Cell Biol 7, 337-343

Ebensperger C, Wilting J, Brand-Saberi B, Mizutani Y, Christ B, Balling R, Koseki H (1995): Pax1 , a regulator of sclerotome development is induced by notochord and floor plate signals in avian embryos. Anat Embryol 191, 297-310

Ernst M (1926): Über Untergang von Zellen während der normalen Entwicklung bei Wirbeltieren. Z Anat Entwicklungsgesch $\underline{79}, 228-262$

Erwig L-P, Henson PM (2008): Clearance of apoptotic cells by phagocytes. Cell Death Differ $\underline{15}$, $243-250$

Fadeel B, Orrenius S (2005): Apoptosis: A basic biological phenomenon with wide-ranging implications in human disease. J Intern Med 258, 479-517

Fallon JF, Simandl BK (1978): Evidence of a role for cell death in the disappearance of the embryonic human tail. Am J Anat 152, 111-130

Fan C-M, Tessier-Lavigne M (1994): Patterning of mammalian somites by surface ectoderm and notochord: Evidence for sclerotome induction by a hedgehog homolog. Cell $\underline{79}, 1175-1186$

Fan C-M, Porter JA, Chiang C, Chang DT, Beachy PA, Tessier-Lavigne M (1995): Long-range sclerotome induction by sonic hedgehog: Direct role of the amino-terminal cleavage product and modulation by the cyclic AMP signaling pathway. Cell $\underline{81,457-465}$

Fischel A (1895): Zur Entwicklung der ventralen Rumpf- und der Extremitätenmuskulatur der Vögel und Säugethiere. Gegenbaurs Morphol Jahrb $\underline{23}$, 544-561

Fleming A, Keynes RJ, Tannahill D (2001): The role of the notochord in vertebral column formation. J Anat $\underline{199}, 177-180$ 
Fuchs E (2005): Social stress in tree shrews as an animal model of depression: An example of a behavioral model of a CNS disorder. CNS Spectr $\underline{10}, 182-190$

Fuchs E, Flügge G (2002): Social stress in tree shrews: Effects on physiology, brain function, and behavior of subordinate individuals. Pharmacol Biochem Behav $\underline{73}, 247-258$

Fukiishi Y, Morriss-Kay GM (1992): Migration of cranial neural crest cells to the pharyngeal arches and heart in rat embryos. Cell Tissue Res $\underline{268}, 1-8$

Funayama N, Sato Y, Matsumoto K, Ogura T, Takahashi Y (1999): Coelom formation: Binary decision of the lateral plate mesoderm is controlled by the ectoderm. Development $\underline{126}, 4129-4138$

Furumoto T-A, Miura N, Akasaka T, Mizutani-Koseki Y, Sudo H, Fukuda K, Maekawa M, Yuasa S, $\mathrm{Fu}$ Y, Moriya H, et al. (1999): Notochord-dependent expression of MFH1 and PAX1 cooperates to maintain the proliferation of sclerotome cells during the vertebral column development. Dev Biol $\underline{210}, 15-29$

Gajović S, Kostović-Knežević L (1995): Ventral ectodermal ridge and ventral ectodermal groove: Two distinct morphological features in the developing rat embryo tail. Anat Embryol 192, 181-187

Galli LM, Knight SR, Barnes TL, Doak AK, Kadzik RS, Burrus LW (2008): Identification and characterization of subpopulations of Pax 3 and Pax 7 expressing cells in developing chick somites and limb buds. Dev Dyn 237, 1862-1874

Gavrieli Y, Sherman Y, Ben-Sasson SA (1992): Identification of programmed cell death in situ via specific labeling of nuclear DNA fragmentation. J Cell Biol 119, 493-501

Gibb S, Maroto M, Dale JK (2010): The segmentation clock mechanism moves up a notch. Trends Cell Biol 20, 593-600 
Glebe D, Aliakbari M, Krass P, Knoop EV, Valerius KP, Gerlich WH (2003): Pre-S1 antigen-dependent infection of Tupaia hepatocyte cultures with human hepatitis B virus. J Virol 77, 9511-9521

Glebe D, Urban S, Knoop EV, Çağ N, Krass P, Grün S, Bulavaite A, Sasnauskas K, Gerlich WH (2005): Mapping of the hepatitis B virus attachment site by use of infection-inhibiting preS1 lipopeptides and Tupaia hepatocytes. Gastroenterology 129, 234-245

Glücksmann A (1934a): Über die Entwicklung der quergestreiften Muskulatur und ihre funktionellen Beziehungen zum Skelet in der Onto- und Phylogenie der Wirbeltiere. Z Anat Entwicklungsgesch $\underline{103}, 303-370$

Glücksmann A (1934b): Über die Entwicklung der Amniotenextremitäten und ihre Homologie mit den Flossen. Z Anat Entwicklungsgesch 102, 498-520

Glücksmann A (1951): Cell deaths in normal vertebrate ontogeny. Biol Rev Camb Philos Soc 26, $59-86$

Goldman DC, Martin GR, Tam PPL (2000): Fate and function of the ventral ectodermal ridge during mouse tail development. Development $\underline{127}, 2113-2123$

Gont LK, Steinbeisser H, Blumberg B, de Robertis EM (1993): Tail formation as a continuation of gastrulation: The multiple cell populations of the Xenopus tailbud derive from the late blastopore lip. Development 119, 991-1004

Goping G, Wood KA, Sei Y, Pollard HB (1999): Detection of fragmented DNA in apoptotic cells embedded in LR white: A combined histochemical (LM) and ultrastructural (EM) study. J Histochem Cytochem $\underline{47}, 561-568$

Gossler A, Hrabĕ de Angelis M (1998): Somitogenesis. Curr Top Dev Biol 3ㄹ, 225-287 
Graham A, Francis-West P, Brickell P, Lumsden A (1994): The signalling molecule BMP4 mediates apoptosis in the rhombencephalic neural crest. Nature $\underline{372}, 684-686$

Granville DJ, Carthy CM, Jiang H, Shore GC, McManus BM, Hunt DWC (1998): Rapid cytochrome $c$ release, activation of caspases 3, 6, 7 and 8 followed by Bap31 cleavage in HeLa cells treated with photodynamic therapy. FEBS Lett $\underline{437}, 5-10$

Griffith CM, Wiley MJ, Sanders EJ (1992): The vertebrate tail bud: Three germ layers from one tissue. Anat Embryol 185, 101-113

Grim M (1970): Differentiation of myoblasts and the relationship between somites and the wing bud of the chick embryo. Z Anat Entwicklungsgesch 132, 260-271

Gros J, Scaal M, Marcelle C (2004): A two-step mechanism for myotome formation in chick. Dev Cell $\underline{6}, 875-882$

Gros J, Manceau M, Thomé V, Marcelle C (2005): A common somitic origin for embryonic muscle progenitors and satellite cells. Nature $\underline{435}, 954-958$

Häcker G (2000): The morphology of apoptosis. Cell Tissue Res $\underline{301}$, 5-17

Halata Z, Grim M, Christ B (1990): Origin of spinal cord meninges, sheaths of peripheral nerves, and cutaneous receptors including Merkel cells. Anat Embryol 182, 529-537

Hamburger V, Hamilton HL (1951): A series of normal stages in the development of the chick embryo. J Morphol $\underline{88}, 49-92$

Hamilton HL, Hinsch GW (1956): The developmental fate of the first somite of the chick. Anat Rec $\underline{125}, 225-245$ 
Hardy K (1999): Apoptosis in the human embryo. Rev Reprod 4, 125-134

Hazelton RD (1970): A radioautographic analysis of the migration and fate of cells derived from the occipital somites in the chick embryo with specific reference to the development of the hypoglossal musculature. J Embryol Exp Morphol 24, 455-466

Hensey C, Gautier J (1998): Programmed cell death during Xenopus development: A spatio-temporal analysis. Dev Biol 203, 36-48

Herculano-Houzel S, Mota B, Wong P, Kaas JH (2010): Connectivity-driven white matter scaling and folding in primate cerebral cortex. Proc Natl Acad Sci USA $\underline{107}, 19008-19013$

Hirano S, Hirako R, Kajita N, Norita M (1995): Morphological analysis of the role of the neural tube and notochord in the development of somites. Anat Embryol 192, 445-457

Hirata M, Hall BK (2000): Temporospatial patterns of apoptosis in chick embryos during the morphogenetic period of development. Int J Dev Biol $\underline{44}, 757-768$

Hirsinger E, Duprez D, Jouve C, Malapert P, Cooke J, Pourquié O (1997): Noggin acts downstream of Wnt and Sonic hedgehog to antagonize BMP4 in avian somite patterning. Development 124 , $4605-4614$

Hollway G, Currie P (2005): Vertebrate myotome development. Birth Defects Res C Embryo Today $\underline{75}, 172-179$

Homma S, Yaginuma H, Oppenheim RW (1994): Programmed cell death during the earliest stages of spinal cord development in the chick embryo: A possible means of early phenotypic selection. $\mathrm{J}$ Comp Neurol $\underline{345}, 377-395$

Huang R, Christ B (2000): Origin of the epaxial and hypaxial myotome in avian embryos. Anat 
Embryol 202, 369-374

Huang R, Zhi Q, Wilting J, Christ B (1994): The fate of somitocoele cells in avian embryos. Anat Embryol 190, 243-250

Huang R, Zhi Q, Neubüser A, Müller TS, Brand-Saberi B, Christ B, Wilting J (1996): Function of somite and somitocoele cells in the formation of the vertebral motion segment in avian embryos. Acta Anat 155, 231-241

Huang R, Zhi Q, Ordahl CP, Christ B (1997): The fate of the first avian somite. Anat Embryol 195 , 435-449

Huang R, Zhi Q, Patel K, Wilting J, Christ B (2000): Contribution of single somites to the skeleton and muscles of the occipital and cervical regions in avian embryos. Anat Embryol 202, 375-383

Hunter RMM (1935): The development of the anterior post-otic somites in the rabbit. J Morphol $\underline{57}$, 501-531

Huppertz B, Frank H-G, Kaufmann P (1999): The apoptosis cascade - morphological and immunohistochemical methods for its visualization. Anat Embryol 200, 1-18

Iatropoulos MJ, Williams GM (1996): Proliferation markers. Exp Toxicol Pathol $\underline{48}, 175-181$

Jacob M, Christ B, Jacob HJ (1979): The migration of myogenic cells from the somites into the leg region of avian embryos. An ultrastructural study. Anat Embryol 157, 291-309

Jacob M, Christ B, Jacob HJ, Poelmann RE (1991): The role of fibronectin and laminin in development and migration of the avian Wolffian duct with reference to somitogenesis. Anat Embryol $\underline{183}$, 385-395 
Jacobson AG (1988): Somitomeres: Mesodermal segments of vertebrate embryos. Development 104 Suppl, 209-220

Jacobson W (1932): Über die Zellvorgänge in den ersten Entwicklungsstadien des knorpel- und knochenbildenden Gewebes. Verh Anat Ges $\underline{41}$, 186-193

Janečka JE, Miller W, Pringle TH, Wiens F, Zitzmann A, Helgen KM, Springer MS, Murphy WJ (2007): Molecular and genomic data identify the closest living relative of primates. Science $\underline{318}$, 792-794

Jeffs P, Osmond M (1992): A segmented pattern of cell death during development of the chick embryo. Anat Embryol 185, 589-598

Jones CM, Lyons KM, Hogan BLM (1991): Involvement of Bone Morphogenetic Protein-4 (BMP4) and Vgr-1 in morphogenesis and neurogenesis in the mouse. Development $111,531-542$

Kaehn K, Jacob HJ, Christ B, Hinrichsen K, Poelmann RE (1988): The onset of myotome formation in the chick. Anat Embryol 177, 191-201

Kahane N, Cinnamon Y, Kalcheim C (1998a): The origin and fate of pioneer myotomal cells in the avian embryo. Mech Dev $\underline{74}, 59-73$

Kahane N, Cinnamon Y, Kalcheim C (1998b): The cellular mechanism by which the dermomyotome contributes to the second wave of myotome development. Development $\underline{125}, 4259-4271$

Kahane N, Cinnamon Y, Bachelet I, Kalcheim C (2001): The third wave of myotome colonization by mitotically competent progenitors: Regulating the balance between differentiation and proliferation during muscle development. Development $\underline{128}, 2187-2198$

Kahane N, Ben-Yair R, Kalcheim C (2007): Medial pioneer fibers pattern the morphogenesis of ear- 
ly myoblasts derived from the lateral somite. Dev Biol $\underline{305}, 439-450$

Kerr JFR, Wyllie AH, Currie AR (1972): Apoptosis: A basic biological phenomenon with wideranging implications in tissue kinetics. Br J Cancer $\underline{26}$, 239-257

Kerr JFR, Searle J, Harmon BV, Bishop CJ: Apoptosis; in: Perspectives on mammalian cell death; hrsg. v. Potten CS; Oxford University Press, Oxford 1987, 93-128

Kessel M, Gruss P (1991): Homeotic transformations of murine vertebrae and concomitant alteration of Hox codes induced by retinoic acid. Cell $\underline{67}, 89-104$

Keynes RJ, Stern CD (1984): Segmentation in the vertebrate nervous system. Nature $\underline{310}, 786-789$

Keynes RJ, Stern CD (1988): Mechanisms of vertebrate segmentation. Development 103, 413-429

Kienel E, Vančo M, Brunnett G, Kowalski T, Clauß R, Knabe W: A framework for the visualization of cross sectional data in biomedical research; in: Mathematics and visualization, Visualization in medicine and life sciences; hrsg. v. Linsen L, Hagen H, Hamann B; Springer, Berlin 2007, 77-98

Kischkel FC, Hellbardt S, Behrmann I, Germer M, Pawlita M, Krammer PH, Peter ME (1995): Cytotoxicity-dependent APO-1 (Fas/CD95)-associated proteins form a death-inducing signaling complex (DISC) with the receptor. EMBO J $\underline{14}, 5579-5588$

Knabe W, Kuhn H-J (1998): Pattern of cell death during optic cup formation in the tree shrew Tupaia belangeri. J Comp Neurol 401, 352-366

Knabe W, Kuhn H-J (1999): The earliest invasion of macrophages into the developing brain and eye of the tree shrew Tupaia belangeri. Anat Embryol 200, 393-402

Knabe W, Kuhn H-J (2000): Capillary-contacting horizontal cells in the retina of the tree shrew Tu- 
paia belangeri belong to the mammalian type A. Cell Tissue Res $\underline{299}, 307-311$

Knabe W, Süss M, Kuhn H-J (2000): The patterns of cell death and of macrophages in the developing forebrain of the tree shrew Tupaia belangeri. Anat Embryol 201, 157-168

Knabe W, Washausen S, Brunnett G, Kuhn H-J (2002): Use of "reference series" to realign histological serial sections for three-dimensional reconstructions of the positions of cellular events in the developing brain. J Neurosci Methods $\underline{121}$, 169-180

Knabe W, Washausen S, Brunnett G, Kuhn H-J (2004): Rhombomere-specific patterns of apoptosis in the tree shrew Tupaia belangeri. Cell Tissue Res $\underline{316}, 1-13$

Knabe W, Washausen S, Happel N, Kuhn H-J (2007): Development of starburst cholinergic amacrine cells in the retina of Tupaia belangeri. J Comp Neurol 502, 584-597

Knabe W, Washausen S, Happel N, Kuhn H-J (2008): Diversity in mammalian chiasmatic architecture: Ipsilateral axons are deflected at glial arches in the prechiasmatic optic nerve of the eutherian Tupaia belangeri. J Comp Neurol 508, 437-457

Knabe W, Obermayer B, Kuhn H-J, Brunnett G, Washausen S (2009): Apoptosis and proliferation in the trigeminal placode. Brain Struct Funct 214, 49-65

Knezevic V, De Santo R, Mackem S (1998): Continuing organizer function during chick tail development. Development $\underline{125}, 1791-1801$

Köck J, Nassal M, MacNelly S, Baumert TF, Blum HE, von Weizsäcker F (2001): Efficient infection of primary Tupaia hepatocytes with purified human and woolly monkey hepatitis B virus. J Virol $\underline{75}, 5084-5089$

Köhler T, Pröls F, Brand-Saberi B (2005): PCNA in situ hybridization: A novel and reliable tool for 
detection of dynamic changes in proliferative activity. Histochem Cell Biol $\underline{123}, 315-327$

Kölliker A: Entwicklungsgeschichte des Menschen und der höheren Thiere. Engelmann, Leipzig 1879

Kriesell W: Das Ovar von Tupaia. Med. Diss. Göttingen 1977

Krull CE (2001): Segmental organization of neural crest migration. Mech Dev 105, 37-45

Kuhn H-J, Schwaier A (1973): Implantation, early placentation, and the chronology of embryogenesis in Tupaia belangeri. Z Anat Entwicklungsgesch 142, 315-340

Kulesa PM, Fraser SE (2002): Cell dynamics during somite boundary formation revealed by timelapse analysis. Science 298, 991-995

Kulesa PM, Schnell S, Rudloff S, Baker RE, Maini PK (2007): From segment to somite: Segmentation to epithelialization analyzed within quantitative frameworks. Dev Dyn 236, 1392-1402

Langman J, Nelson GR (1968): A radioautographic study of the development of the somite in the chick embryo. J Embryol Exp Morphol 19, 217-226

Latasa MJ, Cisneros E, Frade JM (2009): Cell cycle control of Notch signaling and the functional regionalization of the neuroepithelium during vertebrate neurogenesis. Int J Dev Biol $\underline{53}, 895-908$

Leist M, Nicotera P (1997): The shape of cell death. Biochem Biophys Res Commun 236, 1-9

Leist M, Single B, Castoldi AF, Kühnle S, Nicotera P (1997): Intracellular adenosine triphosphate (ATP) concentration: A switch in the decision between apoptosis and necrosis. J Exp Med 185, $1481-1486$ 
Leong AS-Y, Vinyuvat S, Suthipintawong C, Milios J (1995): A comparative study of cell proliferation markers in breast carcinomas. Clin Mol Pathol $\underline{48}$, M83-M87

Li P, Nijhawan D, Budihardjo I, Srinivasula SM, Ahmad M, Alnemri ES, Wang X (1997): Cytochrome $\mathrm{c}$ and dATP-dependent formation of Apaf-1/Caspase-9 complex initiates an apoptotic protease cascade. Cell $\underline{91}, 479-489$

Lim TM, Lunn ER, Keynes RJ, Stern CD (1987): The differing effects of occipital and trunk somites on neural development in the chick embryo. Development 100, 525-533

Linker C, Lesbros C, Gros J, Burrus LW, Rawls A, Marcelle C (2005): $\beta$-catenin-dependent Wnt signalling controls the epithelial organisation of somites through the activation of paraxis. Development $\underline{132}, 3895-3905$

Lipton BH, Jacobson AG (1974): Analysis of normal somite development. Dev Biol 38, 73-90

Liu C, Knezevic V, Mackem S (2004): Ventral tail bud mesenchyme is a signaling center for tail paraxial mesoderm induction. Dev Dyn $\underline{229}, 600-606$

Lufkin T, Mark M, Hart CP, Dollé P, LeMeur M, Chambon P (1992): Homeotic transformation of the occipital bones of the skull by ectopic expression of a homeobox gene. Nature $\underline{359}, 835-841$

Lumsden A (1990): The cellular basis of segmentation in the developing hindbrain. Trends Neurosci $\underline{13}, 329-335$

Malikova MA, van Stry M, Symes K (2007): Apoptosis regulates notochord development in Xenopus. Dev Biol $\underline{311}, 434-448$

Marcelle C, Lesbros C, Linker C (2002): Somite patterning: A few more pieces of the puzzle. Results Probl Cell Differ $\underline{38}, 81-108$ 
McBrien NA, Metlapally R, Jobling AI, Gentle A (2006): Expression of collagen-binding integrin receptors in the mammalian sclera and their regulation during the development of myopia. Invest Ophthalmol Vis Sci $\underline{47}, 4674-4682$

McMahon JA, Takada S, Zimmerman LB, Fan C-M, Harland RM, McMahon AP (1998): Nogginmediated antagonism of BMP signaling is required for growth and patterning of the neural tube and somite. Genes Dev 12, 1438-1452

Meier S (1979): Development of the chick embryo mesoblast. Formation of the embryonic axis and establishment of the metameric pattern. Dev Biol $\underline{73}, 25-45$

Mestres P, Hinrichsen K (1976): Zur Histogenese des Somiten beim Hühnchen. J Embryol Exp Morphol ㅌ6, 669-683

Miller SA, Briglin A (1996): Apoptosis removes chick embryo tail gut and remnant of the primitive streak. Dev Dyn 206, 212-218

Mills CL, Bellairs R (1989): Mitosis and cell death in the tail of the chick embryo. Anat Embryol $\underline{180}, 301-308$

Miura S, Davis S, Klingensmith J, Mishina Y (2006): BMP signaling in the epiblast is required for proper recruitment of the prospective paraxial mesoderm and development of the somites. Development $\underline{133}, 3767-3775$

Müller F, O'Rahilly R (1980): The early development of the nervous system in staged insectivore and primate embryos. J Comp Neurol $\underline{193}, 741-751$

Müller F, O'Rahilly R (1986): Somitic-vertebral correlation and vertebral levels in the human embryo. Am J Anat 177, 3-19 
Müller F, O’Rahilly R (1994): Occipitocervical segmentation in staged human embryos. J Anat $\underline{185}$, $251-258$

Müller F, O'Rahilly R (2003): Segmentation in staged human embryos: The occipitocervical region revisited. J Anat $\underline{203}, 297-315$

Müller F, O'Rahilly R (2004): The primitive streak, the caudal eminence and related structures in staged human embryos. Cells Tissues Organs $\underline{177}, 2-20$

Müller TS, Ebensperger C, Neubüser A, Koseki H, Balling R, Christ B, Wilting J (1996): Expression of avian Pax1 and Pax9 is intrinsically regulated in the pharyngeal endoderm, but depends on environmental influences in the paraxial mesoderm. Dev Biol $\underline{178}, 403-417$

Nakaya Y, Kuroda S, Katagiri YT, Kaibuchi K, Takahashi Y (2004): Mesenchymal-epithelial transition during somitic segmentation is regulated by differential roles of Cdc42 and Rac1. Dev Cell $\underline{7}, 425-438$

Nicholson DW, Ali A, Thornberry NA, Vaillancourt JP, Ding CK, Gallant M, Gareau Y, Griffin PR, Labelle M, Lazebnik YA, et al. (1995): Identification and inhibition of the ICE/CED-3 protease necessary for mammalian apoptosis. Nature $\underline{376}, 37-43$

Nie W, Fu B, O’Brien PCM, Wang J, Su W, Tanomtong A, Volobouev V, Ferguson-Smith MA, Yang F (2008): Flying lemurs - The 'flying tree shrews'? Molecular cytogenetic evidence for a Scandentia-Dermoptera sister clade. BMC Biol $\underline{6}, 18$

Noden DM (1983): The embryonic origins of avian cephalic and cervical muscles and associated connective tissues. Am J Anat $\underline{168}, 257-276$

Noden DM, Francis-West P (2006): The differentiation and morphogenesis of craniofacial muscles. Dev Dyn 235, 1194-1218 
Ohta S, Suzuki K, Tachibana K, Tanaka H, Yamada G (2007): Cessation of gastrulation is mediated by suppression of epithelial-mesenchymal transition at the ventral ectodermal ridge. Development $\underline{134}, 4315-4324$

Olivera-Martinez I, Coltey M, Dhouailly D, Pourquié O (2000): Mediolateral somitic origin of ribs and dermis determined by quail-chick chimeras. Development 127, 4611-4617

Olivera-Martinez I, Thélu J, Dhouailly D (2004): Molecular mechanisms controlling dorsal dermis generation from the somitic dermomyotome. Int J Dev Biol $\underline{48}, 93-101$

O’Rahilly R, Müller F (1984): The early development of the hypoglossal nerve and occipital somites in staged human embryos. Am J Anat 169, 237-257

O’Rahilly R, Müller F (2003): Somites, spinal ganglia, and centra. Enumeration and interrelationships in staged human embryos, and implications for neural tube defects. Cells Tissues Organs $\underline{173}$, $75-92$

O'Rahilly R, Müller F (2007): The development of the neural crest in the human. J Anat 211, 335351

Ordahl CP: Myogenic lineages within the developing somite; in: Molecular basis of morphogenesis; hrsg. v. Bernfield M; John Wiley and Sons, New York 1993, 165-176

Ostrovsky D, Sanger JW, Lash JW (1988): Somitogenesis in the mouse embryo. Cell Differ 23, 17 26

Packard DS Jr (1980): Somitogenesis in cultured embryos of the japanese quail, Coturnix coturnix japonica. Am J Anat 158, 83-91

Packard DS Jr, Jacobson AG (1976): The influence of axial structures on chick somite formation. 
Dev Biol 53, 36-48

Packard DS Jr, Zheng R-Z, Turner DC (1993): Somite pattern regulation in the avian segmental plate mesoderm. Development $\underline{117}, 779-791$

Palmeirim I, Henrique D, Ish-Horowicz D, Pourquié O (1997): Avian hairy gene expression identifies a molecular clock linked to vertebrate segmentation and somitogenesis. Cell $\underline{91}$, 639-648

Parnaik R, Raff MC, Scholes J (2000): Differences between the clearance of apoptotic cells by professional and non-professional phagocytes. Curr Biol 10, 857-860

Pasteels J (1943): Proliférations et croissance dans la gastrulation et al formation de la queue des Vertébrés. Arch Biol 54, 1-51

Peter K (1936): Untersuchungen über Zelluntergang in der Embryogenese. I. Prolegomena: Über die Wertung des physiologischen Zelltuntergangs im allgemeinen. II. Die vermeintliche morphogenetische Zelldegeneration. Z Anat Entwicklungsgesch 105, 409-428

Peters H, Wilm B, Sakai N, Imai K, Maas K, Balling R (1999): Pax1 und Pax9 synergistically regulate vertebral column development. Development $\underline{126}$, 5399-5408

Phillips JR, McBrien NA (2004): Pressure-induced changes in axial eye length of chick and tree shrew: Significance of myofibroblasts in the sclera. Invest Ophthalmol Vis Sci $\underline{45}, 758-763$

Platt JB (1889): Studies on the primitive axial segmentation of the chick. Bull Mus Comp Zool Harv $\underline{17}, 171-190$

Pourquié O (2011): Vertebrate segmentation: From cyclic gene networks to scoliosis. Cell 145, 650663 
Pourquié O, Tam PPL (2001): A nomenclature for prospective somites and phases of cyclic gene expression in the presomitic mesoderm. Dev Cell $\underline{1}, 619-620$

Pourquié O, Coltey M, Bréant C, Le Douarin NM (1995): Control of somite patterning by signals from the lateral plate. Proc Natl Acad Sci USA $\underline{92}$, 3219-3223

Pourquié O, Fan C-M, Coltey M, Hirsinger E, Watanabe Y, Bréant C, Francis-West P, Brickell P, Tessier-Lavigne M, Le Douarin NM (1996): Lateral and axial signals involved in avian somite patterning: A role for BMP4. Cell $\underline{84}, 461-471$

Rabinovitch M (1995): Professional and non-professional phagocytes: An introduction. Trends Cell Biol $\underline{5}, 85-87$

Rabl C (1888): Ueber die Differenzierung des Mesoderms. Verh Anat Ges 2, 140-146

Rawls A, Wilson-Rawls J, Olson EN (2000): Genetic regulation of somite formation. Curr Top Dev Biol 47, 131-154

Reiter A (1944): Die Frühentwicklung der menschlichen Wirbelsäule. II. Mitteilung: Die Entwicklung der Occipitalsegmente und der Halswirbelsäule. Z Anat Entwicklungsgesch $\underline{113}$, 66-104

Remak R: Untersuchungen über die Entwickelung der Wirbelthiere; hrsg. v. Reimer G; Berlin 1855, $1-194$

Resende TP, Ferreira M, Teillet M-A, Tavares AT, Andrade RP, Palmeirim I (2010): Sonic hedgehog in temporal control of somite formation. Proc Natl Acad Sci USA 107, 12907-12912

Rex H (1905): Über das Mesoderm des Vorderkopfes der Lachmöwe. Morphol Jahrb 33, 107-347

Rhee J, Takahashi Y, Saga Y, Wilson-Rawls J, Rawls A (2003): The protocadherin papc is involved 
in the organization of the epithelium along the segmental border during mouse somitogenesis. Dev Biol 254, 248-261

Rickmann M, Fawcett JW, Keynes RJ (1985): The migration of neural crest cells and the growth of motor axons through the rostral half of the chick somite. J Embryol Exp Morphol $\underline{90}, 437-455$

Romeis B: Mikroskopische Technik. 17. Auflage; hrsg. v. Böck P; Urban-Schwarzenberg, Baltimore 1989

Saga Y, Hata N, Koseki H, Taketo MM (1997): Mesp2: A novel mouse gene expressed in the presegmented mesoderm and essential for segmentation initiation. Genes Dev $\underline{11}$, 1827-1839

Sanders EJ (1997): Cell death in the avian sclerotome. Dev Biol 192, 551-563

Sanders EJ, Wride MA (1995): Programmed cell death in development. Int Rev Cytol 163, 105-173

Sanders EJ, Khare MK, Ooi VC, Bellairs R (1986): An experimental and morphological analysis of the tail bud mesenchyme of the chick embryo. Anat Embryol 174, 179-185

Sargis EJ (2001): A preliminary qualitative analysis of the axial skeleton of tupaiids (Mammalia, Scandentia): Functional morphology and phylogenetic implications. J Zool 253, 473-483

Sato Y, Takahashi Y (2005): A novel signal induces a segmentation fissure by acting in a ventral-todorsal direction in the presomitic mesoderm. Dev Biol 282, 183-191

Sato Y, Yasuda K, Takahashi Y (2002): Morphological boundary forms by a novel inductive event mediated by Lunatic fringe and Notch during somitic segmentation. Development 129, 3633-3644

Scaal M, Christ B (2004): Formation and differentiation of the avian dermomyotome. Anat Embryol $208,411-424$ 
Scheffel T: Muster und Funktionen von Apoptose und Proliferation in der dorsalen und ventralen Mittellinie des embryonalen Rückenmarks von Tupaia belangeri (Tupaiidae, Scandentia, Mammalia). Med. Diss. Göttingen 2009

Schemainda H (1979): Über die Entwicklung der occipitalen Somiten. Experimentelle Untersuchungen an Wachtel- und Hühnerembryonen. Verh Anat Ges $\underline{73}, 527-532$

Schlegel J, Peters I, Orrenius S, Miller DK, Thornberry NA, Yamin T-T, Nicholson DW (1996): CPP32/apopain is a key interleukin $1 \beta$ converting enzyme-like protease involved in Fas-mediated apoptosis. J Biol Chem 271, 1841-1844

Schmidt C, Christ B, Patel K, Brand-Saberi B (1998): Experimental induction of BMP-4 expression leads to apoptosis in the paraxial and lateral plate mesoderm. Dev Biol 202, 253-263

Schmidt C, Christ B, Maden M, Brand-Saberi B, Patel K (2001): Regulation of Epha4 expression in paraxial and lateral plate mesoderm by ectoderm-derived signals. Dev Dyn 220, 377-386

Schoenwolf GC (1979): Histological and ultrastructural observations of tail bud formation in the chick embryo. Anat Rec 193, 131-148

Schoenwolf GC (1981): Morphogenetic processes involved in the remodeling of the tail region of the chick embryo. Anat Embryol 162, 183-197

Schoenwolf GC (1984): Histological and ultrastructural studies of secondary neurulation in mouse embryos. Am J Anat $\underline{169}, 361-376$

Sensenig EC (1949): The early development of the human vertebral column. Contrib Embryol Carneg Inst $\underline{33}, 21-42$

Sensenig EC (1957): The development of the occipital and cervical segments and their associated structures in human embryos. Contrib Embryol Carneg Inst $\underline{36}, 141-151$

Serbedzija GN, Fraser SE, Bronner-Fraser M (1990): Pathways of trunk neural crest cell migration in the mouse embryo as revealed by vital dye labelling. Development $\underline{108}$, 605-612 
Sewell W, Kusumi K (2007): Genetic analysis of molecular oscillators in mammalian somitogenesis: Clues for studies of human vertebral disorders. Birth Defects Res C Embryo Today $\underline{81,111-120}$

Shapiro F (1992): Vertebral development of the chick embryo during days 3-19 of incubation. J Morphol 213, 317-333

Shedden PM, Wiley MJ (1987): Early stages of development in the caudal neural tube of the golden syrian hamster (Mesocricetus auratus). Anat Rec 219, 180-185

Shifley ET, Cole SE (2007): The vertebrate segmentation clock and its role in skeletal birth defects. Birth Defects Res C Embryo Today $\underline{81}$, 121-133

Shook D, Keller R (2003): Mechanisms, mechanics and function of epithelial-mesenchymal transitions in early development. Mech Dev $\underline{120}, 1351-1383$

Shtilbans V, Wu M, Burstein DE (2010): Evaluation of apoptosis in cytologic specimens. Diagn Cytopathol $\underline{38}, 685-697$

Stadelmann C, Lassmann H (2000): Detection of apoptosis in tissue sections. Cell Tissue Res $\underline{301}$, 19-31

Stemple DL (2004): The notochord. Curr Biol 14, R873-R874

Stemple DL (2005): Structure and function of the notochord: An essential organ for chordate development. Development 132, 2503-2512

Stern CD, Bellairs R (1984): Mitotic activity during somite segmentation in the early chick embryo. Anat Embryol 169, 97-102

Stern CD, Fraser SE, Keynes RJ, Primmett DRN (1988): A cell lineage analysis of segmentation in the chick embryo. Development 104 Suppl, 231-244

Stickney HL, Barresi MJF, Devoto SH (2000): Somite development in zebrafish. Dev Dyn 219, 
Su D, Ellis S, Napier A, Lee K, Manley NR (2001): Hoxa3 and Pax1 regulate epithelial cell death and proliferation during thymus and parathyroid organogenesis. Dev Biol 236, 316-329

Süss M, Washausen S, Kuhn H-J, Knabe W (2002): High resolution scanning and three-dimensional reconstruction of cellular events in large objects during brain development. J Neurosci Methods $\underline{113}, 147-158$

Takahashi Y, Sato Y (2008): Somitogenesis as a model to study the formation of morphological boundaries and cell epithelialization. Dev Growth Differ 50 Suppl 1, S149-S155

Takahashi Y, Sato Y, Suetsugu R, Nakaya Y (2005): Mesenchymal-to-epithelial transition during somitic segmentation: A novel approach to studying the roles of Rho family GTPases in morphogenesis. Cells Tissues Organs $\underline{179}, 36-42$

Tam PPL (1981): The control of somitogenesis in mouse embryos. J Embryol Exp Morphol $\underline{65}$ Suppl, 103-128

Tam PPL (1988): The allocation of cells in the presomitic mesoderm during somite segmentation in the mouse embryo. Development 103, 379-390

Tam PPL, Trainor PA (1994): Specification and segmentation of the paraxial mesoderm. Anat Embryol 189, 275-305

Tam PPL, Meier S, Jacobson AG (1982): Differentiation of the metameric pattern in the embryonic axis of the mouse. II. Somitomeric organization of the presomitic mesoderm. Differentiation $\underline{21}$, $109-122$

Tam PPL, Goldman D, Camus A, Schoenwolf GC (2000): Early events of somitogenesis in higher vertebrates: Allocation of precursor cells during gastrulation and the organization of a meristic pattern in the paraxial mesoderm. Curr Top Dev Biol $\underline{47}$, 1-32

Teillet M-A, Kalcheim C, Le Douarin NM (1987): Formation of the dorsal root ganglia in the avian 
embryo: Segmental origin and migratory behavior of neural crest progenitor cells. Dev Biol $\underline{120}$, 329-347

Theiler K (1957): Über die Differenzierung der Rumpfmyotome beim Menschen und die Herkunft der Bauchwandmuskeln. Acta Anat $\underline{30}, 842-864$

Theiler K (1958): Zelluntergang in den hintersten Rumpfsomiten bei der Maus. Z Anat Entwicklungsgesch $\underline{120}, 274-278$

Tonegawa A, Takahashi Y (1998): Somitogenesis controlled by noggin. Dev Biol 202, 172-182

Tonegawa A, Funayama N, Ueno N, Takahashi Y (1997): Mesodermal subdivision along the mediolateral axis in chicken controlled by different concentrations of BMP-4. Development $\underline{124}$, 19751984

Tong Y, Zhu Y, Xia X, Liu Y, Feng Y, Hua X, Chen Z, Ding H, Gao L, Wang Y, et al. (2011): Tupaia CD81, SR-BI, claudin-1, and occludin support hepatitis C virus infection. J Virol $\underline{85}$, 2793-2802

Tosney KW, Landmesser LT (1985): Development of the major pathways for neurite outgrowth in the chick hindlimb. Dev Biol 109, 193-214

Tosney KW, Schroeter S, Pokrzywinski JA (1988): Cell death delineates axon pathways in the hindlimb and does so independently of neurite outgrowth. Dev Biol 130, 558-572

Trelstad RL, Hay ED, Revel J-P (1967): Cell contact during early morphogenesis in the chick embryo. Dev Biol 16, 78-106

Ukita K, Hirahara S, Oshima N, Imuta Y, Yoshimoto A, Jang C-W, Oginuma M, Saga Y, Behringer RR, Kondoh H, et al. (2009): Wnt signaling maintains the notochord fate for the progenitor cells and supports the posterior extension of the notochord. Mech Dev 126, 791-803

Urase K, Fujita E, Miho Y, Kouroku Y, Mukasa T, Yagi Y, Momoi MY, Momoi T (1998): Detection of activated caspase-3 (CPP32) in the vertebrate nervous system during development by a cleavage site-directed antiserum. Brain Res Dev Brain Res 111, 77-87 
van Bemmelen JF (1889): Über die Herkunft der Extremitäten- und Zungenmuskulatur bei Eidechsen. Anat Anz $\underline{4}, 240-255$

Venters SJ, Ordahl CP (2002): Persistent myogenic capacity of the dermomyotome dorsomedial lip and restriction of myogenic competence. Development $\underline{129}$, 3873-3885

Venters SJ, Hultner ML, Ordahl CP (2008): Somite cell cycle analysis using somite-staging to measure intrinsic developmental time. Dev Dyn 237, 377-392

Wakamatsu Y, Mochii M, Vogel KS, Weston JA (1998): Avian neural crest-derived neurogenic precursors undergo apoptosis on the lateral migration pathway. Development $\underline{125}, 4205-4213$

Washausen S, Obermayer B, Brunnett G, Kuhn H-J, Knabe W (2005): Apoptosis and proliferation in developing, mature, and regressing epibranchial placodes. Dev Biol 278, 86-102

Weed IG (1936): Cytological studies of developing muscle with special reference to myofibrils, mitochondria, Golgi material and nuclei. Z Zellforsch Mikroskop Anat 25, 516-539

Wible JR, Covert HH (1987): Primates: Cladistic diagnosis and relationships. J Hum Evol 16, 1-22

Wijgerde M, Karp S, McMahon J, McMahon AP (2005): Noggin antagonism of BMP4 signaling controls development of the axial skeleton in the mouse. Dev Biol 286, 149-157

Williams LW (1910): The somites of the chick. Am J Anat $\underline{2}, 55-100$

Wilm B, James RG, Schultheiss TM, Hogan BLM (2004): The forkhead genes, Foxc1 and Foxc2, regulate paraxial versus intermediate mesoderm cell fate. Dev Biol 271, 176-189

Wilson PA, Oster G, Keller R (1989): Cell rearrangement and segmentation in Xenopus: Direct observation of cultured explants. Development 105, 155-166

Wilson V, Beddington RSP (1996): Cell fate and morphogenetic movement in the late mouse primitive streak. Mech Dev $\underline{55}, 79-89$

Wilting J, Kurz H, Brand-Saberi B, Steding G, Yang YX, Hasselhorn H-M, Epperlein H-H, Christ 
B (1994): Kinetics and differentiation of somite cells forming the vertebral column: Studies on human and chick embryos. Anat Embryol 190, 573-581

Wilting J, Ebensperger C, Müller TS, Koseki H, Wallin J, Christ B (1995): Pax-1 in the development of the cervico-occipital transitional zone. Anat Embryol 192, 221-227

Wong GK, Bagnall KM, Berdan RC (1993): The immediate fate of cells in the epithelial somite of the chick embryo. Anat Embryol 188, 441-447

Wong P, Kaas JH (2009): Architectonic subdivisions of neocortex in the tree shrew (Tupaia belangeri). Anat Rec 292, 994-1027

Wood A, Thorogood P (1994): Patterns of cell behaviour underlying somitogenesis and notochord formation in intact vertebrate embryos. Dev Dyn 201, 151-167

Wride MA, Lapchak PH, Sanders EJ (1994): Distribution of TNF alpha-like proteins correlates with some regions of programmed cell death in the chick embryo. Int J Dev Biol $\underline{38}, 673-682$

Wyllie AH (1980): Glucocorticoid-induced thymocyte apoptosis is associated with endogenous endonuclease activation. Nature $\underline{284}, 555-556$

Wyllie AH, Kerr JF, Currie AR (1980): Cell death: The significance of apoptosis. Int Rev Cytol $\underline{68}$, 251-306

Xu X, Chen H, Cao X, Ben K (2007): Efficient infection of the tree shrew (Tupaia belangeri) with hepatitis $\mathrm{C}$ virus grown in cell culture or from patient plasma. J Gen Virol $\underline{88}, 2504-2512$

Yang Y, Ordahl CP (2006): The pattern of MyoD and contractile protein localization in primary epaxial myotome reflects the dynamic progression of nascent myoblast differentiation. Dev Dyn 235 , $382-394$

Yokouchi Y, Sakiyama J, Kameda T, Iba H, Suzuki A, Ueno N, Kuroiwa A (1996): BMP-2/-4 mediate programmed cell death in chicken limb buds. Development $\underline{122}, 3725-3734$

Yusuf F, Brand-Saberi B (2006): The eventful somite: Patterning, fate determination and cell divi- 
sion in the somite. Anat Embryol 211 Suppl 1, 21-30

Zambello E, Fuchs E, Abumaria N, Rygula R, Domenici E, Caberlotto L (2010): Chronic psychosocial stress alters NPY system: Different effects in rat and tree shrew. Prog Neuropsychopharmacol Biol Psychiatry $\underline{34}, 122-130$

Zechel G (1924): Über Muskelknospen beim Menschen, ein Beitrag zur Lehre von der Differenzierung des Myotoms. Z Anat Entwicklungsgesch $\underline{74}, 593-607$

Zimmerman LB, De Jesús-Escobar JM, Harland RM (1996): The Spemann organizer signal noggin binds and inactivates Bone Morphogenetic Protein 4. Cell 6ㅜ, 599-606

Zuo X-H, Guo X-G, Zhan Y-Z, Wu D, Yang Z-H, Dong W-G, Huang L-Q, Ren T-G, Jing Y-G, Wang Q-H, et al. (2010): Host selection and niche differentiation in sucking lice (Insecta: Anoplura) among small mammals in southwestern China. Parasitol Res $\underline{108}, 1243-1251$

Zuzarte-Luis V, Hurle JM (2005): Programmed cell death in the embryonic vertebrate limb. Semin Cell Dev Biol 16, 261-269 


\section{Danksagung}

Herrn Prof. Dr. med. Wolfgang Knabe möchte ich für die Bereitstellung des Themas, für die intensive, fachlich und persönlich engagierte Betreuung sowie für zahlreiche anregende Diskussionen und wertvolle Ratschläge danken.

Herrn Dr. med. Stefan Washausen danke ich für die freundschaftliche Zusammenarbeit und für die zu jeder Zeit gewährte Unterstützung bei der Erstellung von Rekonstruktionen sowie bei der Lösung technischer Probleme.

Herrn Dr. med. Bastian Obermayer sowie Herrn Dr. med. Thomas Scheffel danke ich für ihre Hilfestellung bei der Einarbeitung in die Rekonstruktionstechnik.

Herrn Prof. (em.) Dr. med. Hans-Jürg Kuhn danke ich für die Präparation der untersuchten Embryonen und für die Bereitstellung der erforderlichen Schnittserien.

Herrn Prof. Dr. Guido Brunnett (TU Chemnitz) danke ich für die im Rahmen der Kooperation mit der AG Neuroembryologie geleistete Hilfe bei der Visualisierung dreidimensionaler Rekonstruktionen.

Herrn Prof. Dr. med. Christoph Viebahn danke ich dafür, dass die vorliegende Arbeit in der Abt. Anatomie und Embryologie durchgeführt werden konnte.

Bei Frau Irmgard Weiss bedanke ich mich für ihre stets engagierte und tatkräftige Hilfe bei den Laborarbeiten.

Frau Jutta Hennecke danke ich für die Unterstützung bei der Beschaffung der umfangreichen Literatur. 


\section{Lebenslauf}

Als Sohn von Alfred Büttner und Christiane Büttner, geb. Meisenzahl, wurde ich, Benedikt Büttner, am 10. 04. 1981 in Miltenberg geboren.

Meine Schulzeit verbrachte ich zunächst von 1987 bis 1991 in der Volksschule Bürgstadt. Ab dem Jahr 1991 besuchte ich bis zum Erwerb der allgemeinen Hochschulreife im Jahr 2000 das JohannesButzbach-Gymnasium in Miltenberg.

Meinen Zivildienst leistete ich beim Rettungsdienst des Bayerischen Roten Kreuzes in Miltenberg ab und arbeitete hier nach Beendigung des Zivildienstes bis März 2003 als Rettungssanitäter.

Das Studium der Humammedizin begann ich an der Georg-August-Universität in Göttingen zum Sommersemester 2003. Mit der Arbeit an der vorliegenden Dissertation, die im Rahmen von DFGgeförderten Projekten der AG Neuroembryologie (Leiter: Prof. Dr. W. Knabe) in der Abt. Anatomie und Embryologie (Direktor: Prof. Dr. C. Viebahn) entstanden ist, habe ich im Januar 2006 begonnen.

Den Ersten Abschnitt der Ärztlichen Prüfung absolvierte ich im März 2005. Das Praktische Jahr habe ich in der Universitätsmedizin Göttingen im Fach Anästhesiologie sowie im Albert-Schweitzer-Krankenhaus in Northeim in den Fächern Innere Medizin und Chirurgie absolviert.

Im Dezember 2009 habe ich mein Studium mit der Zweiten Ärztlichen Prüfung abgeschlossen. In den Zeiträumen von Januar 2010 bis März 2010 sowie August 2010 bis November 2010 bin ich als wissenschaftliche Hilfskraft in der Abteilung Gastroenteropathologie der Universitätsmedizin Göttingen tätig gewesen. Von April 2010 bis Juli 2010 arbeitete ich als wissenschaftlicher Mitarbeiter in der Abteilung Neuroanatomie der Georg-August-Universität Göttingen (Direktor: Prof. Dr. J. Staiger). Seit Juni 2011 bin ich in der Universitätsmedizin Göttingen als Assistenzarzt in der Weiterbildung zum Facharzt für Anästhesiologie angestellt (Direktor: Prof. Dr. M Quintel). 